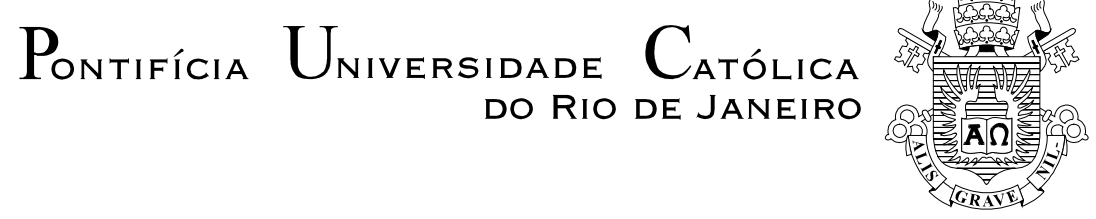

Affonso André Mello de Oliveira

\begin{abstract}
Contribuição e perspectivas do sistema de compartilhamento de bicicletas para mobilidade e sustentabilidade na cidade do Rio de Janeiro
\end{abstract}

Dissertação de Mestrado

Dissertação apresentada como requisito parcial para obtenção do título de Mestre em Engenharia Urbana e Ambiental (opção profissional) pelo Programa de Pós-graduação em Engenharia Urbana e Ambiental da PUC-Rio.

Orientador: Profa.Maria Fernanda Rodrigues Campos Lemos

Rio de Janeiro

Outubro de 2014 


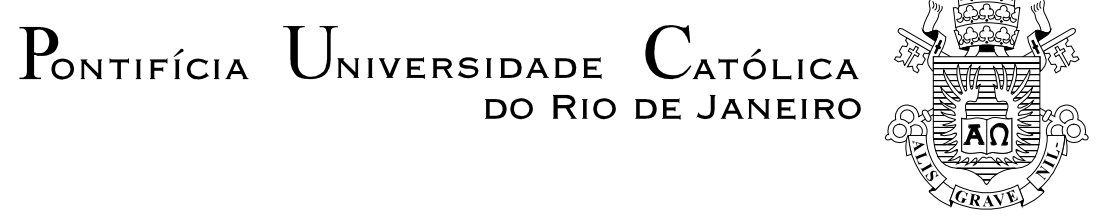

Affonso André Mello de Oliveira

\section{Contribuição e perspectivas do sistema de compartilhamento de bicicletas para mobilidade e sustentabilidade na cidade do Rio de Janeiro}

Dissertação apresentada como requisito parcial para obtenção do título de Mestre em Engenharia Urbana e Ambiental (opção profissional) pelo Programa de Pós-graduação em Engenharia Urbana e Ambiental da PUC-Rio. Aprovada pela Comissão Examinadora abaixo assinada.

Profa. Maria Fernanda Rodrigues Campos Lemos Presidente/Orientador

Departamento de Engenharia Civil/Arquitetura e Urbanismo - PUC-Rio

Prof. Rodrigo Rinaldi de Mattos

Departamento de Engenharia Civil/Arquitetura e Urbanismo - PUC-Rio

Profa. Verena Vicentini Andreatta Secretaria Municipal de Urbanismo e Mobilidade de Niteroí

Prof. Fernando Luiz Cumplido MacDowell da Costa

Prof. José Eugenio Leal Coordenador Setorial de Pós-Graduação do Centro Técnico Científico - PUC - Rio

Rio de Janeiro, 29 de outubro de 2014 
Todos os direitos reservados. É proibida a reprodução total ou parcial do trabalho sem a autorização da universidade, do autor e do orientador.

\section{Affonso André Mello de Oliveira}

Graduou-se em Arquitetura e Urbanismo na Universidade Federal do Rio de Janeiro em 1998. Concluiu MBA em Administração em Marketing no CEFET/RJ em 2005. Atua na área de projetos de arquitetura com experiência no desenvolvimento e coordenação de projetos para emprendimentos comerciais, residenciais e culturais.

Ficha Catalográfica

Oliveira, Affonso André Mello de

Contribuição e perspectivas do sistema de compartilhamento de bicicletas para mobilidade e sustentabilidade na cidade do Rio de Janeiro / Affonso André Mello de Oliveira ; orientador: Maria Fernanda Rodrigues Campos Lemos. - 2014.

174 f. : il. (color.) ; $30 \mathrm{~cm}$

Dissertação (mestrado)-Pontifícia Universidade Católica do Rio de Janeiro, Departamento de Engenharia Civil, 2014.

Inclui bibliografia

1. Engenharia civil - Teses. 2. Engenharia urbana e ambiental. 3. Transportes. 4. Sustentabilidade urbana. 5. Mobilidade. 6. Bicicleta. 7. Sistema de compartilhamento de bicicletas. 8. Rio de Janeiro. I. Lemos, Maria Fernanda Rodrigues Campos. II. Pontifícia Universidade Católica do Rio de Janeiro. Departamento de Engenharia Civil. Programa de PósGraduação em Engenharia Urbana e Ambiental. III. Título. 


\section{Agradecimentos}

O resultado deste trabalho é fruto da contribuição de muitas pessoas, às quais gostaria de expressar minha gratidão, em especial

À Profa. Maria Fernanda Lemos, a orientação e os valiosos conselhos, fundamentais para estruturar e tornar possível este trabalho;

Ao Prof. Fernando MacDowell, a disponibilidade $e$ as sugestões, fundamentais para execução da pesquisa com os usuários do Bike Rio;

Ao Prof. Victor Andrade Carneiro, os conselhos que acabaram me encaminhando para escolha deste tema;

Ao Prof. Celso Romanel e a Paula Enoy, o suporte e o apoio durante todo o curso;

À ONG Transporte Ativo e à Equipe Bike Itaú, as informações fornecidas, fundamentais para esta pesquisa.

E principalmente a Clau, a infinita paciência, a compreensão, o carinho, o companheirismo e tantos mais agradecimentos que não caberiam nesta página. 


\section{Resumo}

Oliveira, Affonso André Mello; Lemos, Maria Fernanda Rodrigues Campos (orientador) Contribuição e perspectivas do sistema de compartilhamento de bicicletas para mobilidade e sustentabilidade na cidade do Rio de Janeiro. Rio de Janeiro, 2014. 174p. Dissertação de Mestrado (opção profissional) - Departamento de Engenharia Civil, Pontifícia Universidade Católica do Rio de Janeiro

O incentivo ao transporte cicloviário vem recebendo crescente atenção nas políticas de transporte como elemento capaz de auxiliar positivamente para a redução do uso do automóvel nas cidades. Entre as diversas ações voltadas para o aumento da participação do transporte cicloviário está a implantação de sistemas de compartilhamento de bicicletas. O objetivo desta pesquisa foi avaliar a contribuição do sistema de compartilhamento de bicicletas da cidade do Rio de Janeiro, o Bike Rio, para a mobilidade e para sustentabilidade urbana com base nos objetivos associados ao SCB. Esta avaliação se baseou principalmente no resultado de pesquisas realizadas com usuários e em dados sobre o sistema de transportes da cidade, sobre as emissões de gases de efeito estufa no município e sobre o funcionamento do Bike Rio, além da comparação com os sistemas de compartilhamento de bicicletas de Paris, Viena e Barcelona. Os resultados deste trabalho também permitiram verificar os principais fatores capazes de limitar a expansão do modal cicloviário na cidade. Apesar de apresentar perspectivas favoráveis para sua expansão, observou-se que o Bike Rio ainda não é capaz de contribuir de modo relevante para a mobilidade e para sustentabilidade na cidade do Rio de Janeiro.

\section{Palavras-chave}

Transportes; sustentabilidade urbana; mobilidade; bicicleta; Sistema de Compartilhamento de Bicicletas; Rio de Janeiro. 


\section{Extended abstract}

Oliveira, Affonso André Mello; Lemos, Maria Fernanda Rodrigues Campos (Advisor) Contribution and perspectives of Bike Sharing Systems for mobility and sustainability in Rio de Janeiro. Rio de Janeiro, 2014. 174p. MSc.Dissertation (professional option) Departamento de Engenharia Civil, Pontifícia Universidade Católica do Rio de Janeiro

The concept of sustainability, when associated with the urban space, goes beyond the limits of the environmental discourse and also includes economic and social factors related to human activities. In this context, different forms of public transport may play a relevant role.

The model of urban development that promotes the use of private automobiles has caused problems to the quality of life of city dwellers. However, there are ways that can help reducing the impact of motor vehicles used by individual drivers. One of them is the promotion of the bicycle as a mean of urban transport. The use of bicycles in an urban centre can be an addition to the existing public transport system by increasing its capacity and limitations and by replacing other existing means of transport for short distances.

In order to promote the use of bicycles as a mean of urban transport, it is important to adopt a series of well integrated public policies that would discourage the individual use of motor vehicles. These policies should offer some essential conditions for the comfort and safety of bicycle users making it more appealing to people. One of the initiatives that could be adopted to promote and expand the use of bicycles is the bike-sharing system already in use in many parts of the world, especially in the last 10 years, with an increasing appeal.

A bike- sharing system can validate the use of bicycles in urban centres by making the need of individuals to travel and reach a certain destination easier and without having to purchase and repair a bicycle. It was in the Netherlands, in the 60 's, that the first attempts to adopt such systems were implemented without much success in the beginning. Recently, new technologies have been developed to improve the control of the use of public bikes thus making the program more financially efficient, in a larger scale. 
Also, it allowed the expansion of the BSS (bike-sharing system) in other countries. However, it is still a recent system of urban transport and, therefore, there is not much research or information available to analyse the real benefits for public transport and urban sustainability. These urban transport systems are usually associated with the question of sustainability mainly because they help to reduce the pollution from gas emissions released by public transport vehicles. However, some researchers claim that the benefits obtained from these systems are over-rated.

The purpose of this research was to evaluate the contribution of the bicycle sharing system - Bike Rio - to the environmental sustainability in the city of Rio de Janeiro, as well as its contribution to urban public transport taking into consideration the objectives associated with its implementation.

These objectives were based on three factors: (1) A program named "Rio, the bike capital" created by the Rio de Janeiro Municipal Administration in order to increase the use of bicycles as a form of public transport, (2) A bidding offer to "provide public space for the implementation, maintenance and operation of a bicycle transport system" foreseeing an increase in the number of bicycles, bicycle parking stations and city boroughs wishing to adopt the Bike Rio system, and (3) all the information found in the Bike Rio website where several objectives of the program are listed. Consequently, 6 (six) objectives of the Bike Rio program were established:

- The use of bicycles as a mean of transport

○ Reduce transit congestion

○ Reduce air pollution

- Promote citizen social responsibility

○ Promote the "humanization" of the urban environment

○ Promote more physical activity and healthy habits among the population.

The objectives of this research were divided in 3 categories: mobility, (2) the environment, and (3) the society. The objectives related with mobility are the use of bicycles as a mean of transport and the reduction of the 
number of car parking lots. The objectives related with the environment are those aimed at reducing air pollution. The objectives related to society are the well-being and the health of individuals as well as the quality of the urban space.

The information and data used to evaluate the Bike Rio program in this research were the following:

○ Transport Plan for the City of Rio de Janeiro

- Data obtained from City Administration and from the Bike Rio website

○ Inventory report on gas emissions and the greenhouse effect in the City of Rio de Janeiro

$\circ$ Research in the internet

○ Theoretical references

The research on bike users was done with interviews asking several questions to establish the following objectives: (1) establish the profile of bike users; (2) verify the usual ways that people travel within the city and the capacity of Bike Rio to replace other means of transport; (3) verify how Bike Rio is already integrated with the other means of transport, and (4) research how bike users rate the BSS and the transport in the city with bicycles.

Research in the internet was done in order to further investigate the available data on non-bicycle users. A question form was sent to people registered on several social media and we received 115 replies. Although research through social media was limited to a smaller social-economic group of people, it allowed us, nevertheless, to reach a larger geographic distribution of people. The replies received from bike users and the research done in the internet also provided a general view of the main obstacles that could jeopardize the further development of a bicycle transport system in the city.

Although the implementation of the Bike Rio program is related to a series of objectives, there is still no set of clear objectives for its operation. Regarding objectives 1, 2, 3 and 6, the methodology used was the one used by Fernández (2011) to evaluate the factors that can determine the success of 
bicycle sharing programs. It is based on its impact and efficiency and makes comparison with the BSS of Paris (Velib), Barcelona (Bicing) and Viena (Citybike). The research of objectives 4 and 5 was done through an evaluation based on the theoretical references of the research itself.

Verification of the existing Urban Transport Plan showed us that there was an increase of $18.20 \%$ in the average number of people that moved in the city, daily, between 2003 and 2012. However, this movement of people did not occur in a homogenous manner. There was an increase of $21.39 \%$ in the average daily displacement of people using public transport and there was an increase of $41.93 \%$ in the average daily movement of people using private automobiles. However, there was a reduction of $1.29 \%$ in the average daily movement of people not using motorized vehicles. This reduction can be explained due to changes in the social-economic conditions of society, considering that job availability and personal income are important factors in the choice of type of transport. Essential movement of people, especially those going to work or to school is taken into consideration when they choose their means of transport in the City of Rio de Janeiro. We noticed that there is a usual concentration of people movement during 3 (three) periods of the day: early morning, noon and late afternoon. Data obtained from the Urban Transport Plan also allowed us to establish that the average number of daily trips made by people using bicycles was 274.788 . That corresponds to $2 \%$ of the total of people displacements in the city.

The BSS system in Rio de Janeiro was initially created in 2008 but services were interrupted in 2010 due to problems such as bicycle theft, problems with the fare-control system and the scale of the implementation of the program. Services were restored in 2011 with a new sponsor, with changes in the business model and with more advanced technology. The system operated properly until 2013, with 60 pick-up stations and 600 bicycles available in several boroughs of the south region of Rio de Janeiro and downtown, reaching an average of 3.000 to 4.000 bike trips a day.

The Municipal Administration of Rio de Janeiro published a bidding offer in September 2013 to extend the Bike Rio program, foreseeing a total of 260 bike parking stations and 2600 bicycles available for the public. Other 
boroughs in the north and west regions of the city would benefit from the program as well. The expansion of the program began during the first quarter of 2014. Our research verified only the average daily displacements, every month in 2012 and 2013, because the program expansion plan is still an ongoing process. We did not notice any special seasonal average data on bike displacements, as well as no significant relation between the number of trips and the weather conditions (Ex.: rain fall). We believe that a verification of longer periods should be carried out in order to establish whether there is indeed a seasonal influence in the use of the Bike Rio system.

The research done with Bike Rio users indicated that the majority of them live in the boroughs already served with the system (78\%), that they are young adults between the ages of 21 and 40 years old (89\%), and that they are mostly males (67\%). Regarding the frequency of their use of the system, $31 \%$ of users informed us that they use the Bike Rio system 1 to 3 times a week. $25 \%$ of users ride a bicycle daily, $24 \%$ of users ride a bike 4 or 5 five times a day and $10 \%$ of users ride a bike less than once a day. The majority of people interviewed $(51 \%)$ informed us that they ride their bicycles for useful purposes, especially to go to work, and $20 \%$ of users ride their bikes to go to school. $16 \%$ of the people interviewed informed us that that they use their bikes for pleasure and $6 \%$ for physical exercise. $39 \%$ of bike users own a car and $41 \%$ have their won bicycles. We also learned that $56 \%$ of the users who own a bicycle prefer to use the Bike Rio system because they find it more practical. $20 \%$ of bike riders use the system for safety reasons, $16 \%$ informed us that it is difficult to find a place to park their own bicycles and $8 \%$ told us it is because of the maintenance costs.

In order to evaluate the connection between Bike Rio and the urban transport systems, we asked the people we interviewed if they would consider another type of transport to complete their daily displacements. The majority of people $(62 \%)$ informed us that they travel exclusively by bicycle. Those who would consider using another type of transport to complement their bike rides informed us that they would use the subway system (75\%) and the bus system (22\%). The reason for the high number of people opting for the 
subway is probably due to the fact that the interviews were conducted near subway stations.

A majority of people (52\%) informed us that they would use the bus public system if there were no BSS in operation. Some people (24\%) said they would walk to their final destination and some people (15\%) informed us that they would take the subway. Only $2 \%$ of the people interviewed told us that they would use their own cars. The main reason presented for using the BBS was the speed to go from place to place, thus avoiding transit congestion or simply because riding a bicycle is faster than walking.

People interviewed were also asked about the locations of their initial and final destination during their daily moving routine. This would allow us to determine and analyze the average distances of their trips. The majority of trips were made within a distance of $3.5 \mathrm{~km}$ and corresponded to displacements made by people within their own boroughs or between neighbouring boroughs.

The last part of our question form tried to identify the way bicycle users evaluate Bike Rio and the general bicycle system in the city. The main problems cited by users of the BSS system were related to its operation: operational failures (59\%), problems with equipment maintenance $(21 \%)$, and failure in the proper distribution of bikes $(21 \%)$. The number of bikes available and bike stations in the BSS system was also considered a negative factor by $24 \%$ of people interviewed. As for the positive factors cited in the interviews, the majority of replies were related to the concept of the BSS itself. $44 \%$ of people interviewed told us that the greatest quality was that it practical, $19 \%$ of users think the BSS is an option for transport and 19\% informed us that they like the idea of a bicycle sharing system.

As a whole, Bike Rio was well evaluated by the users. On a scale of 0 to 5 where 0 is "not-satisfied at all", and 5 is "very satisfied", the average resulting grading was 3.35 . However, only $55 \%$ of the users rated the system 4 or 5 and only $5 \%$ of the people rated the system 0 or 1 . This evaluation of the bicycle transport system by users of Bike Rio indicated that their main concern is safety. Lack of safety in the transit was cited in $48 \%$ of the replies, and the same percentage mentioned the small number of bike-paths and the poor quality of the infrastructure. 
In our internet research, $60 \%$ of the people informed us that they do not use a bicycle as a mean of transport. The reason for not using bikes was the question of safety. $42 \%$ of people informed us they fear to be robbed, $34 \%$ cited the lack of sufficient bike paths and $24 \%$ told us they fear a transit accident. In the group of bike users (40\%), almost half (51\%) told us they never used Bike Rio system, and 49\% use the system or had used the system before. The reason offered by those who never used the BSS system was because they prefer to use their own bicycles. Among those who abandoned the Bike Rio system, $36.4 \%$ of them told us that they prefer to use their own bikes and $27.3 \%$ told us they think there are many failures in the system.

The analysis of all the data collected allowed us to evaluate the degree of efficiency of the Bike Rio system in the reduction of the number of motor vehicles in the city, the increase of the number of bicycle users, the reduction of $\mathrm{CO}_{2}$ and, finally, the incentive to promote more physical exercise and healthy habits among the population. We compared the results obtained with those from Paris, Barcelona and Vienna. The choice of those cities in our research was due to their population numbers (over 1 million inhabitants) and for the availability of data and information.

Promotion of social responsibility was also evaluated based on the reasons offered by BSS users. We also evaluated the promotion of human socialization within the environment taking into consideration the human scale in the urban areas, the desire to improve the quality of public spaces and to reduce the size of areas used by motor vehicles.

Bike Rio represents $0.25 \%$ of the total daily movement of people in the city and $1.28 \%$ of displacements made on bicycles. This reduced participation in the bike system is related to its own scale: 60 bike stations and 600 available bicycles (data from 2013). Bike Rio is 10 times smaller than Bicing in Barcelona, and 40 times smaller than Velib in Paris (cities with smaller urban areas and population than Rio de Janeiro).

Considering the fact that the majority of Bike Rio users are young adults, mostly males, this indicates that transport on bicycles in the city needs to be safer so that more people can also benefit from it. The low level of participation of women and people of different ages indicates that there is a 
need to adopt new wider public policies to improve comfort, safety and the practical use of bicycles. The result of our research with bike users, as well as our research in the internet showed us that the principal negative aspects of the use of bicycles in Rio de Janeiro are related to public safety and the dangers of sharing the public space with motor vehicles. But the construction of new bicycle paths, alone, did not prove be a determining factor to promote more use of bicycles. A reduction of bike users occurred even during a time when new bike paths were being constructed, doubling the extension of paths in the city.

The results of our research indicated that the contribution of Bike Rio for the question of mobility and urban sustainability was very small. The reason was its scale and the low rate and number of people who chose to ride a bike instead of a car. Bike Rio was not successful to attract people who owned cars, unlike their similar programs in Paris, Barcelona and Vienna. Although 39\% of Rio's BSS users owned a car, only $2 \%$ of them told us that they were giving their cars up for the Bike Rio system. Trips made using the BSS represent only $0.002 \%$ of the total movement of people who own a car. The analysis of the bike contribution to the reduction of polluting gases, especially $\mathrm{CO}_{2}$ emissions, indicated that Bike Rio helped reducing only $0.00035 \%$ of the total $\mathrm{CO}_{2}$ emissions a year, caused by the existing Public Transport System in Rio de Janeiro. Such a small contribution to the improvement of air quality and the reduction of problems caused by transit congestion occurs in all the cities served by a BBS system that we investigated. Even in Barcelona, where there were signs of some improvement, the impact in the reduction of motor vehicles displacements in the city was slightly above $0.15 \%$. Those results indicate the need to be more careful when establishing the real advantages of the BSS system for the reduction of gas emissions and transit congestion.

As for the capacity of Bike Rio to attract new users, the results of our research were very encouraging. The majority of people interviewed (59\%) told us they do not own a bicycle. The ones who own bicycles informed us that they do not plan to use their bikes as a mean of regular transport. This indicates that Bike Rio is capable of encouraging the use of bicycles as an alternative mean of urban transport by attracting bicycle owners who usually would not use their bikes to travel within the city. 
As for the question of "promoting the practice of healthy habits and more physical activities among the population", it seems that the expansion of the Bike Rio system could benefit a great segment of the population. The results of our research indicated that $31 \%$ of users who traded their cars for bicycles, use the BSS system 4 or more times a week. In addition, $26 \%$ of people interviewed told us that they use the Bike Rio system for exercising.

Our research did not find any direct evidence linking the Bike Rio program to the promotion of "social responsibility among the population". Although it is a fact that BBS systems are usually linked to the question of sustainability and more benefits to the quality of life in the cities, the results of our interviews with bike users indicated that they use their bikes mostly for personal reasons, at least in Rio de Janeiro. Also, it was not possible to establish a direct influence of Bike Rio in the "humanizing process in urban areas". The experience of BSS systems in cities such as Paris and New York where the implementation of an infrastructure for the system was done before the implementation of the system itself - let us suppose that BSS systems are the beneficiaries of the process rather than being active agents in the promotion of "humanization".

The greatest contribution of Bike Rio to the mobility and urban sustainability found in this research was the integration with the rest of the city's transit system. We noticed that a large number of car owners do not use their motor vehicles for daily displacements in the city. Therefore, the BSS could contribute to this situation by making the use of the public transport system more attractive and, indirectly, playing an important role in the reduction of the use of private cars.

The results obtained in this research indicate that BSS systems can be considered a valuable tool to promote more use of bicycles as means of transport, but not necessarily a determining factor for this activity. In Vienna, the BSS presented the worst performance results although Vienna is the city with the largest number of bicycle daily displacements compared with Paris Rio and Barcelona.

The scale of things is the main factor responsible for the impact of Bike Rio considering all the information obtained in our research. When we 
evaluated its structure, that is the number of bicycles available, we realized that Bike Rio is very efficient and that is an encouraging incentive for its expansion. However, the positive result regarding its efficiency may be linked to the reduced number of bicycles available, a factor that explains the high volume of usage of the system. The reduced number of bicycles available in the system may explain the large use of bikes in a constant rotation. Therefore, we guess that by increasing the number of bicycles available, notwithstanding the real demand, there will be fewer problems related to the efficiency of the system.

The process of expansion of the Bike Rio system started in the first quarter of 2014 but the relationship between the number of bikes available and the size of the urban population, the relationship between the number of bike stations and the extension of the intended riding area will certainly keep the Bike Rio system inferior to the Velib'(Paris), Bicing (Barcelona) and even CityBike (Vienna) systems. Furthermore, the intended expansion of the riding area creates a major logistic challenge for the operation of the system, the main complaint from users. Among the operational problems, the most important one to users is the frequent failure to unlock the bikes from their station bars, as well as the problem to check the availability of bikes at a specific station. This is a very important factor for the operation of the system because the many complaints from users and the frequent failures in the system were the reasons why so many users give up using Bike Rio after a while. Another problem cited was the poor distribution of bicycles throughout the system. As a consequence, any future plans to expand the area served by the Bike Rio program must take into consideration the necessary number of employees and resources to face the increasing demand for maintenance services and the distribution of bicycles.

We recommend that a careful supervision and much attention should be given to the process of extending the Bike Rio system to verify if the increase in the number of bike stations, the number of bicycles and the larger area of the system network will not affect the efficiency of the BSS in Rio de Janeiro. We also recommend that more and wider research be done on the main factors that discourage people from using bicycles as an alternative mean of transport in the city. Thus, it will be possible to determine more precisely the real demand 
for the use of bicycles and the best ways to deal with the main problems to adopt the BSS system as a viable alternative transport mode in Rio de Janeiro. We hope that all the data and information collected in this research may contribute and subsidise other research projects aimed at furthering and complementing this study, raising new questions related to the role of BSS systems, especially in Brazilian cities.

\section{Keywords}

Transportation; urban sustainability; mobility; bicycle; Bicycle Sharing System; Rio de Janeiro. 


\section{Sumário}

1. Introdução 29

$\begin{array}{lll}\text { 1.1. Objetivo } & 31\end{array}$

1.2. Metodologia 32

1.3. Estrutura do trabalho 39

2. Os transportes e a sustentabilidade urbana 41

2.1. Desenvolvimento sustentável das cidades 41

2.2. Os transportes e o desenvolvimento sustentável 43

2.3. O transporte cicloviário 50

2.4. Resumo do capítulo 53

3. Sistemas de compartilhamento de bicicleta 54

3.1. Principais características dos SCB 54

3.2. Histórico dos sistemas de compartilhamento de bicicleta 55

3.2.1. Primeira Geração: White Bikes 55

3.2.2. Segunda Geração: Coin Deposit Systems 57

3.2.3. Terceira Geração: IT-Based Systems 59

3.2.4. Quarta Geração: Demand responsive, multimodal 65 systems

3.3. O papel dos SCB na mobilidade e na sustentabilidade 66 urbana

3.4. Principais componentes dos SCB 73

$\begin{array}{ll}\text { 3.4.1. Frota de bicicletas } & 74\end{array}$

$\begin{array}{ll}\text { 3.4.2. Rede de estações } & 76\end{array}$

$\begin{array}{ll}\text { 3.4.3. Tecnologia } & 79\end{array}$

3.4.4. Estrutura para redistribuição de bicicletas e manutenção 80

3.5. Perfil de usuários dos SCB 82 
3.6. Resumo do capítulo 84

4. Estudo de caso: Impacto e contribuição do Bike Rio para 85 mobilidade e sustentabilidade

4.1. Dados sobre o sistema de transportes no Rio de Janeiro 85

4.2. O Sistema de compartilhamento de bicicleta do Rio de 92 Janeiro: Bike Rio

4.3. Resultados da pesquisa com usuários do Bike Rio 99

4.4. Resultados da pesquisa via internet 109

4.5. Avaliação dos resultados do estudo de caso 113

4.5.1. Redução no número de veículos 118

4.5.2. Aumento na participação do modal cicloviário 125

4.5.3. Redução das emissões de $\mathrm{CO}^{2} \quad 127$

4.5.4. Incentivo à prática de exercício 132

4.5.5. Responsabilidade social e humanização do ambiente 134 urbano

4.5.6. Barreiras para a expansão do Bike Rio 138

4.6. Considerações finais sobre o estudo de caso 145

5. Conclusão 153

Referências bibliográficas $\quad 159$

$\begin{array}{ll}\text { Apêndices } & 165\end{array}$ 


\section{Lista de siglas}

SCB - Sistema de Compartilhamento de Bicicletas

GEE - Gases de Efeito Estufa

ONU - Organização das Nações Unidas

UNEP - United Nations Environment Programme

IPCC - Intergovernmental Panel on Climate Change

OMS - Organização Mundial de Saúde

BRICS - Acrônimo para Brasil, Rússia, Índia, China e África do Sul

PIB - Produto Interno Bruto

Gt - Gigaton

$\mathrm{CO}_{2}$ - Dióxido de Carbono

TI - Transporte Individual

TP - Transporte Público

ANTP - Associação Nacional de Transportes Públicos

AIE - Agência Internacional de Energia

EUA - Estados Unidos da América

PNAD - Pesquisa Nacional por Amostra de Domicílios

IBGE - Instituto Brasileiro de Geografia e Estatística

PNMU - Política Nacional de Mobilidade Urbana

TOD - Transit-Oriented Development

RMRJ - Região Metropolitana do Rio de Janeiro

SMAC/RJ - Secretaria Municipal de Meio Ambiente/Rio de Janeiro OCDE - Organização para Cooperação e Desenvolvimento Econômico 


\section{Lista de tabelas}

Tabela 1 - Modais substituídos pelo SCB em Barcelona, Montreal e Lyon. Fonte: Midgley (2011).

Tabela 2 - Viagens realizadas por modo para RMRJ. Fonte:

PDTU (2013) tabela 3.1, p.6.

Tabela 3 - Variação no número de viagens diárias (em milhares) e na participação dos diferentes modais no sistema de transportes da RMRJ entre 2003 e 2012. Fonte: PDTU (2005; 2013).

Tabela 4 - Matriz de viagens por motivos. Fonte: PDTU (2013), Tabelas 4.1 a 4.3, p.11.

Tabela 5 - Modo de transporte por classe de renda (SMsalário mínimo) segundo motivo de trabalho. Fonte: PDTU (2013), Tabela 4.2.1, p.15.

Tabela 6 - Viagens por modal motorizado e não motorizado para a cidade do Rio de Janeiro. Fonte: PDTU (2013), Tabela 3.2.1, p.10.

Tabela 7 - Viagens por modal motorizado e não motorizado para a cidade do Rio de Janeiro. Comparativo anos 2003 e 2012. Fonte PDTU (2003; 2013).

Tabela 8 - Comparativo da situação atual com a previsão de expansão para o Bike Rio (Apêndice 3)

Tabela 9 - Dados sobre as cidades e os SCB (Apêndices 3, 4 $.5)$.

Tabela 10 - Emissões dos subsetores de energia do

Município do Rio de Janeiro em 2012 (Gg). Adaptado da

Tabela 3 do Inventário das emisões de gases de efeito estufa da Cidade do Rio de Janeiro (SMAC/RJ, 2013, p.12)

Tabela 11 - Redução de emissões de $\mathrm{CO}_{2}$ por grupo de 1000 habitantes (Apêndice 4 e 6).

Tabela 12 - Média de tempo das viagens por SCB. Fonte:

Fernández (2011) e www.bicing.cat (Barcelona).

Tabela 13 - Aspectos positivos e negativos do Bike Rio na opinião dos entrevistados. 
Tabela 14 - Comparativo entre diferentes SCB (Apêndices 3, $4,6)$

Tabela 15 - Principais fatores exógenos que influenciam o modal cicloviário no Rio de Janeiro.

Tabela 16 - Evolução da extensão de ciclovias, por Áreas de Planejamento no Rio de Janeiro 2000-2011. Fonte: SMAC www.armazemdedados.rio.rj.gov.br.

Tabela 17 - Comparativo entre diferentes SCB considerando expansão prevista do Bike Rio (Apêndices 3, 4, 6). 


\section{Lista de figuras}

Figura 1 - Crescimento do número de sistemas públicos de compartilhamento de bicicleta entre 2000-2010. Fonte:

Midgley, 2011.

Figura 2 - Objetivos do Bike Rio.

Figura 3 - Modelo de avaliação da performance do Bike Rio.

Adaptado de ITDP (2013) e Fernández (2011).

Figura 4 - Síntese temática da estrutura de abordagem

teórica. Adaptado de Lemos (2010).

Figura 5 - Modelo de metabolismo das cidades. Adaptado de Newman et al. (1999).

Figura 6 - Objetivos da sustentabilidade nos transportes.

Fonte: Litman, 2014.

Figura 7 - White Bikes of Amsterdam. Fonte: www.provokatie.com.br.

Figura 8 - Bycyklen, Copenhagen. Fonte:

$<$ http://umbebike.wordpress.com>.

Figura 9 - GoBike, Copenhagen. Fonte: < http://gobike..com>.

Figura 10 - Mapa de estações Vélo à la carte.

Fonte:<www.veloalacarte.free.fr $>$.

Figura 11 - Estação 2023 Velo'v, Lyon.

Fonte:<www.velov.grandlyon.com>

Figura 12 - Velib', Paris - Totem para liberação de bicicletas.

Fonte:<edf.keptos.net>

Figura 13 - Crescimento do número de países com SCB entre 2000 e 2013. Fonte: <www.earth-policy.org>

Figura 14 - Crescimento do número de SPC por região entre 2000 e 2013. Fonte: <www.earth-policy.org>

Figura 15 - Quantidade de bicicletas disponíveis por região.

Fonte: <www.earth-policy.org> 
Figura 16 - Gráfico comparativo de velocidade de deslocamento em diferentes modais no ambiente urbano. Fonte: Translink (2008, p.32).

Figura 17 - Alcance da área de influência do transporte público através da bicicleta ou a pé. Fonte: Sassen (2009 apud Fernández, 2011).

Figura 18 - Inserção do SCB no sistema de transportes.

Fonte: Midgley (2011).

Figura 19 - Modelo de bicicleta utilizado em Paris e Barcelona. Fonte:

<http://picgine.com/view/image/id/888181966\#!Velib+obsessio $\mathrm{n}>\mathrm{e}<\mathrm{http}: / /$ en.wikipedia.org/wiki/Bicing>

Figura 20 - Mapa com potencial de viagens por bicicleta na cidade de Londres. Fonte: Transport for London (2010).

Figura 21 - Mapa com a propensão dos residentes em usar a bicicleta. Fonte: Transport for London (2010).

Figura 22 - Veículo de distribuição de bicicletas. Velib' (Paris). Fonte: Ministério Indiano de Desenvolvimento Urbano, 2012.

Figura 23 - Trampe, Noruega. Fonte:

$<w w w$.amusingplanet.com $>$.

Figura 24- Distribuição das viagens por tipo de transporte e hora de início. Fonte: PDTU (2013), Gráfico 6.1.1, p.20.

Figura 25 - Estações e bicicletas do sistema SAMBA. Fonte: Serttel.

Figura 26 - Sistema de retirada de bicicletas através de aplicativo para smartphone.

Figura 27 - Alcance do Bike Rio por bairro em novembro 2013.

Figura 28 - Média mensal de viagens/dia realizadas pelo Bike Rio. Fonte: Equipe Bike Itaú.

Figura 29 - Alcance do Bike Rio após expansão prevista do sistema.

Figura 30 - Estação Bike Rio (Gávea, RJ). 
Figura 31 - Média diária de viagens mensal Bike Rio anos 2012 e 2013. Fonte: Equipe Bike Itaú.

Figura 32- Relação entre viagens e índice pluviométrico para o Bike Rio. Fonte: GEORIO (2012 e 2013) e Equipe Bike Itaú (número de viagens).

Figura 33 - Distribuição dos locais de residência dos entrevistados.

Figura 34 - Porcentagem de entrevistados que residem em bairros atendidos pelo Bike Rio.

Figura 35 - Distribuição dos entrevistados por gênero.

Figura 36 - Distribuição dos entrevistados por idade.

100

Figura 37 - Distribuição dos entrevistados pela frequência de uso.

Figura 38 - Distribuição dos entrevistados pelo objetivo da viagem no momento da entrevista.

Figura 39 - Distribuição dos entrevistados pela posse posse de veículo automotor.

Figura 40- Distribuição dos entrevistados pela posse de bicicleta particular.

Figura 41 - Razões apresentadas para utilizar o SCB pelos entrevistados que possuem bicicleta particular.

Figura 42 - Distribuição dos entrevistados pela utilização de de mais de um modal na viagem.

Figura 43 - Participação de outros modais nas viagens com intermodalidade.

Figura 44 - Participação de modais que estariam sendo substituídos pelo Bike Rio.

Figura 45 - Razões apresentadas para substituição de outros modais pelo Bike Rio.

Figura 46 - Origem ou destino das viagens a partir da estação Botafogo. 
Figura 47 - Origem ou destino das viagens a partir da estação Ipanema.

Figura 48 - Origem ou destino das viagens a partir da estação Siqueira Campos.

Figura 49 - Avaliação dos pontos negativos do sistema Bike Rio.

Figura 50 - Avaliação dos pontos positivos do sistema Bike Rio.

Figura 51- Avaliação do Bike Rio.

Figura 52 - Avaliação dos aspectos negativos do transporte cicloviário no Rio de Janeiro.

Figura 53 - Avaliação dos aspectos positivos do transporte cicloviário no Rio de Janeiro.

Figura 54 - Distribuição dos locais de residência dos entrevistados na pesquisa via web.

Figura 55 - Distribuição dos entrevistados entre usuários e não usuários do transporte cicloviário.

Figura 56 - Distribuição dos entrevistados não usuários do transporte cicloviário por gênero.

Figura 57 - Divisão entrevistados não usuários do transporte cicloviário por idade.

Figura 58 - Entrevistados não usuários do transporte cicloviário que conhecem o Bike Rio.

Figura 59 - Principais razões informadas para não utilizar a bicicleta no Rio de Janeiro.

Figura 60 - Relação entre o grupo que utiliza bicicleta e o Bike Rio.

Figura 61 - Motivos para não utilizar o Bike Rio.

Figura 62 - Motivos para deixar de utilizar o Bike Rio.

Figura 63 - Participação modal do transporte cicloviário. 
Figura 64 - Quantidade média de viagens diárias por cidade (Apêndice 4).

Figura 65 - Númeroo de viagens diárias por bicicleta (Apêndice 4).

Figura 66 - Participação modal dos SCB por cidade (Apêndices 4, 6).

Figura 67 - Performance dos SCB (Apêndices 4, 6).

Figura 68 - Participação das viagens por SCB com finalidade de trabalho ou educação (Apêndices 4,6).

Figura 69 - Distribuição de viagens diárias do Bike Rio. Fonte: $<w w w . m o v e s a m b a . c o m . b r / b i k e r i o>$.

Figura 70 - Porcentagem de viagens realizadas por SCB que substituem o transporte público (Apêndices 4,6).

120

Figura 71 - Relação entre o número de viagens realizadas por SCB que substituem o transporte público e a quantidade de bicicletas (Apêndices 4, 6).

Figura 72 - Porcentagem de viagens realizadas por transporte público substituídas por SCB (Apêndices 4, 6).

Figura 73 - Porcentagem de viagens feitas em conjunto com outros modais de transporte público (Apêndice 4).

Figura 74 - Viagens por SCB em conjunto com outros modais de transporte público (Apêndices 4, 6).

Figura 75 - Porcentagem de viagens de transporte público integradas ao SCB (Apêndices 4, 6).

Figura 76 - Porcentagem de viagens realizadas por SCB que substituem o transporte invidual (Apêndices 4, 6).

Figura 77 - Porcentagem de viagens realizadas por transporte invidivdual motorizado substituídas pelo SBC (Apêndices 4, $6)$.

Figura 78 - Transferência de viagens do T.I. para o SCB por dia por bicicleta. (Apêndices 4,6).

Figura 79- Aumento nas viagens feitas por modal cicloviário em função da implementação do SCB (Apêndices 4, 6). 
Figura 80 - Relação entre aumento nas viagens feitas por modal cicloviário e o número de bicicletas. (Apêndices 4,6).

Figura 81 - Redução de emissões de $\mathrm{CO}^{2}(\mathrm{~kg})$ / bicicleta (Apêndices 4, 6).

Figura 82 - Transporte de bicicletas do Bike Rio. Fonte: www.youtube.com.

Figura 83 - \% de viagens que substituem transporte motorizado (Apêndices 4, 6).

Figura 84 - Avenida das Américas, Barra da Tijuca (esquerda) e Praça São Salvador, Laranjeiras (direita). A escala do carro e a escala humana. Fonte: www.skyscrapercity.com/ showthread.php?t=1049277 e www.folhacarioca.com.br.

Figura 85 - Broadway, Nova York, antes e depois do fechamento para o tráfego de veículos. Fonte: www.thecityfixbrasil.com

Figura 86 - Mapa de estações de SCB. Fonte: Yanofsky (2013) a partir do mapa interativo de Oliver O'Brien (todas as cidades estão na mesma escala).

Figura 87 - Probabilidade de fatalidades a pedestres em função da velocidade de impacto. Fonte: Anderson et al. (1997, apud Johansson, 2009).

Figura 88 - Performance do SCB na redução do transporte individual.

Figura 89 - Performance do SCB na redução das emissões de $\mathrm{CO}^{2}$.

Figura 90 - Performance do SCB na participação no transporte cicloviário. 
Há algo de paradoxal no processo de aprendizagem: olhamos para a história e a tradição para seguir em frente; também podemos olhar para baixo a fim de ir para cima. E a suspensão do juízo pode ser usada como uma ferramenta para tornar o julgamento posterior mais sensível. Essa é uma maneira de aprender com tudo.

Robert Venturi, Aprendendo com Las Vegas 


\section{Introdução}

Projeções da ONU indicam que em 2050 o planeta terá 9,3 bilhões de habitantes e sua população urbana deverá passar de 3,6 para 6,3 bilhões de habitantes ${ }^{1}$. O grande motor desse processo de urbanização é a concentração de investimentos e de oportunidades de emprego nas cidades, onde está situada a maior parte das atividades econômicas relacionadas à indústria e aos serviços. Estima-se que as cidades sejam responsáveis atualmente por $80 \%$ do PIB global ${ }^{2}$.

O IPCC, em seu relatório sobre mudanças climáticas (2007), projeta uma elevação na temperatura do planeta que pode variar entre $0,6^{\circ} \mathrm{C}$ - se forem mantidos os índices atuais de emissões de GEE - e $4^{\circ} \mathrm{C}$ - se houver um forte crescimento econômico com a matriz energética ainda baseada em combustíveis fósseis - até o fim do século 3 .

Desde o início da era industrial, observa-se um aumento nas emissões globais de gases causadores do efeito estufa gerado pelas atividades humanas. Entre 1970 e 2004, houve um volume crescente de $\mathrm{CO}_{2}$ lançado na atmosfera, chegando a atingir $80 \%{ }^{4}$ do total de emissões de GEE. Deste volume, $56,6 \%$ são provenientes da queima de combustíveis fósseis ${ }^{5}$.

As consequências das alterações climáticas são globais e duradouras (Leite et al., 2012) e as cidades poderão ser seriamente afetadas pela elevação do nível dos oceanos, pelo aumento da ocorrência de eventos meteorológicos extremos e pela poluição do solo, do ar e das águas.

\footnotetext{
${ }^{1}$ ONU. World Urbanization Prospects: The 2011 revision. Highlights. p.17. As projeções foram feitas considerando redução no índice de natalidade dos países em desenvolvimento. Caso seja mantido o padrão atual, a população urbana deverá atingir 7.4 bilhões de habitantes em 2050.

Ibid. p.31

3 IPCC. Climate Change 2007: Syntesis Report. p.36. As emissões de $\mathrm{CO}^{2}$ no período passaram de 21 para 38 Gt. O total de emissões de GEE no período passou de 28,7 para 49 Gt.lbid. p.45.

${ }^{4}$ Ibid. p.45. No melhor cenário, com a manutenção dos índices de concentração de GEE do ano 2000, estima-se um aumento de $0,6^{\circ} \mathrm{C}$ até o fim do século XXI. No pior cenário (considerando rápido crescimento econômico e uso intensível de combustíveis fósseis) estimase um aumento de $4,0^{\circ} \mathrm{C}$ na temperatura até o fim do século e um aumento no nível do mar entre 0,26 e 0,59 metros..

${ }^{5}$ lbid. p.36. O total de emissões de GEE no ano de 2004 foi de 49.Gt. Desse total, 56,6\% correspondem ao $\mathrm{CO}_{2}$ oriundo da queima de combustíveis fósseis; $17,3 \%$, ao $\mathrm{CO}_{2}$ lançado por consequência de desmatamentos e da queima de biomassa; $2,8 \%$, ao $\mathrm{CO}_{2}$ de origens diversas; $14,3 \%$, ao $\mathrm{CH} 4 ; 7,9 \%$ ao $\mathrm{N}_{2} \mathrm{O}$ e $1,1 \%$ aos gases $\mathrm{F}$.
} 
Nesse contexto de crescente urbanização e de elevação dos riscos sociais, econômicos e ambientais decorrentes de eventuais mudanças climáticas, torna-se premente a discussão sobre modelos de desenvolvimento sustentável para as cidades que sejam capazes de garantir qualidade de vida para seus habitantes minimizando os efeitos das atividades humanas sobre 0 meio-ambiente.

Em nenhum outro lugar a implementação da sustentabilidade pode ser mais poderosa e benéfica do que na cidade. De fato, os benefícios oriundos dessa posição possuem um potencial tão grande que a sustentabilidade do meio ambiente deve transformar-se no princípio orientador do moderno desenho urbano (Rogers, 2001, p.5).

Os sistemas de transporte consomem mais da metade dos combustíveis fósseis líquidos produzidos atualmente e serão responsáveis pelo consumo de $97 \%$ de todo incremento da produção mundial até 2030 (UNEP, 2011$, p.383 $)^{6}$. Os lançamentos de gases na atmosfera relacionados à queima de combustíveis fazem dos transportes e do tráfego a maior fonte de poluição atmosférica do planeta (Buis et al., 2000, p.20).

O consumo energético do setor de transportes cresce a taxas que oscilam entre 2,0 e 2,5\% anuais desde a década de setenta (Replogle et al., 2012, p.56). Mesmo considerando o desenvolvimento de novas tecnologias capazes de aumentar a eficiência dos motores e de possibilitar o uso de novas fontes de energia, o prazo necessário para sua implantação não será suficiente para conter o impacto do acréscimo de número de veículos e do aumento dos congestionamentos nos centros urbanos.

O crescimento global da frota de automóveis, que poderá chegar a 3 bilhões de veículos até 2050 (ibid., p.57), vem causando problemas de mobilidade urbana e de poluição do ar, especialmente nas cidades dos países menos desenvolvidos, que dispõem de uma infraestrutura de transportes mais precária.

Dentre as diversas ações que podem ser implementadas para reduzir os impactos negativos do uso do automóvel nas cidades, o incentivo ao transporte cicloviário vem ganhando cada vez mais atenção dos governos e

\footnotetext{
${ }^{6}$ Cabe ressaltar que, segundo o relatório, o aumento no consumo de energia se dará nas regiões menos desenvolvidas do planeta. Enquanto os países mais desenvolvidos da Europa, Ásia e América do Norte apresentarão redução no consumo entre 2007 e 2030, China, Índia, Oriente Médio, América Latina, África, Leste da Europa e Eurásia apresentarão crescimento. Figura 3, p.384.
} 
da sociedade como uma forma de contribuir positivamente para a mobilidade e a sustentabilidade urbana.

Para incentivar o uso da bicicleta, diversas cidades vêm implementando, especialmente nos últimos anos, sistemas de compartilhamento de bicicletas. Entretanto, como esse é um processo relativamente recente, sua efetiva contribuição para mobilidade e para sustentabilidade urbana ainda precisa ser mais estudada para que seu verdadeiro impacto e potencialidade possam ser melhor compreendidos.

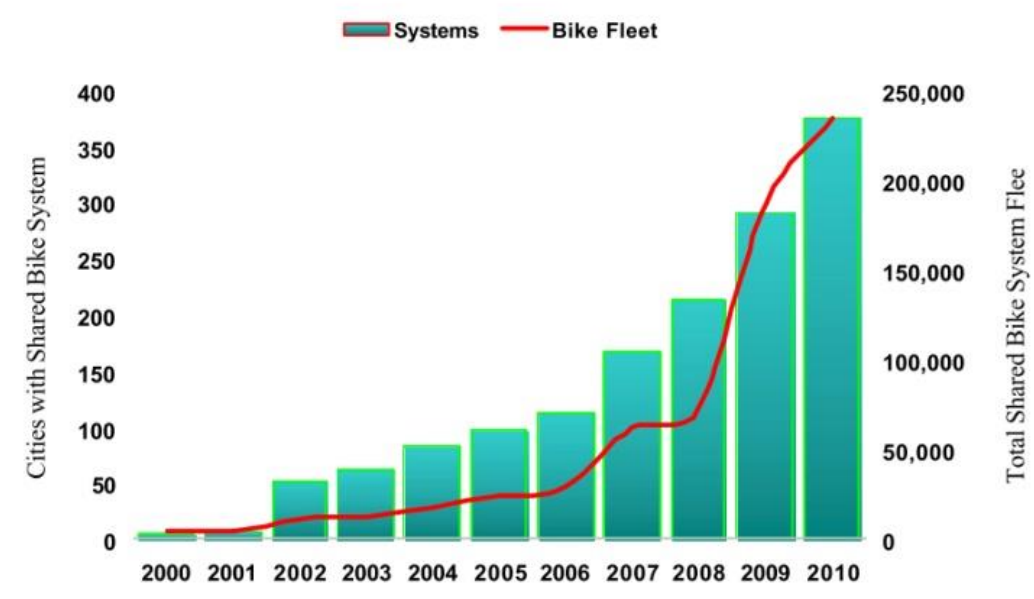

Figura 1 - Crescimento do número de sistemas públicos de compartilhamento de bicicleta entre 2000-2010. Fonte: Midgley, 2011.

\section{1}

\section{Objetivo}

Os sistemas de compartilhamento de bicicleta, assim como o transporte cicloviário de maneira geral, são usualmente associados à sustentabilidade pela sua pretensa capacidade de substituir o transporte motorizado individual, auxiliando na redução dos congestionamentos e das emissões de gases poluentes. A partir do estudo de caso do SCB da cidade do Rio de Janeiro, o Bike Rio, este trabalho pretende contribuir para a discussão da real contribuição dos sistemas de compartilhamento de bicicleta para o desenvolvimento sustentável e a mobilidade urbana. 


\section{2}

\section{Metodologia}

O elemento central deste trabalho é o estudo de caso sobre o Bike Rio e a avaliação de sua eficácia para alcançar seus objetivos cuja determinação se baseou em três fontes:

A primeira fonte foi o programa "Rio Capital da Bicicleta", vinculado à Secretaria Municipal de Meio Ambiente, que visa a "contínua inserção da bicicleta como um modal de transporte" com o objetivo de contribuir para a redução da poluição do ar e para a melhoria da "qualidade de vida e da saúde do cidadão, criando uma cultura sustentável"7.

A segunda fonte foi o edital de concorrência $n^{\circ} 04 / 550.508 / 2013^{8}$ para "concessão de uso de espaço público, com encargos de implantação, manutenção e operação de modal de transportes urbanos por compartilhamento de bicicletas[...]", que prevê o aumento do número de estações, de bicicletas e de bairros atendidos pelo Bike Rio com o objetivo de "desenvolver o programa como um novo modal de transporte público, possibilitando a integração com ônibus, metrô e barcas"'.

A terceira fonte foi o site do Bike $\operatorname{Rio}^{10}$, que elenca como seus objetivos:

- introduzir a bicicleta como modal de transporte público saudável e não poluente;

- combater o sedentarismo da população e promover a prática de hábitos saudáveis;

- redução dos engarrafamentos e da poluição ambiental nas áreas centrais das cidades;

- promover a humanização do ambiente urbano e a responsabilidade social das pessoas.

\footnotetext{
${ }^{7}$ Fonte: Secretaria Municipal de Meio Ambiente. Disponível em: $<$ www.rio.rj.gov.br/web/smac/rio-capital-da-bicicleta >. Acesso em: 05/02/2014.

${ }^{8}$ Publicado originalmente no Diário Oficial do Município do Rio de Janeiro. Ano XXVIII. n.59. p.51. 14 de junho de 2013.

${ }^{9}$ Ibid. p.1.

${ }^{10}$ Disponível em: <www.movesamba.com.br/bikerio/>. Acesso em: 10/11/2013.
} 
Para estruturar esta pesquisa, os objetivos do Bike Rio foram agrupados em três categorias: (1) mobilidade, (2) meio-ambiente e (3) sociedade. $\mathrm{Na}$ categoria mobilidade estão os objetivos relacionados à inserção da bicicleta como modal de transportes e à redução dos congestionamentos; na categoria meio-ambiente, os relacionados à redução da poluição atmosférica; e na categoria sociedade estão os objetivos relacionados ao bem-estar, à saúde dos indivíduos e à qualidade do espaço urbano.
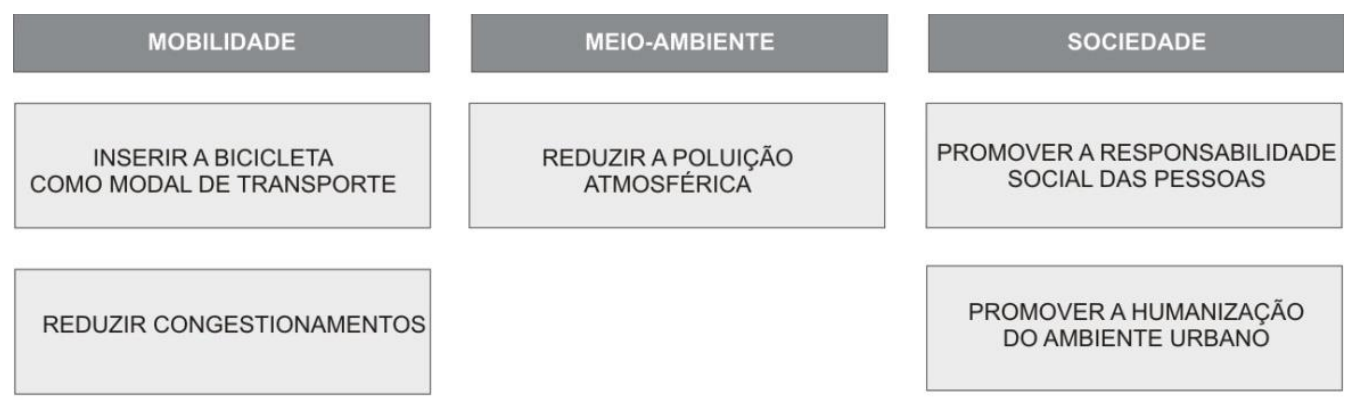

Figura 2 - Objetivos do Bike Rio.

A partir da determinação dos objetivos do Bike Rio e da revisão bibliográfica, procedeu-se ao levantamento de dados. Os dados utilizados para avaliação do Bike Rio foram obtidos a partir de cinco fontes principais:

1. Plano Diretor de Transportes do Rio de Janeiro, nas suas versões de 2005 e 2013;

2. Dados obtidos junto à Equipe Bike Itaú e por meio do site do Bike $\operatorname{Rio}^{11}$;

3. Inventário das emissões de gases de efeito estufa da cidade do Rio de Janeiro (SMAC/RJ, 2013);

4. Pesquisa de campo realizada com usuários do sistema;

5. Pesquisa realizada via internet.

As três primeiras fontes constituem a base de dados relacionados respectivamente ao sistema de transportes, ao SCB e ao volume de emissões de gases lançados na atmosfera. Para compreender a relação entre os

\footnotetext{
${ }^{11}$ Disponível em: < www.movesamba.com.br>.
} 
usuários e o Bike Rio, bem como seu papel como modal de transporte, foi necessário desenvolver uma pesquisa de campo com pessoas que fazem uso do SCB. A amostra desta pesquisa foi definida com base na relação entre o número de usuários cadastrados no $B_{i k e} \operatorname{Rio}^{12}$ e a população da cidade.

Segundo Gil (1989, p.92), a amostra em uma pesquisa social consiste no "subconjunto do universo ou da população por meio do qual se estabelecem ou se estimam as características desse universo ou população". Para determinar a amostra a ser pesquisada foi considerada a fórmula para universo de pesquisa infinito ${ }^{13}$.

$$
n=\frac{\sigma^{2} p \cdot q}{e^{2}}
$$

\footnotetext{
$n=$ tamanho da amostra

$\sigma=$ nível de confiança

$p=$ Percentagem verificada

$q=$ Percentagem complementar

$e=$ erro máximo permitido
}

Para esta pesquisa, foi determinado um nível de confiança de 95\% (2 desvios padrão), a porcentagem verificada foi de $3,2 \%{ }^{14}$ do universo e o erro máximo permitido foi estipulado em $4 \%$.

$$
n=\frac{2^{2} \cdot 0,032 \cdot 0,968}{0,04^{2}} n=77,44
$$

Foram realizadas ao todo cem entrevistas presenciais com base em um formulário padronizado ${ }^{15}$ que explorou questões com o objetivo de: (1) traçar um breve perfil dos usuários; (2) verificar seus padrões de deslocamento e o modal está sendo substituído pelo SCB; (3) verificar como se dá a integração do Bike Rio com os demais modais de transporte e (4) pesquisar como os usuários avaliam o Bike Rio e o transporte cicloviário na cidade.

A pesquisa foi realizada durante o primeiro semestre de 2014 , entre os meses de fevereiro e maio, sempre em dias úteis. Os entrevistados eram

\footnotetext{
${ }^{12}$ Fonte: Equipe Bike Itaú.

${ }^{13}$ Os universos infinitos, conforme definição de Gil (1989), são os que apresentam um número de elementos superior a 100.000. São assim definidos pois, a partir desse número, qualquer que seja "o número de elementos do universo, o número de elementos da amostra será rigorosamente o mesmo".

${ }_{14}$ Segundo dados da Equipe Bike Itaú, havia 203.456 usuários cadastrados no Bike Rio em julho de 2014, o que equivale a $3.2 \%$ da população de 6.320 .446 habitantes da cidade, segundo dados do IBGE. Fonte: <www.cidades.ibge.gov.br>. Acesso em: 10/08/2014.

${ }^{15}$ Apêndice 11.
} 
abordados no momento em que estavam retirando ou devolvendo as bicicletas.

Os locais escolhidos para as entrevistas foram estações do Bike Rio situadas junto a acessos do metrô ou a vias com grande fluxo de tráfego e de oferta de transporte público. A escolha desses pontos se deu com o intuito de captar a relação entre o Bike Rio e os demais modais de transporte e para verificar se o SCB é utilizado para deslocamentos com fim utilitário.

A importância dos deslocamentos utilitários, especialmente os relacionados a trabalho, está em seu caráter pendular, concentrado no tempo e no espaço, que os torna os principais responsáveis pelos congestionamentos, pela superlotação dos transportes públicos e pela concentração de poluentes em determinadas áreas da cidade (Heinen, 2012).

As bases escolhidas para as entrevistas foram as estações 09 (General Osório), 07 (Siqueira Campos), 02 (Cardeal Arcoverde) e 48 (Metrô Botafogo). Optou-se pelos locais onde, em teoria, o transporte utilitário teria maior participação. Dessa forma, caso os resultados indicassem uma pequena participação do transporte utilitário no total de viagens, já seria um claro indicativo de que o Bike Rio é utilizado mais para fins recrativos do que como um modal de transporte.

Em função do pouco tempo que os entrevistados dispunham para responder ao questionário, já que era comum estarem em trânsito no momento da abordagem, houve a preocupação de limitar o número de perguntas para que o tempo de entrevista não ultrapassasse três minutos.

Apesar do objetivo principal desta pesquisa estar relacionado à inserção do SCB como modal de transportes e ao seu papel em uma política de desenvolvimento sustentável, aproveitou-se o contato com os usuários para verificar quais são os aspectos do Bike Rio e do transporte cicloviário considerados mais positivos e quais os mais negativos. Estas informações foram consideradas relevantes, especialmente em função do processo de expansão pelo qual passa o Bike Rio.

A pesquisa de campo, entretanto, não foi capaz de determinar quais os fatores que se configuram efetivamente como barreiras para 0 desenvolvimento do modal cicloviário na cidade, já que os entrevistados, independentemente dos problemas informados, permanecem como usuários do Bike Rio. Para verificar que aspectos relacionados ao uso da bicicleta podem limitar o aumento da sua participação como modal de transporte (e 
consequentemente limitar a expansão do Bike Rio), foi necessário alcançar pessoas que não fazem uso da bicicleta.

Esse universo de "não usuários" corresponde a maior parte da população da cidade ${ }^{16}$ e encontra-se distribuído em uma área de 1.224,56 $\mathrm{km}^{2{ }^{17}}$. Uma pesquisa de campo com uma amostra estatisticamente válida para um universo destas dimensões não pôde ser executada por este trabalho, por isso foi desenvolvido um questionário com a ferramenta SurveyMonkey ${ }^{18}$ posteriormente distribuído pela internet por meio de redes sociais (facebook).

Se, por um lado, esta ferramenta limita a diversidade socio-econômica da amostra, pois a distribuição dos questionários é feita mediante uma rede de contatos, por outro, o alcance territorial possibilitado pela internet permitiu obter respostas de pessoas que dificilmente seriam alcançadas de outro modo.

O principal objetivo desta pesquisa via internet foi avaliar as principais razões apresentadas para não fazer uso do modal cicloviário no Rio de Janeiro. No total, foram obtidas 115 respostas, cujos resultados estão detalhados no capítulo 4.

Apesar de não constituir um resultado estatisticamente válido ${ }^{19}$, as justificativas apresentadas fornecem, em conjunto com as respostas aferidas na pesquisa presencial, um panorama bastante significativo das principais barreiras que devem ser observadas para que o transporte cicloviário possa ser incentivado e para que tenha uma crescente participação no sistema de transportes da cidade.

Com base nos dados levantados e na revisão bibliográfica, determinouse a metodologia para analisar a eficácia do Bike Rio. Segundo o dicionário Houaiss, eficácia é a "virtude ou poder de produzir determinado efeito". Para o dicionário Aurélio, é a "qualidade daquilo que produz o efeito que se

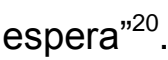

\footnotetext{
${ }^{16}$ O transporte cicloviário na RMRJ corresponde a 2,4\% dos deslocamentos (ver capítulo 4) e a porcentagem da população que não está inscrita no Bike Rio corresponde a $96,8 \%$ do total de habitantes da cidade.

17 Fonte: Bairros Cariocas. Disponível em: <portal.rio.rj.gov.br/bairroscariocas/default.htm>. Acesso em: 15/04/2014.

${ }^{18}$ Ver Apêndice 2.

${ }^{19}$ Para ser válido, a amostra teria que ser muito maior e a diversidade socio-econômica deveria ser considerada.

${ }^{20}$ Grande Dicionário Houaiss da Língua Portuguesa.Versão online. Disponível em:

<http://houaiss.uol.com.br/>. Acesso em 22/07/2014 e Dicionário Aurélio. Versão online.

Disponível em:< http://www.dicionariodoaurelio.com/>. Acesso em: 22/07/2014.
} 
Apesar de a implantação do Bike Rio estar relacionada a uma série de objetivos, não há, seja por parte do poder público, seja por parte do operador do sistema, uma quantificação ou referência temporal que transforme em metas estes objetivos ${ }^{21}$. Para Nóbrega $(2012)^{22}$, a diferença entre objetivo e meta é que o primeiro é um "alvo qualitativo", enquanto a segunda é um alvo "quantitativo" ou, como define o autor, a "meta é a quantificação de um objetivo".

Essa lacuna foi determinante para a definição da metodologia adotada para avaliar a eficácia do SCB.

Para os objetivos relacionados às categorias "mobilidade" e "meio ambiente", esta pesquisa se baseou na metodologia utilizada por Fernández (2011) para avaliar o "sucesso" dos SCB. Em seu trabalho ${ }^{23}$, o autor se propõe a avaliar uma série de indicadores relacionados aos objetivos dos SCB com base no seu impacto e na sua eficiência ${ }^{24}$.

Por impacto, compreende-se relação direta entre os resultados observados para cada SCB ajustados à população de cada cidade ou ao total de deslocamentos no caso dos objetivos relacionados à mobilidade. Por eficiência, a relação entre os resultados observados e a infraestrutura disponível, no caso, a quantidade de bicicicletas.

A ausência de metas que permitam avaliar diretamente a eficácia do Bike Rio determinou a necessidade de escolher outros SCB para que sua avaliação pudesse ser feita com base na comparação com os resultados observados em outras cidades. Foram escolhidos SCB de Paris (Velib'), de Barcelona (Bicing) e de Viena (Citybike). Dois critérios determinaram a escolha destes sistemas: estarem implantados em cidades com mais de 1.000.000 de habitantes e haver disponibilidade de dados para sua comparação com o Bike Rio.

\footnotetext{
21 As metas associadas ao Bike Rio se referem ao aumento do número de estações e bicicletas, bem como o prazo para execução desse trabalho, que consta do edital de concorrência $n^{\circ}$ 04/550.508/2013. Diário Oficial do Município do Rio de Janeiro, ano XXVIII, n. 129 , p. 58-61.

${ }^{22}$ NÓBREGA, K. Disponível em: < http://klebernobrega.wordpress.com /2012/07/16/a-diferencaentre-objetivos-e-metas/>. Acesso em: 15/08/2014.

${ }^{23}$ FERNÁNDEZ, A. C. The contribution of bike-sharing to sustainable mobility in Europe. 2011. 235 f. Tese (Doutorado) - Techinshen Universität Wien, Viena, 2011.

${ }^{24}$ Os objetivos que o autor relaciona aos SCB são: (1) a redução de tráfego de veículos; (2) o aumento da atratividade do transporte público; (3) o aumento do uso da bicicleta; (4) a redução da poluição; (5) a melhoria da qualidade do ar; (6) a melhoria do condicionamento físico do usuário; (6) a redução dos acidentes envolvendo ciclistas; (7) a criação de empregos; (8) a redução dos custos de transporte; (9) a melhoria da imagem da cidade e (10) a melhoria da atratividade da cidade para os turistas. (Fernández, 2011, p. 47). Tradução do autor. Uma metodologia similar também é utilizada pelo ITDP (2013) para avaliar a performance dos SCB.
} 


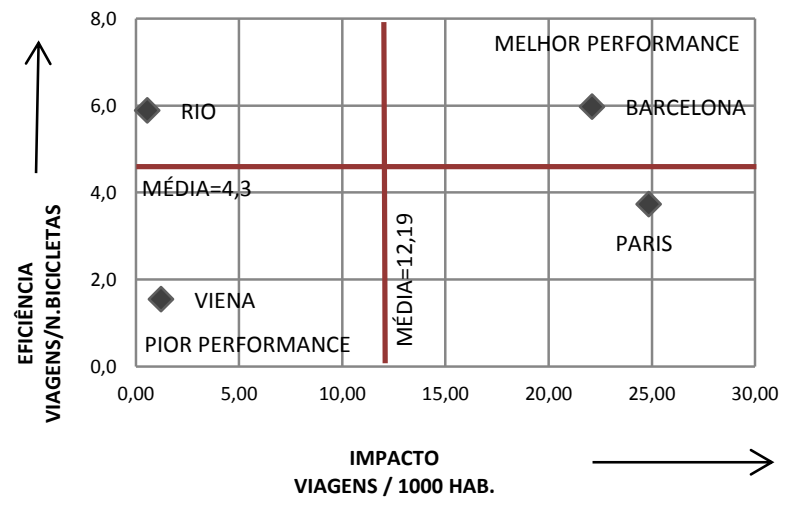

Figura 3 - Modelo de avaliação da performance do Bike Rio. Adaptado de ITDP (2013) e Fernández (2011).

Os objetivos relacionados à categoria "sociedade" foram analisados com base no referencial teórico desta pesquisa, pois sua subjetividade, como se verá no capítulo 4, não permitiu quantificá-los ou compará-los com outros SCB. 


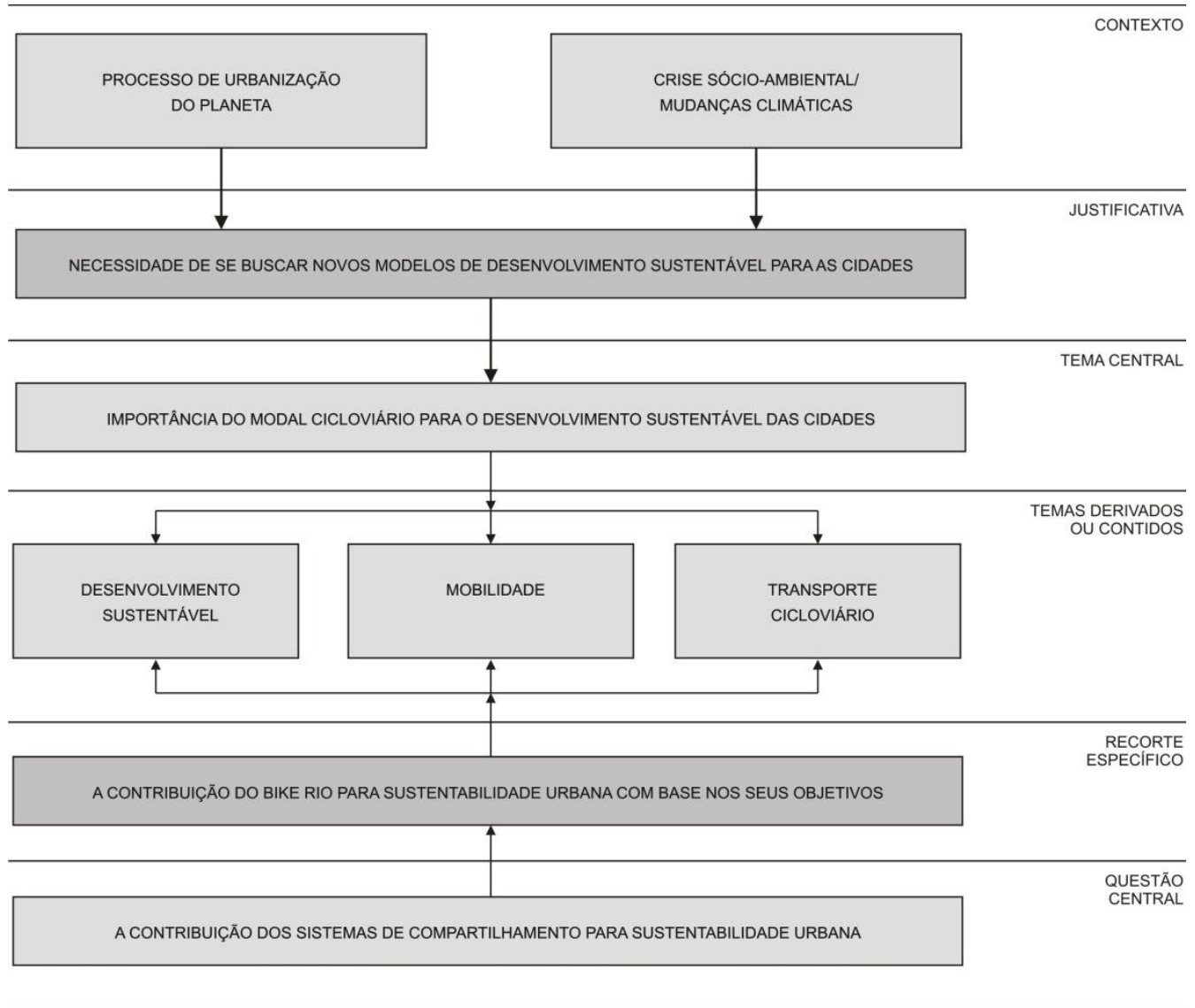

Figura 4 - Síntese temática da estrutura de abordagem teórica. Adaptado de Lemos (2010).

\section{3}

\section{Estrutura do trabalho}

Para alcançar seus objetivos, esta pesquisa se estruturou em cinco capítulos:

1 - Introdução

2 - Sistema de transportes e sustentabilidade urbana

3 - Sistemas de compartilhamento de bicicleta

4 - Estudo de caso: impacto e contribuição do Bike Rio para mobilidade e sustentabilidade

5 - Conclusão 
O corpo principal deste trabalho é composto pelos capítulos 2 (Os transportes e a sustentabilidade urbana), 3 (Sistemas de compartilhamento de bicicleta) e 4 (Estudo de caso).

O capítulo 2 se propõe a discutir os temas derivados desta pesquisa. Em primeiro lugar, buscou-se definir o conceito de sustentabilidade e de desenvolvimento sustentável. Em seguida, é tratada a relação entre os sistemas de transporte e a sustentabilidade das cidades, com especial atenção aos problemas relacionados ao crescente volume de automóveis em circulação. Ao fim, é feita uma breve discussão sobre a contribuição do transporte cicloviário para as políticas de sustentabilidade e de mobililidade e como ferramenta auxiliar na redução da participação do transporte individual motorizado nos deslocamentos urbanos diários.

O capítulo 3 trata exclusivamente dos sistemas de compartilhamento de bicicletas. Após uma breve introdução sobre as principais características e sua inserção como modal de transporte, é apresentado um histórico do seu processo de evolução desde o início, na década de 60, na Europa, até o presente. Em seguida são discutidos os diversos aspectos dos SCB que permitem relacioná-los ao conceito de desenvolvimento sustentável e determinar sua função para a mobilidade urbana. Ao fim são apresentados alguns dos principais componentes dos sistemas de compartilhamento, fundamentais para seu bom funcionamento.

O capítulo 4 é dedicado ao estudo de caso e pode ser dividido em duas partes. Na primeira parte são apresentados os dados utilizados para avaliar o Bike Rio. Após uma introdução com informações sobre o sistema de transportes na cidade do Rio de Janeiro, é feita uma apresentação do Bike Rio composta de um breve histórico e de dados quantitativos sobre sua participação como modal de transportes. Em seguida são apresentados os resultados da pesquisa realizada com usuários que contextualiza essa participação. Por fim, são apresentados também os resultados da pesquisa realizada pela internet. A segunda parte do capítulo é composta pela análise dos dados levantados.

O capítulo 5 apresenta as conclusões da pesquisa, com uma síntese dos resultados observados e recomendações para futuros trabalhos. 


\section{Os transportes e a sustentabilidade urbana}

\section{1}

\section{Desenvolvimento sustentável das cidades}

Segundo Amazonas (2002, apud. Veiga, 2005 p.190), a origem da expressão desenvolvimento sustentável está na "polêmica sobre a possibilidade da expansão da economia poder ser conciliada com a preservação do meio ambiente". De um lado, havia o discurso de que não haveria contradição entre o crescimento econômico e a preservação ambiental; de outro, os que defendiam a impossibilidade de se manter um modelo econômico baseado no crescimento econômico sem que isso acarretasse o esgotamento dos recursos do planeta.

Em uma tentativa de se encontrar uma terceira via entre esses dois discursos, no fim da década de 70 começou a ser empregada publicamente a expressão desenvolvimento sustentável (Veiga, 2005). Seu grande impulso foi a publicação, em 1987, do relatório "Nosso Futuro Comum" apresentado pela Comissão Mundial Sobre Meio Ambiente das Nações Unidas. Neste documento, o desenvolvimento sustentável foi definido como sendo aquele capaz de satisfazer "as necessidades presentes, sem comprometer a capacidade das gerações futuras de suprir suas próprias necessidades" (ONU, 1997).

Este foi um documento intencionalmente político que visava "estabelecer uma aliança com os países da periferia, num processo que seria decisivo para a realização da Rio-92". Seu caráter político e a necessidade de criar uma estratégia para institucionalizar "a problemática ambiental no âmbito das organizações internacionais e dos governos nacionais" foi a razão da amplitude e das ambiguidades que se observam no conceito de desendesenvolvimento sustentável (Veiga, 2005, p.191).

Se, por um lado, essa amplitude, fruto de sua origem política e não científica, permitiu sua disseminação e aceitação praticamente universais, por outro dificultou a definição de um denominador que permitisse institucionalizar 
em âmbito global uma política comum de desenvolvimento sustentável (ibid., 2005).

O conceito de sustentabilidade, por seu caráter normativo, é muito abstrato, o que gera a necessidade de aprofundar o conhecimento sobre os impactos da atuação humana nos ambientes em que estão inseridos, com destaque para as cadeias produtivas, as cidades e o meio natural, de modo a orientar de que forma as questões decorrentes devem ser tratadas (Leite et al., 2012, p.29).

Uma das visões mais difundidas sobre a sustentabilidade no meio urbano é a que considera as cidades como um ecossistema que consome recursos e gera resíduos decorrentes das suas atividades. Nesse caso, para garantir a sustentablidade urbana é necessário controlar a crescente necessidade de consumir insumos e energia e o consequente aumento nos lançamentos de resíduos no meio-ambiente. Como afirmam Newman et al. (1999, p.7):

By looking at the city as a whole and by analysing the pathways along which energy and materials (and pollution) move, it is possible to begin to conceive of management systems and technologies that allow for the reintegration of natural process, increasing the efficiency of resource use, the recycling of wastes as valuable materials, and the conservation (and even production) of energy.

Entretanto, esta visão expressamente "metabólica" é insuficiente para garantir a sustentabilidade urbana pois desconsidera que a cidade é mais do que um organismo que processa recursos, mas é também um lugar onde se processam atividades humanas. Por isso, como afirmam Leite et al. (2012), "o conceito de cidade sustentável reconhece que a cidade precisa atender aos objetivos sociais, ambientais, políticos e culturais, bem como aos objetivos econômicos e físicos dos seus cidadãos".

A necessidade de adaptar o conceito de sustentabildade à complexidade do ambiente urbano é compartilhada por Rogers (2001, p.32), para quem a transposição do conceito de desenvolvimento sustentável para o ambiente urbano suscita a compreensão das relações entre "cidadãos, serviços, políticas de transporte e geração de energia, bem como seu impacto total no meio ambiente local e numa esfera geográfica mais ampla". 


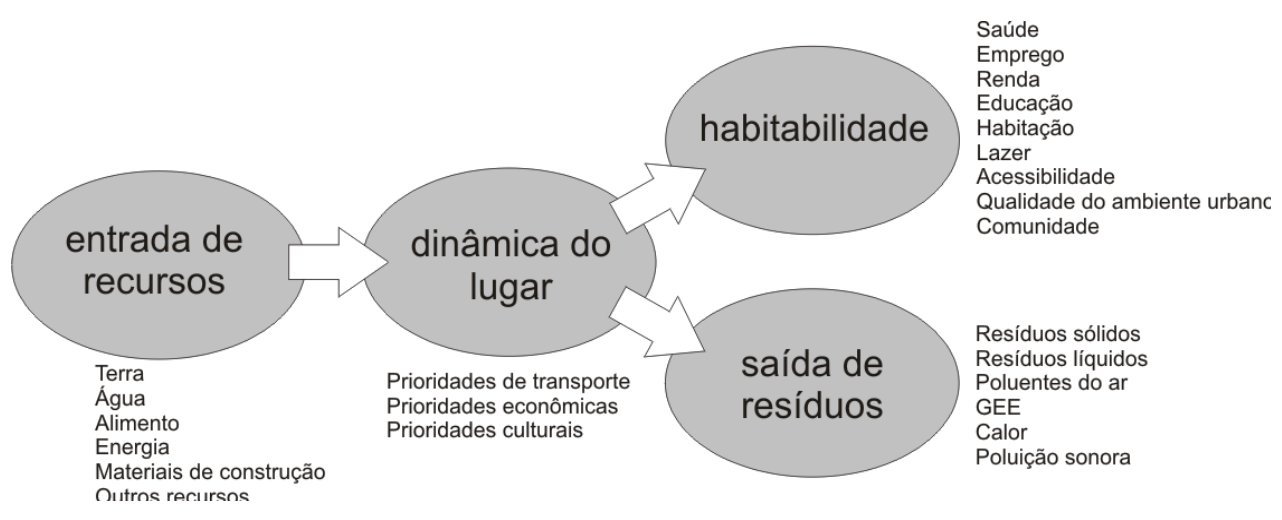

Figura 5 - Modelo de metabolismo das cidades. Adaptado de Newman et al. (1999).

Neste contexto, que incorpora a sustentabilidade econômica, ambiental e social, a mobilidade vem ganhando cada vez mais relevância. Não por acaso a Agenda 21, fruto dos compromissos assumidos pelos participantes da Conferência das Nações Unidas sobre Meio Ambiente e Desenvolvimento realizada em 1992 (Rio-92), incluiu a questão dos transportes como peça chave para o gerenciamento dos recursos naturais e para "melhoria da qualidade ambiental, social e econômica dos aglomerados urbanos" (Replogle et al., 2012, p.55).

Suas recomendações para "a promoção de sistemas de transporte eficientes e ambientalmente saudáveis" incluíam integrar o planejamento de uso da terra e transportes; adotar políticas de favorecimento dos transportes públicos com grande capacidade ${ }^{25}$; estimular meios não motorizados de transporte, com a construção de ciclovias e vias para pedestres seguras nos centros urbanos e suburbanos; dedicar atenção ao manejo eficaz do tráfego, ao funcionamento eficiente dos transportes públicos e à manutenção da infraestrutura; e reavaliar os atuais modelos de consumo e produção com 0 objetivo de reduzir o uso de energia e recursos naturais (ONU, 1995, p.86).

\section{2}

Os transportes e o desenvolvimento sustentável

\footnotetext{
${ }^{25} \mathrm{O}$ documento inclui a ressalva de que as recomendações se aplicam aos "países em que isso for apropriado".
} 
Although no common accepted definition of sustainability, sustainable development or sustainable transport is available (Beatley, 2005), it is generally accepted that sustainable development, and more specifically, sustainable transport, implies finding a proper balance between (current and future) environmental, social and economic qualities. ${ }^{26}$

Seguindo esta linha de pensamento, que considera as dimensões social, ambiental e econômica do desenvolvimento sustentável, Gilbert (2005, p.4) define transporte sustentável como:

- o que permite o acesso básico e o atendimento de modo consistente, humano e ambientalmente saudável das necessidades de desenvolvimento de indivíduos, empresas e sociedades e que possa garantir igualdade de condições entre sucessivas gerações (dimensão social);

- o que é financeiramente acessível, que opere com eficiência, que ofereça opção de escolha entre modais de transporte e que apoie uma economia competitiva, assim como o desenvolvimento regional equilibrado (dimensão econômica);

- o que limita emissões e resíduos dentro da capacidade de absorção do planeta, utiliza recursos renováveis dentro ou abaixo da sua capacidade de renovação e que utiliza recursos não renováveis dentro ou abaixo da capacidade de desenvolvimento de substitutos renováveis enquanto minimiza o impacto no uso da terra e na geração de ruídos (dimensão ambiental) ${ }^{27}$.

Para Leite et al. (2012, p.144), a mobilidade urbana é um dos principais desafios a serem enfrentados para promover o desenvolvimento sustentável nas cidades. Os transportes estão entre os maiores responsáveis pelo lançamento de poluentes na atmosfera acarretando diversos custos ambientais, econômicos e sociais. Nas cidades situadas nos países em desenvolvimento, o sistema de transportes é responsável por cerca de $80 \%$

\footnotetext{
${ }^{26}$ STEG, L.; GIFFORD, R. Sustainable transportation and quality of life. Journal of Transport Geography, n.13, p.60, 2005.

27 Tradução do autor. Texto original: (1) allows the basic access needs of individuals and societies to be met safely and in a manner consistent with human and ecosystem health, and with equity within and between generations; (2) is affordable, operates efficiently, offers choice of transport mode, and supports a vibrant economy; (3) limits emissions and waste within the planet's ability to absorb them, minimizes consumption of non-renewable resources, limits consumption of renewable resources to the sustainable yield level, reuses and recycles its components, and minimizes the use of land and the production of noise. (Gilbert, 2005, p.4).
} 
dos lançamentos de poluentes como monóxido de carbono, componentes orgânicos voláteis, chumbo, nitritos, óxidos sulfúricos e partículas finas em suspensão (Replogle et al., 2012, p.57).

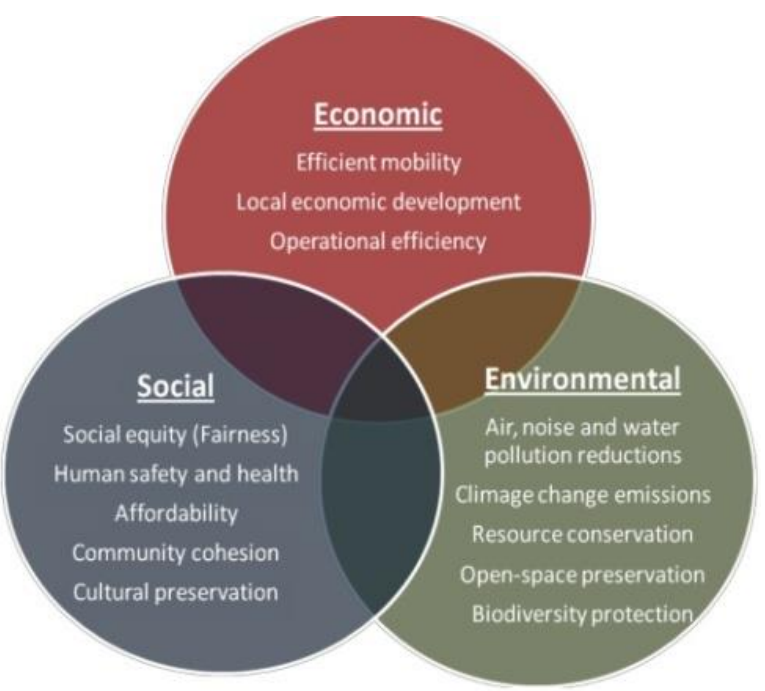

Figura 6 - Objetivos da sustentabilidade nos transportes. Fonte: Litman, 2014.

Esses gases e partículas causam uma série de doenças - principalmente cardiovasculares, respiratórias e pulmonares - e geram impacto direto nos orçamentos de saúde. Na Colômbia, por exemplo, os custos com saúde relacionados à poluição do ar nas cidades atingem $0,8 \%$ do PIB do país, ou algo em torno de 698 milhões de dólares ${ }^{28}$. Um estudo feito pela OCDE nos países membros estimou em US\$ 865 bilhões o custo relacionado aos impactos para saúde da poluição do ar, em função do transporte rodoviário. ${ }^{29}$

O efetivo custo social e econômico dos sistemas de transporte deve contabilizar também despesas indiretas relacionadas a congestionamentos, acidentes de trânsito, manutenção e construção de infra estrutura, poluição sonora e do ar e aos eventuais efeitos para o processo de aquecimento global e de mudanças climáticas. Em Beijing, China, o custo social do transporte motorizado decorrente da poluição, dos acidentes de trânsito e dos

\footnotetext{
${ }^{28}$ SÁNCHEZ-TIRANA et al. (2007) apud UNEP (2011, p.385)

${ }^{29}$ OCDE. The cost of air pollution: health impacts of road transport. 2014. Disponível em: $<$ http://www.oecd-ilibrary.org/docserver/download/9714031e.pdf?expires= 1410895607\&id=id\&accname=0cid54025470\&checksum=3EE2B4528B5E5E43DB5A66E5DF4 5C1F0>. Acesso em: 10/09/2014.
} 
congestionamentos é estimado entre 7,5 e $15 \%$ do PIB da cidade ${ }^{30}$, algo entre 19 e 40 bilhões de dólares ${ }^{31}$.

Segundo a OMS, mais de 1.27 milhões de pessoas morrem por ano em função de acidentes de trânsito, principalmente nos países menos desenvolvidos. As nações do hemisfério sul respondem por $3 / 4$ dos acidentes registrados com veículos, embora a maior parte da frota esteja no hemisfério norte. Até 2020 , os acidentes devem se tornar a terceira maior causa de mortes e invalidez (Cervero, 1998, p.48) e cerca de metade das vítimas é formada por pedestres, ciclistas e motociclistas pela inexistência de infraestrutura adequada para o transporte.

Leite et al. (2012) definem cinco parâmetros que devem ser considerados no planejamento de um eficiente sistema de transportes: (1) desestímulo ao uso do automóvel; (2) melhoria do sistema de transporte coletivo integrado; (3) integração do uso do solo e do sistema de transportes, (4); estímulo ao transporte não motorizado; (5) estímulo por soluções inovadoras de transporte individual; e (6) mobilidade urbana inteligente.

Não é coincidência que o desestímulo ao uso do automóvel apareça em primeiro lugar na lista. Em 1990, havia 500 milhões de automóveis no planeta. Atualmente há cerca de 800 milhões e estimativas feitas pela AIE indicam que este número poderá chegar a 3 bilhões de veículos até 2050 (Replogle et al., 2012, p.57).

A distribuição da frota de automóveis ao redor do planeta ainda é bastante desigual. Enquanto nos Estados Unidos existem 797 veículos para cada 1000 habitantes, entre os países integrantes dos BRICS, por exemplo, a relação é muito menor: no Brasil, são 209; na China, 50; na Rússia, 271; e na Índia, $18^{32}$. O potencial de crescimento do número de veículos nos países em desenvolvimento evidencia a necessidade de se buscar alternativas para mobilidade urbana.

Na última década, houve um aumento de $77,8 \%$ na frota de automóveis nas regiões metropolitanas brasileiras, o que representou mais 8,9 milhões de

\footnotetext{
${ }^{30}$ CREUTZIG et al. (2009 apud UNEP 2011, p.384).

${ }^{31}$ Considerando um PIB de US\$253.3 bilhões (dados de 2011). Fonte: <www.china.org.cn>. Acesso em 18/02/2013.

32 Banco Mundial. Dados sobre número de veículos motorizados para 1000 habitantes. Os dados incluem carros, ônibus e caminhões, mas excluem motocicletas. A população refere-se à média do ano em que os dados foram colhidos. Os dados são referentes aos anos de 2010 (EUA e China); 2009 (Índia e Rússia) e 2008 (Brasil) Disponível em: <http:IIdata.worldbank.org/indicators/IS.VEH>NVEH.P3/countries/1W?dsplay=default>.
} 
veículos em circulação ${ }^{33}$. O número de motocicletas apresentou um crescimento ainda maior, de $289,4 \%$, equivalente a mais 3.1 milhões de unidades nas ruas ${ }^{34}$. As consequências sociais, econômicas e ambientais desse acréscimo já são sentidas nas ruas das principais cidades brasileiras.

Os congestionamentos se tornaram pandêmicos na maioria das cidades, gerando perda de tempo, energia, poluição do ar, stress, prejudicando a produtividade no trabalho e levando motoristas a se tornarem mais imprudentes, elevando o risco de acidentes (Cervero, 1998, p.40) ${ }^{35}$.

De maneira geral, o acréscimo no número de veículos vem acompanhado da redução na participação do transporte público na estrutura de mobilidade urbana das cidades (Cervero, 1998). No Brasil, segundo dados da ANTP, disponíveis para os anos de 2003 a 2011, a participação do transporte público recuou de 29,80\% (2003) para 28,90\% (2011). No mesmo período, o uso do transporte individual passou de $28,8 \%$ para $30,9 \%{ }^{36}$. Ainda que este aumento percentualmente não seja muito expressivo, em valores absolutos representa mais 4,70 billhões de viagens anuais realizadas por automóveis e motos.

Como observa Cervero (1998), persuadir os motoristas a substituir o carro por outros meios de transporte não é uma tarefa simples, pois o veículo individual é mais rápido e fornece a comodidade do deslocamento porta-aporta. Em algumas cidades da Europa e EUA, onde o transporte público é feito exclusivamente através de ônibus, algumas pesquisas demonstraram que o transporte individual chega a ser duas vezes mais rápido que o transporte público. Nas cidades que possuem maior infraestrutura,

\footnotetext{
${ }^{33}$ A frota de automóveis nas regiões metropolitanas representa $44 \%$ do total de automóveis em circulação no país. Fonte: Observatório das Metrópoles - Crescimento da frota de automóveis e motocicletas nas metrópoles brasileiras 2001/2011. Disponível em:

<http:Ilobservatoriodasmetropoles.net> Acesso em: 01/03/2013.

${ }^{34}$ A frota de motocicletas nas regiões metropolitanas representa $23,3 \%$ do total de unidades em circulação no país. Ibid.

${ }^{35}$ Tradução do autor.

${ }^{36}$ ANTP - Sistema de Informações da Mobillidade Urbana: Relatório comparativo 2003-2011. Tab. 05. Os índices se referem ao conjunto de municípios que integram o sistema de informações, com população superior a 60 mil habitantes. O relatório comparativo engloba todo o conjunto de municípios, contudo, no relatório gerencial da ANTP de 2012, p.7. Gráfico 06, observa-se que em função do tamanho do município, há considerável variação na participação dos modais de transporte. Enquanto em municípios com mais de um milhão de habitantes, o TC representa $36 \%$ do total de viagens, nas que possuem entre 60 e $100 \mathrm{mil}$ habitantes, o índice é de $19 \%$. O uso da bicicleta, ao contrário, cresce à medida que o município diminui, sendo de $1 \%$ nas maiores e $13 \%$ nas menores cidades. Entretanto, no caso do Rio de Janeiro, conforme dados do Plano Diretor de Transporte Urbano (2013), houve entre 2003 e 2012 aumento na participação dos transportes coletivos no total de viagens diárias bem como do transporte individual (ver estudo de caso, Capítulo 4).
} 
especialmente ferroviária, o tempo de viagem do transporte individual chega a ser $23 \%$ mais rápido (ibid., 1998, p.41).

O desenvolvimento de políticas de transporte sustentável passa necessariamente pela questão do transporte motorizado individual. Reduzir a influência do automóvel nas cidades é um fator determinante para o desenvolvimento sustentável das cidades, nas suas dimensões social, econômica e ambiental. Como afirma Rogers (2001, p.35):

[...] o automóvel foi o principal responsável pela deterioração da coesa estrutura social da cidade [...] os cerca de 500 milhões de carros em todo o mundo destruíram a qualidade dos espaços públicos e estimularam a expansão urbana para bairros distantes [...] e quanto maiores as cidades, mais antieconômico era expandir o sistema de transporte público, e mais dependentes de seus carros ficavam os cidadãos. Em todo o mundo as cidades estão sendo transformadas para facilitar a vida dos carros, mesmo que sejam eles, e não as indústrias, os responsáveis pela maior parcela de poluição do ar [...] Paradoxalmente, sob a perspectiva do indivíduo, o carro permanece como o produto tecnológico mais desejado e libertador do século.

O espraiamento do tecido urbano comprovou ser um problema para o sistema de transporte público, que não consegue competir com a comodidade do transporte individual. Além disso, a densidade urbana é um fator determinante para o cálculo da quantidade de energia utilizada pelo transporte individual. Segundo Dodman (2009, p. 193) as cidades mais densas apresentam menor consumo energético para o transporte privado, gerando menores emissões de GEE.

A atração das pessoas pelo automóvel, característica da sociedade moderna, criou o que Cervero (1998) chama de "estilo de vida autodependente" ${ }^{37}$, que acarreta, além dos problemas já mencionados, o isolamento "físico e social" de segmentos da sociedade que não têm acesso ao carro, seja pela idade, por limitações físicas ou pela condição social. Essas pessoas acabam sendo colocadas à margem de parte significativa da vida urbana.

O sedentarismo também é uma consequência do "estilo de vida autodependente" e é um fator que contribui para o aparecimento de uma série de doenças crônicas como obesidade, hipertensão, diabetes e doenças cardiovasculares. A obesidade está alcançando proporções de epidemia. Nos EUA, mais de $60 \%$ da população apresenta sobrepeso e $30 \%$ já é considerada obesa. Anualmente, ocorrem mais de 300.000 mortes

\footnotetext{
${ }^{37}$ Auto-dependent lifestyle.
} 
prematuras em decorrência da falta de exercícios e do excesso de peso ${ }^{38}$. No Brasil, dados do IBGE mostram que, na população com mais de 20 anos, o sobrepeso atinge $50,1 \%$ dos homens e $48 \%$ das mulheres e a obesidade, $12,4 \%$ e $16,9 \%$, respectivamente ${ }^{39}$.

Para incentivar a redução do uso do automóvel particular, é necessária uma política de transportes abrangente, capaz de atuar tanto do lado da demanda, com medidas que limitem ou dificultem a circulação de veículos, como do lado da oferta, com mecanismos capazes de absorver de maneira satisfatória os usuários que deixarem de utilizar o transporte individual.

Em 2004, o Ministério das Cidades instituiu o Programa Brasileiro de Mobilidade por Bicicleta - Bicicleta Brasil ${ }^{40}$, com o objetivo de estimular o uso da bicicleta na matriz de deslocamentos urbanos, baseado no conceito de mobilidade urbana sustentável.

\begin{abstract}
A mobilidade urbana sustentável pode ser definida como o resultado de um conjunto de políticas de transporte e circulação que visa proporcionar o acesso amplo e democrático ao espaço urbano, através da priorização dos modos não motorizados e coletivos de transporte, de forma efetiva, que não gere segregações espaciais, socialmente inclusiva e ecologicamente sustentável. Ou seja: baseado nas pessoas e não nos veículos [...] $O$ conceito de mobilidade que vem sendo construído nas últimas décadas encontra substância na articulação e união de políticas de transporte, circulação, acessibilidade e trânsito com a política de desenvolvimento urbano. (Ministério das Cidades, 2004, p.14).
\end{abstract}

O exemplo de cidades como Copenhagen, onde $30 \%$ das viagens são feitas por bicicleta (Cervero, 1998, p.71), demonstra que, resguardadas as particularidades de cada região, é possível transformar a bicicleta em uma efetiva opção de mobilidade que auxilie na redução do uso do transporte individual.

\footnotetext{
${ }^{38}$ Dados da National Health and Nutrition Examination Survey (NHA-NES). In: EWING et al (2003, p.47)

${ }^{39}$ Fonte: IBGE/POF 2008-2009. Disponível em:

$<$ www.ibge.gov.br/home/presidencia/noticias/noticia_visualiza.php?id_noticia=1699>. Acesso em: 30/03/2013.

${ }^{40}$ Portaria 399/2004. Disponível em:< www.cidades.gov.br/index.php/progsemob/184bikebrasil>. Acesso em: 31/05/2013.
} 


\section{3}

\section{O transporte cicloviário}

Os problemas decorrentes do uso crescente do transporte individual poluição e congestionamentos em especial - têm sido historicamente enfrentados com medidas que lidam tanto com o lado da demanda buscando reduzir o volume de tráfego ou distribuí-lo de forma mais homogênea nos diferentes períodos do dia, nas diversas áreas da cidade ou nos diversos modais de transporte disponíveis - quanto do lado da oferta com ações que buscam oferecer alternativas que possam se ajustar às necessidades de deslocamento dos indivíduos (Cervero, 1998, p.62).

Dentre as medidas relacionadas à oferta, a bicicleta pode exercer um relevante papel, tanto como modal alimentador de rotas de transporte público (ibid., p.71) ${ }^{41}$, quanto como alternativa a outros modais para viagens de curta distância (Buis et al., 2000, p.48).

O transporte cicloviário é capaz de competir com outros modais em viagens curtas de até $5 \mathrm{~km}$ - ou no limite máximo de $7,5 \mathrm{~km}$ (considerando a velocidade média de $15 \mathrm{~km} / \mathrm{h}$ e a duração de 30 minutos). Sua limitação é fruto do meio de tração, baseado no esforço físico do usuário (Geipot, 2001, p.11), mas inúmeros fatores também são capazes de influenciar seu raio de ação como o clima, a topografia, as condições de tráfego e a infraestrutura disponível.

Para Wittink et al. (2009, p.19), um dos objetivos mais relevantes de uma política de transporte sustentável deve ser o de maximizar os benefícios que cada modal é capaz de oferecer para atender tanto as necessidades dos indivíduos quanto as necessidades da sociedade.

To optimize bicycle use and its contribution to a city's social, economic and environmental performance, we need a better balance between cycling, walking, private and public transport. This is essentially a political choice. Just as building for cars has brought these vehicles flooding into every nook and cranny of our beleaguered cities, planning and integrating cycling can increase its modal share. Where this is carefully done, by reducing space available to cars and enhancing and increasing space for walking, public transport and cycling, some car trips may be eliminated altogether, through more judicious

\footnotetext{
${ }^{41}$ Segundo Cervero (1998, p.71), mais de $30 \%$ das viagens totais realizadas na Holanda e aproximadamente $25 \%$ das viagens para estações de trem são feitas através de bicicleta.
} 
planning of routes, and some will actually shift to other, more sustainable and city-friendly modes (Wittink et al. coord., 2009, p.20).

Apesar de normalmente estar associado à sustentabilidade em função da baixa ou nula emissão de poluentes, inúmeras outras características relacionadas ao desenvolvimento sustentável podem ser associadas ao transporte cicloviário:

- sua utilização não causa impacto na fauna e na flora e não gera resíduos (Fernández, 2011, p.23);

- possui "baixa perturbação ambiental", produzindo praticamente nenhum ruído com sua utilização (Pucher et al. 2012, Geipot, 2001, p.9);

- o ciclo de fabricação da bicicleta é muito reduzido se comparado ao de outros modais de transporte (Fernàndez, 2011, p.23).

- consome uma quantidade de recursos não renováveis muito inferior à de qualquer modal motorizado. A energia necessária para sua movimentação é fruto do esforço humano (Geipot, 2001, p.12; Pucher et al.,2012);

- possui um custo de implantação inferior ao dos demais modais de transporte (Shaheen et al, 2010; Pucher et al., 2008) ${ }^{42}$.

- reduz o custo operacional do transporte público, pois o modal cicloviário não necessita de pontos de abastecimento de combustível e a manutenção de sua infraestrutura demanda um número de funcionários menor do que a de outros modais (Fernández, 2011, p.23).

- pode contribuir para redução da demanda por transporte público e consequentemente pela redução da necessidade de investimentos na sua ampliação (NY, 2009);

\footnotetext{
42 Buis et al. (2000), em seu estudo sobre o significância econômica do transporte cicloviário, argumentam que a diferença de custo da infra estrutura cicloviária para a rodoviária não é tão significativa quando comparado o valor por metro quadrado da sua implantação. Os autores argumentam que o custo de pavimentação de uma ciclovia e de uma rodovia são similares já que para incentivar o uso da bicicleta é muito importante que se executem infraestruturas de alta qualidade. $O$ que acarreta um custo maior para o transporte rodoviário é a área total necessária para seu pleno funcionalmento, que é superior ao da infra-estrutura cicloviária. Sobre esse aspecto, para que houvesse ganho econômico expressivo no uso da bicicleta, seria necessário que o aumento da participação do modal cicloviário fosse suficiente para acarretar a redução da necessidade de investimentos rodoviários.
} 
- o equipamento possui baixo custo de aquisição e manutenção (Geipot, 2001, p.9);

- seu custo de utilização é mais barato quando comparado a modais de transporte público e, especialmente, ao transporte individual (Pucher et al., 2012);

- pode auxiliar na redução de congestionamentos não somente pela substituição de outros modais, mas por necessitarem de uma parcela muito menor do espaço necessário para o uso e estacionamento de veículos. Em uma hora podem passar até 1.500 bicicletas por metro de largura de via. Uma via de $3 \mathrm{~m}$ comporta um fluxo de 4.500 bicicletas, enquanto permite a passagem de 450 automóveis aproximadamente e no espaço destinado a uma vaga de carro, podem ser acomodadas 10 bicicletas. (Geipot, 2001,p.11);

- segundo o escritório regional para Europa da OMS, os benefícios do uso da bicicleta são 4 a 5 vezes maiores do que seus custos de investimento $^{43}$ (Dehaye, 2007 apud Fernández, 2011, p.23).

- especialmente para países menos desenvolvidos, nos quais os custos do transporte são altos para uma parcela significativa da população, a bicicleta permite maior democratização da mobilidade urbana, melhorando o acesso ao mercado de trabalho e aos equipamentos urbanos (Pucher, 2012);

- o uso da bicicleta também é um meio bastante efetivo para garantir que parte da população faça exercícios regulares. Seus efeitos positivos na saúde pública superam em muito os efeitos negativos decorrentes de eventuais acidentes. A utilização diária da bicicleta por um período de 30 minutos por pessoas que praticam poucos exercícios possibilita uma redução de $50 \%$ do risco de desenvolver doenças cardio-vasculares, diabetes e obesidade (Buis et al., 2000). Além disso, a transferência de usuários de modais motorizados para não motorizados acarreta redução das emissões de poluentes e consequentemente melhoria na saúde da população de maneira geral (Fernández, 2011, p.24).

${ }^{43}$ Considerando redução de custos relacionados a saúde, acidentes, estacionamento e prejuízos ambientais. 


\section{4}

\section{Resumo do capítulo}

O conceito de desenvolvimento sustentável, quando associado ao espaço urbano, ultrapassa os limites do discurso ambiental para considerar também os aspectos econômicos e sociais relacionados à complexidade das atividades humanas. Neste contexto, os sistemas de transporte podem exercer um papel relevante pois têm o potencial de contribuir positivamente para a qualidade de vida nas cidades, atuando nas dimensões social, econômica e ambiental do desenvolvimento sustentável.

O modelo de desenvolvimento urbano que privilegia o uso do automóvel particular vem causando sérios prejuízos à qualidade de vida nas cidades e a perspectiva de crescimento da frota de veículos, especialmente nos países em desenvolvimento, evidencia a necessidade de se buscar alternativas a esse modelo.

Entre as diversas alternativas que podem ser implantadas para tentar reduzir o impacto do transporte individual na qualidade de vida das cidades está o incentivo ao transporte cicloviário. A bicicleta tem o potencial de atuar tanto de forma complementar ao sistema de transportes público, aumentando o seu alcance e a sua atratividade, quanto substituindo modais motorizados, inclusive o transporte individual, em viagens de curta distância.

O incentivo ao transporte não motorizado demanda um conjunto de políticas públicas integradas que por um lado desestimulem o uso do transporte individual e por outro ofereçam aos usuários condições de conforto e segurança que tornem a bicicleta um modal de transporte atrativo no contexto da mobilidade urbana. 


\section{Sistemas de compartilhamento de bicicleta}

\section{1}

\section{Principais características dos SCB}

Por seus benefícios sociais, econômicos e ambientais, o transporte cicloviário vem gradativamente recebendo mais atenção na busca por soluções que possibilitem a redução do papel desempenhado pelo automóvel na mobilidade urbana. Entre as diversas estratégias para incremento da participação da bicicleta como meio de transporte, a implementação de sistemas de compartilhamento de bicicletas vem se difundindo rapidamente, especialmente na última década, e vem sendo incorporada às políticas de mobilidade em cidades por todo o planeta.

Esses sistemas oferecem a possibilidade de utilizar a bicicleta sem a necessidade de arcar com os custos decorrentes da aquisição e da manutenção do equipamento e podem ser utilizados a partir de uma demanda específica de deslocamento, permitindo percorrer trajetos de sentido único sem a necessidade de retornar ao ponto de origem para devolver a bicicleta (Shaheen et al., 2010, p.1).

Os SCB diferem do aluguel de bicicletas, segundo Midgley (2009, p.23), por:

- permitirem a devolução das bicicletas em local distinto ao da retirada;

- permitirem o acesso fácil e rápido e na maioria das vezes automatizado às bicicletas;

- fazerem uso de tecnologias como telefonia móvel ou smart cards;

- possuírem diferentes modelos de negócio;

- serem projetados como parte do sistema público de transportes.

De maneira geral, os SCB consistem em uma frota de bicicletas, uma rede de estações de auto-serviço (nas quais os equipamentos podem ser guardados quando não estão em uso), um sistema para registro de usuários e 
para consulta sobre a disponibilidade de bicicletas nas estações, e uma estrutura operacional para manutenção dos equipamentos e distribuição de bicicletas nas estações (Translink, 2008, p.3).

Quando projetados como parte do sistema público de transportes, os SCB são voltados especialmente para os deslocamentos de curta distância, substiituindo outros modais, funcionando com "ponte" entre áreas que não são servidas de maneira eficiente pelo sistema de transportes ou exercendo a função de alimentadores dos transportes públicos de maior capacidade (Translink, 2008; Shaheen et al., 2012).

Por isso a maioria dos SCB limita o tempo máximo da viagem como forma de fomentar sua rotatividade e têm como premissa manter um custo de utilização baixo para o cliente como forma de atrair usuários para o uso da bicicleta.

\section{2}

\section{Histórico dos sistemas de compartilhamento de bicicleta}

Os primeiros sistemas públicos de compartilhamento de bicicleta surgiram na Europa, no fim da década de 60. Operavam em pequena escala, sem fins lucrativos, e foram criados com foco nos aspectos sociais e ambientais do uso da bicicleta (Shaheen et al., 2012). Sua evolução histórica costuma ser dividida pela maioria dos autores em três fases, ou gerações.

\subsection{1}

\section{Primeira Geração: “White Bikes” ou "Free Bike Systems”44}

Em julho de 1965, o Provos - movimento social holandês - contestando a "cultura do automóvel" (Liberato, 2004) e com o objetivo de melhorar o sistema de transportes na cidade de Amsterdam, lançou o "Plano das Bicicletas Brancas". Este plano previa que o poder público adquirisse bicicletas para serem disponibilizadas para livre utilização da população.

\footnotetext{
${ }^{44}$ Definição de Shaheen et al. (2012)
} 
[...] Basta com o asfáltico terror da classe média motorizada! Todo dia, as massas oferecem novas vítimas em sacrifício ao último patrão a quem se dobraram: a auto-ridade. O sufocante monóxido de carbono é seu incenso. A visão de milhares de automóveis infecta ruas e canais [...] A bicicleta branca estará sempre aberta. A bicicleta branca é o primeiro meio de transporte coletivo gratuito [...] A bicicleta branca está à disposição de quem quer que dela necessite. Uma vez utilizada, nós a deixamos para o usuário seguinte. As bicicletas brancas aumentarão em número até que haja bicicletas suficientes para todos, e o transporte branco fará desaparecer a ameaça automobilística. A bicicleta branca simboliza simplicidade e higiene diante da cafonice e da sujeira do automóvel. Uma bicicleta não é nada, mas já é alguma coisa. ${ }^{45}$

O plano não foi aceito pelas autoridades, levando o Provos a criar seu próprio sistema composto por cinquenta unidades de bicicletas pintadas de branco que ficavam nas ruas para uso público (Wikipedia, 2013). Como observa Liberato (2004), o "Provos foi percursor de uma crítica ecológica e social ao automóvel" e seu plano, apesar de não ter tido êxito e ter sido extinto pouco tempo depois de implantado em função dos furtos, dos danos e do confisco dos equipamentos (DeMaio, 2009 apud Fernández, 2011, p.29), serviu de inspiração para diversos outros sistemas de compartilhamento de bicicletas.
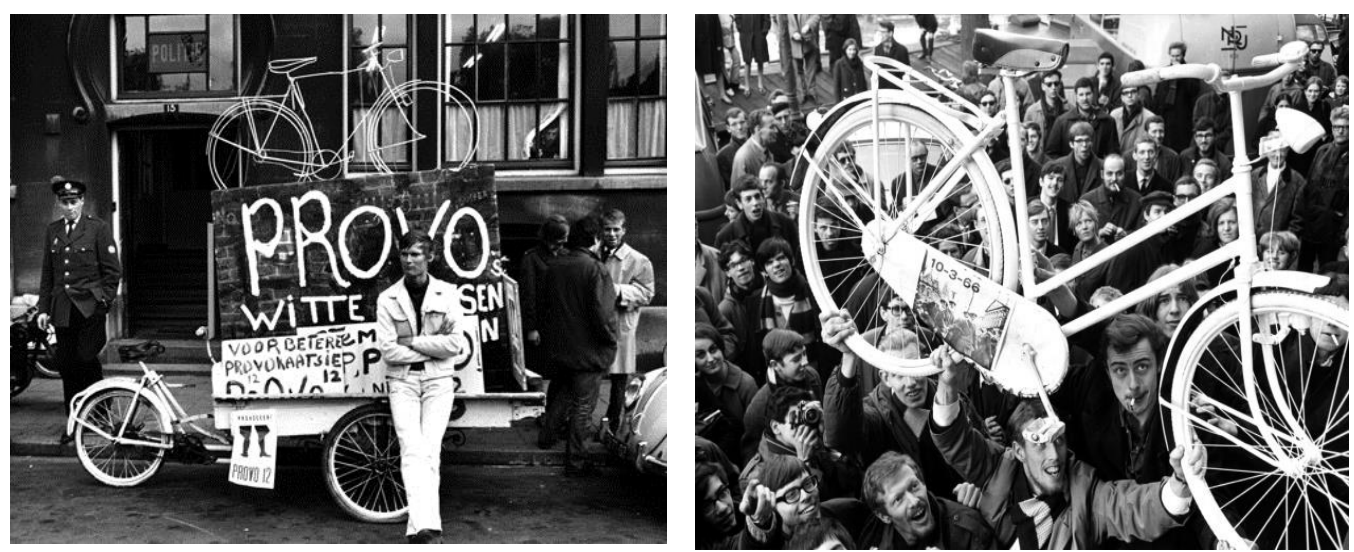

Figura 7 - White Bikes of Amsterdam. Fonte: www.provo-katie.com.br.

Outros SCB gratuitos foram implantados nas cidades de La Rochelle (França) e Bremen (Alemanha), respectivamente em 1973 e 1974. O sistema alemão durou apenas 3 meses. Foi o tempo necessário para que a frota fosse reduzida de 300 para 55 bicicletas. Outros exemplos de SCB de $1^{1 \stackrel{a}{ } \text { geração }}$ foram implementados em Milão (Itália), na década de 80, e em Cambridge (Inglaterra) em 1993. Nos dois casos, os resultados foram semelhantes aos

\footnotetext{
45 Trecho traduzido do Plano das Bicicletas Brancas. Fonte: GUARNACCIA, M. Provos: Amsterdam e o nascimento da contracultura. p.76. São Paulo: Conrad, 2001.
} 
de Bremen. Roubos e danos aos equipamentos decretaram seu fim em pouco tempo. (Fernández, 2011, p. 31) ${ }^{46}$.

As principais características dos SCB de primeira geração eram a gratuidade da bicicleta, a ausência de locais fixos para guardar e retirar as bicicletas, a ausência de sistemas de trancamento e a pintura, usualmente de uma cor brilhante (Shaheen et al. 2011, p.3). Como não havia tecnologia capaz de controlar os usuários, os deslocamentos e o tempo das viagens, não era possível punir quem roubasse ou danificasse os equipamentos.

Segundo Fernández (2011), tais aspectos foram cruciais para o fracasso desses programas, sobrepondo-se às suas vantagens (facilidade para pegar e devolver as bicicletas e necessidade de pequena estrutura organizacional para operação) e tornando-os inviáveis economicamente.

\subsection{2}

\section{Segunda Geração: Coin-Deposit Systems ${ }^{47}$}

Os problemas apresentados pelos SCB gratuitos levaram o governo municipal e a City Bike Foundation of Copenhagen (Dinamarca) a desenvolver um novo modelo cujas principais caracterísiticas eram a necessidade de efetuar depósitos para liberação das bicicletas e a existência de bases fixas para sua retirada e devolução.

O Bycyklen, lançado em 1995, foi o primeiro programa de segunda geração implantado em larga escala da Europa ${ }^{48}$. Possuía, na época do lançamento, 1.100 bicicletas (Shaheen et al., 2012), especialmente desenhadas para uso intensivo e utilitário, com design diferenciado, pneus de borracha sólida e rodas nas quais era possível fixar publicidade (DeMaio, 2004, p.42).

\footnotetext{
${ }^{46}$ Segundo Shaheen et al. (2011), o projeto Yelo Bici, de La Rochelle, foi "lançado como uma medida ambientalmente progressiva" e foi o primeiro caso de sucesso de SCB na França. Os autores, contudo, não discorrem sobre o que levou este sistema a ter um destino diferente dos demais de primeira geração.

47 Definição de Shaheen et al. (2012).

48 O sistema de Copenhagen foi o primeiro a ser implantado em larga escala. Contudo, segundo DeMaio (2004) Grenå e Nakskov, também na Dinamarca, já haviam implantado, respectivamente, em 1991 e 1993 os primeiros sistemas de segunda geração.
} 
As bicicletas eram liberadas mediante o depósito de uma taxa de 20 coroas dinamarquesas que era devolvida na entrega do equipamento. Além disso, só era permitido circular em áreas pre-determinadas da cidade, ficando sob responsabilidade da polícia supervisionar sua circulação (Fernández, 2011, p.31).

Segundo Shaheen et al. (2009, apud Fernández, 2011), o seu financiamento provinha de verbas oriundas da venda de espaços publicitários nas bilicletas e a manuteção do sistema era feita por um departamento da Rehabilitation Agency of Copenhagen em conjunto com organizações não governamentais que contratavam e treinavam pessoas com risco de exclusão social.

Os resultados obtidos pelo Bycyklen fizeram com que o modelo fosse copiado e expandido para diversas cidades da Europa e da América do Norte, como Viena (Áustria), Helsinki (Finlândia), Aveiro (Portugal), Hannover (Alemanha), Minneapolis, Austin e Princeton (EUA), entre outras (Shaheen et al., 2012; Fernández, 2011).

Os sistemas de segunda geração se mostraram mas caros dos que os de primeira geração, por isso era frequente a criação de organizações sem fins lucrativos para administrar os programas e em muitos casos o poder público tinha que contribuir com o financiamento dessas organizações (Shaheen et al., 2010, p.3).
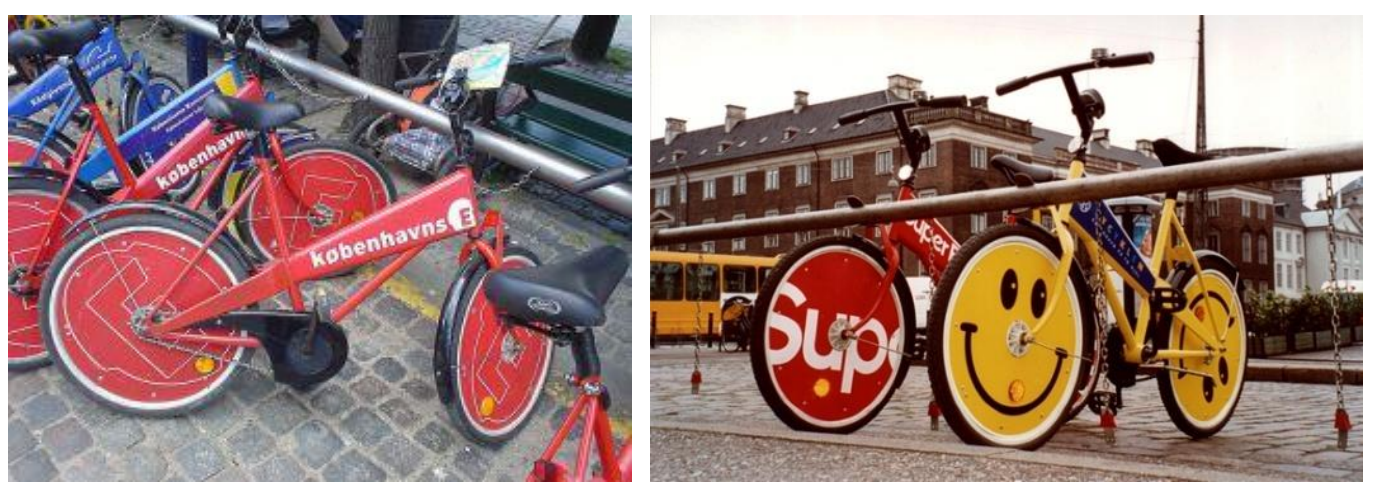

Figura 8 - Bycyklen, Copenhagen. Fonte: <http://umbebike.wordpress.com>.

Apesar deste novo modelo de SCB exigir um depósito prévio para liberação das bicicletas, o valor não podia ser alto para não desestimular o uso do sistema. Além disso, os usuários continuavam anônimos. Por isso, os problemas com furtos e danos persistiram. 
Both the first and second generation bikesharing schemes provided welcome opportunities to cycle but did not provide adequate enough support nor reliable service to alter motorized transportation choices and influence people to make significant changes (Bonnette, 2007 apud Shaheen et al.,2011, p.4).

Os problemas dos SCB de segunda geração, assim como os da primeira, continuaram a afetar seu balanço financeiro e os que que ainda conseguem permanecer em funcionamento provavelmente desaparecerão ou serão substituídos por sistemas de terceira geração (Fernández, 2011).

As atividades do Bycyklen foram encerradas em 2012. Em seu lugar será implementado um novo sistema, GoBike, que prevê a incorporação de inovações tecnológicas às bicicletas. Todas virão com um tablet/PC integrado que possibilitará ao usuário consultar informações sobre trajetos, mapas, horários de trens e outros meios de transporte entre outras informações ${ }^{49}$.
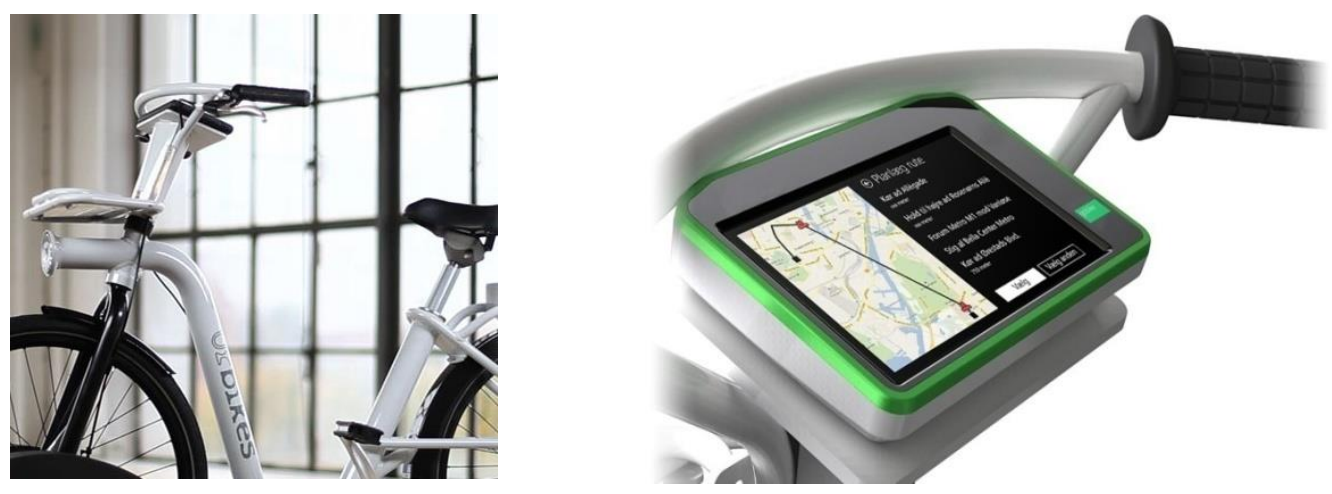

Figura 9 - GoBike, Copenhagen. Fonte: < http://gobike..com>.

\subsection{3}

Terceira Geração: IT-Based Systems ${ }^{50}$

A partir das experiências adquiridas com a operação dos sistemas de segunda geração, foram desenvolvidas tecnologias que permitiram maior controle sobre os usuários e sobre os equipamentos. Isso possibilitou reduzir o impacto financeiro dos roubos e dos danos que caracterizou as gerações anteriores e é o principal fator responsável pelo salto observado no número de SCB nos últimos anos. A maioria desses novos sistemas se utiliza de

\footnotetext{
${ }^{49}$ Disponível em: <gobike.com/solution>. Acesso em: 12/12/2013.

50 Definição de Shaheen et al. (2012).
} 
alguma forma de controle sobre os usuários. São a chamada "terceira geração".

O primeiro desses sistemas foi implantado na Universidade de Portsmouth (UK), em 1996, para ligar duas áreas do campus que ficavam afastadas cerca de $3 \mathrm{~km}$ uma da outra. Com o objetivo de conectá-las de uma forma rápida e "ecológica", foi desenvolvido um sistema automatizado para cadastramento de usuários e para liberação das bicicletas.

Os usuários precisavam se registrar no programa para receberem um smartcard que era utilizado para abrir os locais onde as bicicletas ficavam guardadas. Caso não fossem devolvidas, ou o período de utilização fosse muito prolongado, o usuário poderia ser identificado e punido pelo operador do sistema (Black; Porter, 2010 apud Fernández, 2011, p.34).

O primeiro sistema de terceira geração a ser implantado de forma abrangente foi o Vélo à la carte, na cidade de Rennes (França), em 1998. Administrado pela empresa Clear Channel, possuía 25 estações e 200 bicicletas que ficavam disponíveis para utilização durante as 24 horas do dia, 7 dias por semana, mediante prévia inscrição. O período máximo de viagem era limitado a 2 horas e as estações estavam interconectadas por um sistema que possibilitava controlar o número de bicicletas disponíveis, permitindo também a sua redistribuição, feita através de pequenos veículos utilitários ${ }^{51}$.

$51<w w w . v e l o a l a c a r t e . f r e e . f r>$. Acesso em: 10/05/2014. 


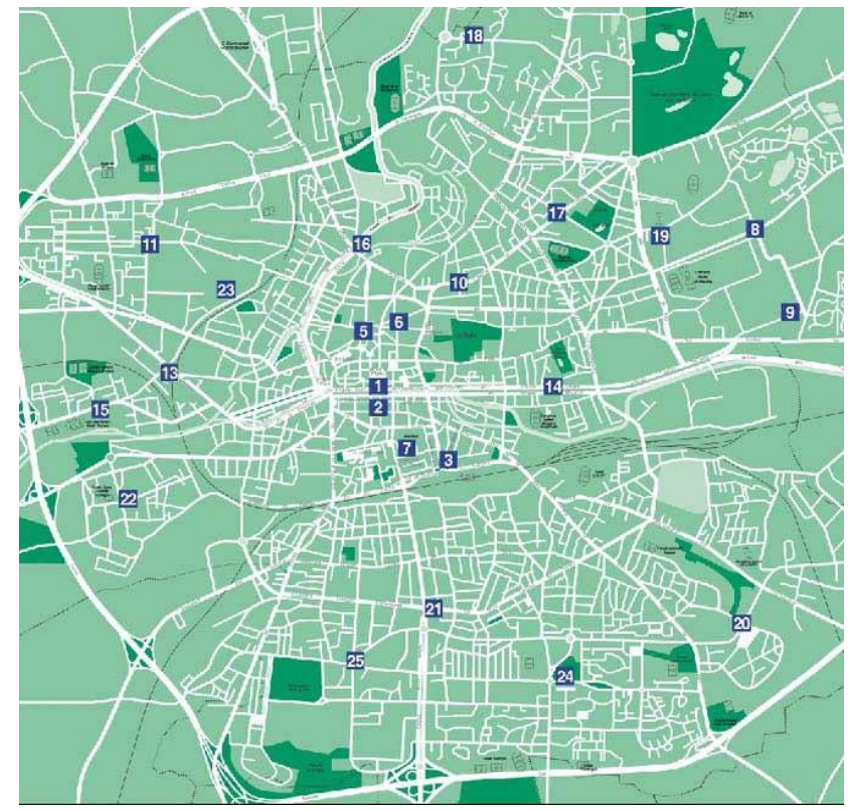

Figura 10 - Mapa de estações Vélo à la carte. Fonte:<www.veloalacarte.free.fr>.

Em 2009, o Vélo à la carte foi encerrado e susbtituído pelo Le Vélo Star com 900 bicicletas e 81 estações "posicionadas seguindo a lógica de um sistema de transportes [...] considerando os hábitos dos habitantes e sua necessidade de deslocamento" sendo "portanto, acessivel, intermodal e complementar." 52

Em 2005, uma empresa concorrente da Clear Channel, a JCDecaux, lançou em Lyon, França, o Vélóv, que popularizou a terceira geração de SCB (Shaheen et al., 2012). Este SCB conta com 340 estações e 4.000 bicicletas que atendem as cidades de Lyon e de Villeurbanne. Pelo contrato de operação, a JCDecaux tem direito à renda obtida pelo uso dos espaços publicitários disponíveis (Fernández, 2011, p.34).

\footnotetext{
52 https://www.levelostar.fr/fr/stations.html. Acesso em: 14/12/2013.
} 


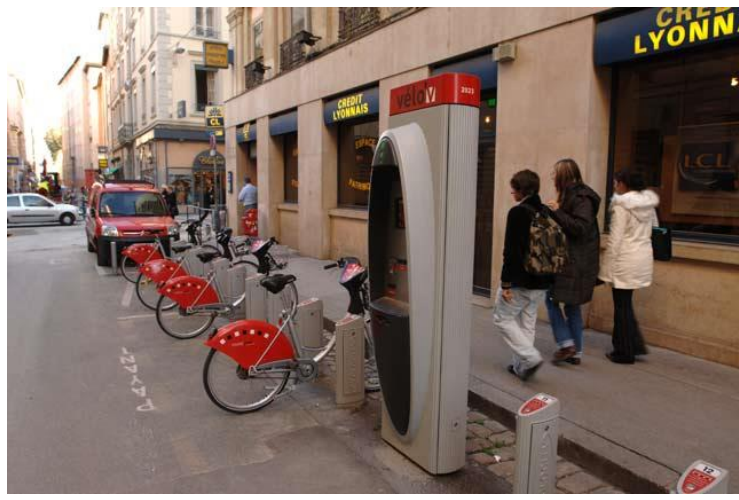

Figura 11 - Estação 2023 Velo'v, Lyon. Fonte:<www.velov.grandlyon.com>

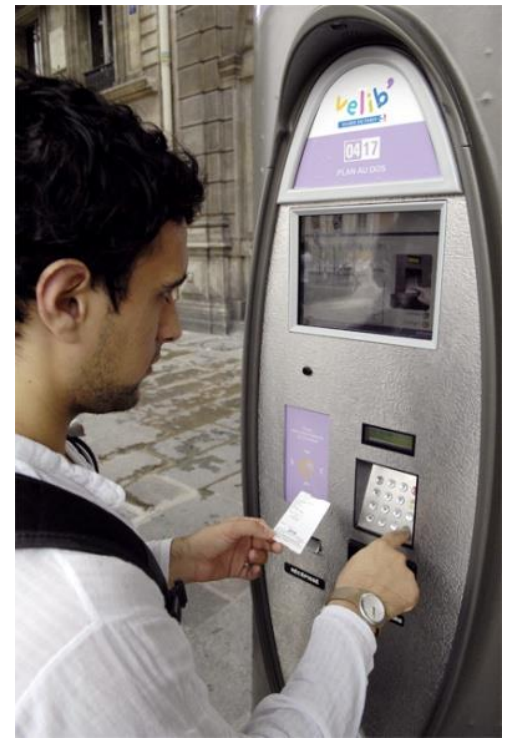

Figura 12 - Velib', Paris - Totem para liberação de bicicletas.

Fonte:<edf.keptos.net>

O usuário do Vélóv pode se deslocar gratuitamente por um período que varia entre 30 minutos e uma hora, dependendo do tipo de assinatura ${ }^{53}$. Após esse período, para incentivar a rotatividade, é cobrada uma taxa proporcional ao período de utilização. Esse mesmo modelo de operação foi posteriormente utilizado em Paris para implantação do sistema Velib', que se tornou o mais conhecido SCB de terceira geração e é atualmente o maior sistema em operação na Europa.

Os SCB de terceira geração se espalham atualmente por todo o planeta. Ainda que a Europa concentre o maior número desses sistemas, a Ásia é atualmente seu maior mercado potencial. Dos dez maiores programas em operação atualmente, oito situam-se no continente asiático, em cidades chinesas ${ }^{54}$.

O mais conhecido SCB chinês está situado na cidade de Hangzhou e até pouco tempo era o maior em operação no país ${ }^{55}$. Inaugurado em 2008, possui $60.600^{56}$ bicicletas e 2.435 estações em uma cidade cuja população na

\footnotetext{
53 www.velov.grandlyon.com. Acesso em: 14/12/2013.

${ }^{54}$ Fonte: < www.earth-policy.org>

${ }^{55}$ Foi ultrapassado pelo da cidade de Wuhan, com 90.000 bicicletas. LARSEN, J. Bike-sharing programs hit the streets in over 500 cities worldwide. 2013. Disponível em: <http://www.earthpolicy.org/plan_b_updates/2013/update112>.

${ }^{56}$ A quantidade de bicicletas do SCB de Hangzhou varia em função da fonte. Para Shaheen et al. (2011) são 60.600; para Larsen (2013), são 69.750; para o ITDP <www.publicbike.net> são 65.000 .
} 
área urbana é de 5.5 milhões de habitantes ${ }^{57}$. O sistema faz parte de um amplo projeto chamado Public Transit Priority lançado com o objetivo de estimular o uso do transporte público e conter o uso do automóvel particular reduzindo os efeitos negativos da poluição, dos congestionamentos e da falta de segurança no trânsito.

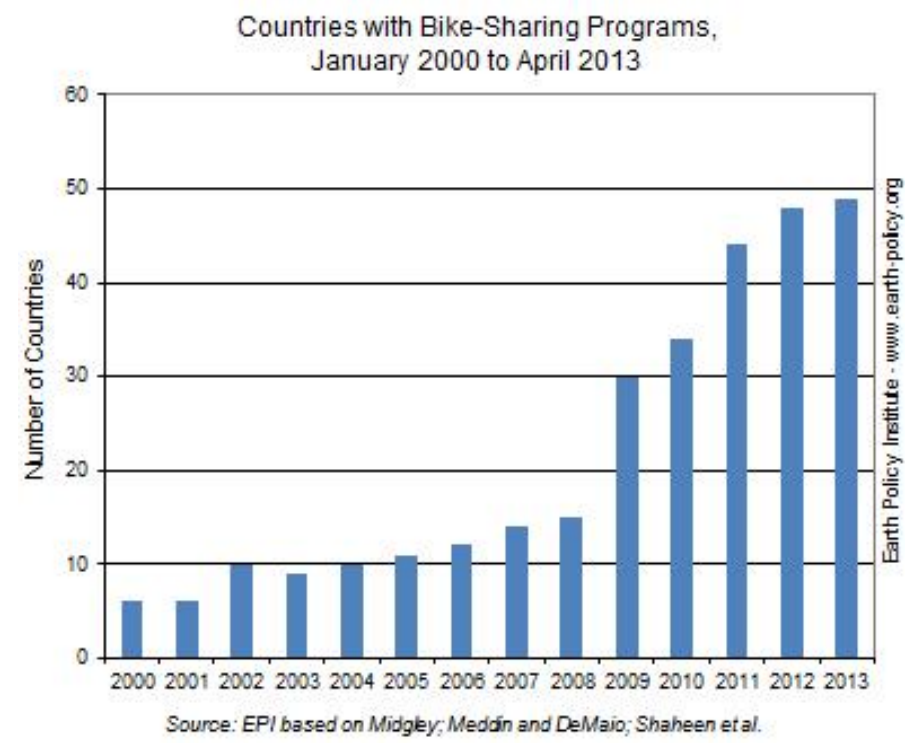

Figura 13 - Crescimento do número de países com SCB entre 2000 e 2013. Fonte: <www.earth-policy.org>

O SCB de Hangzhou é tratado como uma forma de incentivar a integração modal entre ônibus, metrô e bicicleta. Permite a utilização das bicicletas sem custo por um período de até uma hora e oferece desconto de $10 \%$ na utilização de BRTs e ônibus para seus usuários (Shaheen et al., 2011, p.4). Dados do ITDP (2013) indicam que são feitas por dia, em média, 325.000 viagens através desse sistema.

57 Dados de 2008. População total: 7.966 milhões de habitantes, dos quais 5.52 nos distritos urbanos. Fonte: <www.hangzhou.gov.cn>. Acesso em: 15/12/2013. 


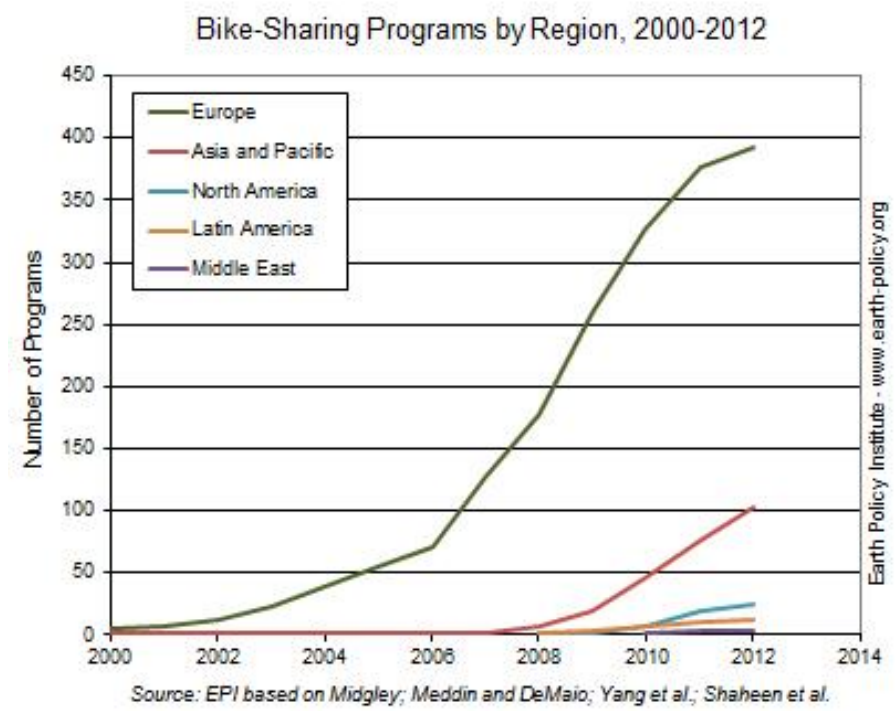

Figura 14 - Crescimento do número de SPC por região entre 2000 e 2013. Fonte: <www.earth-policy.org>

A evolução no número de SCB a partir da terceira geração demonstra que o desenvolvimento de tecnologias que permitiram o controle dos usuários e do tempo máximo de viagem (estimulando a rotatividade),possibilitou uma inversão do balanço entre os fatores negativos e positivos que limitaram as gerações anteriores. O modelo de financiamento através da venda de espaços publicitários também permitiu injetar recursos que possibilitaram aumentar o alcance dos sistemas, elevando a confiança nos seus serviços.

Contudo, conforme observa Fernández (2011), o vandalismo ainda é um fator que não deve ser negligenciado para manutenção da viabilidade econômica dos SCB. Além disso, a dependência das receitas decorrentes dos contratos de publicidade pode acabar prejudicando seu desenvolvimento no futuro. 


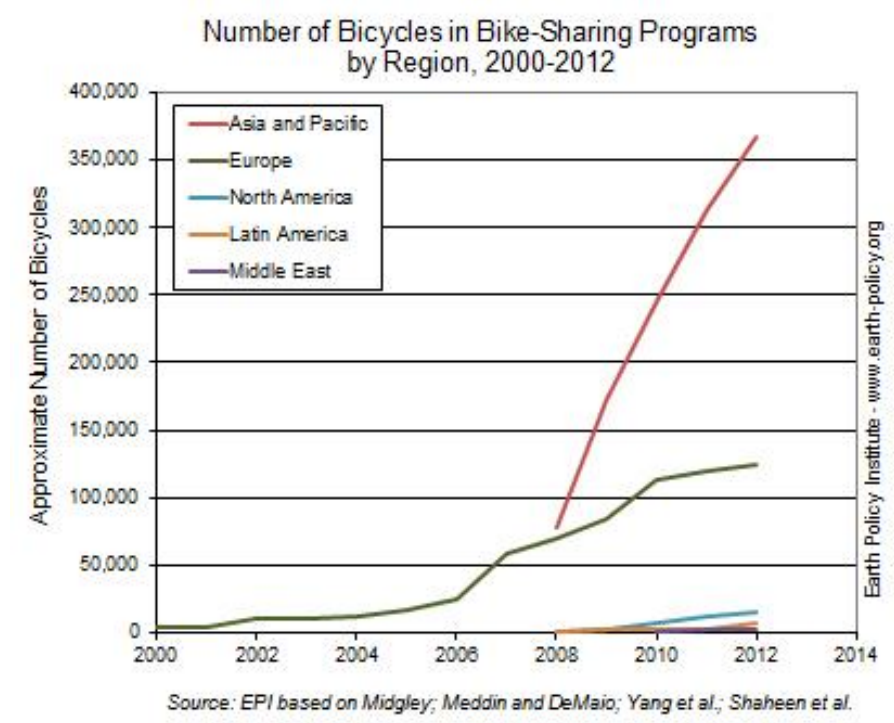

Figura 15 - Quantidade de bicicletas disponíveis por região. Fonte: <www.earth-policy.org>

\subsection{4}

\section{Quarta Geração: Demand responsive, multimodal systems ${ }^{58}$}

O aumento no número de SCB vem possibilitando o desenvolvimento de novas experiências para sua operação, utilização e manutenção. As inovações implementadas têm servido de base para o que alguns autores já chamam de quarta geração dos $\mathrm{SCB}^{59}$.

Suas principais características são a existência de estações flexíveis (ou até mesmo inexistência de bases para fixar as bicicletas), inovações no processo de distribuição das bicicletas, integração com os demais modais de transporte e avanços tecnológicos na operação e na utilização das bicicletas (Shaheen et al., 2012).

O sistema canadense Bixi, por exemplo, possui estações móveis que podem ser transferidas de local em função da demanda. Outra inovação, é a possibilidade, oferecida pelas novas tecnologias, de desconsiderar a necessidade de um equipamento urbano exclusivo para fixar as bicicletas. Através

\footnotetext{
${ }^{58}$ Definição de Shaheen et al. (2012).

59 Ao contrário das três gerações anteriores, muitas dessas experiências ainda estão em desenvolvimento, por isso não é consenso entre os autores considerar a existência de uma quarta geração de SCB com características semelhantes. Neste trabalho, optou-se por considerar as características descritas por Shaheen et al. (2012) como determinantes para caracterizar os sistemas de quarta geração, bem como sua nomenclatura.
} 
do celular, o usuário pode receber um código que permite destravar as bicicletas, possibilitando fixá-las em diversos equipamentos urbanos, aumentando a rede de estações e reduzindo os custos das instalações e da operação da infraestrutura.

O sistema Yélo, em La Rochelle, França, disponibiliza um smartcard que permite a utilização de todo o sistema de transportes da cidade ${ }^{60}$. Em Guangzhou, China, o sistema opera integrado ao BRT e ao metrô ${ }^{61}$. Em Montreal e no Rio de Janeiro, as estações são alimentadas por painéis solares, reduzindo o custo de infra estrutura e economizando energia. Em Paris, o Velib' utiliza pequenos veículos utilitáros especialmente desenhados para o transporte de bicicletas, facilitando sua distribuição e reduzindo a necessidade de utilizar veículos mais poluentes.

O desenvolvimento de novas tecnologias foi a chave para viabilizar a expansão global dos sistemas de compartilhamento de bicicleta. Seu aprimoramento deverá permitir a constante evolução e a expansão dos SCB nos próximos anos.

\section{3}

\section{O papel dos SCB na mobilidade e na sustentabilidade urbana}

Por suas características, os SCB oferecem uma série de benefícios ambientais, sociais e para a mobilidade urbana. As bicicletas compartilhadas permitem efetuar deslocamentos de curta distância, oferecendo uma opção de transporte barata e não poluente para conectar regiões próximas ou para acessar áreas mais afastadas integrando-se ao sistema de transporte público. Segundo Shaheen et al. (2012b, p.14), os benefícios dos SCB incluem:

- redução do tráfego de veículos;

- aumento das opções de mobilidade urbana;

- aumento da utilização do transporte público;

- geração benefícios econômicos decorrentes da substituição de outros modais, mais caros, pela bicicleta;

\footnotetext{
60 <Yelo.agglo-larochelle.fr/velo>. Acesso em: 15/12/2013.

${ }^{61}$ Shaheen et al. (2012) observam que essa integração aumenta os custos de operação do sistema, pela necessidade de integrá-lo a diversas outras áreas da administração pública.
} 
- favorecimento do turismo;

- redução os custos da infra-estrutura de transportes, já que a sua implantação é mais barata do que a dos demais modais de transporte;

- redução do consumo de combustível;

- beneficios para a saúde dos usuários;

- aumento da conscientização sobre os problemas ambientais ${ }^{62}$.

Para os deslocamentos de curta distância, os SCB são uma alternativa flexível e rápida de transporte, podendo substituir o automóvel, outros modais motorizados e mesmo as caminhadas. Para os deslocamentos de longa distância, os SCB podem atuar complementando a rede de transportes públicos, funcionando como alimentadores para redes de ônibus, trens ou metrô (Shaheen et al., 2012).

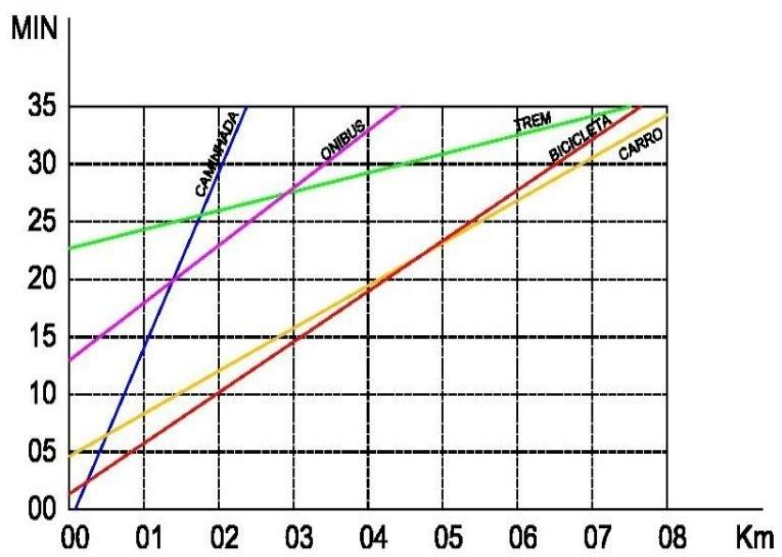

Figura 16 - Gráfico comparativo de velocidade de deslocamento em diferentes modais no ambiente urbano. Fonte: Translink (2008, p.32).

Para Keijer et al. (2000, apud Martens 2004, p.282), a integração do modal cicloviário com os demais modais de transporte público possibilita à bicicleta atuar como uma alternativa relativamente competitiva ao carro particular, ajudando a resolver um dos problemas "chave" do transporte público: o acesso à rede de estações de trens, de metrô e aos pontos de ônibus (Martens, 2004).

\footnotetext{
62 Potencial bikesharing benefits include: 1) incresased mobility; 2) economic benefits (including cost savings from modal shifts and increased tourism); 3) ower implementation and operational costs (in contrast to shuttle services); 4) reduced traffic congestion; 5) reduced fuel use; 6) increased public transit use; 7) increased health benefits; and 8) great environmental awareness. Livre tradução do autor.
} 
Uma das grandes desvantagens do transporte público em relação ao carro particular está na comodidade que este último possibilita ao usuário conectando diretamente os pontos de origem e destino (Fernández, 2011, p.39). Por esta razão, a utilização da bicicleta para complementar as viagens, bike-and-ride ${ }^{63}$, vem ganhando cada vez mais atenção como uma alternativa muiltimodal para auxiliar na redução do uso de veículos particulares nas cidades.

\begin{abstract}
Bike-and-ride offers a number of environmental and societal benefits over the use of the private car. The environmental benefits include reduction in energy use, air and noise pollution. The magnitude of these benefits will depend on the number and lenght of the car trips that are being replaced by bike-and-ride [...] In addition [...] replacement of car trips by bike-and-ride could lower congestion levels on specific corridors or on access road to stations [...] Finally, bike-andride may strengthen the economic performance of specific types and lines of public transport, as it may attract an additional group of consumers (Martens, 2004, p.282).
\end{abstract}

Em seu estudo, Martens (2004) observou que existe uma relação entre o modal de transporte público e a participação da bicicleta como seu alimentador. Os modais mais rápidos e de maior capacidade, como os trens, atraem mais usuários bike-and-ride do que os meios mais lentos e de menor capacidade, como ônibus locais ou trams.

Segundo Shaheen et al. (2012b p.35), muitos especialistas consideram a integração com os transportes públicos um fator determinante para o sucesso de um SCB. Essa integração pode ser feita de diversas formas, mas em especial através da implantação de bases para retirada e devolução das bicicletas junto a hubs de transporte e da implementação de políticas de integração tecnológica e tarifária.

Bike-share systems create new options for short trips, enhance mobility around the city and increase access to the city's existing transit services. In a survey of bike-share users in Paris, $89 \%$ said that Vélib' allowed them to move around Paris more easily and $54 \%$ said that they traveled more in Paris with advent of the Velib' program [...] Bike-share systems encourage transit use by extending the distance that people will go to reach transit, by allowing them to avoid slow buses/connector services, and by providing links between subways stations that otherwise do not connect (NYC, 2009).

Ao se integrar ao sistema de transportes público, a bicicleta compartilhada aumenta o seu alcance territorial para além da distância que

\footnotetext{
${ }^{63}$ Uso combinado da bicicleta e transporte público para uma viagem.
} 
seria usualmente percorrida a pé pelo usuário a um custo menor do que utilizando outros alimentadores motorizados (Pucher et al., 2009, p.79).

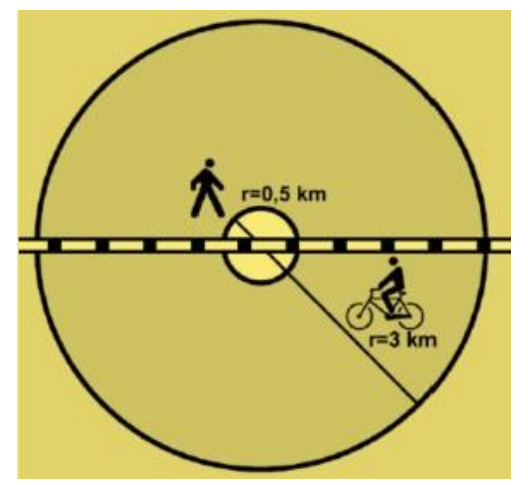

Figura 17 - Alcance da área de influência do transporte público através da bicicleta ou a pé. Fonte: Sassen (2009 apud Fernández, 2011).

Embora a disposição para caminhadas varie entre diferentes culturas e regiões, as pessoas usualmente se dispõem a caminhar por um período de 10 minutos, a partir do qual começa a haver uma maior tendência pela escolha de outros modais de transporte. Como as distâncias percorridas pelo transporte cicloviário costumam variar numa faixa de 1 a $5 \mathrm{~km}$, os sistemas de compartilhamento de bicicleta podem ocupar um importante "niche in the urban transportation system in terms of trip length and costs". (Midgley, 2008, p.5).

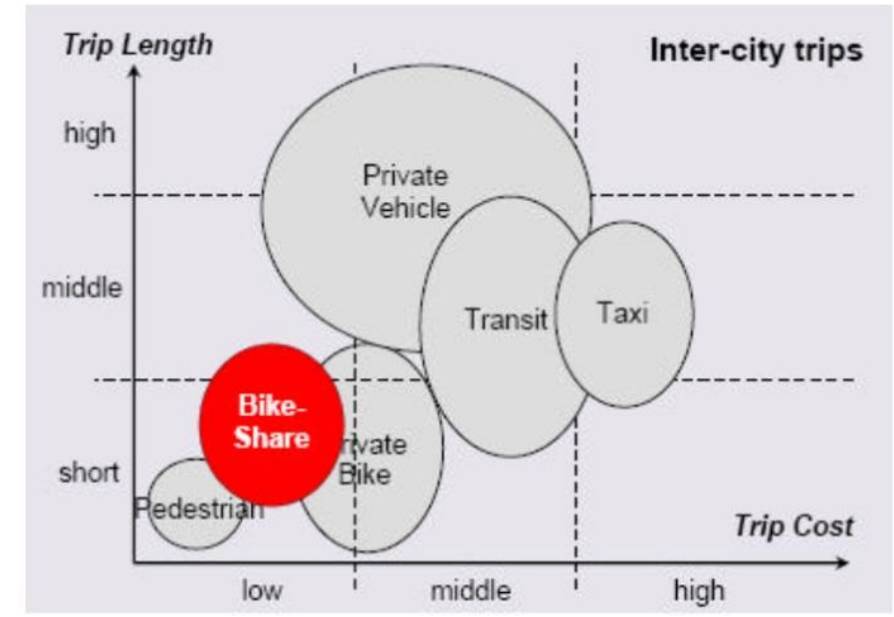

Figura 18 - Inserção do SCB no sistema de transportes. Fonte: Midgley (2011).

A distância que as pessoas normalmente se dispõem a percorrer através de modais não motorizados também está relacionada a uma série de 
outros fatores que incluem o motivo da viagem, a forma urbana, o tráfego de veículos, a segurança, a capacidade física, a posse de veículo próprio e a disponibilidade de estacionamento.

Quando o motivo da viagem está relacionado ao trabalho, dados do Reino Unido e dos EUA indicam que há uma maior disposição para percorrer distâncias mais longas. Enquanto o transporte cicloviário é normalmente utilizado para deslocamentos entre 1 e $5 \mathrm{~km}$, quando o motivo da viagem está associado ao trabalho essa distância pode alcançar 8 km (Translink, 2008, v.2. p.5).

Ajudar a reduzir o número de veículos em circulação é um dos objetivos mais comumente associados aos SCB. Entretanto, como observam DeMaio et al. (2007, p.7), as evidências demonstram que as bicicletas compartilhadas ainda não conseguem contribuir de forma significativa para essa finalidade. Por um lado, os motoristas relutam em abandonar a comodidade das viagens "porta-a-porta" proporcionadas pelo automóvel; por outro lado, muitas pessoas que poderiam utilizar os sistemas de compartilhamento por morarem mais próximas ao local de trabalho preferem usar sua própria bicicleta. Além disso, alguns estudos demonstram que a maior parte dos usuários de SCB estão se transferindo do transporte público e não do transporte motorizado individual (ibid., 2004b, p.43).

\begin{tabular}{|l|c|c|c|}
\hline $\begin{array}{l}\text { Substituição de modais pelo } \\
\text { sistema de compartilhamento }\end{array}$ & Barcelona & Montreal & Lyon \\
\hline & & & \\
\hline ônibus ou metrô & $51 \%$ & $33 \%$ & $50 \%$ \\
\hline carro ou motocicleta & $10 \%$ & $2 \%$ & $7 \%$ \\
\hline taxi & - & $8 \%$ & - \\
\hline caminhada & $26 \%$ & $25 \%$ & $37 \%$ \\
\hline bicicleta particular & $6 \%$ & $28 \%$ & $4 \%$ \\
\hline novas viagens & - & $4 \%$ & $2 \%$ \\
\hline
\end{tabular}

Tabela 1 - Modais substituídos pelo SCB em Barcelona, Montreal e Lyon. Fonte: Midgley (2011).

Shaheen et al. (2010, p.13), por outro lado, consideram que os SCB possuem potencial para atuar positivamente na redução do volume de veículos em circulação:

In a recent survey of SmartBike (Washington, D.C.) members, researchers found that bikesharing drew nearly $16 \%$ of individuals who would otherwise have used personal vehicles for tripmaking. [...] In Paris, 20\% of Velib'users also reported using personal vehicles less frequently. 
Em um estudo realizado entre o fim de 2011 e o início de 2012 nas cidades de Toronto, Montreal, Washington e Minnesota, com o objetivo de estudar a mudança de comportamento dos habitantes em função da implantação de sistemas de compartilhamento, Shaheen et al. (2013) encontraram evidências de que a implementação de sistemas de compartilhamento de bicicletas "resulted in a considerable decline in personal driving and taxi use, suggesting that public bikesharing is reducing urban transportation emissions, while at the same time freeing capacity of bus and rail networks within large cities". Em Montreal, 37\% dos entrevistados afirmaram utilizar menos o carro em função do uso das bicicletas compartilhadas. Em Toronto, esse índice foi de 25\%, em Washington, 41\% e em Minnesota, 56\%.

A implantação de um SCB é usualmente apontada com uma uma forma de reduzir as emissões de GEE oriundas do sistema de transportes. Segundo Buis et al. (2000, p.33), o investimento no transporte cicloviário pode ser bastante vantajoso pois a expansão do sistema de transporte público demandaria, segundo os autores, maiores investimentos para atingir os mesmos resultados ambientais.

Entretanto, Midgley (2011, p.17) alerta para as estimativas exageradas de redução das emissões de GEE que são normalmente associadas à implementação de sistemas de compartilhamento de bicicleta, pois ainda não há um número suficiente de pesquisas capazes de comprovar seus reais benefícios neste aspecto.

A capacidade de um SCB em auxiliar na redução do volume de emissões de poluentes está diretamente relacionada à taxa de transferência de usuários do transporte individual. Um estudo realizado por Fishman et al. (2014) para as cidades de Melbourne (Austrália), Washington e Minnesota (EUA) e Londres (Reino Unido) demonstrou que nas primeiras três cidades foi possível observar um ganho ambiental na redução das emissões, mas em Londres, onde a taxa de transferência do transporte individual é muito reduzida (2\%), as emissões decorrentes da operação do sistema (distribuição de bicicletas e manutenção) representam mais que o dobro do volume que deixou de ser lançado na atmosfera pelo uso das bicicletas.

De maneira geral, ainda há poucos dados disponíveis sobre os reais benefícios dos sistemas de compartilhamento (Shaheen et al., 2012b). Os 
mais relevantes estão relacionados ao aumento do uso do modal cicloviário após a implantação dos SCB (Midgley, 2011, p.16).

Os sistemas de compartilhamento são associados ao incremento do modal cicloviário ao atuar diretamente na atração de novos usuários para o uso da bicicleta e, indiretamente, impactando positivamente na percepção da bicicleta como um efetivo meio de transporte pela população (Translink, 2008). Em Lyon, 96\% dos usuários do Velo'v no seu primeiro ano nunca haviam usado bicicleta na cidade (NYC, 2009, p17).

Contudo, como observa Fernández (2011, p.94), é muito difícil dimensionar a real influência dos SCB no aumento da participação da bicicleta no sistema de transportes pois normalmente sua implantação ocorre no âmbito de programas mais abrangentes de promoção da bicicleta, associados na maioria das vezes, à construção e à melhoria da infraestrutura cicloviária.

Em Paris, por exemplo, o Velib' é apenas um dos componentes do plano de mobilidade da cidade. Ao observar que a abertura de novas vias para carros acarretava o aumento do tráfego e a degradação de áreas da cidade sem resolver o problema dos congestionamentos, as autoridades decidiram, em 2001, inverter a lógica que até então dominava o planejamento viário da cidade. A cidade passou a reduzir o espaço destinado aos carros (vias e estacionamento) para convertê-los em espaços para pedestres, em ciclovias e em faixas exclusivas para transporte público (Nadal, 2007).

Além dessas medidas, a constante expansão de linhas de metrô, a criação de novas linhas de BRT e de VLT, além de políticas de restrição do uso do aumóvel, levaram a uma redução de $20 \%$ no tráfego de veículos entre 2001 e 2006. Ao mesmo tempo houve um aumento na qualidade do ar ao longo das vias que sofreram intervenções (ibid., 2007).

A melhoria na qualidade do ar é uma das maneiras de o transporte cicloviário beneficiar a saúde da população reduzindo incidência de doenças cardio-respiratórias decorrentes da poluição. (Garrad et al., 2012).

Ao conseguir trazer novos usuários para o transporte cicloviário, os SCB possibilitam a incorporação da "mobilidade ativa" nos deslocamentos diários. Segundo dados do Ministério da Saúde ${ }^{64}$, quase metade da população brasileira está acima do peso. A porcentagem de brasileiros com sobrepeso

\footnotetext{
${ }^{64}$ Sociedade Brasileira de Endocrinologia e Metabologia. Disponível em: <www.endocrino.org.br/numeros-da-obesidade-no-brasil/> $>$. Acesso em: 10/08/2014.
} 
que era de 42,7\% em 2006, passou para 48,5\% em 2011 e esse problema começa a se manifestar cada vez mais cedo. Entre 18 e 24 anos, 29,4\% dos homens e 25,4\% das mulheres já se encontram acima do peso, porcentagem que aumenta com a idade.

Esse aumento nas taxas de obesidade da população está relacionado principalmente a dois fatores: a mudanças nos padrões de consumo alimentar e a redução da atividade física (Mendonça et al., 2004). Segundo Wen et al. (2006 apud Garrad et al., 2012), dirigir para o trabalho está associado a um aumento de $13 \%$ no risco de ganho de peso e obesidade. A prática regular de exercícios, "apesar de não provocar uma perda de peso corporal tão intensa quanto a dieta hipocalórica" é benéfica para várias "comorbidades da obesidade", especialmente a hipertensão e a hiperglicemia, e atenua o "risco de morbidade e mortalidade em indivíduos com sobrepeso e obesos" (Negrão et al., 2000, p.153).

As evidências sugerem que 30 minutos diários de exercícios com intensidade moderada são suficientes para prevenir riscos para saúde relacionados à obesidade e à hipertensão. Esse tempo pode, inclusive, ser dividido em períodos menores, de 10 minutos, sem prejuízo para seus benefícios (Garrad et al., 2012; NYC, 2009), fazendo dos SCB, enquanto modal de transporte diário, uma opção atrativa para prática de exercício regular.

\section{4}

\section{Principais componentes dos sistemas SCB}

Em que pese os benefícios do transporte cicloviário para mobilidade e sustentabilidade urbana, o sucesso de um SCB está diretamente relacionado à qualidade da infraestrutura que é oferecida ao usuário. Os principais elementos que compõem um sistema de compartilhamento de bicicletas e determinam a qualidade da sua relação com o usuário são:

- frota de bicicletas;

- rede de Estações;

- tecnologia; 
- estrutura para redistribuição de bicicletas e manutenção do sistema.

\subsection{1}

\section{Frota de bicicletas}

As bicicletas são o componente mais importante para a experiência de uso de um SCB. Apesar das suas características variarem em função da disponibilidade de investimento, os equipamentos devem ser confortáveis para o usuário e robustos para garantir maior durabilidade e reduzir seu custo de manutenção e a necessidade de substituição (Dhingra et al., 2010).

A maioria dos SCB utiliza um padrão comum de bicicleta com algumas modificações geralmente relacionadas à necessidade de garantir maior resistência para bicicletas que são utilizadas com muita intensidade e à maior segurança contra furtos. Muitos componentes das bicicletas são projetados exclusivamente para os $\mathrm{SCB}$, inibindo o roubo de peças para revenda (ITDP,2013, p.76).

Essa maior resistência faz com que de maneira geral, tais bicicletas sejam mais pesadas do que uma bicicleta comum. Seu peso costuma variar de $16 \mathrm{~kg}$ a $22 \mathrm{~kg}$, enquanto uma bicicleta comum costuma pesar entre $12 \mathrm{~kg} \mathrm{e}$ $18 \mathrm{~kg}^{65}$. Essa é uma questão importante para o conforto do usuário, já que influencia no esforço necessário para pedalar.

Outro aspecto importante para o conforto do usuário são as regulagens de altura do banco. Como a frota é constituída por um mesmo modelo de bicicleta, quanto mais ajustes forem possíveis, maior será o número de pessoas em condições de fazer uso do sistema.

O projeto das bicicletas deve tentar reduzir o custo operacional de manutenção. Segundo o ITDP (2013), os elementos que mais demandam manutenção nas bicicletas são: os pneus, que precisam ser constantemente calibrados; as correias, que precisam ser lubrificadas e ajustadas; e as pastilhas de freio, que precisam ser constantemente trocadas.

Em Shangai (China), por exemplo, foi desenvolvido um modelo de bicicleta que utiliza pneus feitos com espuma de borracha, que não

\footnotetext{
${ }^{65}$ www.bikeoff.org.
} 
necessitam ser calibrados, correias que não necessitam de lubrificação, e freios a disco, que são mais duráveis e funcionam melhor em dias de chuva (ITDP, 2013). As bicicletas da capital francesa possuem o sistema de troca de marchas, o dínamo e os freios localizados dentro do eixo das rodas além de carregarem um chip que reporta à central de controle informações sobre as condições do equipamento. ${ }^{66}$
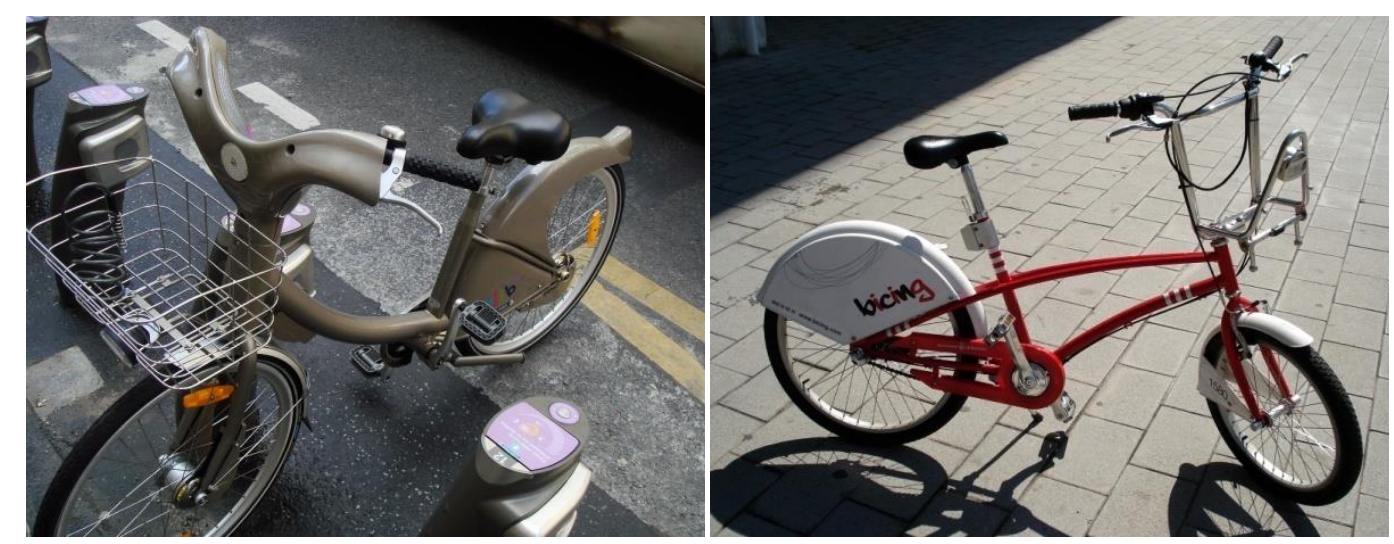

Figura 19 - Modelo de bicicleta utilizado em Paris e Barcelona. Fonte: <http://picgine.com/view/image/id/888181966\#!Velib+obsession> e <http://en.wikipedia.org/wiki/Bicing>

A maioria dos SCB utiliza bicicletas de 3 velocidades, já que não são projetadas para atingir grandes velocidades.

As bicicletas precisam dispor de equipamentos de segurança como luzes, campainha, espelho retrovisor e quaisquer outros elementos que sejam obrigatórios pela legislação vigente local.

A maioria dos operadores caracteriza a frota distinguindo-a das bicicletas comuns para aumentar a segurança contra furtos. Isso é feito tanto através da criação de um design exclusivo para a biciceta como através do uso de cores chamativas ou da aplicação de logomarcas distintivas (Translink, 2008, p.36).

A aparência geral da bicicleta compõe a "marca" do SCB e a imagem que se deseja transmitir para a população é um importante fator a ser considerado no design e na programação visual das bicicletas (Índia, 2012, p.14).

A determinação da quantidade de bicicletas necessárias para um SCB deve ter como parâmetro o número de usuários para uma determinada região, garantindo o suprimento da demanda pelo transporte (ITDP, 2013).

${ }^{66}$ ibid. 
Definir esse quantitativo é um desafio para implementar os SCB, pois pode-se trabalhar tanto com uma demanda existente como com uma demanda potencial, considerando que o sistema será eficaz em atrair novos usários.

Por isso, é usual que, principalmente nos grandes centros urbanos, os SCB sejam implantados em fases, iniciando-se pelas áreas mais densas e onde há maior demanda de viagens, garantindo a cobertura de um número significativo de origens e destinos, bem como a conveniência e a confiança do usuário (ITDP, 2013).

Entretanto, esses projetos "piloto" podem inviabilizar o SCB caso não cubram de forma satisfatória os pontos de origem e destino necessários para complementar o sistema público de transportes e para atender à demanda de viagens. Em Washington, por exemplo, o sistema foi inicialmente implantado com apenas dez estações e 120 bicicletas gerando, em média, uma viagem por dia por bicicleta. Após uma reavaliação foi substituído por um sistema com 1.100 bicicletas e 100 estações. Após sua reinauguração, as bicicletas passaram a ser utilizadas entre 6 e 7 vezes por dia cada uma, em média, durante os meses de verão, demonstrando a importância da escala e da saturação da área de cobertura para o sucesso de um SCB (DePhillis, 2010 apud Índia, 2012).

\section{4 .2}

\section{Rede de estações}

A localização e a quantidade de estações para retirada e para devolução das bicicletas são fatores fundamentais para o sucesso de um SCB. Sua área de cobertura deve ser ampla o suficiente para comportar uma demanda de origens e destinos que garantam a rotatividade do sistema e otimizem o uso das bicicletas (ITDP, 2013, p.43).

Áreas de uso misto, com grande capacidade de geração de viagens, são usualmente as maiores geradoras de demanda de viagens. Para a criação de uma rede eficiente de estações, deve haver uma certa uniformidade na sua densidade para garantir que os usuários possam retirar e devolver as bicicletas em qualquer ponto de forma fácil e conveniente (ibid.). 
Existe praticamente um consenso entre os autores que tratam deste tema de que a rede de estações deve ser implantada considerando uma distância média de 300 metros entre as bases, o que gera uma rede com 14 a 16 estações por km² (Translink, 2008; ITDP, 2013; Índia, 2012; Büttner et al., 2011; Midgley, 2011).

Entretanto, uma distribuição uniforme das estações nem sempre corresponde aos padrões de demanda de uma determinada região. A implantação da rede de estações deve considerar um sistema "ponto-a-ponto" baseado no estudo das origens e destinos mais significativos para os usuários e assim determinar com mais precisão não só a quantidade de estações mas o seu dimensionamento. Em geral áreas mais populosas requerem um número maior de estações - com menos bicicletas - e viceversa (Translink, 2008, p.39).

Em Paris, nos arredores de duas das maiores estações de metrô existem doze estações pequenas do Velib' (com aproximadamente 60 pontos por estação), enquanto em monumentos como a Torre Eiffel e o Domme des Invalides há uma quantidade menor de estações, mas com um número maior de "vagas" em cada uma (NYC, 2009 apud Fernández, 2011).

Em Londres, por exemplo, a implantação do SCB foi precedida de uma ampla pesquisa visando uma melhor compreensão do potencial de cada região da cidade para o uso da bicicleta ${ }^{67}$. Uma pesquisa feita com 42.000 moradores permitiu conhecer seu padrão de locomoção e determinar as áreas onde deveriam "ser concentrados os esforços para converter viagens usualmente realizadas por carros, metrô ou ônibus em viagens feitas por bicicleta" (TFL, 2010).

\footnotetext{
${ }^{67}$ The London Travel Demand Survey compõe o projeto Cycle Revolution que visa transformar Londres em uma "cyclised city", através da execução de três grandes projetos: (A) implantação de um sistema de compartilhamento; (B) melhoria na infra-estrutura cicloviária e a criação de superhighways para encorajar o uso utilitário da bicicleta; e (C) ações de promoção e educação relacionadas ao transporte cicloviário.

Disponível em: <www.london.gov.uk/sites/default/files/cycling-revolution-london.pdf>.

Acesso em: 20/01/2014.
} 


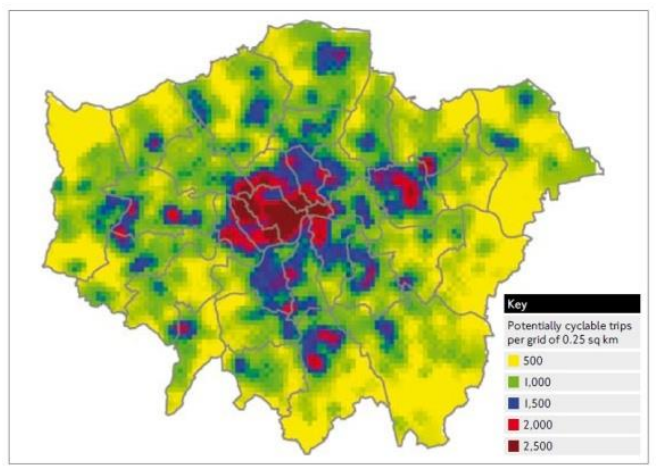

Figura 20 - Mapa com potencial de viagens por bicicleta na cidade de Londres. Fonte: Transport for London (2010)

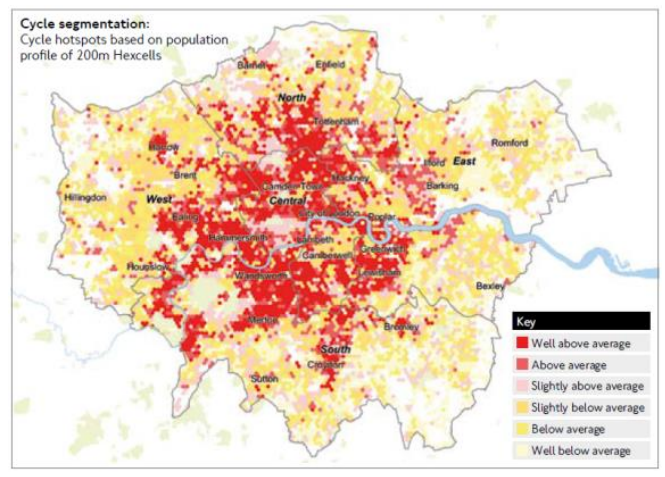

Figura 21 - Mapa com a propensão dos residentes em usar a bicicleta. Fonte: Transport for London (2010)

O cruzamento desses dados com o perfil socio-demográfico dos moradores possibilitou mapear o potencial cicloviário nos termos da propensão ao uso da bicicleta. Dessa forma, as autoridades puderam verificar que as maiores possibilidades de conversão de viagens para o modal cicloviário se concentravam nas áreas centrais, estendendo-se, a partir do centro, para áreas mais afastadas, além de algumas regiões da periferia da cidade.

Considerando que os deslocamentos utilitários costumam ter, em média, entre $1 \mathrm{~km}$ e $5 \mathrm{~km}$, as pesquisas de origem e destino podem ser feitas junto às principais estações de transporte público visando os passageiros que chegam ou saem das estações por intermédio de outros meios de transporte como táxis ou ônibus para completar sua jornada. Assim, é possível determinar onde o sistema possui mais chances de ter êxito e os pontos realmente relevantes para alcance das bicicletas (Índia, 2012, p.5).

A localização das estações pode também influenciar as rotas empreendidas pelos usuários. Para aumentar a integração da bicicleta ao sistema de transportes pode-se conectar as estações e os pontos de ônibus de maior demanda a áreas não servidas por transporte público. Para estimular a substituição do carro pela bicicleta, é importante conhecer as rotas mais frequentes que possam ser substituídas e posicionar estações ao longo dessas rotas. Para auxiliar na redução da saturação do transporte público, as estações do SCB podem ser localizadas junto aos pontos de maior demanda do transporte público (Fernández, 2001, p.148).

O dimensionamento das estações é feito em função do número de bicicletas necessárias para operação do sistema, mas para evitar que as estações fiquem lotadas, devem-se prever pontos de fixação extra. Essa 
relação é um dos aspectos mais varíaveis no planejamento de um SPC pois estações podem variar de tamanho em função da demanda. Podem comportar poucas unidades, como nas áreas menos populosas de Paris, ou acomodar centenas de bicicletas, como nas áreas centrais de Hangzhou e Shangai (ITDP, 2013).

Para atrair um número maior de usuários, as estações devem ser de fácil visualização e estar localizadas próximas a hubs de transporte e em locais de grande circulação (Translink, 2008, p.39). Entretanto, áreas residenciais com menor demanda não devem ser negligenciadas, pois constituem-se em pontos de origem ou de destino de viagens.

As estações podem ser usadas também para indicar o início de uma ciclovia. Sua proximidade com a rede cicloviária ou com vias compartilhadas é um fator de redução do tempo de deslocamento e de aumento da segurança, atraindo mais usuários para o sistema (ibid.).

\subsection{3}

\section{Tecnologia}

Os sistemas de informação são o "sistema nervoso" do SCB, conectando as estações, a central de controle e os usuários através de software específico e de mecanismos de transmissão de dados (ITDP, 2013, p.74). Foi a implementação desses sistemas (que possibilitam a troca de informações em tempo real e o rastreamento dos usuários) que permitiu a evolução dos SCB para a 3ª geração e sua posterior expansão global.

A maioria dos SCB exige que seja feito cadastro prévio de usuários sendo a internet a plataforma mais comum para isso. Para retirar as bicicletas existem duas plataformas que são mais utilizadas nos SCB de $3^{\text {a }}$ geração: smart cards e telefonia celular.

Nos sistemas que utilizam cartões, é possível retirar as bicicletas utilizando o cartão de crédito, o cartão específico do sistema ou mesmo o cartão usado para acessar a rede de transporte público. Nesses casos, as estações possuem um totem de auto-atendimento onde é possível inserir os cartões ou mesmo comprar passes de curta duração através do cartão de crédito. 
Nos sistemas via telefone, é necessário entrar em contato com a central que controla o sistema para liberar a bicicleta ou para receber um código via sms que permita retirar a bicicleta da base (Translink, 2008, p.34). Alguns sistemas que utilizam o telefone permitem 0 uso de aplicativos para smartphones que se conectam diretamente à central de controle para liberação das bicicletas.

É importante que esses sistemas possibilitem aos usuários acessar informações em tempo real sobre a disponibilidade de bicicletas e de "vagas" em cada estação, evitando deslocamentos excessivos.

Os SCB podem utilizar tanto sistemas automáticos como manter os sistemas manuais. A principal diferença entre os dois é que nos manuais há um funcionário que auxilia no processo de retirada e devolução das bicicletas. (ITDP, 2013, p.65). Os sistemas automáticos demandam estações mais complexas e caras, mas em compensação o custo com mão de obra é reduzido.

A tecnologia aplicada aos SCB geralmente está relacionada ao tamanho da cidade (Translink, 2008). Quanto maior a área de alcance do sistema, mais tecnologia deve ser incorporada a sua operação. Para o Instituto para la Diversificacíon y Ahorro de la Energía da Espanha (2007, p.84), em municípios com mais de 200.000 habitantes deve ser utilizado o sistema automático. Em cidades menores, o sistema manual pode ser o mais indicado.

\subsection{4}

\section{Estrutura para redistribuição de bicicletas e manutenção do sistema}

Uma das atividades mais importantes para a operação de um SCB é manter a disponibilidade de bicicletas nas estações. A assimetria de demanda entre estações e entre diferentes períodos do dia acarreta a concentração de bicicletas em alguns pontos e sua ausência em outros.

An optimized network needs more than large numbers of conveniently located stations; it must also antecipate the asymmetric travel demands of most large cities. Not surprisingly stations located at the top of hills are chronically empty of bikes - as the customers ride down the hill but do not wish to make the return 
trip up hill. Bikes also tend to collect in stations in the city centeres and stay there (Translink, 2008, p.40).

Uma operação de distribuição bem executada é um fator "crítico" para a viabilidade de um SCB sob a perspectiva do usuário (Índia, 2012, p.19). Estações congestionadas ou a indisponibilidade de bicicletas são fatores que afetam diretamente o grau de satisfação dos clientes (Fernández, 2011, p.184). Segundo o autor, a distribuição irregular das bicicletas nas estações pode ser causada por três fatores: (1) topografia, (2) área de operação muito extensa e (3) demanda irregular.

Prever com precisão a demanda exata de cada estação ao longo do dia é muito complexo, por isso a maioria dos operadores de SCB possui uma equipe de funcionários e uma frota de veículos com a função de redistribuir as bicicletas. Em Paris, por exemplo, é utilizada uma frota de 20 veículos $^{68}$ dedicada exclusivamente a transportar bicicletas de bases congestionadas para bases onde há falta de equipamentos.

Algumas medidas podem ser adotadas para otimizar a distribuição de bicicletas e reduzir a necessidade de viagens e de veículos dedicados à redistribuição de bicicletas. Em se tratando de um sistema de transportes tão diretamente associado à redução das emissões de GEE, evitar a circulação de veículos emissores de poluentes é muito significativo.

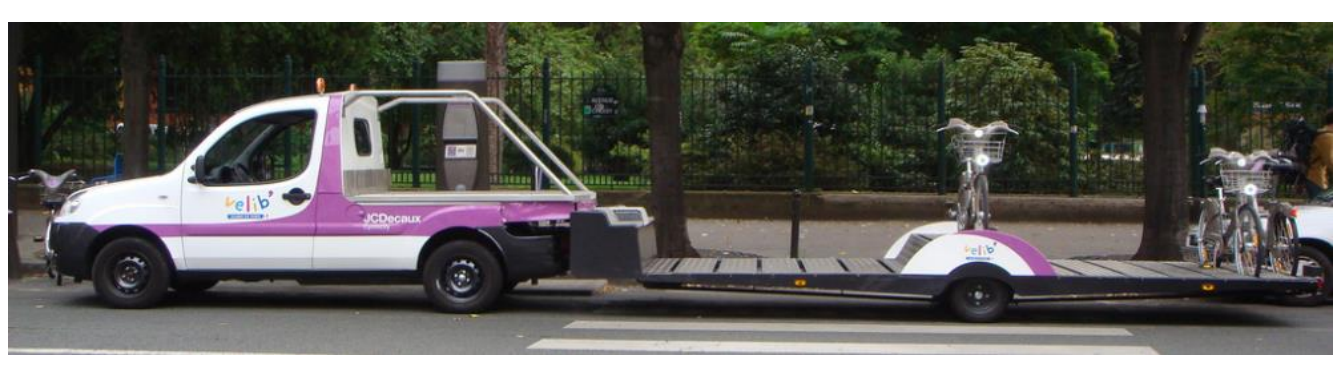

Figura 22 - Veículo de distribuição de bicicletas. Velib' (Paris). Fonte: Ministério Indiano de Desenvolvimento Urbano, 2012.

Em Paris, por exemplo, são oferecidos 15 minutos extra em uma próxima viagem para quem devolver as bicicletas em locais mais elevados, onde é comum a falta de bicicletas. Em Segovia (Espanha) são oferecidas bicicletas elétricas para facilitar o acesso às estações situadas em áreas mais elevadas (Fernández, 2011, p.184). Na Noruega, a cidade de Trondheim desenvolveu um mecanismo que auxilia os ciclistas a subir ladeiras. $O$

\footnotetext{
${ }^{68}$ Dados de 2008. Fonte: Translink, 2008.
} 
Trampe consiste em uma espécie de pedal que ao ser acionado percorre um trilho ao longo da via e impulsiona o ciclista para o alto. Em San Sebastián (Espanha) o governo implantou um plano de transporte público vertical no qual esteiras rolantes e elevadores fazem a ligação da rede de ciclovias nas partes alta e baixa da cidade (Espanha, 2007, p.91).
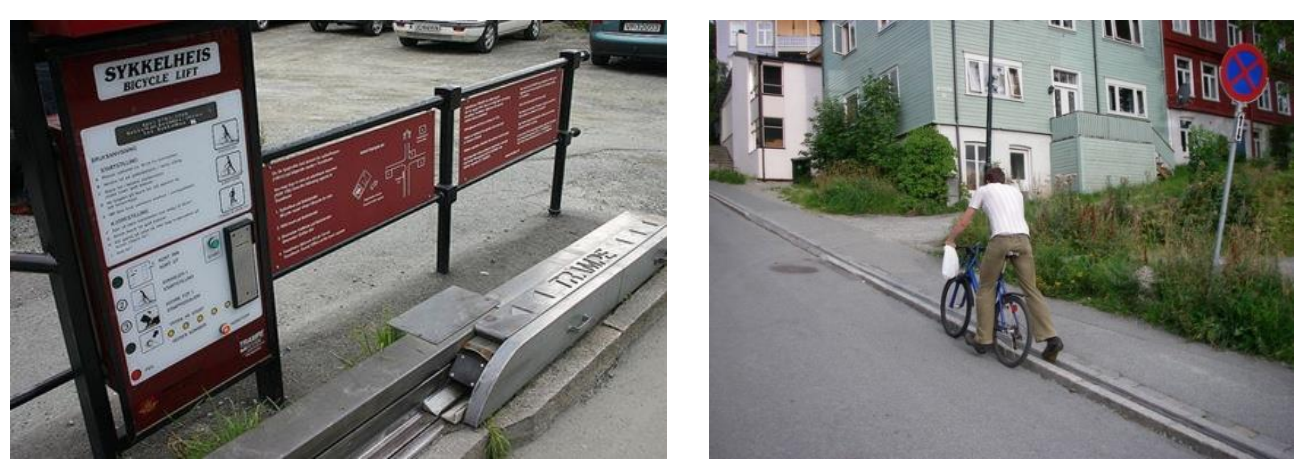

Figura 23 - Trampe, Noruega. Fonte: <www.amusingplanet.com>.

A manutenção de um SCB cobre tanto ações preventivas quanto de reparo para as bicicletas e para as estações. Além de ser um fator crítico para o funcionamento e para a imagem dos sistemas de compartilhamento, a operação de manutenção é responsável por considerável parcela dos seus custos, especialmente nos SCB de grande porte. O custo anual de manutenção do Velib' é estimado em cerca de US\$1.000,00 por bicicleta, excluindo-se a necessidade de reposição de bicicletas (ITDP, 2013, p.118).

\section{5}

\section{Perfil de usuários dos sistemas de compartilhamento}

Os usuários de SCB podem ser divididos em dois grupos principais:

- os que utilizam o sistema para fim utilitário;

- os que utilizam o sistema para uso recreativo ou esporádico.

Para cada motivo corresponde um usuário com características e necessidades distintas (Fernández, 2011, p. 57). Os usuários para fim utilitário, por exemplo, costumam adquirir passes mensais ou anuais. Em Paris, $61 \%$ dos usuários do Velib' cadastrados no plano anual fazem uso das 
bicicletas para o trabalho ou estudo. Estes usuários, em muitos casos (33\%), moram nos subúrbios da capital francesa e utilizam as bicicletas em conjunto com outros modais de transporte para acessar a cidade (NYC, 2009, p.66). Em Nova York, dados de março de 2014 indicam que os usuários com passes anuais representaram $95 \%$ de todas as viagens. Entretanto, com o início da primavera no hemisfério norte, já despontava uma tendência de aumento no número de passes diários (NYC, 2014, p.3)

Os usuários eventuais e os turistas são também um grupo significativo para os SCB. Em Lyon, aproximadamente $40 \%$ das viagens são realizadas por usuários com passes semanais e, em Paris, nos primeiros seis meses de operação, foram vendidos 2.5 milhões de passes diários (NYC, 2009, p.66).

O uso do SCB para o trabalho ou para o estudo se caracteriza pela concentração das viagens em horários específicos do dia, especialmente pela manhã e no fim da tarde, e é mais frequente em dias úteis. O uso recreativo ou esporádico, por outro lado, se caracteriza por ser mais distribuído durante o dia e inclusive durante a noite. Em Paris, onde o metrô encerra as atividades a 1:00h, 25\% das viagens são realizadas entre $21: 00 \mathrm{~h}$ e 3:00h (ibid.).

Os deslocamentos utilitários tendem a ser mais rápidos do que os recreativos, o que representa uma perspectiva de maior rotatividade em estações próximas a áreas onde há um grande número de empresas ou trabalhadores e de menor rotatividade em áreas turísticas.

Os SCB, em sua maioria, são abertos ao público em geral, entretanto alguns sistemas podem restringir o grupo de usuários conforme seus objetivos. O sistema Bicing, de Barcelona, por exemplo, é voltado exclusivamente para residentes na Espanha. Os turistas não têm acesso ao sistema, que solicita comprovação da residência no momento de inscrição ${ }^{69}$.

${ }^{69}$ www. https://www.bicing.cat/. 


\section{6}

\section{Resumo do capítulo}

Os SCB são uma forma de institucionalizar o uso da bicicleta nas cidades, oferecendo a oportunidade de usar o transporte cicloviário com base na necessidade de deslocamento, sem precisar arcar com os custos de aquisição e manutenção do seu próprio equipamento. Em sua maioria, são projetados para oferecer uma opção de mobilidade para viagens de curta distância e para integrar-se à rede de transporte público como modal alimentador.

O primeiro SCB surgiu na década de sessenta do século passado, quando um movimento social holandês, preocupado com as consequencias socio-ambientais da crescente utilização do automóvel na cidade de Amsterdam, propôs a implementação de um sistema de compartilhamento gratuito de bicicletas. Sua origem está associada à sustentabilidade, ainda que este conceito só viesse a se difundir alguns anos depois.

A expansão global dos sistemas de compartilhamento é um fenômeno mais recente, fruto do desenvolvimento de tecnologias capazes de controlar os usuários e as bicicletas, reduzindo o número de roubos e os atos de vandalismo e viabilizando economicamente sua implantação.

Como esse processo de expansão dos SCB, especialmente os de grande porte, é recente, há ainda poucos dados capazes de determinar seus reais benefícios para a mobilidade e para o desenvolvimento sustentável das cidades. Muitos autores consideram que há uma valorização excessiva dos benefícios das bicicletas compartilhadas e que os SCB ainda não conseguem contribuir de maneira significativa para a redução de congestionamentos e de emissão de poluentes. 


\section{Estudo de caso: impacto e contribuição do Bike Rio para mobilidade e sustentabilidade}

O objetivo principal deste capítulo é caracterizar o papel desempenhado pelo SCB na mobilidade da cidade do Rio de Janeiro. Em primeiro lugar, será apresentado um panorama do sistema de transportes da cidade, baseado principalmente nos dados da atualização de 2013 do Plano Diretor de Transportes Urbanos do Rio de Janeiro. Em seguida, será feita uma apresentação do Bike Rio através de um breve histórico e de dados referentes à sua inserção como modal de transportes. Ao fim do capítulo serão apresentados os resultados das pesquisas feitas com os usuários e pela internet, fornecendo os subsídios para avaliação do papel do Bike Rio para mobilidade e para sustentabilidade urbana e para avaliação de sua eficácia em atingir os objetivos propostos para sua implantação.

\section{1}

\section{O sistema de transportes no Rio de Janeiro}

A Região Metropolitana do Rio de Janeiro é composta por 19 municípios que possuem uma população conjunta de 11.835 .708 habitantes, representando $74 \%$ da população do Estado. Desse total, 6.320 .446 pessoas $(52,6 \%)$ vivem na capital ${ }^{70}$.

Segundo o PDTU $^{71}$ (2013), são realizadas por dia 22.595 .000 viagens na RMRJ. Apesar de a capital representar pouco mais da metade da

\footnotetext{
${ }^{70}$ População da RMRJ: Dados do censo de 2010. Fonte: IPEA, Projeto Governança Meropolitana no Brasil, p.10. Disponível em: <http://www.ipea.gov.br/redeipea/images/pdfs/governanca_metropolitana/rel_1_1_rm_rio_de_ja neiro.pdf $r>$. Acesso em 15/05/2014. Em 2014 os municípios de Rio Bonito e Cachoeiras de Macacu foram incorporados à RMRJ, totalizando 21 municípios, mas para esta pesquisa essa inclusão não foi considerada. O PDTU (2013) inclui a cidade de Mangaratiba dentro da RMRJ; população da cidade do Rio de Janeiro: Fonte: IBGE. Disponível em: <cidades.ibge.gov.br/xtras/perfil.php?lang=\&codum=330455>. Acesso em: 15/05/2014.

${ }^{71}$ Plano Diretor de Transporte Urbano da Região Metropolitana do Rio de Janeiro.
} 
população, a cidade do Rio de Janeiro é origem de $61,3 \%$ desse total de deslocamentos, o que equivale a 13.853.000 viagens.

\begin{tabular}{|c|c|c|}
\hline Modo de transporte & $\begin{array}{c}\text { Viagens diárias, em } \\
\text { milhares }\end{array}$ & \% \\
\hline A pé & 6.634 & $29,4 \%$ \\
\hline Barcas & 105 & $0,5 \%$ \\
\hline Bicicleta/Ciclomotor & $\mathbf{5 4 6}$ & $\mathbf{2 , 4 \%}$ \\
\hline Condutor de auto & 2.540 & $21,2 \%$ \\
\hline Metrô & 665 & $0,8 \%$ \\
\hline Motocicleta & 170 & $0,2 \%$ \\
\hline Moto-táxi & 39 & $0,3 \%$ \\
\hline Ônibus executivo & 70 & $7,9 \%$ \\
\hline Ônibus Intermunicipal & 1.781 & $29,5 \%$ \\
\hline Ônibus municipal & 6.671 & $0,1 \%$ \\
\hline Ônibus pirata & 16 & $0,7 \%$ \\
\hline Outros & 169 & $5,4 \%$ \\
\hline Passageiro de auto & 1.225 & $1,1 \%$ \\
\hline Táxi & 256 & $1,9 \%$ \\
\hline Trans. Escolar & 428 & $0,2 \%$ \\
\hline Trans. Fretado & 55 & $2,5 \%$ \\
\hline Trem & 568 & $2,9 \%$ \\
\hline Van & 658 & $\mathbf{1 0 0 , 0 \%}$ \\
\hline TOTAL GERAL & $\mathbf{2 2 . 5 9 5}$ & \\
\hline
\end{tabular}

Tabela 2 - Viagens realizadas por modo para RMRJ. Fonte: PDTU (2013) tabela 3.1, p.6.

Como pode ser observado na Tabela 2, a maior parte dos deslocamentos realizados na RMRJ é feita através de ônibus $(37,8 \%)^{72}$. Em seguida aparecem as viagens feitas a pé $(29,4 \%)$ e as realizadas por transporte motorizado individual $(16,6 \%)^{73}$. A participação do transporte cicloviário é de $2,4 \%$, o que equivale a 546.000 viagens por dia.

\begin{tabular}{|c|c|c|c|c|c|c|c|c|c|c|c|c|}
\hline $\begin{array}{l}\bar{\pi} \\
\frac{\pi}{0} \\
\text { ह }\end{array}$ & $\stackrel{\circ}{\frac{0}{\alpha}}$ & 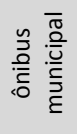 & 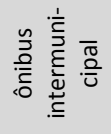 & 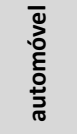 & 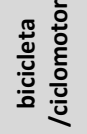 & 足 & $\stackrel{\varepsilon}{\varrho}$ & $\frac{\pi}{0}$ & 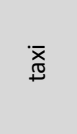 & $\begin{array}{l}0 \\
\stackrel{2}{\circ} \\
\text { E }\end{array}$ & 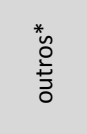 & $\begin{array}{l}\bar{\pi} \\
\stackrel{0}{0}\end{array}$ \\
\hline 2003 & 6.741 & 5.255 & 1.332 & 2.970 & 646 & 355 & 304 & 82 & 139 & 101 & 1.992 & 19.916 \\
\hline$\%$ & 33,85 & 26,39 & 6,69 & 14,91 & 3,24 & 1,78 & 1,52 & 0,41 & 0,7 & 0,51 & 10 & 100 \\
\hline 2012 & 6.634 & 6.671 & 1.781 & 3.765 & 546 & 665 & 568 & 105 & 256 & 170 & 1.435 & 22.596 \\
\hline$\%$ & 29,36 & 29,52 & 7,88 & 16,66 & 2,42 & 2,94 & 2,51 & 0,46 & 1,13 & 0,75 & 6,35 & 100 \\
\hline $\begin{array}{c}\text { Diferença } \\
\% \\
2003 / 2012\end{array}$ & $-1,59$ & 26,95 & 33,71 & 26,77 & $-15,48$ & 87,32 & 86,84 & 28,05 & 84,17 & 68,32 & $-27,96$ & 13,46 \\
\hline
\end{tabular}

Tabela 3 - Variação no número de viagens diárias (em milhares) e na participação dos diferentes modais no sistema de transportes da RMRJ entre 2003 e 2012. Fonte: PDTU (2005; 2013).

Dados comparativos dos anos de 2003 e 2012 demonstram uma trajetória decrescente na participação dos modais não motorizados (tanto em valores absolutos como proporcionais), especialmente do transporte

\footnotetext{
${ }^{72}$ Soma das viagens feitas por ônibus executivo, intermunicipal, municipal e pirata.

${ }^{73}$ Soma das viagens feitas por condutor de auto, motocicleta e passageiro de auto.
} 
cicloviário, nos deslocamentos dentro da RMRJ. No mesmo período, observa-se o crescimento da participação do transporte motorizado individual.

As características socio-econômicas da população podem oferecer indícios sobre as razões desse movimento de transferência dos modais não motorizados para os motorizados. A matriz de viagens por motivos dentro da RMRJ indica uma diferença na ordem dos principais motivos de deslocacamento quando são comparados os modais motorizados com os não motorizados. O trabalho aparece como principal motivo de viagens relacionadas ao transporte motorizado, tanto individual quanto coletivo. No caso do transporte não motorizado, o trabalho aparece em terceiro lugar, depois de educação e "outros"74. Isso permite supor que um aumento no número de trabalhadores, especialmente os formais, com direito a vale transporte, poderia transferir usuários do transporte não motorizado para o motorizado.

\footnotetext{
${ }^{74} \mathrm{O}$ motivo residência não foi considerado pois as pessoas usualmente saem e voltam para suas casas.
} 


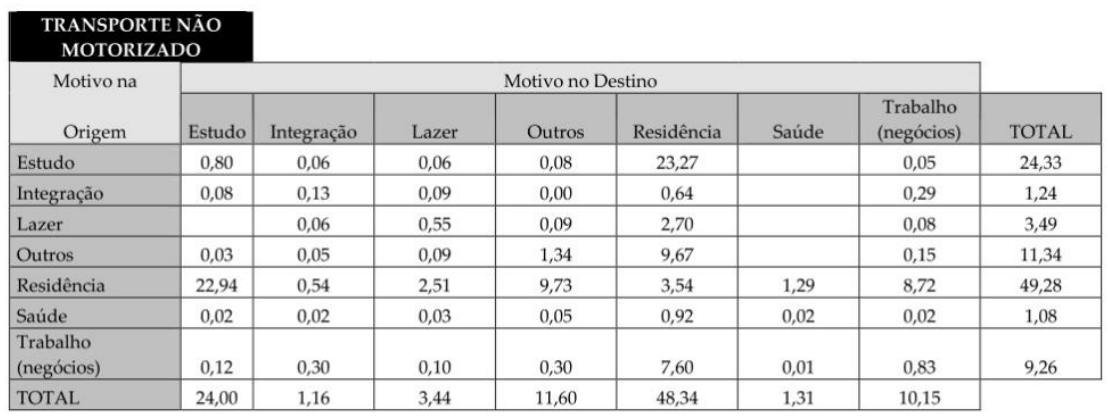

\begin{tabular}{|c|c|c|c|c|c|c|c|c|}
\hline \multicolumn{8}{|c|}{$\begin{array}{l}\text { TRANSPORTE } \\
\text { COLETIVO }\end{array}$} & \multirow[b]{3}{*}{ TOTAL } \\
\hline Motivo na & \multicolumn{7}{|c|}{ Motivo no Destino } & \\
\hline & Estudo & Integração & Lazer & Outros & Residência & Saúde & $\begin{array}{l}\text { Trabalho } \\
\text { (negócios) }\end{array}$ & \\
\hline Estudo & 0,32 & 0,63 & 0,01 & 0,00 & 8,79 & 0,02 & 0,09 & 9,86 \\
\hline Integração & 0,60 & 3,09 & 0,34 & 0,32 & 7,18 & 0,24 & 6,76 & 18,52 \\
\hline Lazer & 0,01 & 0,30 & 0,05 & 0,09 & 1,47 & & 0,00 & 1,92 \\
\hline Outros & & 0,61 & & 0,95 & 3,17 & 0,13 & 0,05 & 4,91 \\
\hline Residência & 8,55 & 7,80 & 2,10 & 3,99 & 2,86 & 1,83 & 13,74 & 40,88 \\
\hline Saúde & 0,01 & 0,25 & 0,01 & 0,27 & 1,49 & 0,34 & 0,03 & 2,40 \\
\hline Trabalho (negócios) & 0,30 & 5,82 & 0,04 & 0,35 & 13,40 & & 1,60 & 21,51 \\
\hline TOTAL & 9,79 & 18,50 & 2,55 & 5,98 & 38,36 & 2,56 & 22,26 & \\
\hline
\end{tabular}

\begin{tabular}{|c|c|c|c|c|c|c|c|c|}
\hline \multicolumn{8}{|c|}{$\begin{array}{l}\text { TRANSPORTE } \\
\text { INDIVIDUAL }\end{array}$} & \multirow[b]{3}{*}{ TOTAL } \\
\hline Motivo na & \multicolumn{7}{|c|}{ Motivo no Destino } & \\
\hline & Estudo & Integração & Lazer & Outros & Residência & Saúde & $\begin{array}{l}\text { Trabalho } \\
\text { (negócios) }\end{array}$ & \\
\hline Estudo & 1,08 & & 0,06 & 0,06 & 4,75 & 0,01 & 0,14 & 6,10 \\
\hline Integração & & 0,02 & 0,05 & & 0,63 & & 0,09 & 0,78 \\
\hline Lazer & & & 1,32 & 0,04 & 6,32 & 0,04 & & 7,72 \\
\hline Outros & 0,03 & 0,02 & 0,06 & 1,94 & 11,46 & 0,13 & 0,54 & 14,17 \\
\hline Residência & 5,49 & 0,87 & 5,61 & 10,27 & 4,01 & 2,94 & 17,56 & 46,76 \\
\hline Saúde & & & 0,20 & 0,28 & 2,02 & 0,18 & 0,24 & 2,93 \\
\hline $\begin{array}{c}\text { Trabalho } \\
\text { (negócios) }\end{array}$ & 0,35 & 0,35 & 0,29 & 0,74 & 15,69 & 0,09 & 4,03 & 21,53 \\
\hline TOTAL & 6,95 & 1,25 & 7,60 & 13,33 & 44,87 & 3,39 & 22,61 & \\
\hline
\end{tabular}

Tabela 4 - Matriz de viagens por motivos. Fonte: PDTU (2013), Tabelas 4.1 a 4.3, p.11.

Quando são observados somente os dados de viagens por motivo de trabalho, o trabalho formal responde por $79,8 \%$ do total de viagens feitas em transporte público, $77,3 \%$ em transporte individual e 57,2\% em transporte não motorizado. Para o trabalho informal, a relação é, respectivamente, 14,6\%, $19,1 \%$ e $36,1 \%{ }^{75}$.

Quanto às taxas de desemprego nas principais regiões metropolitanas do Brasil, entre 2003 e 2012 houve uma queda significativa, passando de $12,4 \%$ para $5,5 \%(2012)^{76}$.

Nas viagens por motivo de trabalho, o modo mais utilizado é o transporte público, sendo que o trabalho formal é o predominante. Nas viagens não motorizadas há um acréscimo em relação ao modo motorizado do trabalho informal, sinalizando que as pessoas na informalidade tendem a se locomover mais a pé ou de bicicleta/ciclomotor (PDTU, 2013, p.13).

\footnotetext{
75 Tabela 4.4.1 PDTU (2013) p.13.

${ }^{76}$ Fonte: Jornal Valor Econômico. Dados da Pesquisa Mensal de Emprego do IBGE. Disponível em: <www.valor.com.br/brasil/2990916/desemprego-medio-em-2012-e-o-mais-baixo-desde2003-diz-ibge>. Acesso em: 20/08/2014.
} 
Outro dado que pode explicar a queda na participação do transporte não motorizado é a renda familiar. Os dados do PDTU (2013) indicam que quanto maior a renda familiar per capita, maior é a participação do transporte motorizado individual. Por outro lado, quanto menor é a renda, maior é a participação do transporte não motorizado.

\begin{tabular}{|c|c|c|}
\hline Viagens não motorizadas por motivo trabalho (negócios) & 1.313 .183 & \\
\hline Até $2 \mathrm{SM}$ & 975.498 & 74,3 \\
\hline Mais de 2 até $5 \mathrm{SM}$ & 161.931 & 12,3 \\
\hline Mais de $5 \mathrm{SM}$ & 175.755 & 13,4 \\
\hline Viagens em transporte individual motivo trabalho (negócios) & 1.707 .230 & 27 \\
\hline Até $2 \mathrm{SM}$ & 558.004 & 32,7 \\
\hline Mais de 2 até $5 \mathrm{SM}$ & 454.733 & 26,6 \\
\hline Mais de 5 SM & 694.493 & 40,7 \\
\hline Viagens em transporte público por motivo trabalho (negócios) & 4.638 .370 & 73 \\
\hline Até $2 \mathrm{SM}$ & 2.430 .166 & 52,4 \\
\hline Mais de 2 até $5 \mathrm{SM}$ & 1.624 .843 & 35,0 \\
\hline Mais de $5 \mathrm{SM}$ & 583.361 & 12,6 \\
\hline
\end{tabular}

\footnotetext{
Tabela 5 - Modo de transporte por classe de renda (SM-salário mínimo) segundo motivo de trabalho. Fonte: PDTU (2013), Tabela 4.2.1, p.15.
}

Os dados da Tabela 5 indicam que a maior parte dos usuários do transporte não motorizado (74,3\%) têm rendimento per capita mensal de até 2 salários mínimos (classes $\mathrm{D}$ e $\mathrm{E}^{77}$ ). Acima desta faixa de renda, cresce a participação do transporte coletivo e do motorizado individual.

Segundo dados da PNAD/IBGE, entre 2003 e 2009 mais de 29 milhões de pessoas "ingressaram nas fileiras da chamada nova classe média (classe C)", oriundas das classes D e E (Neri, 2010, p.10). Isso quer dizer que a redução nas taxas de desemprego foi acompanhada, no período, pelo aumento da renda das famílias, especialmente as das classes mais baixas.

Apesar de não ser possível afirmar com segurança as razões do declínio do transporte não motorizado, a redução das taxas de desemprego associada à elevação da renda das famílias na última década, pode ser uma razão para o fenômeno.

\footnotetext{
${ }^{77}$ Fonte: IBGE. Lista de Classes Sociais. Disponível em: <http://www.datosmarketing.com.br/listas-detalhes-classes-sociais.asp>. Acesso em: 10/08/2014.
} 
O transporte utilitário, especialmente relacionado a trabalho e estudo é muito relevante para a mobilidade urbana no Rio de Janeiro. Um indicador dessa relevância pode ser observado pelo gráfico de distribuição das viagens ao longo do dia na RMRJ. Em todos os modais observa-se o mesmo padrão de concentração de viagens: no início da manhã, no meio do dia e no fim da tarde.

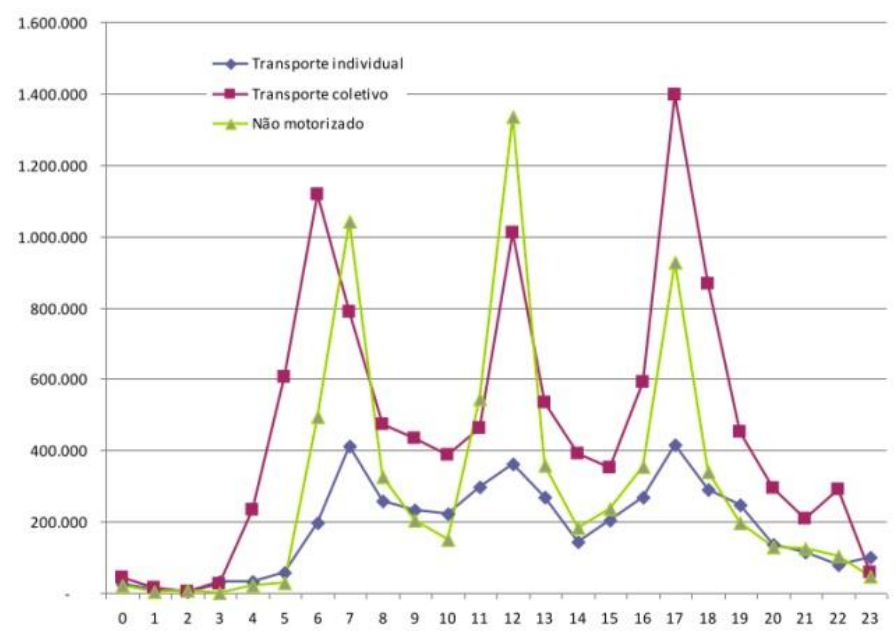

Figura 24- Distribuição das viagens por tipo de transporte e hora de início. Fonte: PDTU (2013), Gráfico 6.1.1, p.20.

Os dados do PDTU em sua maioria estão agrupados considerando toda a RMRJ. Como a avaliação do impacto e da eficácia do Bike Rio neste trabalho será feita considerando exclusivamente a cidade do Rio de Janeiro, foi necessário, para evitar distorções nos resultados, estimar o número de viagens feitas por modal cicloviário na capital.

Dentre os dados disponibilizados por município, a pesquisa domiciliar do PDTU (2013) indicou que na cidade do Rio de Janeiro o transporte motorizado coletivo ${ }^{78}$ responde por $51,1 \%$ do total de deslocamentos, o transporte motorizado individual ${ }^{79}$, por $22,8 \%$ e o transporte não motorizado $^{80}$, por $26,1 \%$.

78 Ônibus executivo; ônibus municipal; ônibus intermunicipal; ônibus pirata; metrô; trem; transporte escolar; transporte fretado; barcas e van.

${ }^{79}$ Condutor de auto; passageiro de auto; táxi; motocicleta; moto-táxi; outros.

${ }^{80}$ A pé e bicicleta. 


\begin{tabular}{|c|c|c|c|c|}
\hline & \multicolumn{2}{|c|}{ Transporte motorizado } & \multirow{2}{*}{$\begin{array}{c}\text { Transporte } \\
\text { não } \\
\text { motorizado }\end{array}$} & \multirow{2}{*}{ Total } \\
\hline & Coletivo & Individual & & \\
\hline$\%$ & 51,1 & 22,8 & 26,1 & 100 \\
\hline Viagens & 7.078 .883 & 3.158 .484 & 3.615 .633 & 13.853 .000 \\
\hline
\end{tabular}

Tabela 6 - Viagens por modal motorizado e não motorizado para a cidade do Rio de Janeiro. Fonte: PDTU (2013), Tabela 3.2.1, p.10.

Em comparação com os dados do PDTU referentes ao ano de 2003, observa-se para a capital a mesma tendência da região metropolitana: aumento na participação do transporte motorizado e redução na participação do transporte não motorizado.

\begin{tabular}{cccccc}
\hline & & \multicolumn{2}{c}{ Transporte motorizado } & Transporte não & \multirow{2}{*}{ Total } \\
& & Coletivo & Individual & motorizado & \\
\hline \multirow{2}{*}{2003} & $\%$ & 49,8 & 19,0 & 31,3 & 100 \\
& Viagens & 5.831 .329 & 2.225 .447 & 3.662 .748 & 11.719 .524 \\
\hline \multirow{2}{*}{2012} & $\%$ & 51,1 & 22,8 & 26,1 & 100 \\
& Viagens & 7.078 .883 & 3.158 .484 & 3.615 .633 & 13.853 .000 \\
\hline Diferença & & $21,39 \%$ & $41,93 \%$ & $-1,29 \%$ & \multirow{2}{*}{$18,20 \%$} \\
$2003 / 2012$ & & & & & \\
\hline
\end{tabular}

Tabela 7 - Viagens por modal motorizado e não motorizado para a cidade do Rio de Janeiro. Comparativo anos 2003 e 2012. Fonte PDTU (2003; 2013).

Como não é possível determinar com os dados disponíveis se a tendência de redução do transporte cicloviário na cidade do Rio de Janeiro acompanhou a intensidade com que se deu no âmbito da região metropolitana, esta pesquisa considerou que a participação do transporte cicloviário no total das viagens realizadas por modal não motorizado na cidade é a mesma da região metropolitana, ou seja, 7,6\% ${ }^{81}$. Dessa forma, a estimativa de viagens diárias realizadas por bicicleta na cidade do Rio de Janeiro para o ano de 2012 foi de $274.788^{82}$, o que equivale a $2,0 \%$ do total de deslocamentos diários da cidade.

${ }^{81}$ PDTU (2013), Tabela 3.1.1, p.7.

82 A Prefeitura, através da SMAC, informa serem registradas na cidade 1.5 milhões de viagens diárias por bicicleta (incluindo o uso comercial para entrega e serviços). Contudo, além de não haver indicação da origem dos dados, esse número equivaleria a praticamente metade da contagem de viagens por transporte motorizado individual do PDTU. Fonte: Secretaria Municipal de Urbanismo. Disponível em: <http://www.rio.rj.gov.br/web/smac/rio-capital-dabicileta>. Acesso em: 10/07/2014. 


\section{2}

\section{O sistema de compartilhamento de bicicleta do Rio de Janeiro: Bike Rio}

O primeiro contrato de concessão para operação do sistema de compartilhamento de bicicleta da cidade do Rio de Janeiro foi lançado em dezembro de 2008, dentro do projeto "Pedala Rio". Batizado de SAMBA (Solução Alternativa para Mobilidade por Bicicletas de Aluguel), previa a implantação de 50 estações e de uma frota de até 1.000 bicicletas que seriam distribuídas por bairros da zona sul do Rio de Janeiro ${ }^{83}$.

O sistema oferecia quatro tipos de passes. Para usuários que fariam uso frequente do sistema, havia o passe anual, ao custo de $R \$ 100,00$ e o semestral, ao custo de $\mathrm{R} \$ 50,00$. Para usuários ocasionais eram disponibilizados passes de 3 dias $(R \$ 15,00)$ e diário $(R \$ 10,00)$.
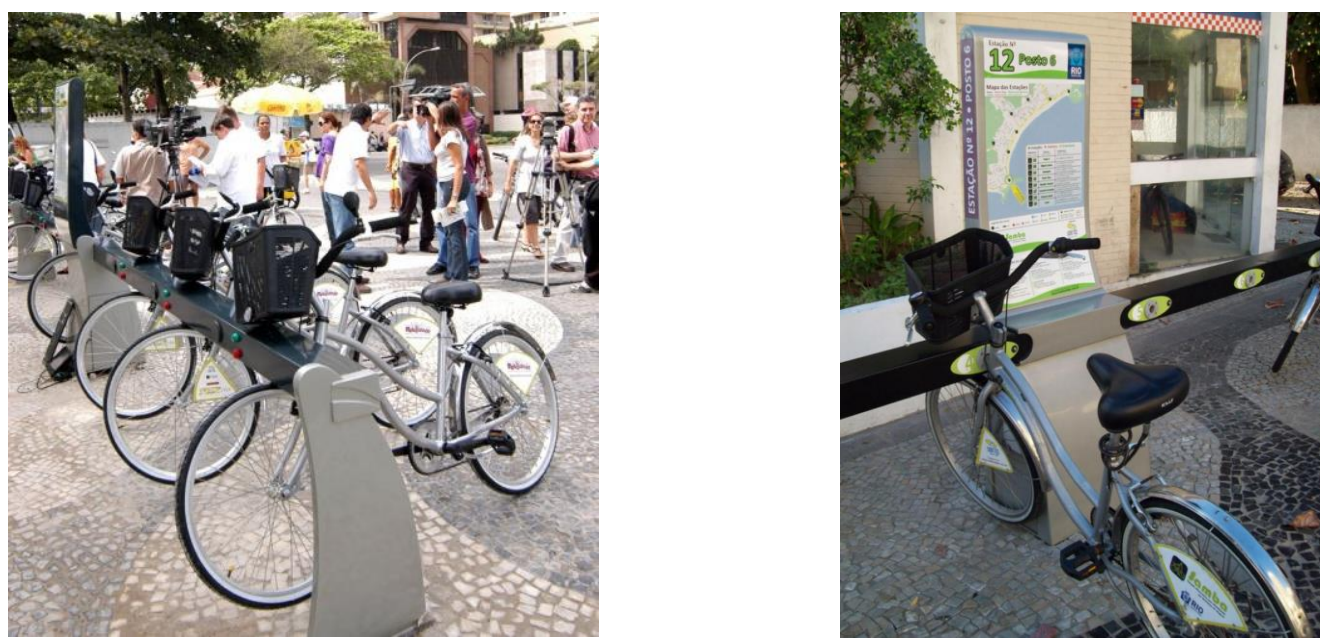

Figura 25 - Estações e bicicletas do sistema SAMBA. Fonte: Serttel

Entretanto, uma série de problemas envolvendo "roubos de bicicletas, o sistema de bilhetagem e a localização das bases", insuficientes para o pleno funcionamento do serviço, fizeram com que o programa acabasse sendo suspenso em 2010 com apenas 19 bases instaladas ${ }^{84}$.

Em outubro de 2011, operado pela mesma empresa (Serttel), mas contando com o patrocínio do Banco Itaú, o sistema foi reinaugurado com um

\footnotetext{
${ }^{83}$ Fonte: Serttel. Disponível em: <http://ie.org.br/site/ieadm/arquivos/arqnot2716.pdf>. Acesso em 10/08/2014.

${ }^{84}$ Fonte: O Globo 10/10/2010. Disponível em:

<http://oglobo.globo.com/rio/bicicletas/mat/2011/09/30/projeto-pedala-rio-promete-entrar-noseixos-partir-de-novembro-925478858.asp>. Acesso em: 05/07/2014.
} 
novo nome, uma nova estratégia de marketing e um sistema que incorporou a tecnologia dos aplicativos para smartphones para retirada das bicicletas, aquisição de passes e consulta em tempo real sobre a disponibilidade de bicicletas nas estações. O sistema de travamento foi aprimorado e as bicicletas e estações passaram a utilizar a cor laranja, o que ajudou a reduzir os índices de vandalismo e "zerar os registros de furto" ${ }^{85}$. Nesta nova fase, o Bike Rio passou a operar com 60 estações e $600^{86}$ bicicletas distribuídas por bairros da zona sul e no centro ${ }^{87}$.

Para utilizar as bicicletas o usuário deve primeiramente se cadastrar no site do sistema fornecendo seus dados pessoais. O Bike Rio disponibiliza atualmente dois tipos de passe: mensal e diário. O primeiro custa $R \$ 10,00$ e é válido por 30 dias, o segundo custa $R \$ 5,00$ e vale por 24 horas $^{88}$. O passe mensal pode ser adquirido pela internet ou através de um aplicativo para smartphone. O passe diário só pode ser adquirido através do aplicativo para celular ou ligando para a central de atendimento.

A liberação das bicicletas nas estações é feita através do celular, utilizando o aplicativo ou ligando diretamente para a central de atendimento, informando a estação desejada e o número da "vaga" onde se encontra a bicicleta que se pretende retirar. Informações obtidas por meio da imprensa informam que $70 \%$ dos usuários fazem uso dos aplicativos para retirar as bicicletas $^{89}$.

\footnotetext{
${ }^{85}$ Ibid. 26/04/2012. Disponível em: <http://oglobo.globo.com/rio/aluguel-de-bicicletas-bate-500mil-viagens-empresa-quer-estender-sistema-toda-cidade-4749773>. Acesso em: 20/07/2014. ${ }_{87}^{86}$ Fonte: <www.movesamba.com.br/bikerio>.

${ }^{87}$ Após a inauguração do Parque Madureira (2012), foram instaladas 3 estações do Bike Rio no local, mas o total de 60 já considera estas três estações.

${ }^{88} \mathrm{~A}$ utilização das bicicletas no Parque Madureira é gratuita.

${ }^{89}$ Veja Rio. A nova fase do Bike Rio. 13/06/2013. Disponível em: $<$ http://vejario.abril.com.br/especial/a-nova-fase-do-bike-rio-744030.shtml >. Acesso em: 02/07/2014.
} 

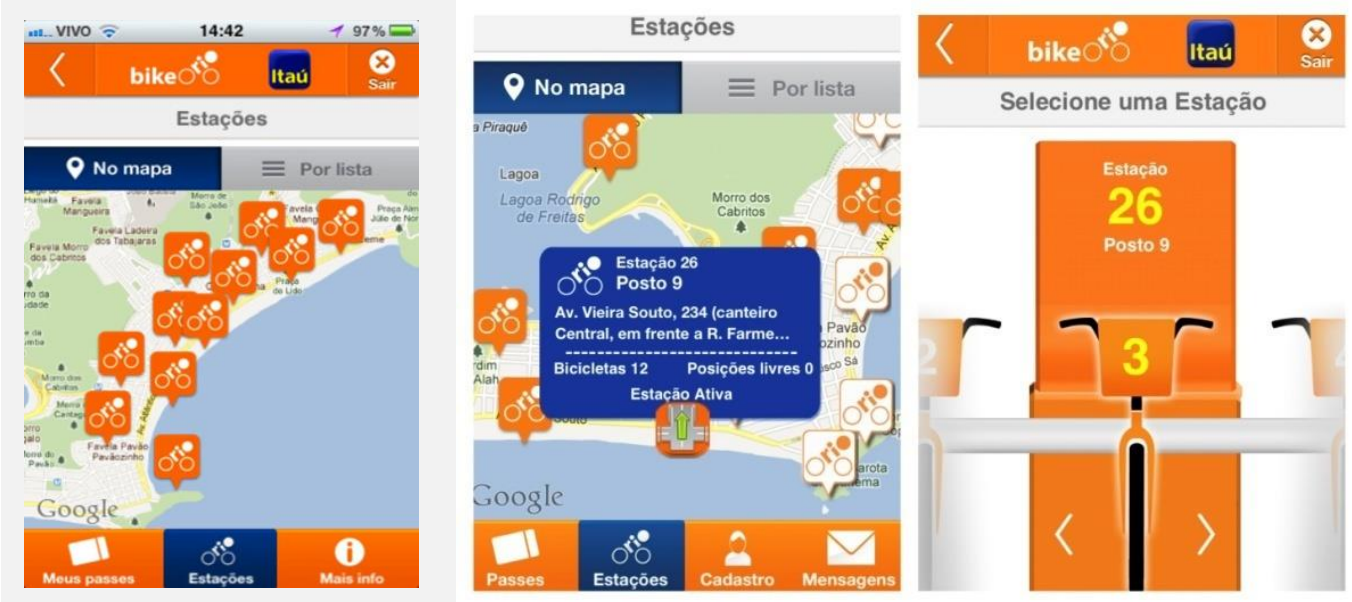

Figura 26 - Sistema de retirada de bicicletas através de aplicativo para smartphone.

O tempo máximo de cada viagem está limitado a 60 minutos e deve ser respeitado um intervalo mínimo de 15 minutos entre cada viagem. Caso o usuário não devolva a bicicleta dentro do prazo limite, é cobrada uma taxa de $\mathrm{R} \$ 5,00$ por cada hora excedente. O sistema opera diariamente das 06:00h às 24:00h.

Até o fim de 2013, o Bike Rio encontrava-se implantado em bairros da zona sul, no centro e em Madureira, na zona norte ${ }^{90}$. O conjunto desses bairros corresponde a uma área equivalente a 4,06\% do município $(4.968,74$ $\left.\mathrm{ha}^{91}\right)$. Se considerarmos apenas as áreas incluídas sob a cota 100, o Bike Rio alcança $4,24 \%$ da área total da cidade $(4.035,57 \mathrm{ha})^{92}$.

Apesar de ocuparem menos de $5 \%$ da área do município, os bairros alcançados pelo SCB representam 9,97\% do total de habitantes (630.306) e $12,88 \%$ (310.247) do total de domicílios, concentrando grande parte dos serviços e dos equipamentos de lazer da cidade ${ }^{93}$.

\footnotetext{
90 Madureira possui apenas 03 estações inseridas no Parque Madureira, configurando-se o Bike Rio mais como um equipamento de lazer do que como modal de transporte neste bairro.

91 Fonte: Bairros Cariocas. <http://portalgeo.rio.rj.gov.br/bairroscariocas/default.htm>. Acesso em: 25/06/2014. A área total do município do Rio de Janeiro é de 122.456 ha.

92 Apêndice 3.

93 Esses bairros atraem uma grande população flutuante, mas em razão da dificuldade de dimensionar esse contingente, serão considerados apenas os dados referentes à população local.
} 


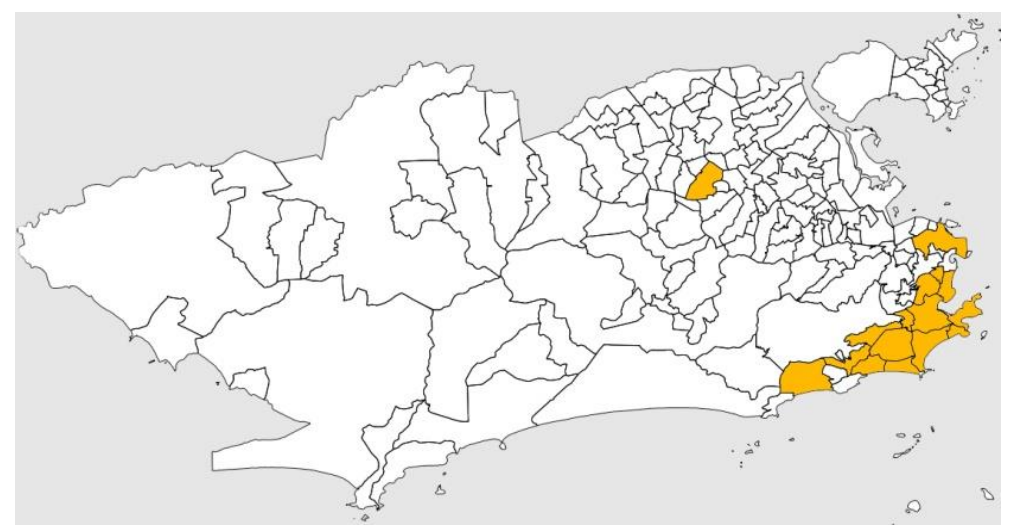

Figura 27 - Alcance do Bike Rio por bairro em novembro 2013.

Nesta nova fase, inaugurada no fim de 2011, o sistema conseguiu se estabelecer e desde o início de 2012 manteve uma média de viagens diárias oscilando numa faixa entre 3.000 e 4.000 (Figura 28).

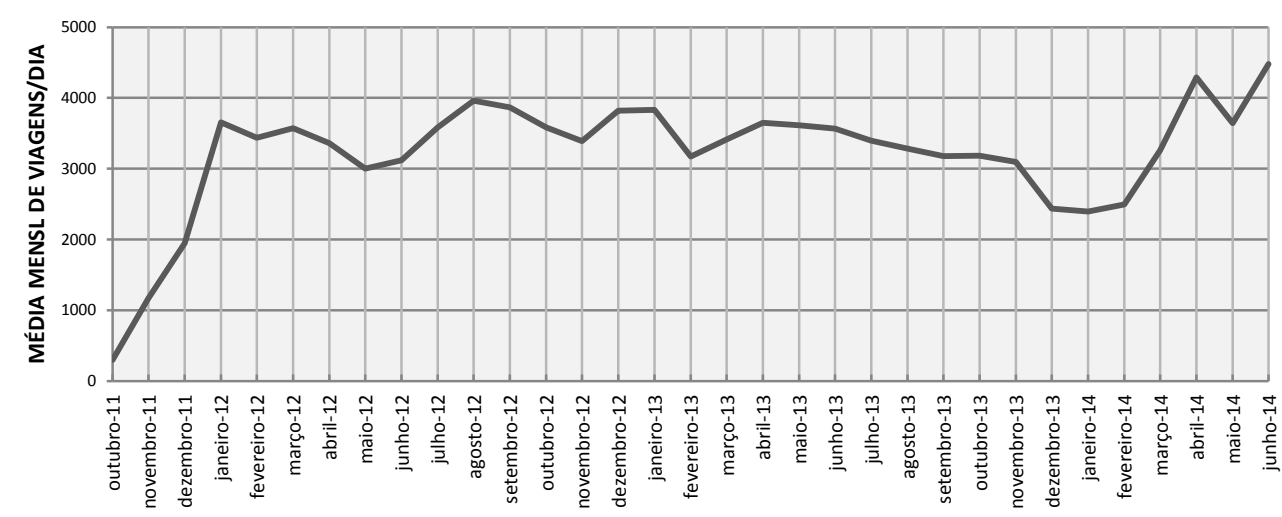

Figura 28 - Média mensal de viagens/dia realizadas pelo Bike Rio. Fonte: Equipe Bike Itaú.

Em setembro de 2013, a prefeitura do Rio de Janeiro lançou um novo edital para "concessão de uso de espaço público, com encargos de implantação, manutenção e operação de sistema de compartilhamento de bicicletas na cidade do Rio de Janeiro" "94. Pelos termos do edital, o vencedor deverá ampliar o número de estações para 260 e a frota de bicicletas para 2.600 unidades em um prazo de até 12 meses. ${ }^{95}$

\footnotetext{
${ }^{94}$ Processo 04/550.508/2013. Fonte: Diário Oficial do Rio de Janeiro. Ano XXVII. n.129.

95 O prazo começa a ser contado após a aprovação dos projetos "com as caracterísiticas físicas das estações e das bicicletas, bem como o plano da operação e manutenção do sistema de compartilhamento de bicicletas."
} 


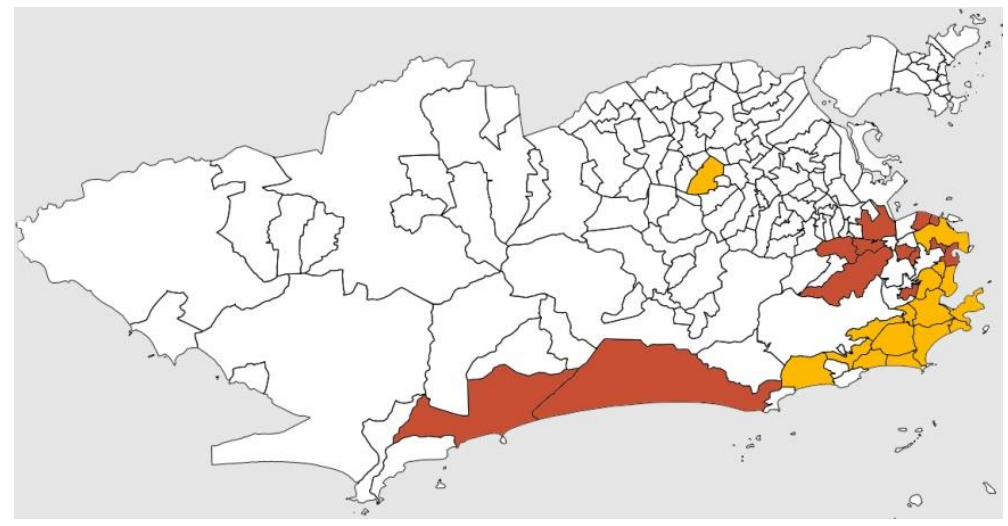

Figura 29 - Alcance do Bike Rio após expansão prevista do sistema.

O edital prevê a instalação de 57 novas estações na zona sul, 57 no centro e imediações, 16 na Tijuca e imediações, 10 em Vila Isabel e imediações, 47 na Barra da Tijuca e 13 no Recreio dos Bandeirantes. Essa expansão representa um aumento de $131 \%$ na área efetiva ${ }^{96}$ de alcance do Bike Rio e de $92,2 \%$ na população residente.

\begin{tabular}{|c|ccc|cc|cc|cc|}
\hline & área total & $\begin{array}{c}\text { área } \\
\text { efetiva* }\end{array}$ & $\begin{array}{c}\text { \% do total } \\
\text { da cidade }\end{array}$ & população & $\begin{array}{c}\text { \% do total } \\
\text { da cidade }\end{array}$ & domicílios & $\begin{array}{c}\text { \% do total } \\
\text { da cidade }\end{array}$ & estações & bicicletas \\
\hline $\begin{array}{c}\text { Fase } 01- \\
\text { até } 2013\end{array}$ & $4.968,74$ & $4.035,57$ & $4,2 \%$ & $630.306,00$ & $10,0 \%$ & $310.247,00$ & $12,9 \%$ & 60 & 600 \\
\hline Fase 02 & $10.346,28$ & $9.357,84$ & $9,8 \%$ & $581.416,00$ & $9,2 \%$ & $249.964,00$ & $10,4 \%$ & 200 & 2000 \\
\hline & & & & & & & & & 260 \\
Total & $15.315,02$ & $13.393,41$ & $14,1 \%$ & $1.211 .722,00$ & $19,2 \%$ & $560.211,00$ & $23,3 \%$ & 2600 \\
\hline crescimento & $108,2 \%$ & $131,9 \%$ & & $92,2 \%$ & & $80,6 \%$ & & $333,3 \%$ & $333,3 \%$ \\
\hline
\end{tabular}

Tabela 8 - Comparativo da situação atual com a previsão de expansão para o Bike Rio ${ }^{97}$ (Apêndice 3)

A Empresa Serttel, que já operava o Bike Rio, foi a vencedora da licitação e o processo de ampliação do sistema teve início no $1^{\circ}$ trimestre de $2014^{98}$ com a instalação de novas estações na zona sul e no centro. Antes do início da instalação das novas estações, foi feito um trabalho de manutenção e substituição das estações já existentes, razão pela qual houve uma redução na média mensal de viagens no final de 2013 e início de 2014 (Figura 28).

É possível observar que a faixa de oscilação da média mensal de viagens/dia após o início da expansão do sistema apresenta uma tendência

96 Área efetiva, para esta pesquisa, é a área total dos bairros alcançados pelo sistema descontada a parcela situada acima da cota 100.

${ }^{97}$ Fonte: Diário Oficial do Rio de Janeiro. Ano XXVII. n.129 e Bairros Cariocas. Disponível em: <portalgeo.rio.rj.gov.br/bairroscariocas/index_bairro.htm>.

${ }^{9} \mathrm{Em} 23$ de março de 2014, por exemplo, foram inauguradas 20 novas estações na região central da cidade. Paralelamente, vêm sendo instaladas estações em parte da zona sul, especialmente nos bairros da Glória e Catete, que não eram servidos pelo sistema. 
de elevação para patamares superiores a 4.000 viagens/dia. Contudo, é necessário aguardar o término do processo de implantação das novas estações para que se possa ter uma definição mais precisa de como ficará a média diária de viagens do Bike Rio.

Pelo contrato estabelecido com a prefeitura, o concessionário poderá explorar publicidade nas bicicletas, nas estações e em eventuais totens de auto atendimento que sejam implantados. Também deverá atender especificações técnicas contidas no edital como alimentar as estações com energia solar e disponibilizar sua comunicação com a central de controle através de rede sem fio para evitar a necessidade de execução de infraestrutura subterrânea ou aérea, como já é feito atualmente. As estações deverão comportar até 16 bicicletas cada.
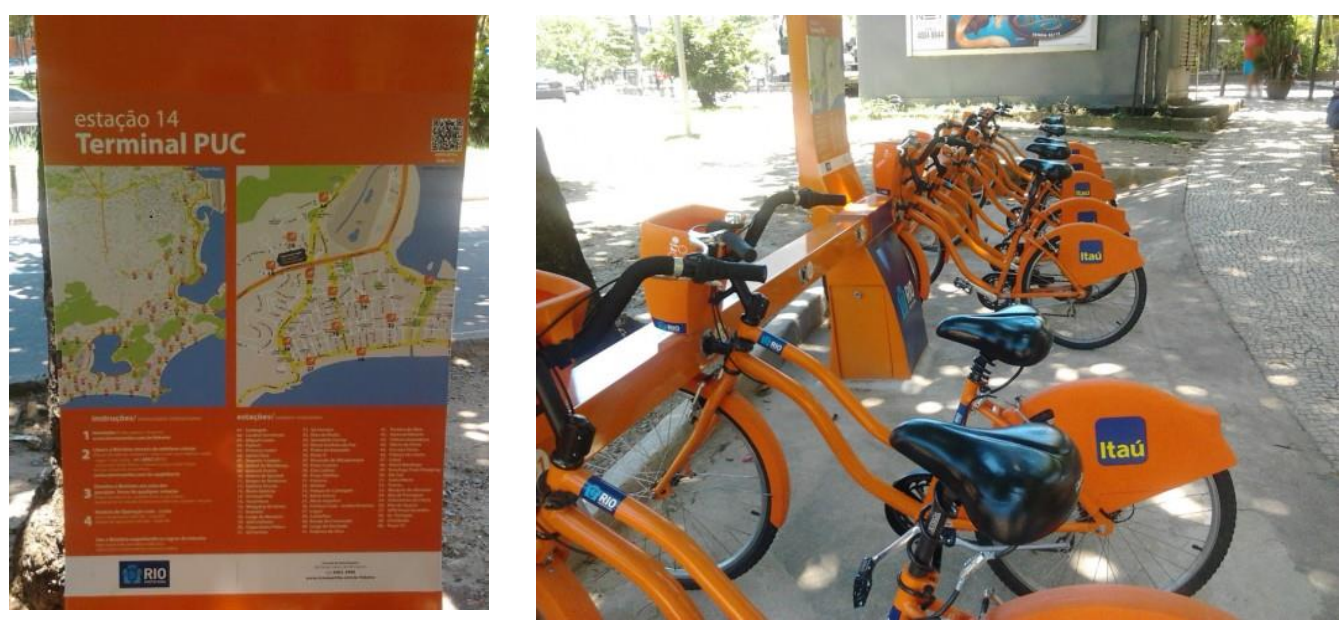

Figura 30 - Estação Bike Rio (Gávea, RJ).

O Bike Rio conta com mais de $200.000^{99}$ usuários cadastrados. Isso não quer dizer que todos sejam usuários ativos, pois é possível estar cadastrado e não efetuar o pagamento do passe. Não foi possível obter com o operador o histórico mensal de usuários ativos para esta pesquisa.

Como o Bike Rio está passando por um processo de mudanças cujo impacto ainda não pode ser mensurado, esta pesquisa irá se deter nos dados de 2012 e 2013 para sua avaliação.

\footnotetext{
${ }^{99} 203.456$ cadastrados em 12/07/2014. Fonte: Equipe Bike Itaú .
} 

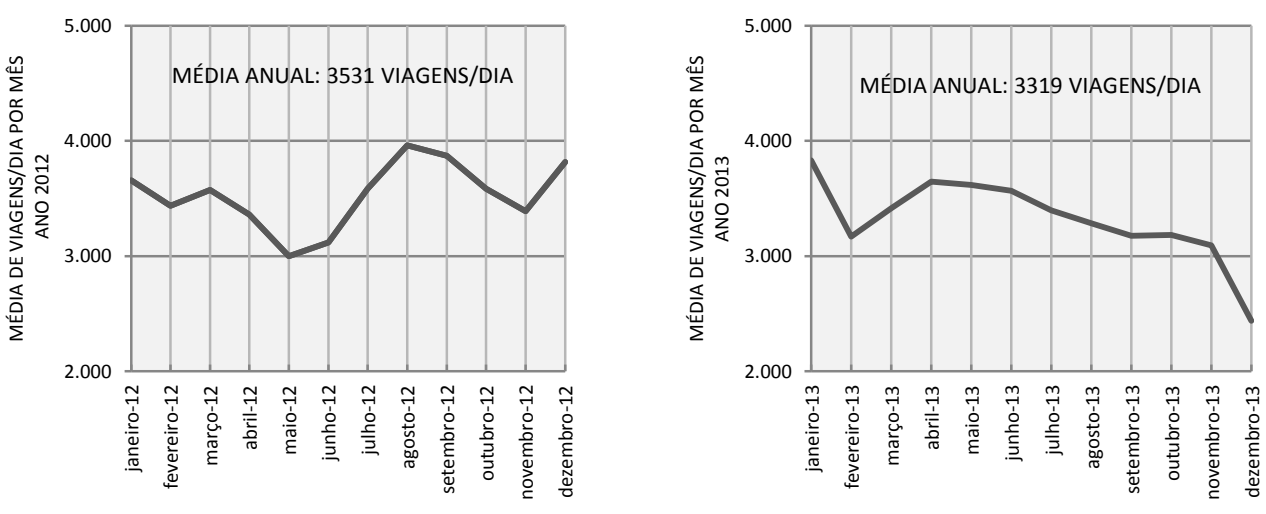

Figura 31 - Média diária de viagens mensal Bike Rio anos 2012 e 2013. Fonte: Equipe Bike Itaú.

Os gráficos da Figura 31 demonstram não haver um padrão sazonal típico para a média mensal de viagens. Com exceção de uma queda observada na média mensal de viagens no mês de fevereiro, há praticamente uma inversão de tendências. Enquanto em 2012, os meses de outono e início de inverno tiveram as menores médias de viagem/dia, em 2013 observa-se o movimento contrário, com as maiores médias ocorrendo justamente neste período.

Foi feita uma tentativa de relacionar a variação mensal no número de viagens diárias à média pluviométrica no período correspondente, mas não foi encontrada uma correlação forte o suficiente para relacionar diretamente estas duas variáveis. Sugere-se um acompanhamento anual dessa variação para que seja possível determinar se isso foi um fato isolado ou se realmente não há um padrão sazonal de viagens para o Bike Rio.

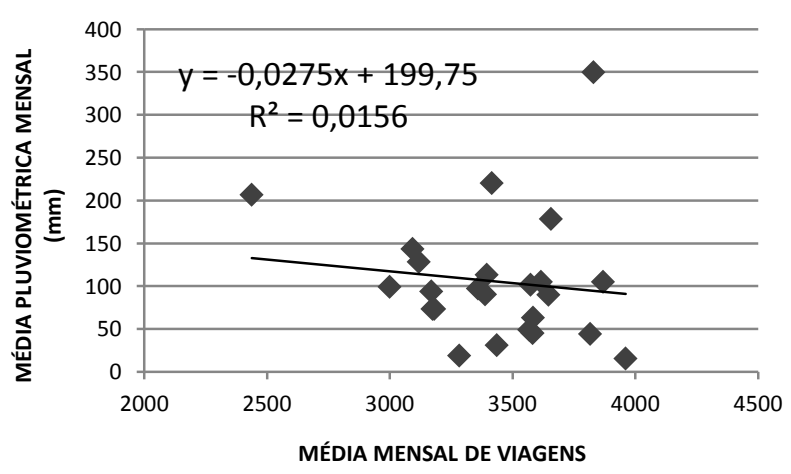

Figura 32- Relação entre viagens e índice pluviométrico para o Bike Rio. Fonte: GEORIO (2012 e 2013) e Equipe Bike Itaú (número de viagens). 


\section{3}

\section{Resultados da pesquisa com usuários do Bike Rio}

A pesquisa com usuários do Bike Rio teve como objetivos: (1) traçar um breve perfil dos usuários; (2) verificar de que maneira o sistema é utilizado e com que frequência; (3) verificar se há transferência de usuários de outros modais para transporte cicloviário e quais os fatores determinantes para isso; e (4) os aspectos positivos e negativos do Bike Rio.

A maioria dos entrevistados (78\%) reside em áreas atendidas pelo Bike Rio, contudo, os resultados demonstraram que o SCB é utilizado também por pessoas residentes em outras regiões da cidade e, inclusive, em outros municípios da RMRJ ${ }^{100}$.

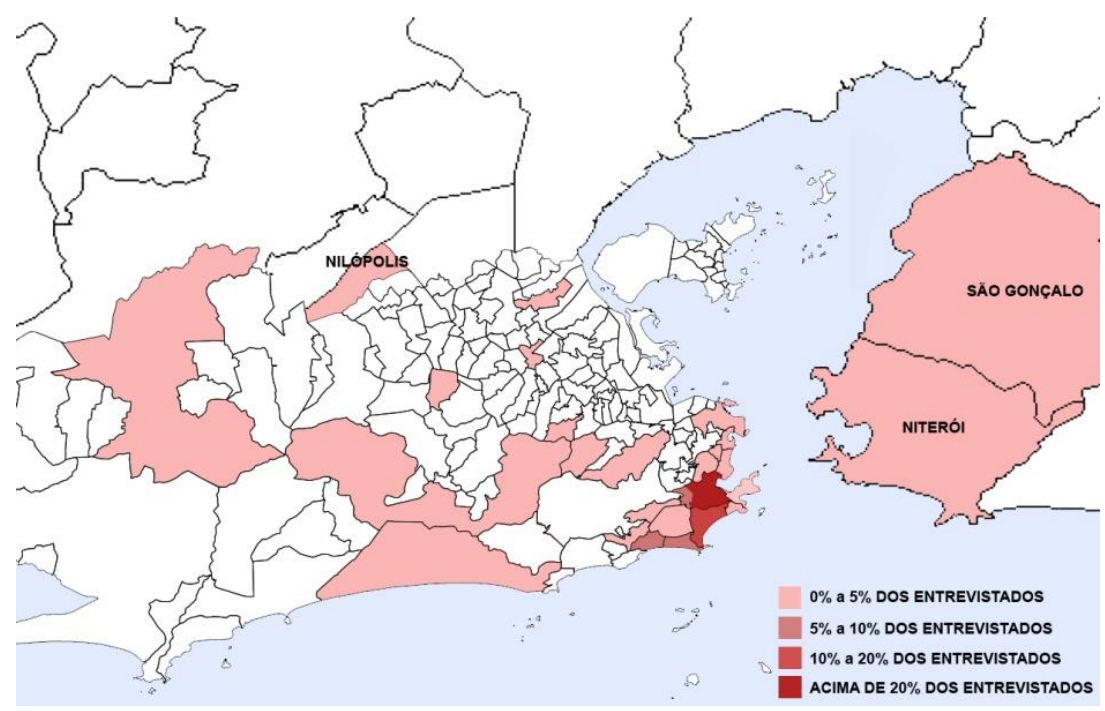

Figura 33 - Distribuição dos locais de residência dos entrevistados.

Apesar das mulheres serem pouco mais da metade da população carioca $(53,2 \%)^{101}$, a pesquisa indicou uma porcentagem de usuários do sexo masculino superior à do sexo feminino $(67 \%$ a $33 \%) .^{102}$

\footnotetext{
${ }^{100}$ Os entrevistados que informaram residir em outros estados ou países não foram incluídos no mapa da figura 39.

${ }_{101}^{101}$ Fonte: IBGE (2010).

102 Não houve escolha de entrevistados durante a pesquisa. Os usuários eram abordados no momento em que chegavam à estação para retirar ou devolver a bicicleta.
} 


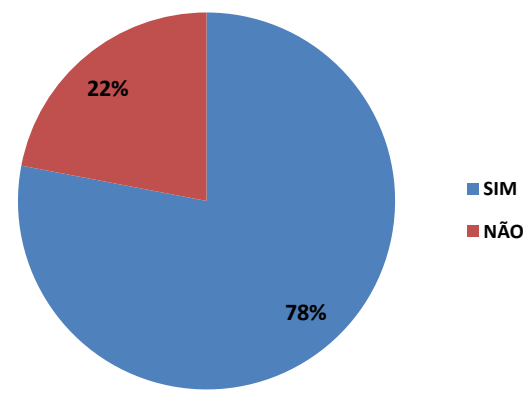

Figura 34 - Porcentagem de entrevistados que residem em bairros atendidos pelo Bike Rio.

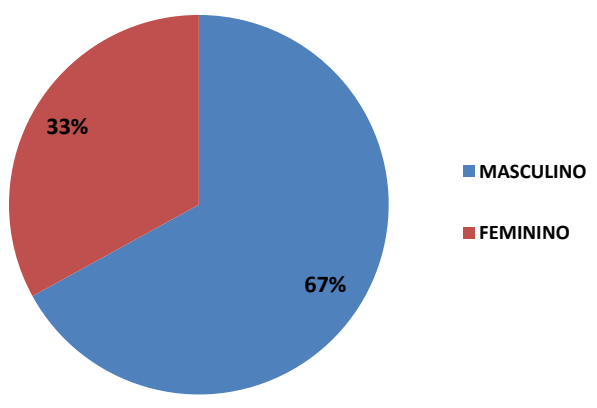

Figura 35 - Distribuição dos entrevistados por gênero.

Quanto à distribuição por idade, a pesquisa demonstrou que o Bike Rio é utilizado predominantemente por jovens adultos. $49 \%$ dos entrevistados tinham idade entre 21 e 30 anos e $40 \%$, entre 31 e 40 anos. Não houve usuários com idade inferior a 20 anos nem superior a 51 anos.

Quando perguntados sobre a frequência com que fazem uso do SCB, $49 \%$ dos entrevistados responderam que utilizam o sistema 4 ou mais vezes por semana e apenas $2 \%$ dos usuários informaram utilizar o sistema apenas nos finais de semana ${ }^{103}$.

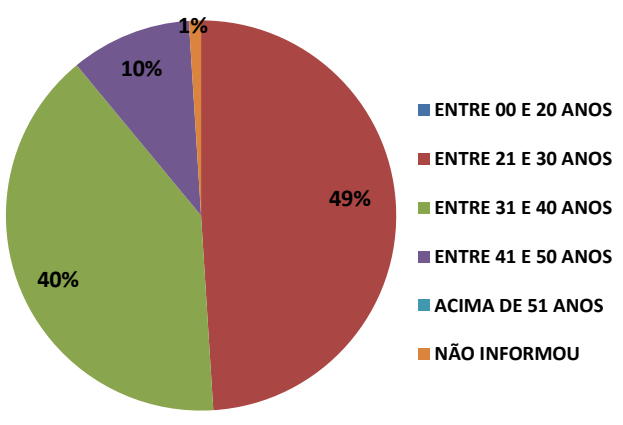

Figura 36 - Distribuição dos entrevistados por idade.

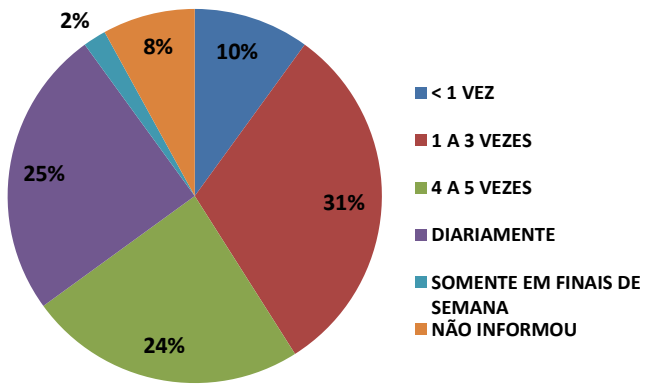

Figura 37 - Distribuição dos entrevistados pela frequência de uso.

Quanto ao motivo da viagem, a maioria dos entrevistados (78\%) estava fazendo uso da bicicleta para fins utilitários, especialmente em viagens relacionadas a trabalho (51\%). Neste grupo (viagens a trabalho) a frequência de utilização do Bike Rio é maior do que a média geral. 60,8\% utilizam o

${ }^{103}$ A existência de respostas informando utilização apenas em finais de semana quando as entrevistas foram realizadas apenas em dias úteis está relacionada a situações incomuns ao dia-a-dia dos usuários, como greve de ônibus. 
sistema 4 ou mais vezes por semana, enquanto na média geral o índice é de $49 \%$.

Os entrevistados também foram questionados sobre a propriedade de veículo particular. A maioria informou não possuir veículo próprio, mas a porcentagem de usuários que possuem carro ou moto é bastante significativa (39\%). Neste caso, a porcentagem de usuários do Bike Rio que estava realizando viagens a trabalho e que possui veículo foi praticamente a mesma da média geral: $37,2 \%$.
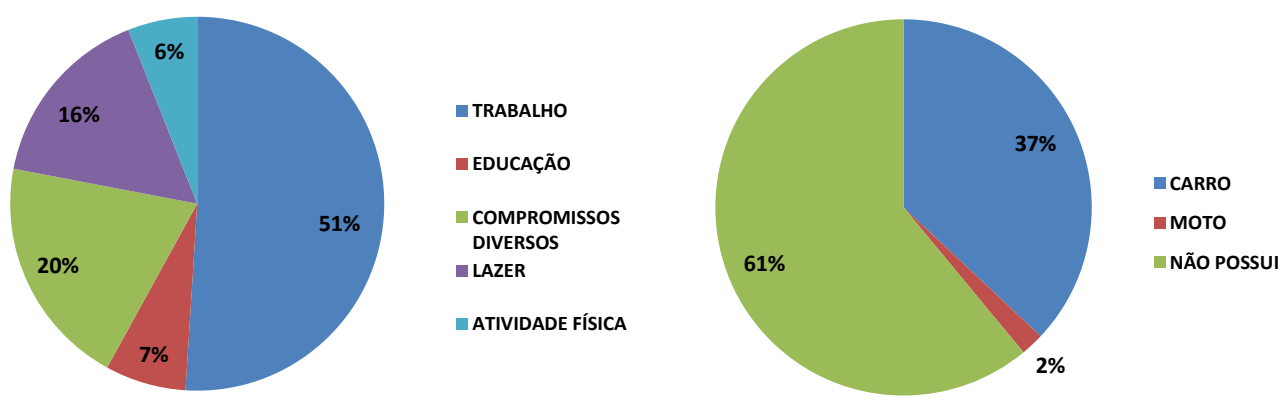

Figura 38 - Distribuição dos entrevistados pelo objetivo da viagem no momento da entrevista.
Figura 39 - Distribuição dos entrevistados pela posse posse de veículo automotor.

Quanto à posse de bicicleta particular, $41 \%$ dos entrevistados informaram possuir sua própria bicicleta. A pesquisa buscou verificar as principais razões que levam as pessoas que possuem bicicleta a utilizar o sistema de compartilhamento. A principal razão apresentada foi a praticidade em poder fazer apenas uma viagem (56\%), seguida da segurança em não expor seu próprio equipamento a risco de assalto ou vandalismo (20\%).

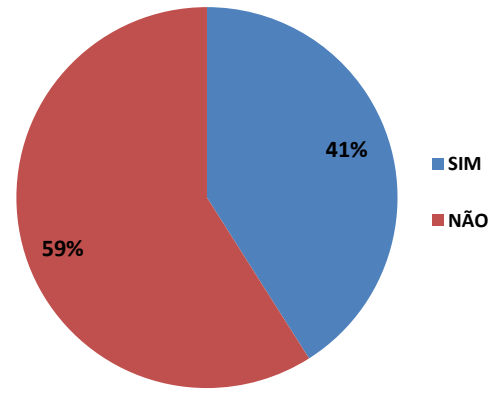

Figura 40- Distribuição dos entrevistados pela posse de bicicleta particular.

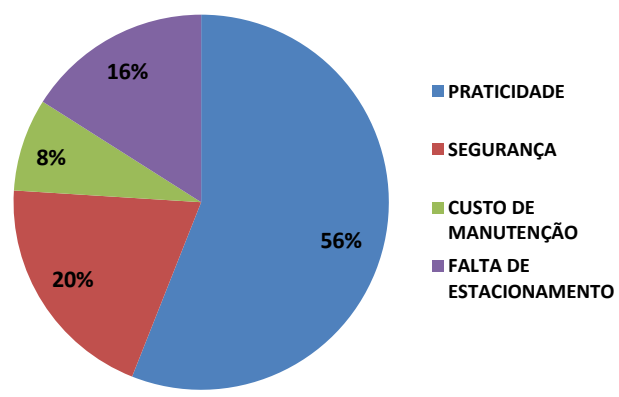

Figura 41 - Razões apresentadas para utilizar o SCB pelos entrevistados que possuem bicicleta particular. 
Para avaliar a utilização do Bike Rio como alimentador do sistema de transportes, os entrevistados foram questionados se haveria ou teria havido a participação de outro modal de transporte entre a origem e o destino finais da viagem. A maioria dos usuários estava se deslocando exclusivamente por bicicleta (62\%). Entre os que fizeram uso de outros modais (38\%), o metrô foi o mais utilizado (75\%), seguido do ônibus (22\%). A escolha dos pontos de abordagem dos entrevistados favoreceu a quantidade de usuários do metrô, mas o resultado demonstra que o Bike Rio é utilizado tanto para percorrer pequenas distâncias diretamente quanto como alimentador do transporte público.

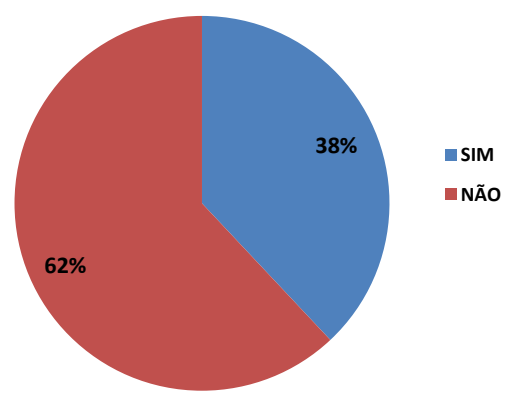

Figura 42 - Distribuição dos entrevistados pela utilização de de mais de um modal na viagem.

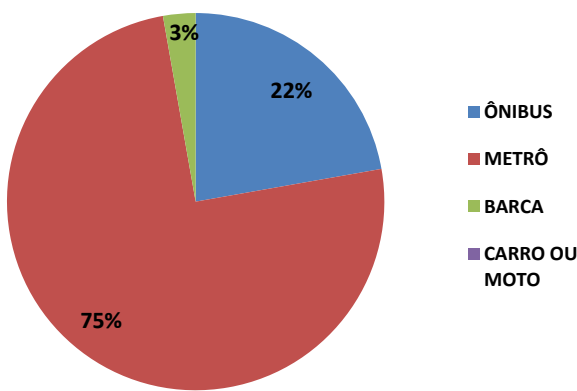

Figura 43 - Participação de outros modais nas viagens com intermodalidade.

Os entrevistados também foram questionados sobre qual modal seria utilizado para efetuar o deslocamento caso não houvesse o Bike Rio. O ônibus foi o principal meio de transporte apontado pelos usuários (52\%), seguido por viagens a pé $(24 \%)$ e de metrô (15\%). Apenas $2 \%$ informaram que utilizariam o próprio veículo caso não houvesse o sistema público de compartilhamento, o que é um indicativo relevante para avaliação do papel desempenhado pelo Bike Rio para redução de congestionamentos e de emissões de poluentes.

Em seguida, foram perguntados sobre as principais razões que os levaram a optar pelo Bike Rio ao invés do modal respondido na questão anterior. Neste caso, foi permitido dar mais de uma resposta e não havia uma lista de opções pré-definidas, deixando o entrevistado livre para expressar sua opinião sem interferências. O que se observa dos resultados é que existe um fator predominante para a escolha do Bike Rio: a rapidez proporcionada pela bicicleta, tanto para fugir dos congestionamentos quanto para chegar ao destino mais rapidamente do que através de uma caminhada. Também foram 
relevantes para a escolha da bicicleta a possibilidade de praticar exercício e a sua agradabilidade.

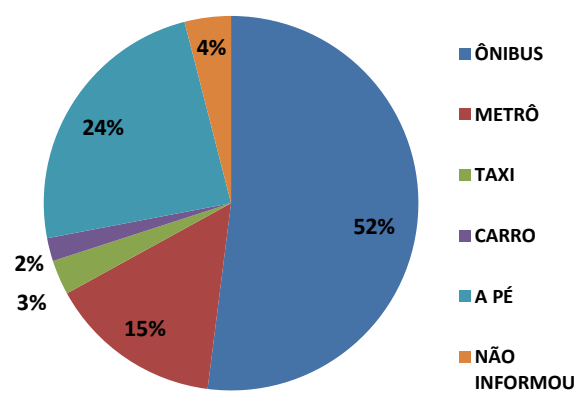

Figura 44 - Participação de modais que estariam sendo substituídos pelo Bike Rio.

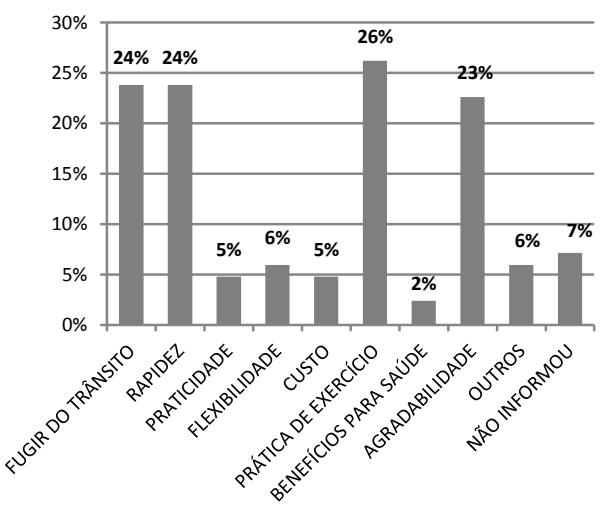

Figura 45 - Razões apresentadas para substituição de outros modais pelo Bike Rio.

Os entrevistados também foram questionados sobre a origem e o destino de suas viagens (com a bicicleta) com o objetivo de mapear as as distâncias percorridas e os principais fluxos a partir dos pontos das entrevistas.

$\mathrm{Na}$ estação Botafogo, observou-se que a maior parte dos usuários fazia viagens de curta distância, dentro do próprio bairro (29\%), e que a demanda se reduzia conforme aumentava a distância percorrida. Os bairros contíguos de Copacabana, Humaitá e Urca aparecem com 11\% de usuários cada um, o que caracteriza o Bike Rio como um modal realmente voltado para percorrer curtas distâncias. A exceção é a ligação com o Centro (um deslocamento superior a $5 \mathrm{~km}$ ) que apareceu em segundo lugar com 16\% dos usuários.

Essas viagens entre Botafogo e Centro (e vice-versa) tinham por objetivo: trabalho, $70 \%$; estudo, 20\%; e compromissos diversos, $10 \%$. As principais razões apresentadas para fazer esse trajeto, mais longo, utilizando a bicicleta foram a rapidez (40\%), praticar exercício (30\%) e fugir do trânsito (20\%). 


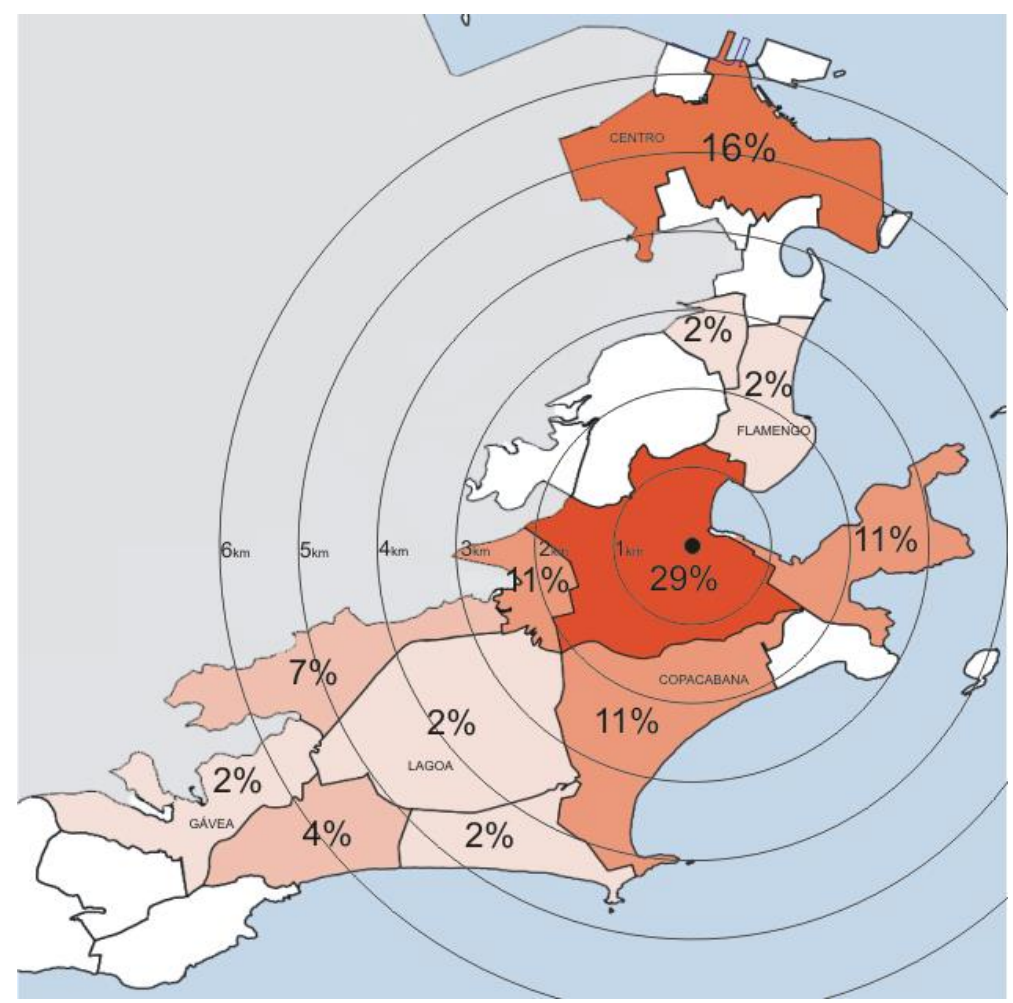

Figura 46 - Origem ou destino das viagens a partir da estação Botafogo.

$\mathrm{Na}$ Estação Ipanema ocorreu um fenômeno distinto. Nenhum entrevistado tinha como origem ou destino o próprio bairro, mas a distância percorrida permaneceu como um fator relevante já que os bairros contíguos do Leblon, Copacabana e Lagoa aparecem, respectivamente, com 50\%, 17\% e $8 \%$ das viagens. Glória e Laranjeiras, os bairros mais distantes que aparecem na pesquisa, representaram $6 \%$ de usuários cada, mas isso provavelmente se deve a questões circunstanciais e ao número de entrevistas realizadas. O mais provável, neste caso, é que o aumento da amostra da pesquisa acarrete a redução da participação desses dois bairros. Nestes casos, tanto a prática de exercício, quanto fugir do trânsito e a agradabilidade aparecem com $25 \%$ das razões para efetuar os deslocamentos mais longos. 


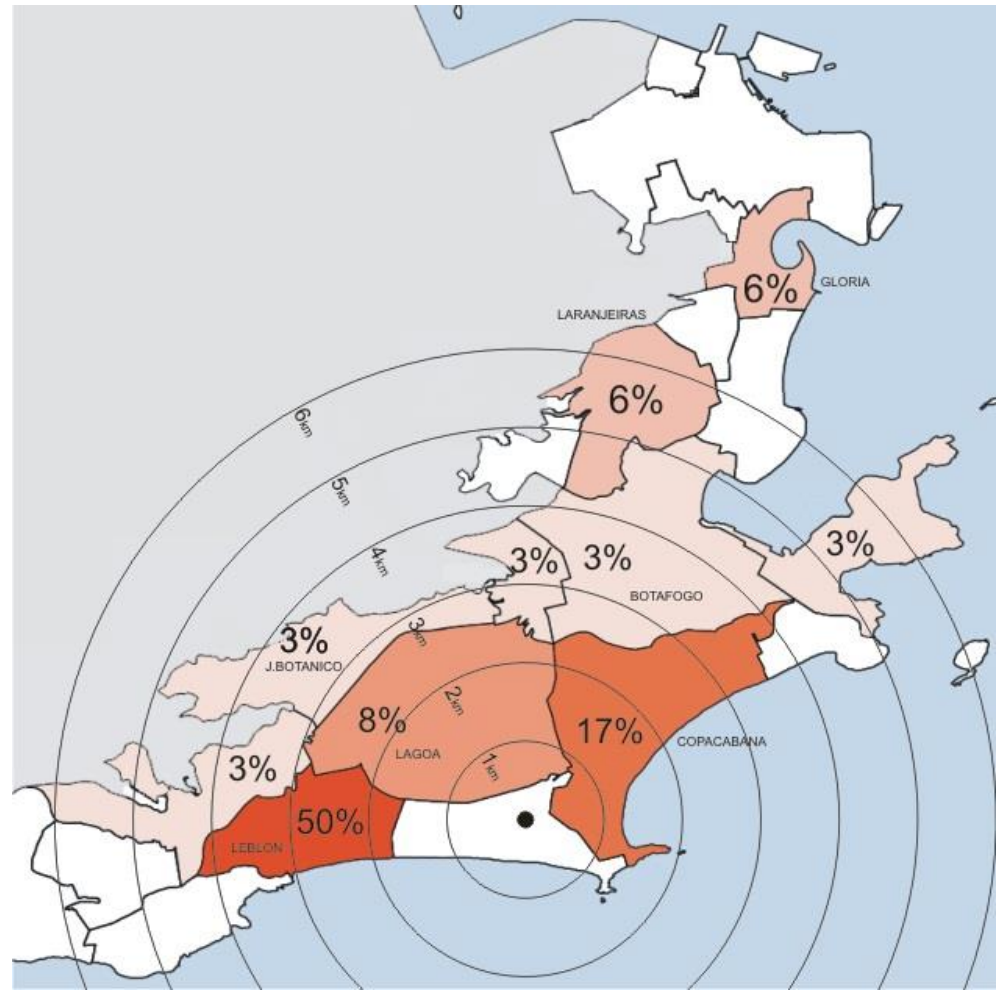

Figura 47 - Origem ou destino das viagens a partir da estação Ipanema.

O perfil da estação Siqueira Campos é similar ao de Botafogo: a maioria dos usuários utilizou a bicicleta dentro do próprio bairro (47\%), seguido de Botafogo (20\%), Leme, Ipanema, Leblon e Humaitá (7\%). O Centro também apareceu com 7\% dos entrevistados, mas em função do tamanho da amostra da estação Siqueira Campos, não há como determinar se essa é uma rota significativa ou se foi circunstancial. Uma pesquisa envolvendo maior amostragem é aconselhável neste caso. 


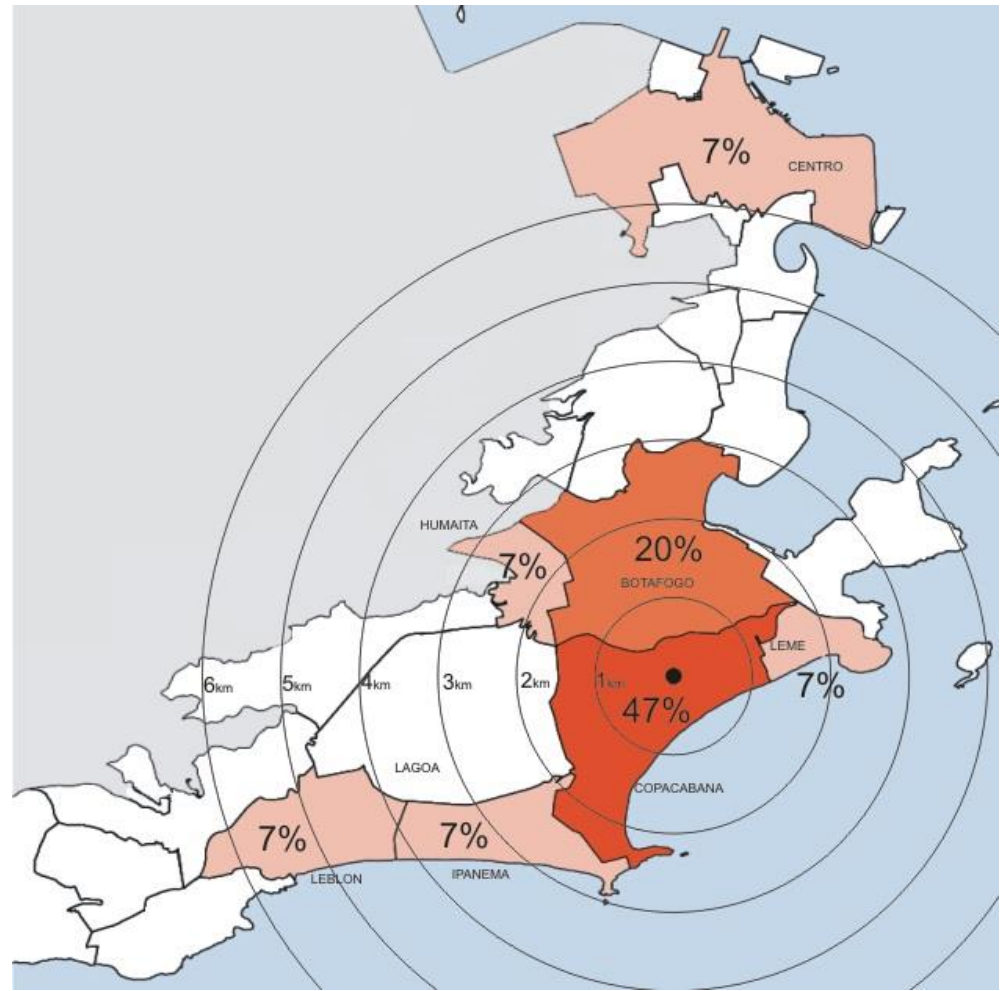

Figura 48 - Origem ou destino das viagens a partir da estação Siqueira Campos.

A última parte do questionário buscou identificar a maneira como os usuários avaliam o Bike Rio e o modal cicloviário na cidade do Rio de Janeiro. Nos dois casos, foi solicitado aos usuários que indicassem quais eram, em sua opinião, os aspectos mais positivos e os mais negativos tanto do SCB quanto do transporte cicloviário. Nestas questões também foi permitido aos entrevistados darem mais de uma resposta.

Quanto aos aspectos negativos, a pesquisa indicou uma grande porcentagem de usuários insatisfeitos com a operação do Bike Rio. As falhas no sistema, especialmente no momento de retirar as bicicletas, foram citadas por $59 \%$ dos entrevistados. Também relacionadas à operação do SCB, foram citadas falhas na manutenção (21\%) e falhas na distribuição das bicicletas nas estações (21\%). Outro aspecto relevante foi a quantidade de estações e de bicicletas, citada por $24 \%$ dos entrevistados como insuficiente. 


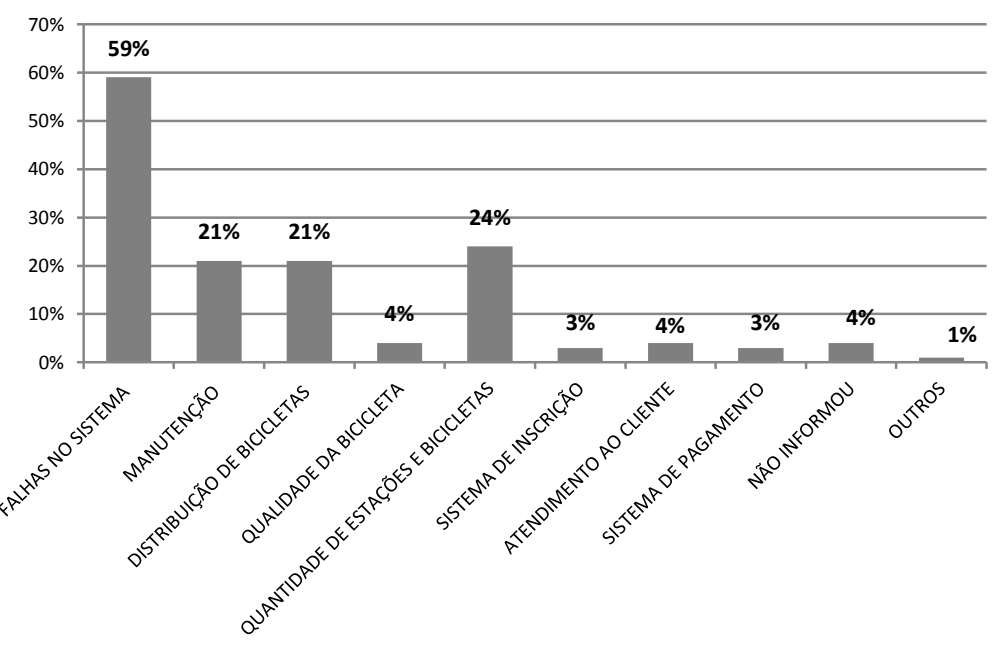

Figura 49 - Avaliação dos pontos negativos do sistema Bike Rio.

Quando questionados sobre os aspectos positivos do Bike Rio, a maioria das respostas se relacionou ao conceito do sistema. Para $44 \%$ dos entrevistados, a praticidade do SCB é sua maior virtude. Em seguida, foram apontados a sua função como opção de mobilidade (19\%), e o próprio conceito do sistema (também com 19\%). A quantidade de estações e de bicicletas também foi apontada por parte dos usuários como uma característica positiva do sistema (16\%), embora em menor escala do que os que apontaram esse aspecto como fator negativo. O custo de utilização do sistema foi citado por $11 \%$.

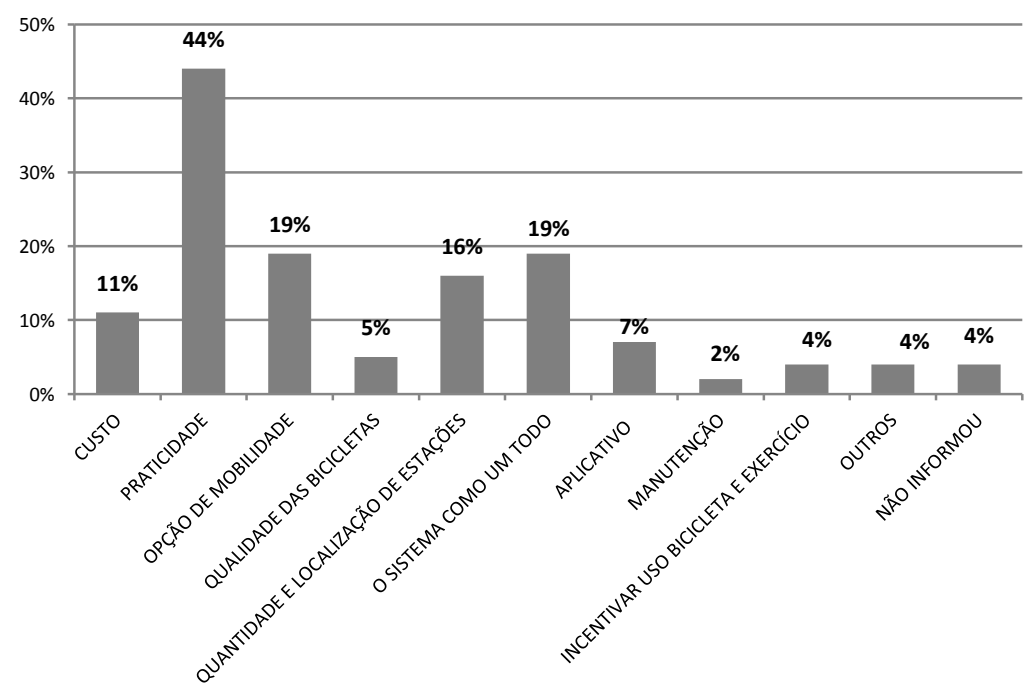

Figura 50 - Avaliação dos pontos positivos do sistema Bike Rio.

De maneira geral, o sistema foi bem avaliado pelos usuários. Quando solicitados que dessem uma nota de 0 a 5 , considerando uma escala de 
satisfação na qual zero era muito insatisfeito e 5 , muito satisfeito com o sistema, a média de notas foi 3.35. Mas $55 \%$ dos entrevistados deram nota 4 ou 5 e apenas $6 \%$ deram nota 0 ou 1.

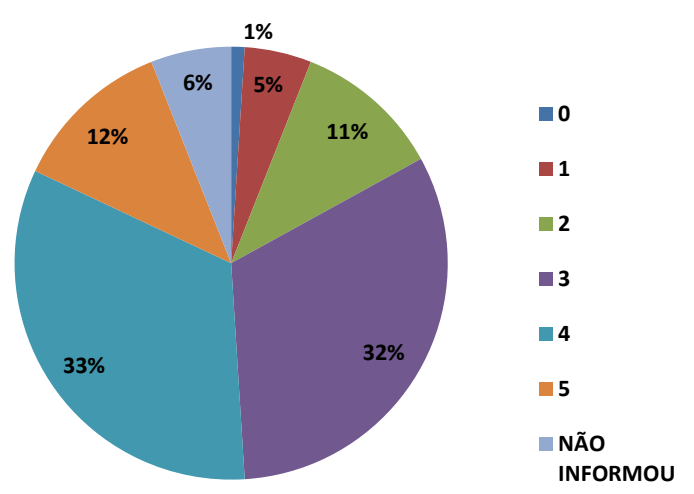

Figura 51- Avaliação do Bike Rio.

Quando questionados sobre os aspectos que consideravam mais negativos para o uso da bicicleta na cidade do Rio de Janeiro, os dois principais fatores apontados pelos usuários do Bike Rio foram a rede insuficiente de ciclovias (48\%) e a falta de segurança no tráfego (48\%).

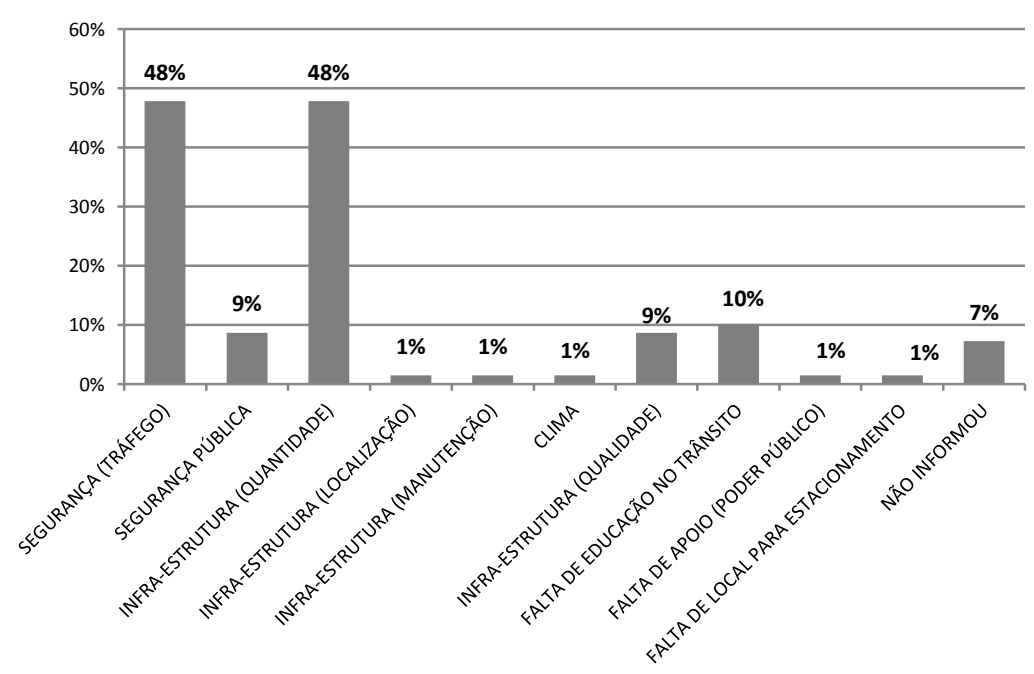

Figura 52 - Avaliação dos aspectos negativos do transporte cicloviário no Rio de Janeiro.

Quanto aos aspectos positivos do transporte cicloviário no Rio de Janeiro, os entrevistados apontaram, em primeiro lugar, a rede de ciclovias (24\%), seguida da aprazibilidade do uso da bicicleta (22\%), da função da 
bicicleta para reduzir o tráfego de veículos (15\%), e da opção de mobilidade e da possibilidade de fugir do tráfego, ambas com $10 \%$.

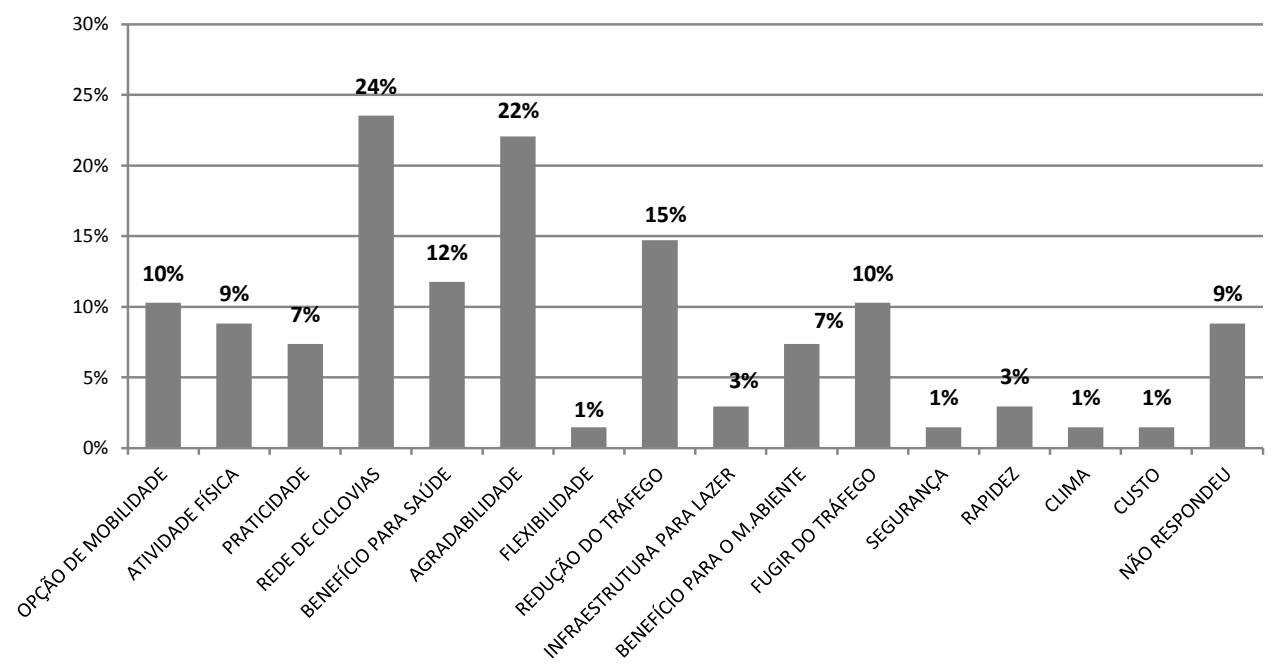

Figura 53 - Avaliação dos aspectos positivos do transporte cicloviário no Rio de Janeiro.

Os resultados obtidos com esta pesquisa levaram a uma nova questão: até que ponto os fatores negativos associados ao transporte cicloviário se constituem em barreiras para a expansão do uso da bicicleta e do SCB na cidade?

Para tentar obter uma resposta, foi necessário buscar a opinião de pessoas que não fazem uso da bicicleta na cidade. Para isso foi desenvolvido um outro questionário disseminado pelas redes sociais (internet), conforme explicado no capítulo 1.

\section{4}

\section{Resultados da pesquisa via internet}

A pesquisa via internet foi realizada entre maio e julho de 2014 e foram obtidas 115 respostas de pessoas residentes em diversas áreas da cidade e também no município de Niterói. 


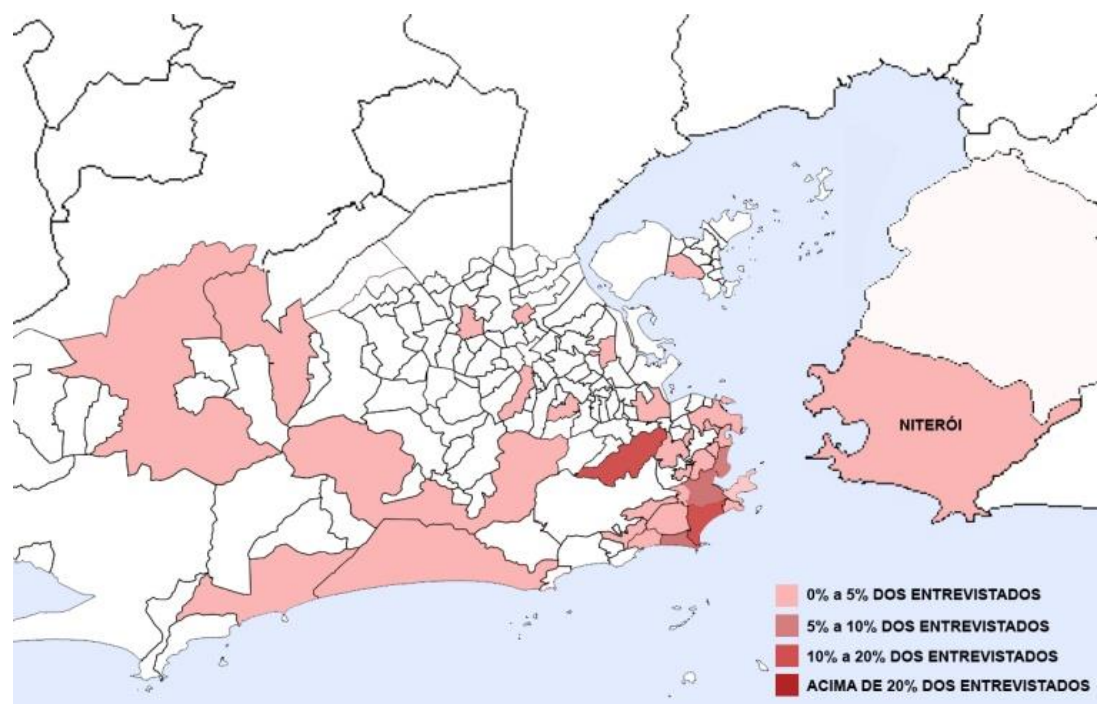

Figura 54 - Distribuição dos locais de residência dos entrevistados na pesquisa via web.

Entre os que responderam ao questionário, $60 \%$ informaram não serem usuários de bicicleta na cidade do Rio de Janeiro. Neste grupo, que é o foco principal desta pesquisa, $45 \%$ eram do sexo masculino e $45 \%$ do sexo feminino.

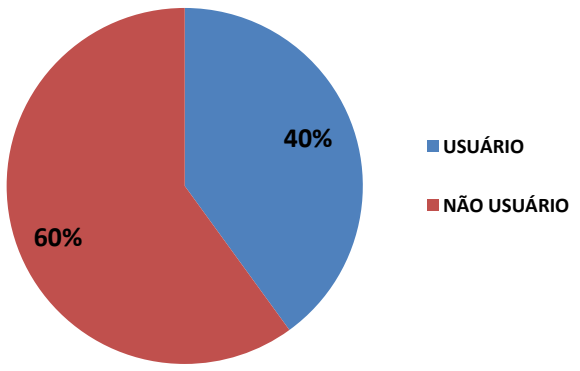

Figura 55 - Distribuição dos entrevistados entre usuários e não usuários do transporte cicloviário.

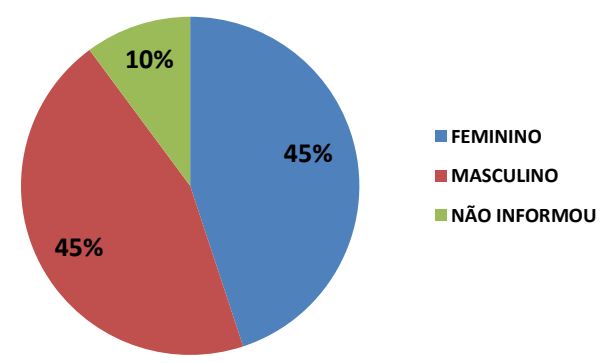

Figura 56 - Distribuição dos entrevistados não usuários do transporte cicloviário por gênero.

Quanto à idade, a maioria dos entrevistados que não faz uso da bicicleta estava na faixa etária entre 31 e 40 anos (46\%), seguido da faixa entre 21 e 30 anos (22\%) e da faixa entre 41 e 50 anos (18\%). Quando perguntados se conheciam o Bike Rio, $88 \%$ responderam positivamente. 

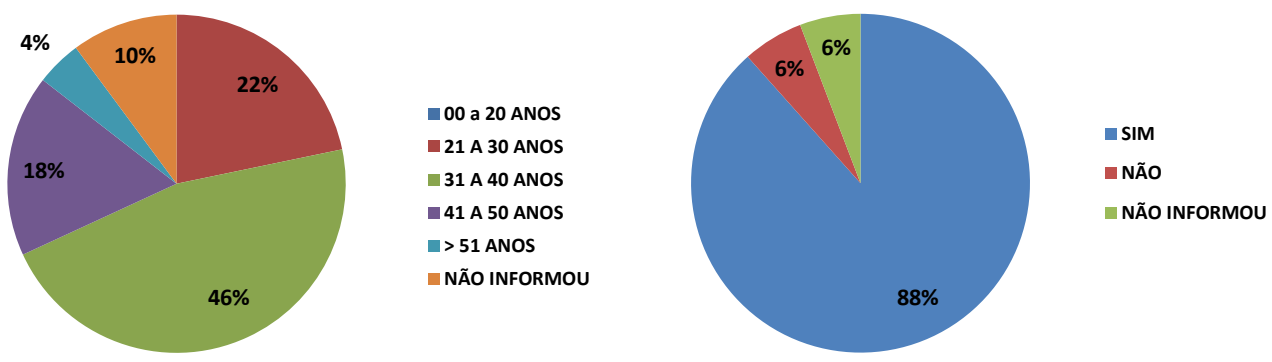

Figura 57 - Divisão entrevistados não usuários do transporte cicloviário por idade.
Figura 58 - Entrevistados não usuários do transporte cicloviário que conhecem o Bike Rio.

Como o objetivo principal desta pesquisa foi verificar as principais barreiras para o uso do modal cicloviário na cidade, os entrevistados que responderam não serem usuários de bicicleta foram direcionados para uma pergunta sobre as principais razões que os levavam a não utilizar o transporte cicloviário. Neste caso as respostas eram livres e foi permitido fornecer mais de um motivo por resposta.

O resultado demonstrou que a principal barreira ao uso da bicicleta para este grupo é a segurança pública. O receio de assaltos foi citado por $42 \%$ dos entrevistados. Em segundo lugar, foi citada a falta de ciclovias (34\%) e em terceiro, a falta de segurança em função do tráfego de veículos (24\%).

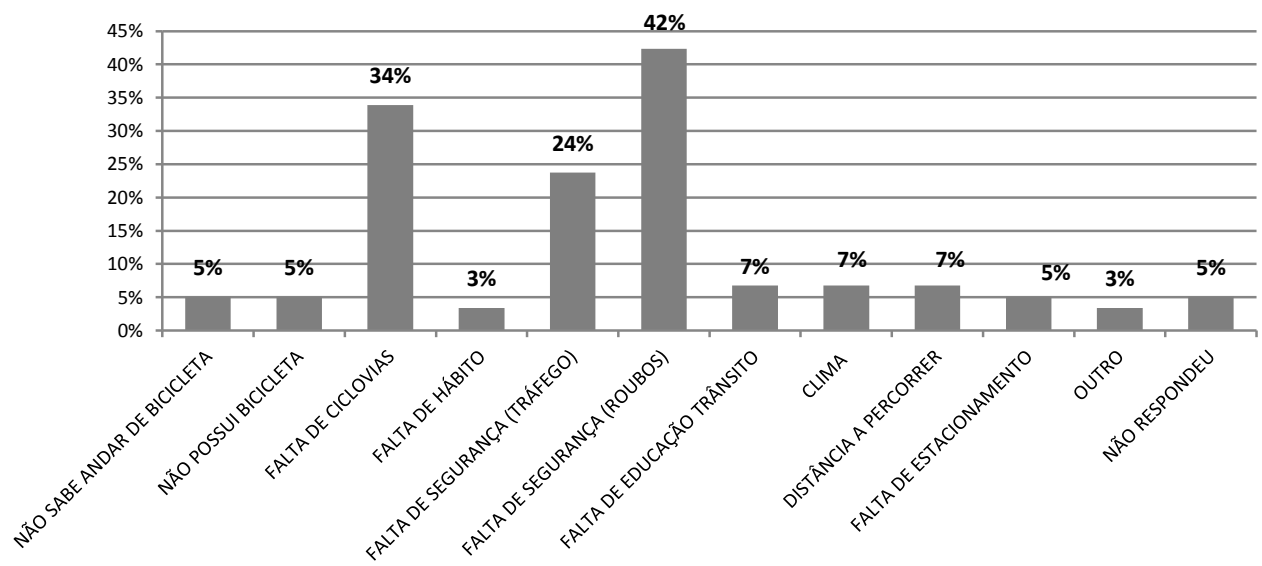

Figura 59 - Principais razões informadas para não utilizar a bicicleta no Rio de Janeiro.

Com relação ao grupo que utiliza a bicicleta (40\% dos entrevistados), aproveitou-se o questionário para saber qual a relação deste grupo com o SCB na cidade. A maioria dos entrevistados (46\%) informou que nunca fez 
uso do Bike Rio, entretanto, $50 \%$ dos que informaram utilizar a bicicleta no Rio de Janeiro ou já foram (24\%) ou continuam sendo usuários do SCB (26\%).

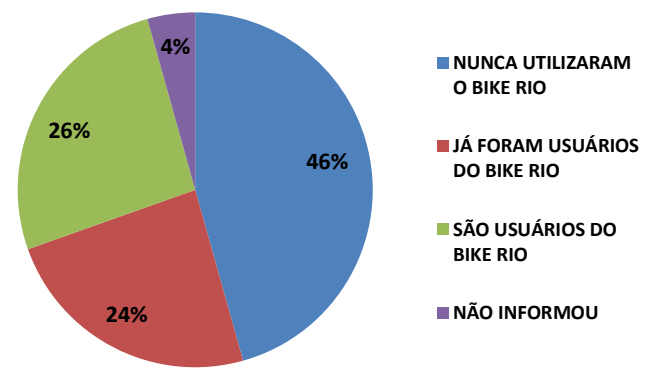

Figura 60 - Relação entre o grupo que utiliza bicicleta e o Bike Rio.

Os entrevistados que responderam nunca haver feito uso do Bike Rio foram direcionados para uma questão sobre os motivos para não usar as bicicletas compartilhadas. A principal razão apresentada foi a preferência pelo uso de sua própria bicicleta $(57,1 \%)$. Nenhum outro motivo alcançou mais de $10 \%$ das respostas. Este grupo utiliza a bicicleta majoritariamente para fins recreativos: $80,9 \%$ informaram utilizar a bicicleta exclusivamente para lazer e prática de exercício e apenas 9,5\% informaram fazer uso exclusivo utilitário da bicicleta.

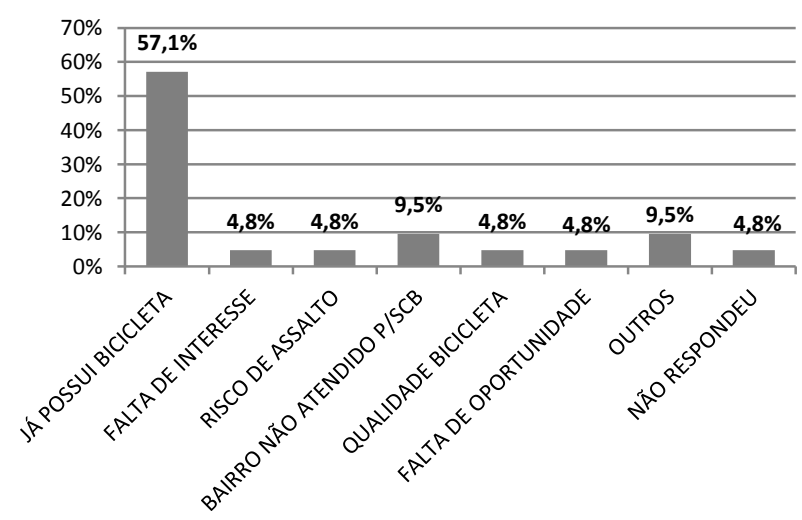

Figura 61 - Motivos para não utilizar o Bike Rio.

Os entrevistados que afirmaram já terem sido usuários do Bike Rio foram direcionados para uma pergunta sobre as razões pelas quais deixaram de utilizar o sistema. A principal razão apresentada foi a posse de bicicleta 
própria $(36,4 \%)$, mas as falhas no sistema $(27,3 \%)$ também apareceram como um motivo para terem deixado de usar o Bike Rio. Considerando que 9,1\% mencionaram falhas na manutenção das bicicletas, os problemas operacionais do Bike Rio foram, pela pesquisa, o motivo de $36,4 \%$ dos usuários para deixar de usar SCB.

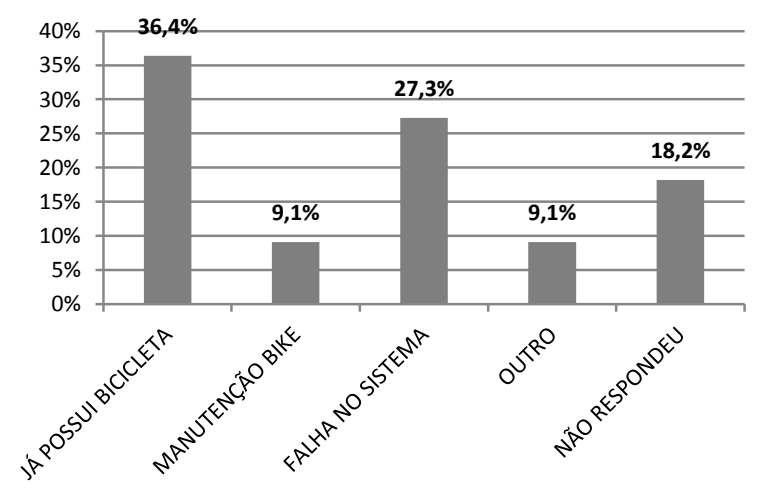

Figura 62 - Motivos para deixar de utilizar o Bike Rio.

\section{5}

\section{Avaliação dos resultados do levantamento de dados}

O objetivo deste subcapítulo é avaliar o impacto do Bike Rio para a mobilidade e para a sustentabilidade com base nos resultados obtidos no levantamento de dados e nos objetivos para implantação do SCB.

Considerando os objetivos do Bike Rio, foram determinados quatro indicadores para avaliar a eficácia do sistema:

- redução do número de veículos em circulação;

- aumento na participação do modal cicloviário;

- redução nas emissões de $\mathrm{CO}^{2}$;

- substituição de modais motorizados pela bicicleta.

A promoção da humanização do ambiente urbano e da responsabilidade social nas pessoas será comentada no subcapítulo 4.5.5. No fim do capítulo será feita uma breve análise sobre as principais barreiras para expansão do Bike Rio com base nos resultados obtidos nas pesquisas presencial e pela internet. 
A avaliação foi feita com base no impacto e na eficiência do Bike Rio em cada um dos indicadores analisados. Os resultados foram comparados aos de outras três cidades para que fosse possível determinar parâmetros para classificar como positivos ou não os resultados observados. As cidades de Paris, Viena e Barcelona foram escolhidas em função do número de habitantes (superior a 1.000.000) e da disponibilidade de dados nos critérios de avaliação.

\begin{tabular}{lcccccccc}
\hline \multicolumn{1}{c}{ CIDADE } & NOME & $\begin{array}{c}\text { ÁREA } \\
\text { CIDADE }\end{array}$ & $\begin{array}{c}\text { ÁREA } \\
\text { ALCANCE }\end{array}$ & $\begin{array}{c}\text { \% ÁREA } \\
\text { DE } \\
\text { ALCANCE }\end{array}$ & $\begin{array}{c}\text { NÚMERO } \\
\text { ESTAÇÕES }\end{array}$ & $\begin{array}{c}\text { NUM. } \\
\text { BICICLETAS }\end{array}$ & POPULAÇÃO & $\begin{array}{c}\text { BICICLETAS } \\
/ 1000 \text { HAB }\end{array}$ \\
\hline RIO & KM & KM $^{2}$ & $\%$ & & & & & \\
PARIS* & BIKE RIO & 1224,56 & 40,35 & $3,30 \%$ & 60 & 600 & 6230446 & 0,10 \\
VIENA & VELIB' & 206,5 & 206,5 & $100,00 \%$ & 1800 & 23000 & 3395290 & 6,77 \\
BARCELONA & BICING & 102,2 & 41 & $40,12 \%$ & 420 & 6000 & 1620943 & 3,70 \\
\hline
\end{tabular}

Tabela 9 - Dados sobre as cidades e os SCB (Apêndices 3, 4 e 5) ${ }^{104}$.

O transporte cicloviário responde por $2,00 \%{ }^{105}$ do total de deslocamentos realizados na cidade do Rio de Janeiro. Apesar dessa participação ser muito inferior à de cidades como Copenhagen (35\%), Amsterdam (27\%) ou Berlim (13\%), é um índice similar ao de Londres (1,9\%), Montreal $(2,4 \%)$ e Paris $(2,5 \%)^{106}$. Viena e Barcelona possuem, respectivamente, $6 \%$ e $4 \%{ }^{107}$.

\footnotetext{
${ }^{104}$ No caso de Paris, a área da cidade e a população consideradas se referem ao conjunto formado pelo departamento 75 (Paris) e por 29 comunas onde há estações do Velib'. No caso do Rio de Janeiro, a área de alcance se refere aos bairros alcançados pelo Bike Rio em 2013, incluindo Madureira. A área de alcance de Viena foi calculada com base no mapa da cidade, considerando um polígono formado por uma linha imaginária a 500 metros das estações mais afastadas do centro. A área de alcance de Barcelona foi retirada de ITDP (2013).

105 Ver seção 4.3.

106 Pucher et al. (2012); Travel in London Report 6 (2013).

${ }^{107}$ Barcelona: <http://copenhagenize.eu/>; Viena: WENINGER, A. From 5 to 10\%: the challenge to double Vienna's modal share of Cycling. 2012.
} 


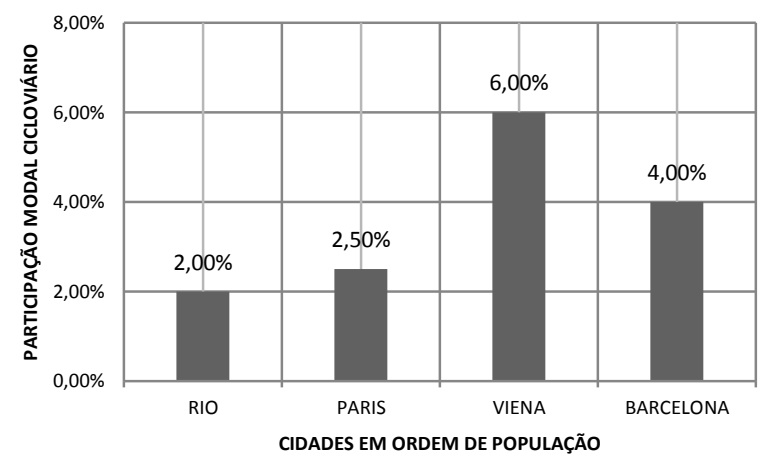

Figura 63 - Participação modal do transporte cicloviário.

Os SCB de Paris e de Barcelona possuem uma quantidade de bicicletas e de estações muito superior à das demais cidades, o que se reproduz em uma grande diferença no número total de viagens médias diárias entre estas duas cidades e o Rio de Janeiro e Viena.

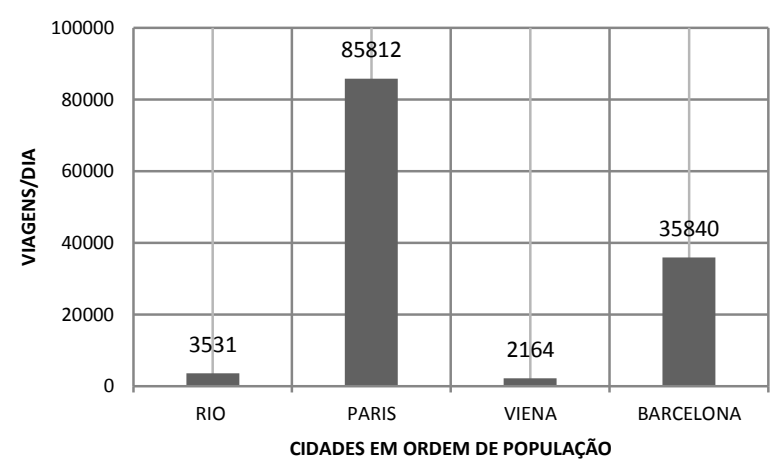

Figura 64 - Quantidade média de viagens diárias por cidade (Apêndice 4).

Segundo o ITDP (2003, p.41), a relação entre o número de viagens e a quantidade de bicicletas disponíveis é uma das medidas que devem ser maximizadas para que um SCB seja "eficiente, econômico e viável" ${ }^{108}$. Esta medida representa a taxa de rotatividade das bicicletas e é aconselhável que esteja entre 4 e 8 viagens por dia por bicicleta. Um resultado inferior a 4 pode representar um sistema superdimensionado e com problemas para garantir sua viabilidade econômica. Um resultado acima de 8 pode representar uma uitlização excessiva dos equipamentos, acarretando o risco de falta de

${ }^{108}$ Efficient, reliable and cost-effective no original. 
bicicletas nas estações e, em consequência, a necessidade de uma operação de distribuição mais abrangente com maiores custos de manutenção.

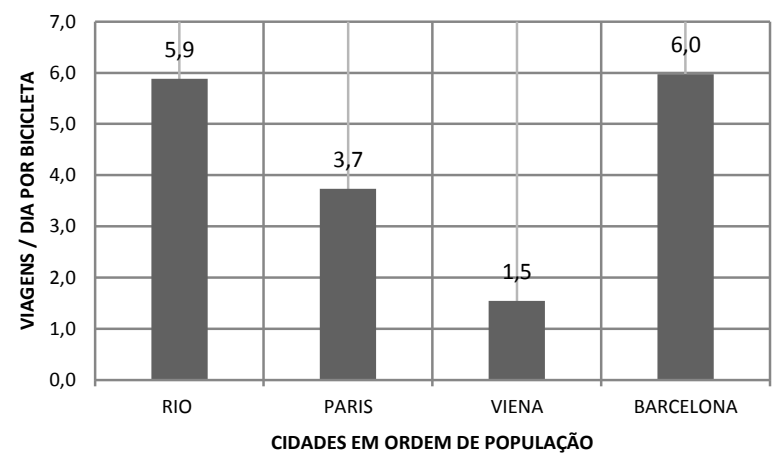

Figura 65 - Númeroo de viagens diárias por bicicleta (Apêndice 4).

Nessa relação entre o número de viagens e a quantidade de bicicletas, denominada eficiência (Fernández, 2011; ITDP, 2013), o Bike Rio consegue não só estar dentro da faixa considerada ideal pelo ITDP (2013), como possui uma taxa de rotatividade muito próxima à de Barcelona (5.9 e 6,0 vezes ao dia em média, respectivamente), que apresentou os melhores resultados. Entretanto, o seu reduzido alcance territorial e demográfico, além da pouca quantidade de bicicletas disponíveis, faz com que o impacto do Bike Rio no total de deslocamentos realizados diariamente na cidade seja bastante reduzido.

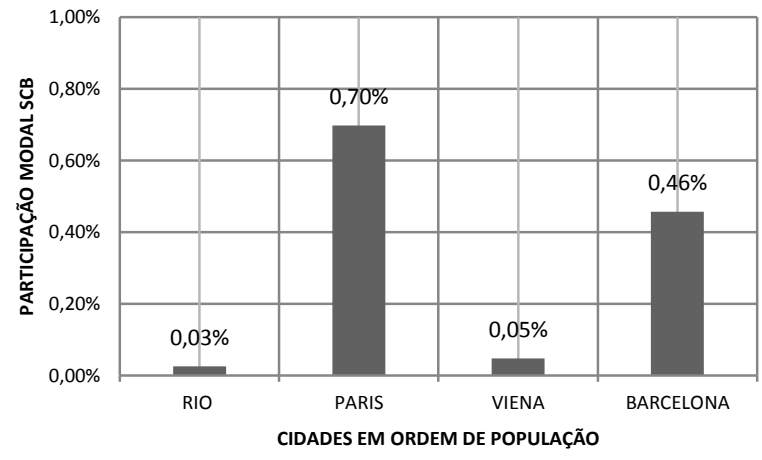

Figura 66 - Participação modal dos SCB por cidade (Apêndice 4 e 6).

Os sistemas de melhor performance, segundo o ITDP (2013), são os que conseguem aliar uma grande penetração de mercado (relação entre 
número de viagens e habitantes) ${ }^{109}$ a um número ideal de viagens por bicicleta (eficiência). No caso do Rio de Janeiro, a performance do Bike Rio é muito prejudicada por sua baixa penetração de mercado.

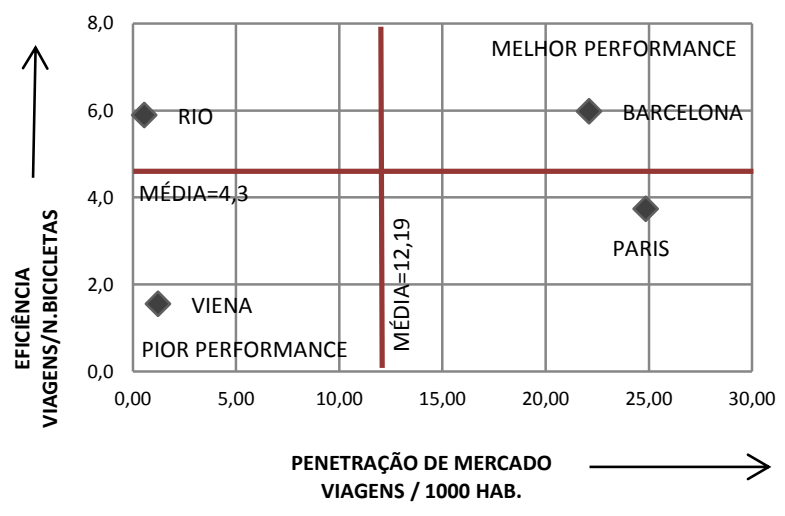

Figura 67 - Performance dos SCB (Apêndice 4 e 6).

Entre os casos estudados, Barcelona aparece como o SCB de melhor performance, obtendo os resultados mais significativos tanto para o número de viagens por 1000 habitantes como para o número de viagens por bicicleta. O Velib', em função do grande número de bicicletas, perde um pouco da sua eficiência, o que demonstra a importância de se expandir o sistema de forma cuidadosa, para evitar que um eventual superdimensionamento não inviabilize financeiramente o seu funcionamento.

No outro extremo está Viena, cujo SCB possui baixa eficiência e baixa penetração de mercado. De todos os 4 sistemas de compartilhamento, o Citybike é o mais antigo, inaugurado em 2003 (Apêndice 4). Apesar da baixa performance do seu SCB, entre as cidades estudadas Viena é a que possui a maior participação modal do transporte cicloviário.

\footnotetext{
${ }^{109}$ Para o ITDP (2013) a relação entre o número de viagens e o de habitantes deve considerar a população residente na área de alcance do sistema. Contudo é muito complexo precisar exatamente este número, especialmente nas comparações entre cidades de países diversos. Por isso, neste trabalho considerou-se a população de toda a cidade ou da cidade e áreas adjacentes (caso de Paris).
} 


\subsection{1}

\section{Redução no número de veículos}

A redução do número de veículos em circulação é uma condição chave para a eficácia do Bike Rio em alcançar seus objetivos, pois é determinante, tanto para a redução das emissões de GEE oriundas do sistema de transportes, quanto para redução dos congestionamentos.

Sua avaliação está diretamente relacionada à quantidade de usuários que deixaram de utilizar o transporte motorizado individual para utilizar a bicicleta compartilhada. Contudo, para uma análise mais abrangente desse processo de transferência entre modais, é importante observar alguns outros fatores que ajudam a explicar a maior ou menor capacidade de um SCB em atuar na transferência de usuários para as bicicletas compartilhadas.

Uma das variáveis que deve ser observada é a participação do transporte utilitário (especialmente para o trabalho) nas viagens feitas pelo Bike Rio. Como visto na seção 4.2, os deslocamentos em função do trabalho são o principal motivo de viagens para os modais de transporte motorizados. Quanto maior for a participação deste tipo de deslocamento nas viagens realizadas pelo SCB, maior será a probabilidade de que possa atuar como indutor da transferência do transporte individual motorizado para o cicloviário. Ademais, uma das principais características dos deslocamentos para o trabalho é o seu caráter pendular, que acarreta congestionamentos, superlotação nos transportes públicos e concentração de poluentes.

Segundo a pesquisa feita com usuários do Bike Rio, $58 \%{ }^{110}$ das viagens informadas tinham como motivo viagens relacionadas a trabalho ou a estudo, o que coloca o Bike Rio praticamente no mesmo padrão do Velib'.

\footnotetext{
${ }^{110}$ As viagens cujo motivo informado foi "compromissos diversos" foram desconsideradas pois os dados comparativos das outras cidades só incluem as viagens para trabalho e educação.
} 


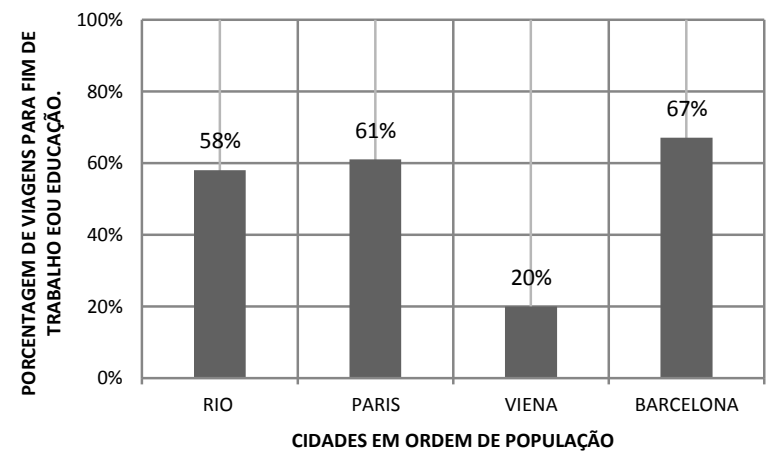

Figura 68 - Participação das viagens por SCB com finalidade de trabalho ou educação (Apêndice 4 e 6).

Um acompanhamento diário do fluxo de viagens realizadas pelo Bike Rio a cada período de 2 horas ${ }^{111}$ demonstrou que há uma concentração de viagens no fim da tarde, a partir das 16:00h. O SCB carioca apresenta um padrão de distribuição de viagens ao longo do dia diferente dos demais modais de transporte da cidade, que possuem 3 "picos" diários de viagens.

Esse resultado sugere que a maioria das pessoas que utiliza o SCB no fim da tarde, não o faz pela manhã. Isso pode ser consequência do clima da cidade (altas temperaturas), da falta de estrutura dos locais de trabalho para receber os funcionários que fazem uso da bicicleta ou mesmo de falhas no sistema que reduzem a confiabilidade do Bike Rio. Como a pesquisa com usuários não os questionou sobre as razões para utilizar a bicicleta especialmente em um período do dia, esta é uma questão que fica aberta para futuras pesquisas.

\footnotetext{
${ }^{111}$ Esse acompanhamento foi feito por meio da contagem de viagens disponibilizada pelo site do Bike Rio, registrando a cada período de 2 horas o número de viagens contabilizadas no site. As datas escolhidas foram dias úteis com condições climáticas similares: poucas nuvens e sem precipitação. Fonte: <www.movesamba.com.br>.
} 


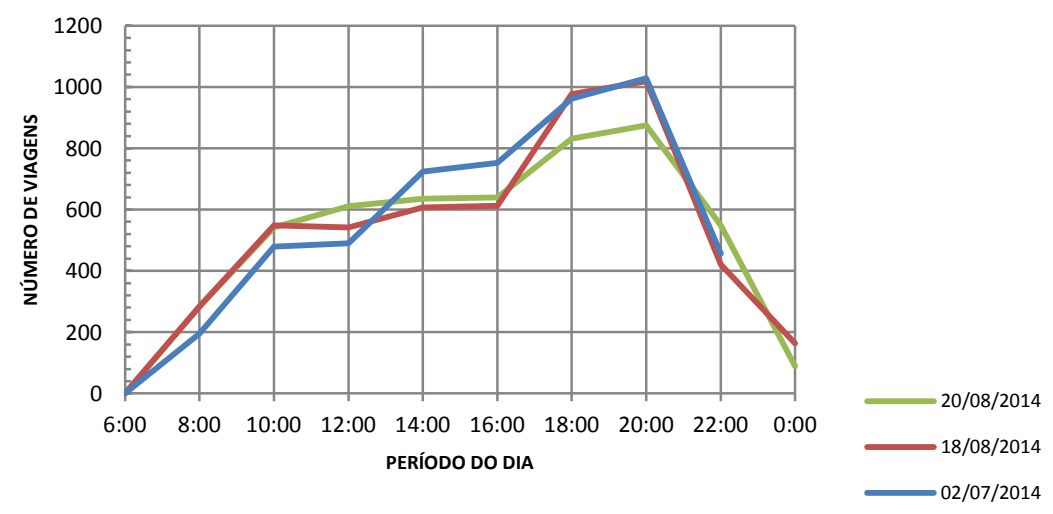

Figura 69 - Distribuição de viagens diárias do Bike Rio. Fonte: $<w w w . m o v e s a m b a . c o m \cdot b r / b i k e r i o>$.

Os dados obtidos na pesquisa com usuários fornecem subsídios para analisar a integração entre o SCB e os demais transportes públicos da cidade. Conforme visto no subcapítulo 3.3, os SCB podem atuar na melhoria das condições de mobilidade urbana de maneira indireta, reduzindo o congestionamento dos transportes públicos, especialmente na hora do rush, e abrindo a possibilidade de absorver novos usuários sem a necessidade de investimentos no aumento de sua capacidade.

A pesquisa presencial indicou que o Bike Rio consegue atrair usuários do transporte coletivo, principalmente dos ônibus. $70 \%{ }^{112}$ dos entrevistados responderam que utilizariam o transporte público para efetuar seu deslocamento caso não houvesse disponibilidade do sistema de compartiIhamento.

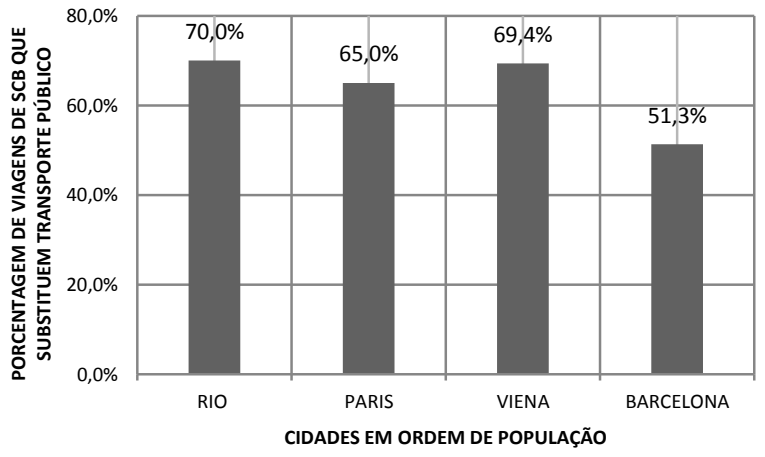

Figura 70 - Porcentagem de viagens realizadas por SCB que substituem o transporte público (Apêndice 4 e 6 ).

${ }^{112}$ O serviço de táxi foi considerado como transporte público nesta pesquisa. 
A principal razão apresentada para utilizar a bicicleta ao invés do TP foi a rapidez, tanto em comparação com os deslocamentos a pé, quanto em comparação com outros modais motorizados (em função do trânsito ou do tempo de espera pelo transporte). Também é um aspecto relevante que $26 \%$ dos entrevistados tenham informado preferir usar a bicicleta ao invés de outros modais pela possibilidade de praticar exercício e que $20 \%$ tenham informado preferir o Bike Rio por ser mais agradável do que utilizar o transporte público. Essa elevada transferência do TP faz com que a eficiência do Bike Rio seja superior à dos demais SCB neste aspecto.

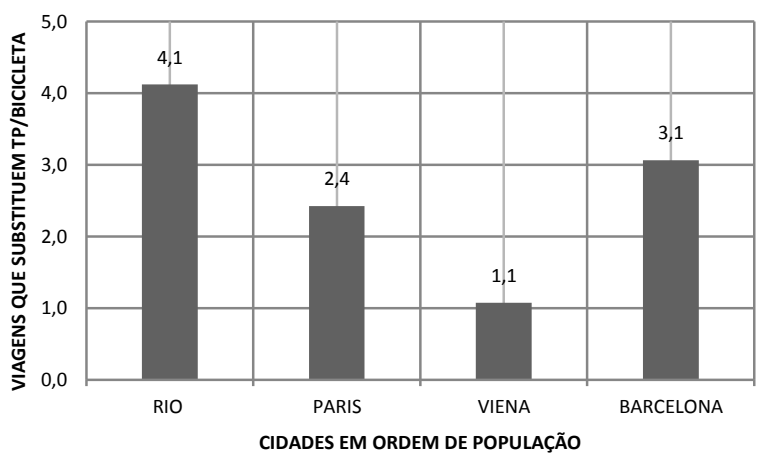

Figura 71 - Relação entre o número de viagens realizadas por SCB que substituem o transporte público e a quantidade de bicicletas (Apêndice 4 e 6).

Entretanto, em função da escala do Bike Rio, esse resultado, ainda que positivo, acaba se tornando praticamente irrelevante no contexto da mobilidade urbana.

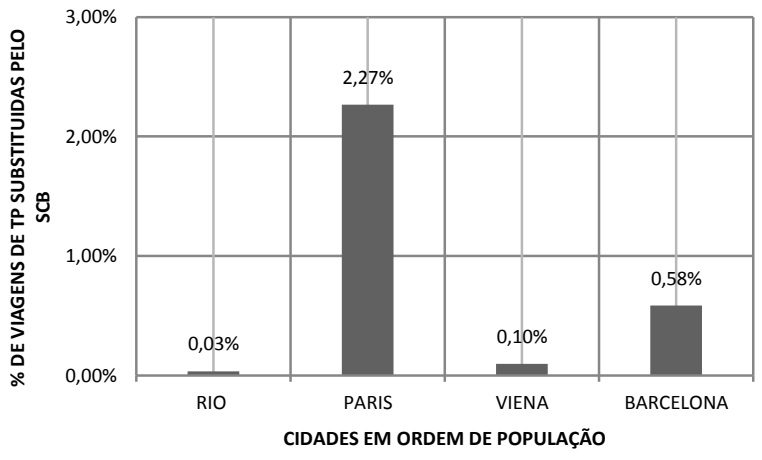

Figura 72 - Porcentagem de viagens realizadas por transporte público substituídas por SCB (Apêndice 4 e 6). 
Além de poder atuar reduzindo a pressão sobre os transportes públicos, os SCB também podem funcionar como alimentadores ou como elementos complementares do sistema de transportes, atraindo novos usuários para o transporte público. $37 \%$ dos entrevistados informaram que sua viagem seria complementada por outro modal, especialmente o metrô ${ }^{113}$.

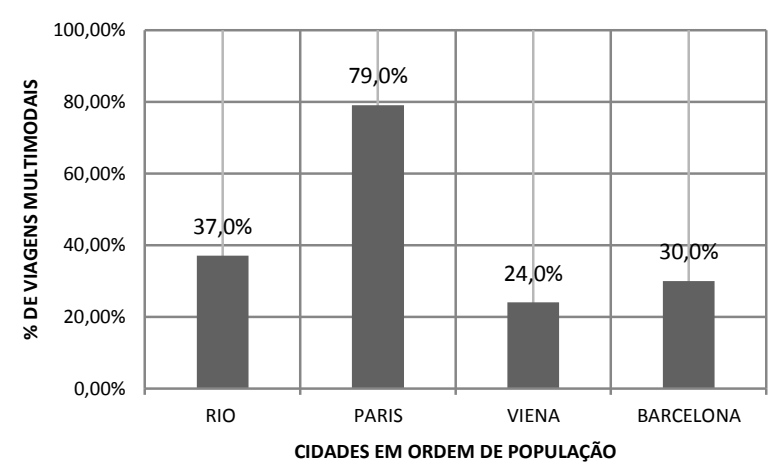

Figura 73 - Porcentagem de viagens feitas em conjunto com outros modais de transporte público (Apêndice 4 e 6).

Quando relacionamos esta porcentagem de viagens ao número de bicicletas, mais uma vez o Bike Rio se mostra bastante eficiente, demonstrando que o SCB carioca consegue atuar de forma integrada ao sistema de transportes. Essa é uma característica que deve ser considerada no planejamento da sua expansão, tendo em vista o objetivo de "desenvolver o programa como um novo modal de transporte público, possibilitando a integração com ônibus, metrô e barcas".114

113 Este resultado foi influenciado pelo local das entrevistas. A maioria dos usuários que informou fazer uso conjunto do modal cicloviário e metroviário estava nas estações de Botafogo e General Osório e suas viagens tinham como origem ou destino bairros não atendidos pelo transporte ferroviário, como Humaitá, Jardim Botânico e Leblon.

114 Edital 04/550.508/2013 Publicado originalmente no Diário Oficial do Município do Rio de Janeiro. Ano XXVIII. n.59. p.51. 14 de junho de 2013. 


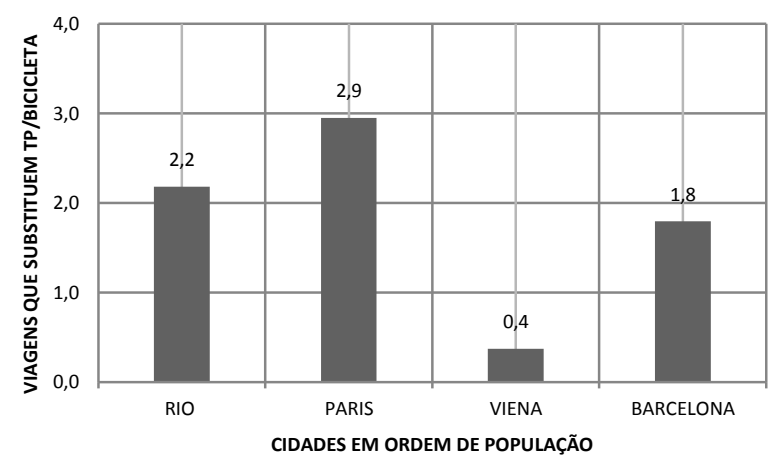

Figura 74 - Viagens por SCB em conjunto com outros modais de transporte público (Apêndice 4 e 6 ).

Entretanto, assim como observado na transferência entre modais, a escala do Bike Rio é um limitador para que o sistema atue de forma eficaz como alimentador do sistema de transportes.

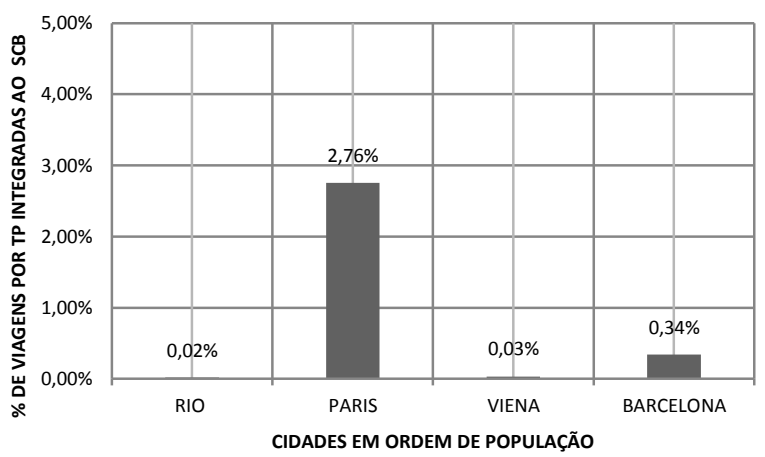

Figura 75 - Porcentagem de viagens de transporte público integradas ao SCB (Apêndice 4 e 6).

Outra variável significativa para avaliar o potencial do SCB em reduzir o número de veículos em circulação é a porcentagem de usuários que possuem carro particular. Os resultados da pesquisa de campo indicaram que $37 \%$ dos usuários são proprietários de carro particular e $2 \%$ de motocicleta. Entretanto, isso acaba não se refletindo diretamente na redução do número de veículos em circulação porque a maioria dos entrevistados informou que o Bike Rio não estava substituindo o seu próprio veículo, mas sim o transporte público. 


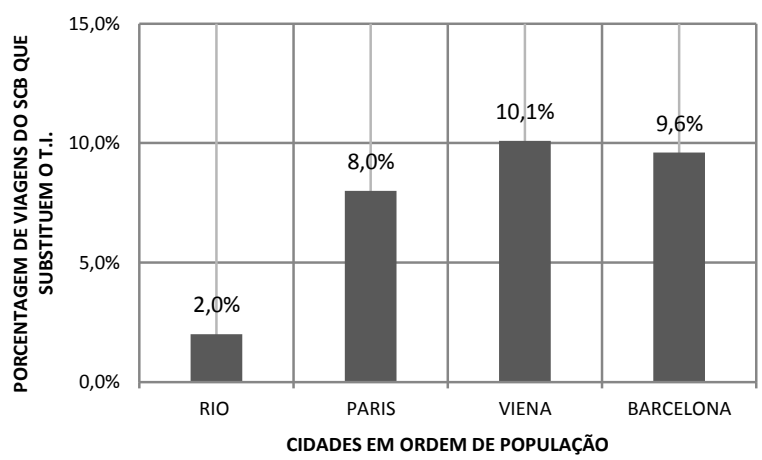

Figura 76 - Porcentagem de viagens realizadas por SCB que substituem o transporte invidual (Apêndice 4 e 6 ).

Os resultados demonstraram que o Bike Rio não consegue captar usuários do transporte individual motorizado na mesma intensidade que os demais SCB analisados mesmo havendo uma predisposição de parcela significativa dos entrevistados em não utilizar seus veículos particulares. Essa baixa transferência de usuários, associada à pequena abrangência do Bike Rio, reduz a influência que o sistema possa ter na redução de viagens por transporte individual motorizado na cidade do Rio de Janeiro. Ainda que todas as viagens diárias feitas com o Bike Rio estivessem substituindo o transporte individual, isso representaria apenas $0,1 \%$ do total de deslocamentos por $\mathrm{TI}$ motorizado na cidade ${ }^{115}$.

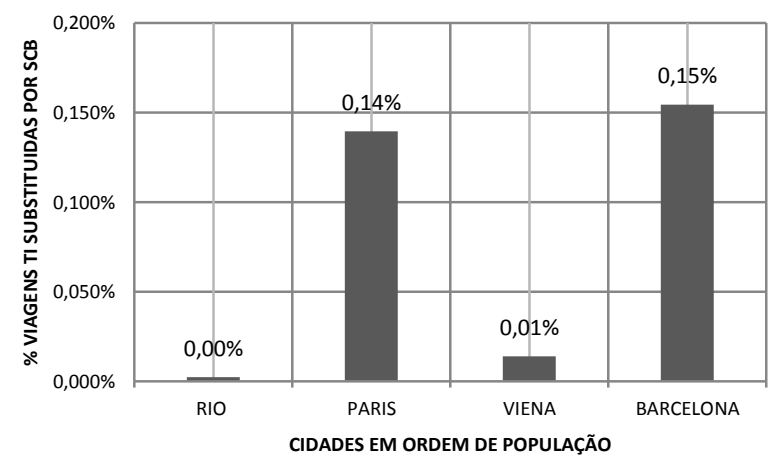

Figura 77 - Porcentagem de viagens realizadas por transporte invidivdual motorizado substituídas pelo SBC (Apêndice 4 e 6).

\footnotetext{
${ }^{115}$ Considerando 3.158 .484 viagens feitas por transporte motorizado individual $(22,8 \%$ do total de viagens diárias na cidade do Rio de Janeiro). Fonte: PDTU (2013).
} 
Quando se observa a eficiência dos SCB em substituir o transporte individual, a baixa taxa de transferência faz com que o Bike Rio fique em último lugar na comparação com as outras cidades.

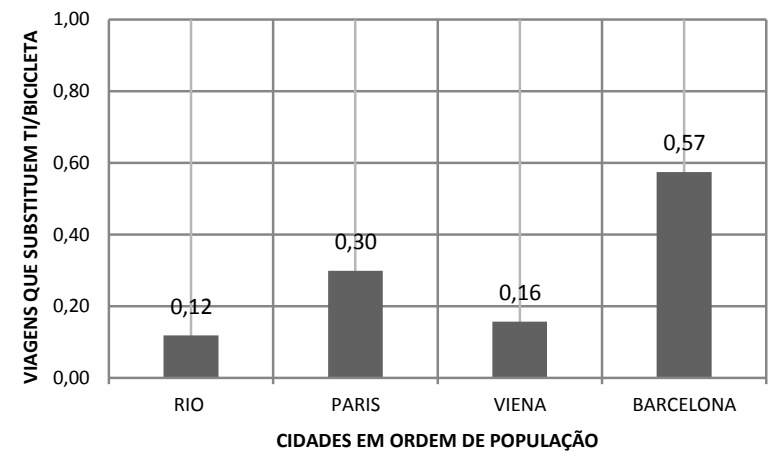

Figura 78 - Transferência de viagens do T.I. para o SCB por dia por bicicleta. (Apêndice 4 e 6 ).

Os resultados observados em Paris e Barcelona, que possuem SCB mais abrangentes e com uma porcentagem de transferência do TI motorizado superior à do Bike Rio, indicam que os SCB ainda não conseguem atuar de maneira eficaz para a redução do número de veículos em circulação nas cidades.

\section{5 .2}

\section{Aumento na participação do modal cicloviário}

O impacto dos SCB no transporte cicloviário pode ser avaliado por intermédio do acréscimo no número de viagens feitas por bicicleta após a sua implantação. Segundo Fernández (2011, p.90), os SCB podem contribuir para aumentar o uso da bicicleta de duas maneiras: direta e indiretamente.

The direct increase of cycling generated in a city as a result of the operation of a $B B S^{116}$ is indeed the number of bike-sharing trips reported [...] it exists also an indirect increase of cycling as a result of the "critical mass effect" of the bikesharing bicycles. Some people might be convinced to ride their own bicycle

\footnotetext{
${ }^{116}$ Bicycle Sharing System.
} 
because they see more cyclists on the streets and this may produce on them a subjective feeling of safety of being fashionable.

$\mathrm{Na}$ pesquisa com usuários, $59 \%$ dos entrevistados informaram não possuir bicicleta particular, o que indica que o Bike Rio consegue atuar incentivando o uso do transporte cicloviário. Além disso, mesmo entre os usuários que possuem bicicleta (41\% restantes), nenhum declarou que faria uso do seu próprio equipamento para realizar o deslocamento caso não houvesse o SCB. Esses dois fatores permitem assumir que todas as viagens diárias realizadas pelo Bike Rio (3.531 viagens em média) correspondem a um acréscimo no uso do modal cicloviário. Isso representa $1,3 \%$ das 274.788 viagens feitas por bicicleta diariamente na cidade, segundo estimativa desta pesquisa.

Pela ausência de dados para as demais cidades, assumiu-se que $100 \%$ das viagens realizadas pelo Velib', pelo Bicing e pelo Citybike também representam um aumento direto no uso do modal cicloviário.

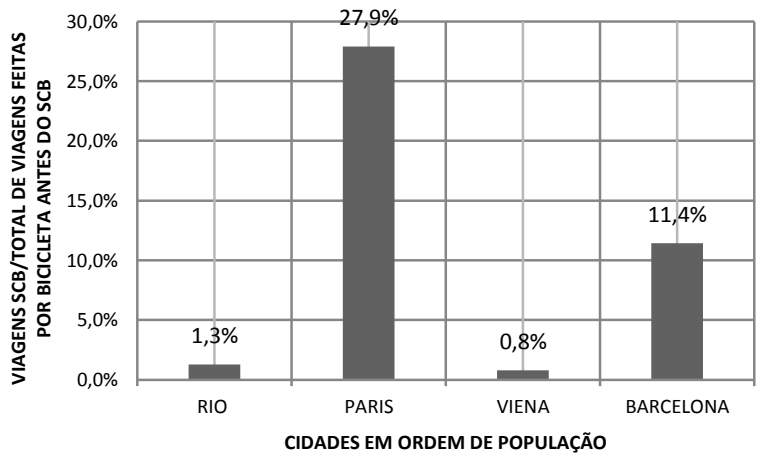

Figura 79- Aumento nas viagens feitas por modal cicloviário em função da implementação do SCB (Apêndice 4 e 6 ).

O que se observa desses dados é que a escala do Bike Rio é um fator determinante para o seu reduzido impacto no uso da bicicleta. Como o aumento nas viagens diárias por modal cicloviário considerou a totalidade de deslocamentos realizados através dos SCB, sua eficiência é a mesma observada na Figura 65. 


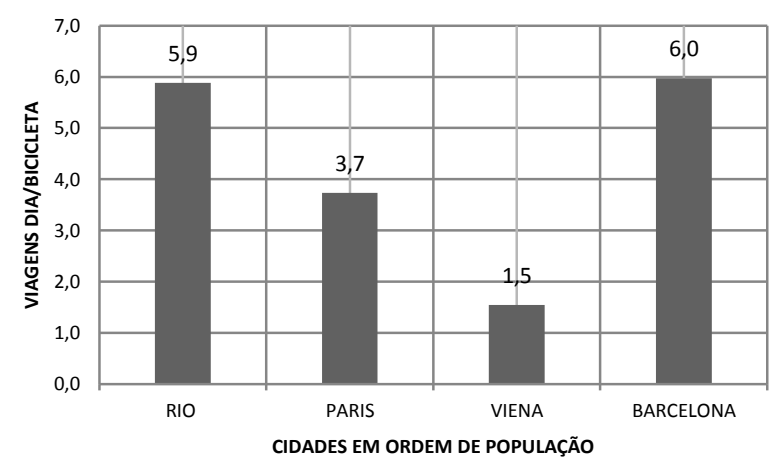

Figura 80 - Relação entre aumento nas viagens feitas por modal cicloviário e o número de bicicletas. (Apêndice 4 e 6).

A elevada eficiência do Bike Rio oferece uma perspectiva positiva de que o aumento do número de estações, bicicletas e bairros atingidos pelo SCB poderá auxiliar no aumento da participação do modal cicloviário na cidade.

Por outro lado, os dados disponíveis não permitem avaliar eventuais impactos indiretos do Bike Rio no aumento da participação do modal cicloviário na mobilidade urbana, especialmente porque os dados do PDTU (2013) indicaram uma redução no número de viagens por transporte não motorizado na cidade.

De qualquer modo, a influência indireta dos SCB no aumento da participação do modal cicloviário é muito difícil de ser avaliada pois esses sistemas normalmente são implantados em um contexto mais abrangente, que envolve muitas vezes a construção de infraestrutura cicloviária e a implementação de medidas para redução do uso do automóvel.

\subsection{3}

Redução das emissões de $\mathrm{CO}^{2}$

Reduzir as emissões de GEE é "um dos projetos estabelecidos como estratégicos pela Prefeitura da Cidade do Rio de Janeiro". A Política Municipal 
de Mudanças Climáticas ${ }^{117}$ estabeleceu como metas de redução "evitar $8 \%$ das emissões de 2005 em 2012 [...] 16\% em 2016 [...] e 20\% em 2020" (SMAC/RJ, 2013, p.1).

Entretanto, segundo o "Inventário das Emissões de Gases de Efeito Estufa da Cidade do Rio de Janeiro", entre 2005 e 2012 as emissões de GEE quase dobraram na cidade em decorrência, especialmente, do crescimento econômico, do aumento da frota de automóveis e do início das operações da Companhia Siderúrgica do Atlântico (ibid., 2013, p.2).

$\mathrm{Na}$ cidade do Rio de Janeiro, o setor de transportes responde por $40 \%$ do volume de GEE lançados na atmosfera e o transporte rodoviário é responsável pela maior parcela destas emissões (Tabela 10).

Tanto Fernández (2011) quanto Fishman et al. (2014) utilizam como método para estimar a redução do volume de emissões de gases a relação entre a distância, em quilômetros, que deixou de ser percorrida por veículos motorizados individuais e o volume de gases que deixou de ser emitido, assumindo que usuários que fazem uso do transporte público não são responsáveis por emissões.

\begin{tabular}{|c|c|c|c|c|c|}
\hline SETORES & $\mathrm{CO} 2$ & $\mathrm{CH} 4$ & N20 & $\mathrm{CO}_{2} \mathrm{e}^{118}$ & $\%$ \\
\hline Consumo do setor energético & $3.169,56$ & 0,03 & 0,01 & $3.171,93$ & $19,2 \%$ \\
\hline Residencial & $1.888,15$ & 0,01 & & $1.889,65$ & $11,4 \%$ \\
\hline Comercial/serviços & $1.626,88$ & & & $1.626,88$ & $9,9 \%$ \\
\hline Público & 562,33 & & & 562,33 & $3,4 \%$ \\
\hline Agropecuário & 0,68 & & & & \\
\hline Transportes & $6.600,77$ & 1,13 & 0,42 & $6.753,77$ & $40,9 \%$ \\
\hline Rodoviário & $4.847,00$ & 1,13 & 0,37 & $4.985,51$ & $73,8 \%$ \\
\hline Ferroviário & 93,05 & & & 93,05 & $1,4 \%$ \\
\hline Aéreo & $1.650,38$ & & 0,05 & $1.664,87$ & $24,7 \%$ \\
\hline Hidroviário & 10,34 & & & 10,34 & $0,2 \%$ \\
\hline Indústria & $2.497,19$ & 0,03 & 0,01 & $2.499,79$ & $15,1 \%$ \\
\hline Total & $16.345,56$ & 1,20 & 0,44 & $16.504,35$ & $100,0 \%$ \\
\hline
\end{tabular}

Tabela 10 - Emissões dos subsetores de energia do Município do Rio de Janeiro em 2012 (Gg). Adaptado da Tabela 3 do Inventário das emisões de gases de efeito estufa da Cidade do Rio de Janeiro (SMAC/RJ, 2013, p.12)

Para esse cálculo, é necessário dispor de dados sobre as distâncias médias percorridas nas viagens realizadas por meio das bicicletas compartilhadas. Estas distâncias nas três cidades européias são: 2,75 km em Barcelona $^{119}, 1,80 \mathrm{~km}$ em Paris e $3,10 \mathrm{~km}$ em Viena ${ }^{120}$. Como esta pesquisa

\footnotetext{
${ }^{117}$ Lei 5.248 , de 27 de janeiro de 2011.

${ }^{118} \mathrm{CO}_{2 e}$ corresponde a dióxido de carbono equivalente e é obtido pela multiplicação do volume de GEE emitidos pelo seu potencial de aquecimento global. O Inventário das emissões de gases (SMAC/RJ, 2013) considera os valores estabelecidos no quarto relatório do IPCC (2007): 1 para $\mathrm{CO}^{2}, 21$ para $\mathrm{CH}_{4}$ e 310 para $\mathrm{N}_{2} \mathrm{O}$.

${ }^{119}$ Fonte: <www.bicing.cat>. Acesso em: 14/09/2014.
} 
não teve acesso a dados dessa natureza sobre o Bike Rio, assumiu-se uma distância de 3,50 km para a cidade do Rio de Janeiro, pois os resultados da pesquisa com usuários indicaram que a maioria dos deslocamentos estava inserida dentro deste raio (Subcapítulo 4.4).

Como o percentual de transferência do transporte individual motorizado observado para o Bike Rio foi de $2 \%$ das viagens diárias, estimou-se 25.776 viagens de $3.50 \mathrm{~km}$ de extensão por ano, totalizando $90.217 \mathrm{~km}$ que deixaram de ser percorridos por meio do TI motorizado.

Segundo Pacca (2007, p.7), para uma eficiência média de 11,3 km/l, um carro a gasolina emite $192 \mathrm{~g}$ de $\mathrm{CO}_{2}$ por quilômetro percorrido. Apesar das emissões decorrentes do uso de etanol serem menores do que as da gasolina, pela impossibilidade em determinar a porcentagem de quilômetros percorridos por carros abastecidos com aquele combustível, ou mesmo por veículos movidos a gás, assumiu-se que todos os veículos utilizam gasolina como combustível.

Dessa forma, a redução anual de $\mathrm{CO}_{2}$ diretamente relacionada ao Bike Rio foi estimada em 0,017Gg, o que representa $0,00035 \%$ das emissões decorrentes do transporte rodoviário e 0,00011\% do total de emissões na cidade (Apêndice 6).

Quando comparado aos demais SCB, observa-se que a taxa de transferência do transporte individual é um fator determinante para que um SCB possa atuar de forma eficaz na redução das emissões de $\mathrm{CO}_{2}$. Viena, com um número de viagens diárias total por SCB menor que o do Rio de Janeiro consegue atingir resultados quase dez vezes mais significativos na redução das emissões de $\mathrm{CO}_{2}$

\begin{tabular}{lcccccc}
\hline CIDADE & $\begin{array}{c}\text { NUMERO VIAGENS/DIA QUE } \\
\text { SUBSTITUEM TI }\end{array}$ & $\begin{array}{c}\text { DISTÂNCIA PERCORRIDA } \\
\text { POR VIAGEM }\end{array}$ & $\begin{array}{c}\text { KM } \\
\text { DIA }\end{array}$ & KM ANO & KG C02 & $\begin{array}{c}\text { KG CO2/ } \\
1000 \text { hab }\end{array}$ \\
\hline RIO & 71 & 3,5 & 247 & 90.217 & 17322 & 2,78 \\
PARIS & 6865 & 1,8 & 12357 & 4.510 .279 & 865974 & 250,94 \\
VIENA & 219 & 3,1 & 678 & 247.305 & 47483 & 26,66 \\
BARCELONA & 3441 & 2,7 & 9290 & 3.390 .751 & 651024 & 401,63 \\
\hline
\end{tabular}

Tabela 11 - Redução de emissões de $\mathrm{CO}_{2}$ por grupo de 1000 habitantes (Apêndice 4 e 6).

${ }^{120}$ Fonte: Fernández (2011, p.99). 
Quando analisada a eficiência do sistema, o Bike Rio apresenta resultados mais positivos, aproximando-se do índice de Viena. Eventuais contribuições indiretas do Bike Rio à redução do uso do TI motorizado não foram avaliadas em função da impossibilidade de quantificar os benefícios decorrentes, por exemplo, da maior atratividade do transporte público em função do SCB.

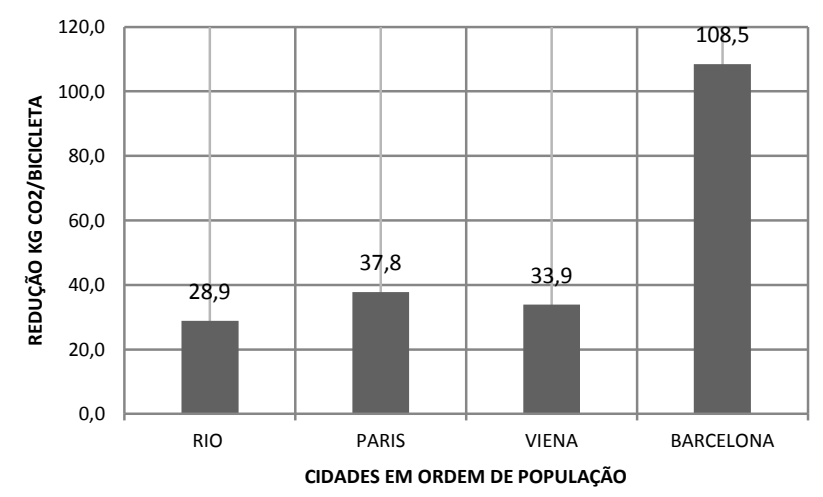

Figura 81 - Redução de emissões de $\mathrm{CO}^{2}$ (kg) / bicicleta (Apêndice 4 e 6).

Além do dióxido de carbono ( $\mathrm{CO}_{2}$ ), os transportes, especialmente o rodoviário, também são responsáveis pela emissão de metano $\left(\mathrm{CH}_{4}\right)$ e óxido nitroso $\left(\mathrm{N}_{2} \mathrm{O}\right)$. Como estes gases em conjunto ${ }^{121}$ equivalem a $2,8 \%$ das emissões de $\mathrm{CO}_{2}$ (Tabela 10), optou-se por desconsiderar seu cálculo nesta pesquisa.

Se o uso da bicicleta compartilhada pode ser associado à redução de emissões de GEE pela substituição de viagens realizadas por veículos motorizados, a manutenção de suas atividades e até mesmo o processo de fabricação das bicicletas e dos demais equipamentos se constituem em fontes geradoras de poluição.

Os SCB normalmente se utilizam de pequenos veículos utilitários para redistribuir as bicicletas e para os serviços de manutenção. Por isso, tanto Fernández (2011) quanto Fishman et al. (2014) consideram que o real benefício ambiental do uso das bicicletas compartilhadas deve considerar o balanço

\footnotetext{
121 Já considerando a aplicação do índice de equivalência. Ver nota 109.
} 
das emissões ${ }^{122}$ e não somente a sua redução pela substituição do transporte individual motorizado.

Quantificar o volume emitido em função das atividades dos sistemas de compartilhamento esbarra em muitas limitações, já que é preciso ter conhecimento da frota de veículos e das rotas por eles percorridas em um determinado período. No caso do Rio de Janeiro, não foi possível obter esss $\operatorname{dados}^{123}$.

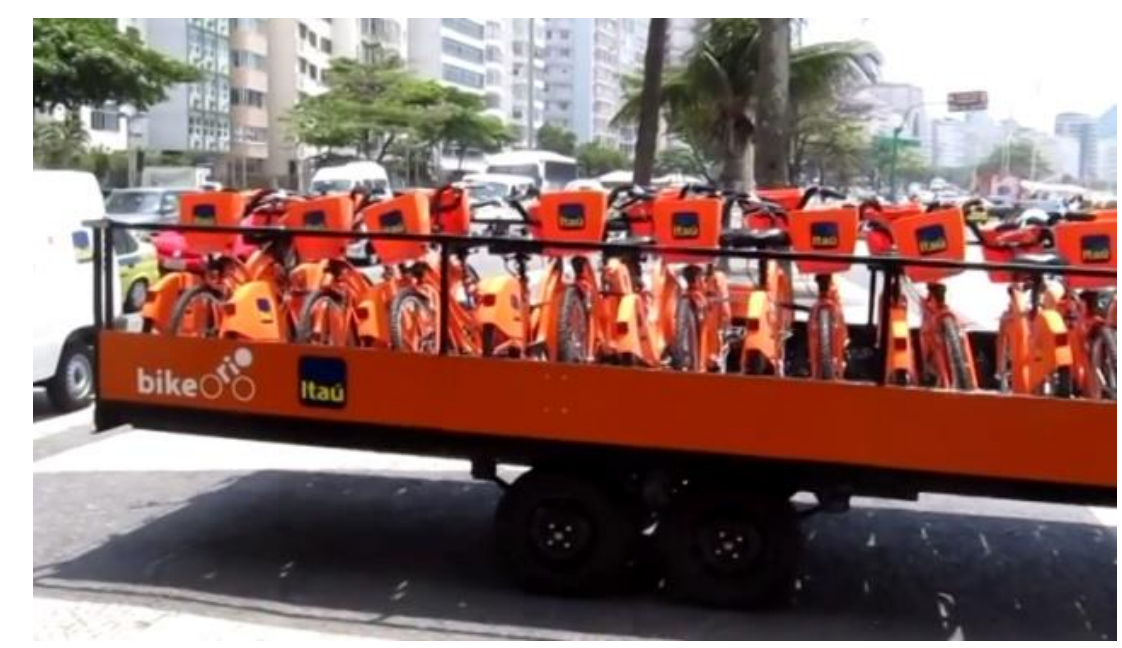

Figura 82 - Transporte de bicicletas do Bike Rio. Fonte: www.youtube.com.

Os veículos utilizados pelo operador do Bike Rio são automóveis comerciais leves nos quais são acopladas carretas para transporte das bicicletas e dos equipamentos. Por esta razão, a pesquisa, considerou que seu consumo equivale ao dos veículos utilizados para o cálculo de emissões de $\mathrm{CO}_{2}$.

Para que o balanço de emissões seja positivo no Rio de Janeiro, é necessário que a frota de veículos de apoio não ultrapasse $247 \mathrm{~km}$ por dia (Tabela 11). Para estimar as emissões decorrentes da operação do Bike Rio foi necessário utilizar dados disponíveis de um SCB que mais se assemelhasse ao carioca. Entre os diversos sistemas analisados por Fernández (2011) e por Fishman et al. (2014), o que mais se aproximou do

\footnotetext{
${ }^{122}$ As emissões decorrentes do deslocamento de funcionários, fabricação das bicicletas e de serviços de manutenção dos equipamentos não são consideradas pelos autores.

${ }_{123}$ Segundo informações passadas por e-mail em 06/08/2014 pela Equipe Bike Itaú.
} 
Bike Rio em número de bicicletas foi o de Melbourne (Austrália) com 600 unidades $^{124}$.

Segundo Fishman et al. (2014), os veículos de serviço do SCB de Melbourne percorrem anualmente $27.851 \mathrm{~km}$. Considerando a relação de $192 \mathrm{~g} \mathrm{CO}^{2} / \mathrm{km}^{125}$, o resultado é um volume total de emissões de 0,005 $\mathrm{Gg}$ $\mathrm{CO}_{2} / \mathrm{ano}$, o que equivale a $38,87 \%$ da redução estimada em função do uso do Bike Rio. Considerando esse dado, a redução de emissões passa a ser $0,012 \mathrm{Gg}$ de $\mathrm{CO}_{2}$, ou $0,00025 \%$ do total anual do sistema de transportes.

\subsection{4}

\section{Incentivo à prática de exercício}

Para Fernández (2011), um indicativo da relevância de um SCB para o estímulo à prática de exercício físico pode ser medido pela porcentagem da população inscrita no sistema. Esse indicativo, porém, é limitado, especialmente no caso do Bike Rio, já que estar inscrito não significa necessariamente ser um usuário ativo, ou mesmo que faça uso sistemático das bicicletas compartilhadas. Segundo o próprio autor, em Viena, por exemplo, somente $3 \%$ dos inscritos no Citybike fazem uso regular do sistema (2011, p.118).

Como a relação entre saúde e uso da bicicleta é tratada por esta pesquisa a partir do estímulo que os SCB podem oferecer para a prática regular de exercício físico, uma maneira de avaliar sua eficácia é verificar a porcentagem de usuários que substitui os deslocamentos motorizados pela bicicleta.

Segundo os resultados da pesquisa com usuários do Bike Rio, $72 \%$ dos entrevistados haviam optado pela bicicleta em substituição a modais de transporte motorizados.

\footnotetext{
${ }^{124} 51$ estações e 600 bicicletas. Fonte: < http://www.melbournebikeshare.com.au/faq>. Acesso em: 10/09/2014.

${ }^{125}$ Em sua pesquisa Fishman et al. calculam o volume de emissões com base em uma relação de 2,3 e 2,7kg/litro de petróleo e diesel, respectivamente consumidos.
} 


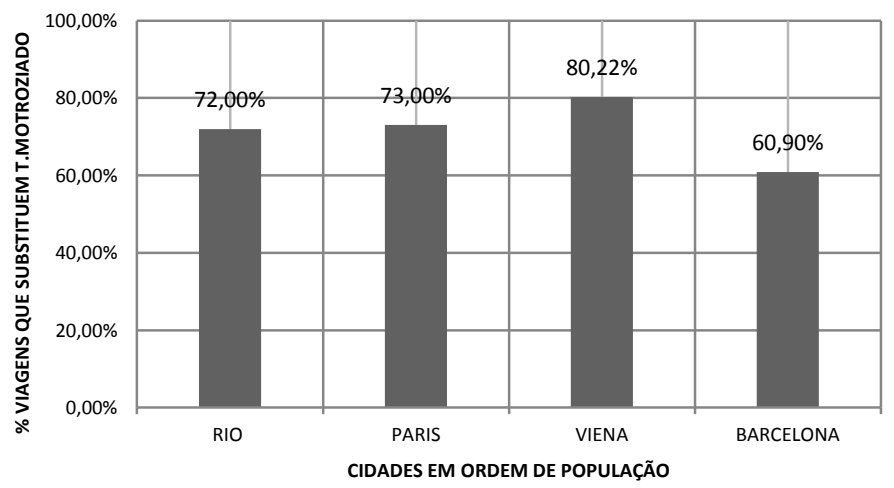

Figura 83 - \% de viagens que substituem transporte motorizado (Apêndice 4 e 6).

Entretanto, como visto no subcapítulo 3.3, para que os exercícios físicos possam oferecer benefícicios à saúde, eles devem ser realizados com frequência. Ao relacionar os usuários que informaram substituir modais motorizados pela bicicleta com os que informaram utilizar o Bike Rio quatro ou mais vezes por semana, chegou-se a um percentual de $31 \%$ de usuários (Apêndice 1).

O fluxo diário de viagens observado para o Bike Rio está concentrado em um período do dia, o que permite supor que a maior parte dos usuários utiliza a bicicleta compartilhada apenas uma vez ao dia.

\begin{tabular}{lr}
\hline & \multicolumn{1}{c}{ TEMPOMÉDIO } \\
VIAGEM / MINUTOS \\
\hline PARIS & 18 \\
VIENA & 14,1 \\
BARCELONA & 14,35 \\
MÉDIA & $\mathbf{1 5 , 5 0}$ \\
\hline
\end{tabular}

Tabela 12 - Média de tempo das viagens por SCB. Fonte: Fernández (2011) e www.bicing.cat (Barcelona).

Como esta pesquisa não dispõe de dados sobre o tempo médio de deslocamentos realizados através do Bike Rio, utilizou-se a média das demais cidades que é de 15,50 minutos (Tabela 12). Assumindo esse tempo de deslocamento, o sistema carioca beneficiaria 31\% dos usuários com 15 minutos de exercícios pelo menos 4 vezes por semana, o que representa um alcance de $0,02 \%$ da população da cidade.

Quando essa porcentagem de viagens é associada ao número de bicicletas, verifica-se um índice de eficiência de 1,8. A comparação com os demais SCB, neste caso, é dificultada pela falta de dados disponíveis que 
permitam correlacionar a substituição de modais motorizados com o uso frequente dos SCB. Uma pesquisa realizada pela ClearChannel Adshel (que opera o sistema de Barcelona) indicou que $45 \%$ dos usuários inscritos em seus sistemas de compartilhamento utilizavam as bicicletas mais de 5 vezes por semana (NYC, 2009, p.17), mas não foi possível determinar se esses usuários estariam substituindo modais motorizados.

\subsection{5}

\section{Responsabilidade social e humanização do ambiente urbano}

O último dos objetivos do Bike Rio é o que apresenta as maiores dificuldades para definir parâmetros que possibilitem sua avaliação, pois "responsabilidade social" e "humanização do ambiente urbano" são conceitos que não são explicados ou detalhados por seu operador.

O conceito de responsabilidade social está normalmente associado ao ambiente corporativo, relacionando-se à forma como as empresas integram suas atividades às preocupações sociais e ambientais e como lidam com seus impactos, o que segundo Ferrel et al. (2001, apud Trevisan et al., 2013) consiste, entre outras coisas, em minimizar os efeitos negativos de suas ações na sociedade.

Uma possibilidade de transpor esse conceito de "minimizar os efeitos negativos de suas ações na sociedade" para a relação entre as pessoas e o sistema de transportes foi avaliar se os usuários do Bike Rio fazem uso da bicicleta motivados por seus benefícios socio-ambientais ou se a escolha é motivada por interesses pessoais.

A pesquisa com usuários ofereceu algumas respostas a essa questão. Em primeiro lugar, quando os usuários foram perguntados sobre as razões pelas quais preferiam utilizar a bicicleta a outros modais de transporte, $100 \%$ das respostas relacionaram-se a benefícios individuais (rapidez, praticidade, custo, etc. $\left.{ }^{126}\right)$.

Em segundo lugar, quando questionados sobre os principais pontos positivos do Bike Rio, apenas 7\% dos entrevistados informaram aspectos que possam ser relacionados a benefícios socio-ambientais (4\% informaram que 0

${ }^{126}$ Apêndice 1. 
Bike Rio incentiva a prática de exercício físico, $2 \%$ informaram que o sistema auxilia na redução da poluição e $1 \%$, que incentiva o uso da bicicleta).

Mesmo sendo uma questão que permitia dar mais de uma resposta, 93\% dos entrevistados apresentaram apenas justificativas relacionadas a benefícios pessoais para utilizar o Bike Rio $^{127}$.

A ausência de uma definição clara sobre o conceito de "humanização do ambiente urbano" também levou à necessidade de buscar uma forma de relacioná-lo ao SCB.

Segundo o dicionário Houaiss, humanizar é "tornar mais sociável, civilizar". Para Santos et al. (1985, p.13), as cidades são compostas pelo espaço construído, de caráter predominantemente privado e pelo espaço aberto, de uso público. Estes espaços de uso público, nos quais a rua se insere, são o "palco" onde ocorrem "as manifestações socio-culturais características de um grupo".

O modelo de desenvolvimento urbano que privilegia o uso do automóvel reduz, segundo Garrad et al. (2012), a interação social e a qualidade de vida nas cidades.

The provision of road space to enable high-volume, high-speed car travel comes at a cost to other road users and local residents in terms of community disruption, noise pollution, social isolation, urban sprawl, restrictions on children's independent mobility and opportunities for outdoor play and social interactions.

Como observa Gehl (2010), a necessidade de acomodar um crescente número de veículos em circulação, aliada à "ideologia" da arquitetura e do urbanismo modernistas, além das forças do mercado, colocaram as preocupações com a "dimensão humana" do espaço urbano em segundo plano.

A common feature of almost all cities - regardless of global location, economic viability and stage of development - is that the people who still use city space in great numbers have been increasingly poorly treated. Limited space, obstacles, noise, pollution, risk of accident and generally disgraceful conditions are typical for city dwellers in most of the world's cities. (Gehl, 2010). 

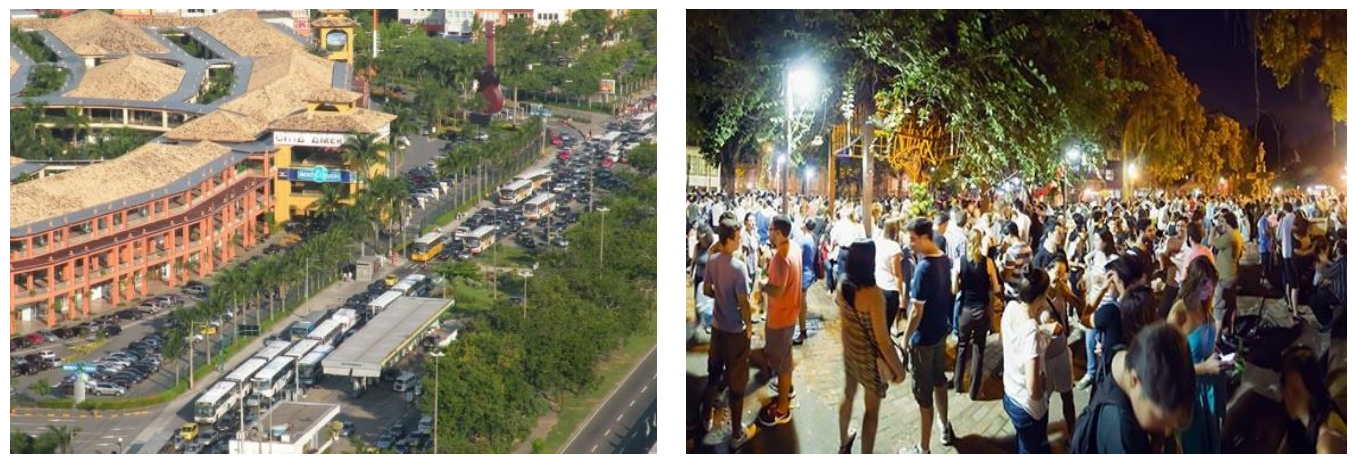

Figura 84 - Avenida das Américas, Barra da Tijuca (esquerda) e Praça São Salvador, Laranjeiras (direita). A escala do carro e a escala humana. Fonte: www.skyscrapercity.com/ showthread.php?t=1049277 e www.folhacarioca.com.br.

Os habitantes de muitas cidades já começaram a se dar conta da redução de sua qualidade de vida e de como isso pode estar relacionado ao modelo de planejamento e gerenciamento das cidades (Cervero, 1998, p.40).

Segundo Gehl (2004, p.17), as atividades exercidas pelas pessoas nos espaços públicos podem ser divididas em três categorias: (1) necessárias; (2) opcionais e (3) sociais. As atividades obrigatórias, como ir ao trabalho, são mais independentes das condições do entorno, já as opcionais e sociais são exercidas caso haja desejo e condições físico-climáticas propícias. Havendo qualidade nos espaços públicos, haverá um maior número de atividades acontecendo nas ruas, elevando a sensação de segurança dos espaços públicos e atraindo cada vez mais pessoas.

Por isso é importante dar especial atenção a qualidade e à escala humana do ambiente urbano para que a cidade possa oferecer às pessoas a oportunidade de interagirem e de estarem em contato com grupos e atividades distintas, mantendo a cidade "viva".

Good city quality at eye level should be considered a basic human right wherever people go in cities. It is on the small scale, in the $5 \mathrm{~km} / \mathrm{h}$ urban landscape, that people encounter the city close up. It is here that the individual out walking has time to enjoy quality - of suffers from its lack. (GEHL, 2010).

A criação de um ambiente urbano agradável favorece a utilização dos modais não motorizados de maneira geral, fazendo com que as pessoas se disponham a caminhar - e pedalar - por distâncias maiores do que usualmente estariam dispostas em um ambiente desfavorável.

Urban designers such as Richard Untermann have demonstrated that acceptable walking distances can be stretched considerably [...] by creating pleasant, interesting urban spaces [...] The distance for walking in unappealing environs is shown in the irony that many Americans will go to great lengths to 
find a parking spot close to the entrance of a shopping mall, but think nothing of walking 1 or 2 miles once inside the mall (Cervero, 1998, p.150).

O conceito de humanização a ser adotado por esta pesquisa está relacionado, portanto, à necessidade de reduzir o espaço destinado aos veículos e de valorizar a escala humana e a qualidade nos espaços públicos. A questão é determinar até que ponto os SCB são, ou podem ser, agentes indutores desse processo.
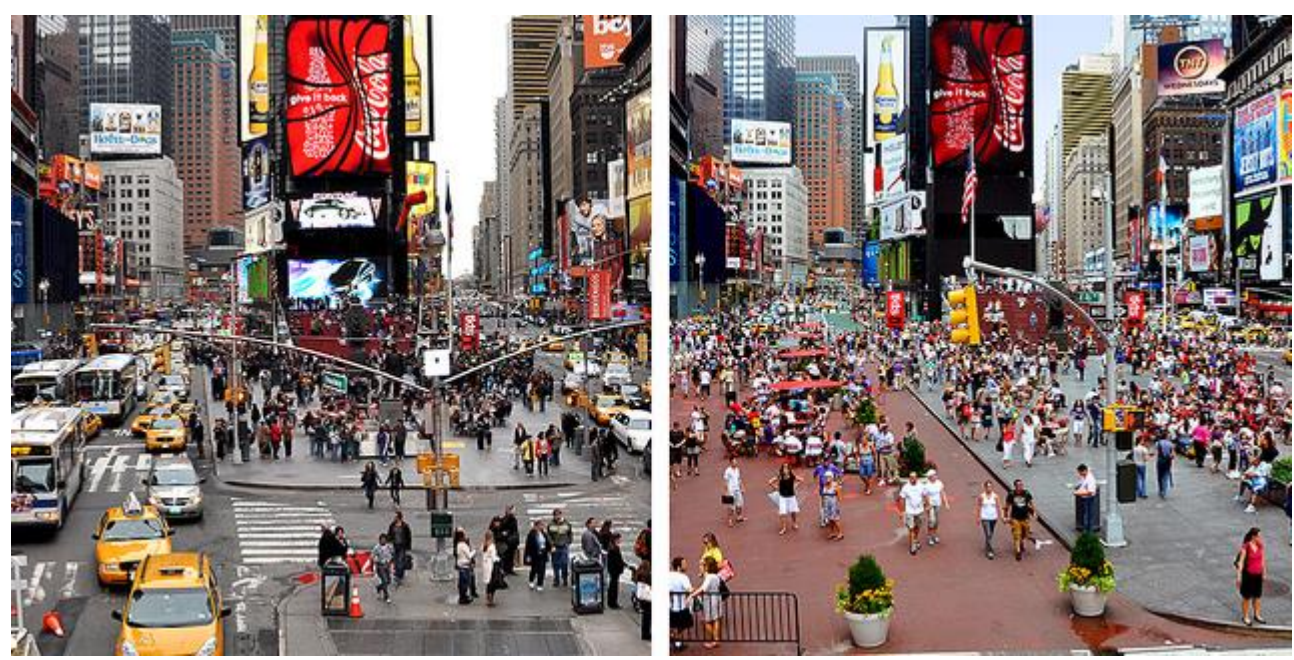

Figura 85 - Broadway, Nova York, antes e depois do fechamento para o tráfego de veículos. Fonte: www.thecityfixbrasil.com

O que se pôde observar dos exemplos estudados neste trabalho e da revisão bibliográfica é que a implementação de um SCB (especialmente os que obtêm melhores resultados) está normalmente inserida dentro de um programa mais abrangente de redução do uso do automóvel e de promoção do transporte cicloviário nas cidades.

Em Paris, por exemplo, no ano de 2001 as autoridades iniciaram um projeto chamado Espaces Civilisés que previa, entre outras ações, a implantação de uma rede de ciclovias e a melhoria dos espaços públicos destinados aos pedestres e aos ciclistas (NYC, 2009, p.27). Em Barcelona, a inauguração do Bicing foi precedida por uma década na qual foram construídos mais de $100 \mathrm{~km}$ de ciclovias. (Fernández, 2011, p.94). Em Nova York, entre 2007 e 2009, foram construídos 300 km de ciclovias (o programa CitiBike só foi implementado em 2013).

Como observa Gehl (2010):

[...] there are good reasons to be cautious about sending inexperienced bicyclists out on two wheels in cities where bicycle traffic and networks do not 
have the critical mass to allow city bikes to reinforce ongoing development [...] city bikes ${ }^{128}$ must be a link in efforts to build and reinforce bicycle culture - not the spearhead.

Os sistemas de compartilhamento de bicicletas são uma das das ferramentas possíveis para aumentar do uso da bicicleta, mas necessitam de infraestrutura adequada para que possam atuar. Por isso, mais do que promover a humanização do espaço urbano, os SCB necessitam desta humanização para alcançar todo seu potencial. Seu sucesso está diretamente relacionado a um espaço público voltado para o ciclista, não o contrário.

\subsection{6}

\section{Barreiras para a expansão do Bike Rio}

O objetivo principal desta pesquisa foi compreender a dinâmica da relação do Bike Rio com o sistema de transportes e sua contribuição para o desenvolvimento sustentável da cidade. Entretanto, como desde o início de 2014 seu programa de expansão vem sendo implementado, aproveitou-se a oportunidade do contato direto com os usuários para verificar os aspectos melhor avaliados e os que se constituem nas maiores barreiras para esta expansão e para o desenvolvimento do modal cicloviário na cidade. Os resultados oferecem subsídios para avaliação do Bike Rio e podem auxiliar positivamente no seu aprimoramento.

Neste subcapítulo foram relacionados os principais fatores apontados pelos entrevistados como positivos e como negativos ${ }^{129}$ tanto do Bike Rio quanto do transporte cicloviário e foram analisadas brevemente as principais barreiras para seu processo de expansão.

Com relação aos fatores que estão diretamente relacionados aos sistemas de compartilhamento, chamados endógenos ${ }^{130}$, os resultados demonstraram que os aspectos considerados mais positivos estão rela-

\footnotetext{
${ }^{128}$ City bike é como o autor se refere às bicicletas compartilhadas.

129 Foram considerados os fatores que apareceram em pelo menos $10 \%$ das respostas. A quantidade de bicicletas (Tabela 13) foi mantida pois é um fator relevante para o cálculo de demanda dos SCB.

${ }_{130}$ Petersen, T. Identification of Key Attributes for Bike Sharing Systems: optimising Bike Sharing in European Cities. Working Document n. D 3.2. Intelligent Energy Europe. 2010.
} 
cionados diretamente ao conceito do SCB, enquanto as maiores fontes de reclamações estão relacionadas à sua operação ${ }^{131}$.

\begin{tabular}{cccc}
\hline \multicolumn{4}{c}{ FATORES ENDÓGENOS } \\
\hline NEGATIVOS & $\%$ USUÁRIOS & POSITIVOS & $\%$ USUÁRIOS \\
\hline FALHAS NO SISTEMA & $59,0 \%$ & PRATICIDADE & $44,0 \%$ \\
MANUTENÇÃO & $21,0 \%$ & SISTEMA COMO UM TODO & $19,0 \%$ \\
DISTRIBUIÇÃO DE BICICLETAS & $21,0 \%$ & OPÇÃO DE MOBILIDADE & $19,0 \%$ \\
QUANTIDADE DE ESTAÇÕES & $15,0 \%$ & QUANTIDADE DE ESTAÇÕES & $12,0 \%$ \\
QUANTIDADE DE BICICLETAS & $9,0 \%$ & CUSTO & $11,0 \%$ \\
\hline
\end{tabular}

Tabela 13 - Aspectos positivos e negativos do Bike Rio na opinião dos entrevistados.

Dentre os problemas operacionais, o mais relevante para os entrevistados foram as falhas do sistema - no momento de retirar as bicicletas e nas consultas sobre disponibilidade de equipamentos nas estações. A principal razão destes problemas decorre de uma característica que, a princípio, deveria ser uma das grandes virtudes do Bike Rio: a conexão por rede sem fio entre as estações e a central de controle.

Esta tecnologia reduz os custos de implantação das estações e permite maior flexibilidade para adaptá-las ou mesmo para implementar bases provisórias $^{132}$. Entretanto, para que este tipo de sistema funcione corretamente há a necessidade de uma rede de comunicação sem fio estável, o que não ocorre no Rio de Janeiro. Como o edital de concessão do Bike Rio exige que as estações sejam implementadas com alimentação "100\% por energia solar e comunicação de dados sem fio (wireless) com a central de controle" ${ }^{\prime 133}$, este é um aspecto muito relevante a ser observado pelo seu operador. Além de ser a maior fonte de reclamação apontada pelos usuários, as falhas no sistema do Bike Rio também foram indicadas como a principal razão para desistência em utilizar o SCB por 27,3\% das pessoas que responderam esta questão pela pesquisa feita pela internet.

A distribuição das bicicletas também foi um fator muito citado como aspecto negativo do Bike Rio (21\%). Como observa Fernández (2011, p.184), estações congestionadas ou a indisponibilidade de bicicletas podem afetar o grau de satisfação dos clientes. Segundo o autor, a distribuição assimétrica de bicicletas nas estações pode ser causada por três fatores: (1) topografia,

\footnotetext{
${ }^{131}$ Foram relacionados apenas os aspectos apontados por pelo menos $10 \%$ dos entrevistados.

132 A alimentação elétrica é feita por painéis solares instalados ao lado das estações.

133 Diário Oficial do Município do Rio de Janeiro, ano XXVII, n.129, p.58-61, 2013.
} 
(2) área de operação muito extensa e (3) demanda irregular. A expansão territorial do Bike Rio em curso demanda, por isso, um acompanhamento muito atento do operador para dimensionar a equipe e os equipamentos necessários para atender o possível aumento na demanda por serviços de redistribuição de bicicletas.

Outro aspecto relevante nos resultados da pesquisa com usuários foi a quantidade de estações, citada por $15 \%$ dos entrevistados como um fator negativo do Bike Rio e por $12 \%$ dos entrevistados como um fator positivo. A princípio não foi observada uma razão específica para que aparecesse tanto de forma positiva quanto negativa. Observou-se uma predominância um pouco maior de usuários que informaram utilizar o sistema 4 ou mais vezes por semana no grupo que considera o número de estações um fator negativo, mas não é uma diferença suficientemente relevante para configurar uma tendência (Apêndice 1).

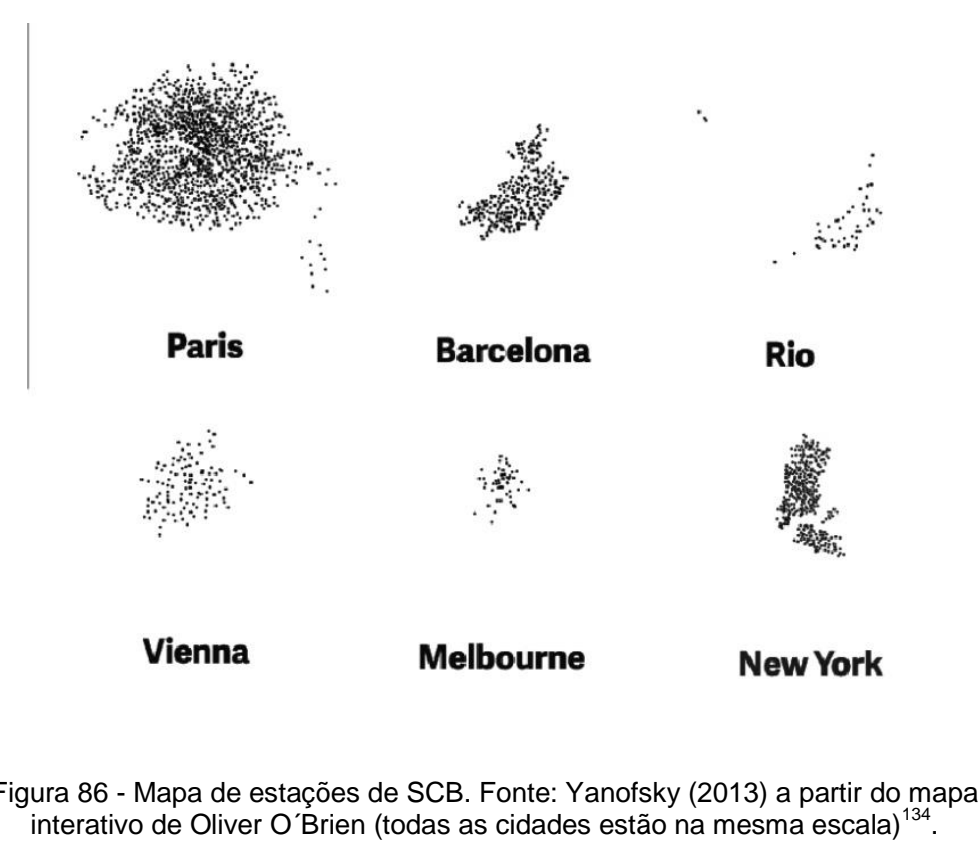

A capacidade de identificar uma área e atender plenamente sua demanda é o fator mais "crítico" para o sucesso de um SCB (ITDP, 2013, p.43). A maioria dos autores considera aconselhável uma rede de estações distantes aproximadamente 300 metros umas das outras (ITDP, 2013; Índia, 2012; Translink, 2008), padrão utilizado na cidade de Paris, por ser uma

\footnotetext{
${ }^{134}$ Disponível em: <http://qz.com/89019/29-of-the-worlds-largest-bike-sharing-programs-in-onemap/>. Acesso em: 10/05/2014.
} 
distância facilmente percorrida a pé. Segundo o The Bike Share Planning Guide (ITDP, 2013), a quantidade de estações ideal deve manter uma relação entre 10 e 16 estações por quilômetro quadrado.

\begin{tabular}{lccccccc}
\hline Cidade & $\begin{array}{c}\text { Área } \\
\text { efetiva } \\
\left(\mathrm{km}^{2}\right)\end{array}$ & $\begin{array}{c}\text { Quantidade de } \\
\text { estações }\end{array}$ & $\begin{array}{c}\text { Quantidade de } \\
\text { bicicletas }\end{array}$ & População & $\begin{array}{c}\text { Densidade de } \\
\text { estações } / \mathrm{km}^{2}\end{array}$ & $\begin{array}{c}\text { Quantidade de } \\
\text { bicicletas / estação }\end{array}$ & $\begin{array}{c}\text { Quantidade de } \\
\text { pessoas / bicicleta }\end{array}$ \\
\hline RIO & $\mathbf{4 0 , 3 5}$ & $\mathbf{6 0}$ & $\mathbf{6 0 0}$ & $\mathbf{6 2 3 0 4 4 6}$ & $\mathbf{1 , 4 8}$ & $\mathbf{1 0 , 0 0}$ & $\mathbf{1 0 3 8 4 , 0 7}$ \\
PARIS & 206,5 & 1800 & 23000 & 3395290 & 8,72 & 12,78 & 147,62 \\
VIENA & 56,96 & 116 & 1400 & 1781105 & 2,04 & 12,07 & 1272,22 \\
BARCELONA & 41 & 420 & 6000 & 1620943 & 10,24 & 14,29 & 270,16 \\
\hline
\end{tabular}

Tabela 14 - Comparativo entre diferentes SCB (Apêndice 3, 4 e 6)

Com relação aos fatores relacionados às características sociais, econômicas, demográficas e físicas do ambiente, chamados exógenos ${ }^{135}$, os resultados demonstraram uma maior convergência de opiniões sobre os aspectos negativos do transporte cicloviário na cidade do Rio de Janeiro. Segurança - relacionada ao tráfego- e a rede de ciclovias apareceram praticamente empatadas, sendo citadas por 47,8\% e 46,4\% dos entrevistados, respectivamente. Existe uma relação muito próxima entre estes dois fatores, pois a principal razão que leva as pessoas a reclamarem da rede de ciclovias está associada ao receio de trafegar por vias compartilhadas com veículos.

\begin{tabular}{cccc}
\hline \multicolumn{4}{c}{ FATORES EXÓGENOS } \\
\hline NEGATIVOS & \% USUÁRIOS & POSITIVOS & $\%$ USUÁRIOS \\
\hline SEGURANÇA (TRÁFEGO) & $47,8 \%$ & REDE DE CILCOVIAS & $23,5 \%$ \\
REDE DE CICLOVIAS & $46,4 \%$ & APRAZIBILIDADE & $19,1 \%$ \\
& & BENEFÍCIO PARA SAÚDE & $11,8 \%$ \\
& & OPÇÃO DE MOBILIDADE & $10,3 \%$ \\
& & REDUZIR TRÁFEGO & $10,3 \%$ \\
& & FUGIR DO TRÂNSITO & $10,3 \%$ \\
\hline
\end{tabular}

Tabela 15 - Principais fatores exógenos que influenciam o modal cicloviário no Rio de Janeiro.

Na pesquisa feita pela internet, as principais razões apresentadas para não utilizar a bicicleta foram a segurança pública (42\%), seguida da falta de ciclovias (34\%) e da falta de segurança no tráfego (24\%). A preocupação com a segurança pública - especialmente roubo da bicicleta - pode abrir uma

${ }^{135}$ Ver nota 124. 
perspectiva positiva para adoção do Bike Rio ao transferir os custos da falta de segurança do usuário para o operador do sistema.

Outro aspecto que evidencia a importância da questão da segurança para o crescimento do transporte cicloviário é a reduzida participação de mulheres observada na pesquisa com usuários do Bike Rio $67 \%$ dos usuários eram do sexo masculino e $33 \%$ do feminino).

So strong is the association between cycling mode share of transportation and female rates of cycling that some observers have suggested that gender equity in cycling is an indicator of a cycling-friendly environment (Baker, 2009). Similar patterns are also observed for children (Garrard et al., 2009) and older adults (Pucher et al., 2003; Pucher et al., 2010), though these are not as well documented as the gender differences in cycling (Garrard et al., 2012).

A segurança está entre os fatores mais signficativos que influenciam a decisão pessoal em adotar a bicicleta como meio de transporte para realização das atividades diárias. A maioria das pesquisas demonstra que a percepção de falta de segurança é o maior impedimento para a utilização da bicicleta (Pucher et al., 2000, p.5) ${ }^{136}$.

Cabe, por isso, diferenciar segurança percebida de segurança objetiva. A primeira - também chamada de subjetiva - expressa o modo como o usuário percebe os eventuais riscos, sejam eles reais ou não. É medida a partir de experiências pessoais e de pessoas próximas (Heinen, 2011, p.26), além das características socio-econômicas e culturais do grupo envolvido. $A$ segurança objetiva representa a situação "real", mensurável, relacionada ao número de acidentes envolvendo ciclistas.

Esses dois conceitos de segurança podem corresponder ou não. Conforme argumentam Klobucar et al. (2007, apud Heinen, 2011, p.26), apesar dos efeitos da infraestrutura na segurança objetiva do ciclista ainda serem incertos, sua existência aumenta o nível de segurança subjetiva. Maiores níveis de segurança em países como Dinamarca, Holanda e Alemanha são a razão mais provável para os índices significativos de utilização da bicicleta por mulheres, idosos e crianças (Pucher et al., 2008, p.505).

Uma maior participação da bicicleta no sistema de transportes também é um fator de segurança. Para Jacobsen (2003), a probabilidade de um

\footnotetext{
136 O artigo não considera dados de cidades norte-americanas para chegar a essas conclusões. Contudo, tanto a literatura quanto pesquisas realizadas em outras cidades confirmam que esta afirmação pode ser estendida às demais áreas.
} 
acidente envolvendo carros e ciclistas (ou pedestres) é inversamente proporcional ao número de usuários de transporte não motorizado ${ }^{137}$.

A motorist is less likely to collide with a person walking and bicycling when there are more people walking or bicycling. Modeling this relationship as a power curve yields the result that at the population level, the number of motorists colliding with people walking or bicycling will increase at roughly 0.4 power of the number of people walking or bicycling. For example, a community doubling its walking can expect a $32 \%$ increase in injuries $\left(2^{0,4}=1,32\right)$. Taking into account the amount of walking and bicycling, the probability that a motorist will strike an individual person walking or bicycling declines with the roughly $-0,6$ power of the number of persons walking or bicycling. An individual's risk while walking in a community with twice as much walking will reduce to $66 \%$ $\left(2^{0,4} / 2=2^{-0,6}=0,66\right)$. Accordingly, policies that increase the numbers of people walking and bicycling appear to be an effective route to improving the safety of people walking and bicycling (Jacobsen, 2003, p.208).

O potencial de fatalidades envolvendo acidentes entre ciclistas e motoristas está relacionado à energia cinética envolvida nos acidentes entre carros e bicicletas. Em velocidades inferiores a $32 \mathrm{~km} / \mathrm{h}$, raramente as colisões levam a acidentes fatais (Kim et al., 2007 apud Jacobsen et al. 2012). Entretanto, se o veículo estiver a $45 \mathrm{~km} / \mathrm{h}$, a maioria dos acidentes resultará em fatalidades ${ }^{138}$ (Johansson, 2009, p.828).

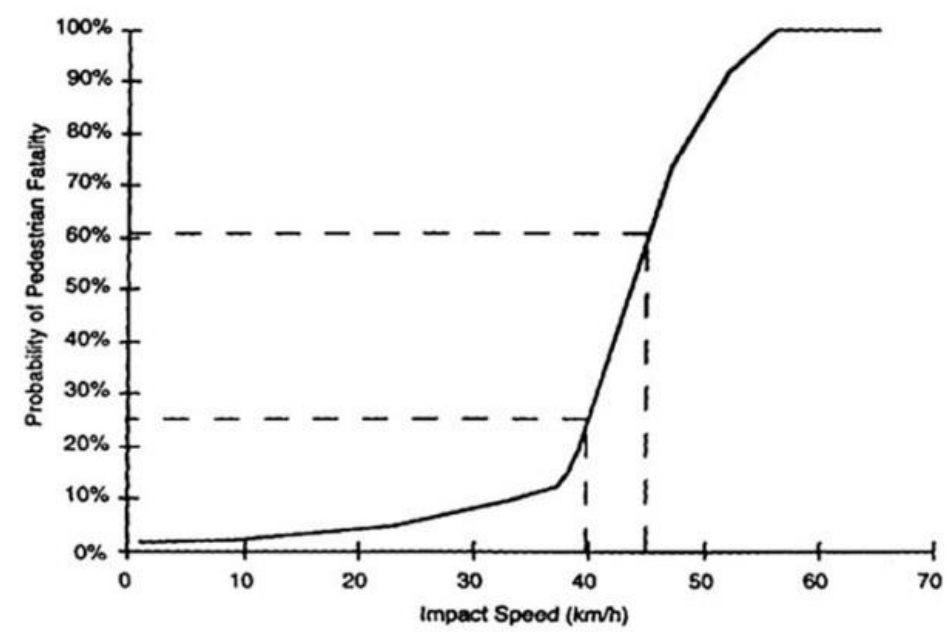

Figura 87 - Probabilidade de fatalidades a pedestres em função da velocidade de impacto. Fonte: Anderson et al. (1997, apud Johansson, 2009).

\footnotetext{
${ }^{137} \mathrm{O}$ autor utiliza dados que indicam haver uma taxa muito similar de fatalidades por 100.000 entre Holanda e EUA como forma de justificar a não linearidade entre os números de usuários e de fatalidades.

${ }^{138} \mathrm{O}$ texto se refere a acidentes com pedestres, contudo, a literatura sobre o tema usualmente utiliza os valores e dados tanto para pedestres como para ciclistas.
} 
Garantir a segurança dos usuários envolve uma série de ações executadas tanto por agentes públicos quanto privados que englobam aspectos relacionados aos campos da medicina, da saúde e da administração públicas, do planejamento urbano e da engenharia de tráfego (Jacobsen et al., 2012). Políticas públicas que integram esses aspectos são o principal fator responsável pela queda no número de vítimas fatais em muitos países europeus (Pucher et al., 2000, p.18).

Se a segurança é um dos principais fatores considerados pelos usuários para decidir uitilizar o modal cicloviário, a infra-estrutura exerce grande influência sobre a sua percepção. Nos países e nas cidades onde há uma rede de ciclovias mais extensa, os índices de participação do transporte cicloviário são maiores e são menores os índices de acidentes fatais (Pucher, 2001).

De maneira geral, os investimentos em infra-estrutura cicloviária geram mais impacto na percepção qualitativa (subjetiva) do que nos valores quantitativos (objetivos) e nesse contexto a conectividade e a segurança são "dimensões estratégicas" que precisam ser consideradas por planejadores, arquitetos e engenheiros na concepção dos projetos (Silva et al., 2011).

\begin{tabular}{l|r|r|r|r|r|r}
\hline \multirow{2}{*}{ Ano } & \multicolumn{7}{|c}{ Extensão (Km) } \\
\cline { 2 - 7 } & Município & AP-1 & AP-2 & AP-3 & AP-4 & \multicolumn{1}{|c}{ AP-5 } \\
\hline 2000 & 97,2 & $\mathbf{0 , 5}$ & $\mathbf{4 8 , 7}$ & 3,1 & 22,9 & 22 \\
2001 & 97,2 & $\mathbf{0 , 5}$ & $\mathbf{4 8 , 7}$ & 3,1 & 22,9 & 22 \\
2002 & 125,5 & $\mathbf{0 , 5}$ & $\mathbf{5 4 , 7}$ & 7,4 & 35,3 & 27,6 \\
2003 & 134,1 & $\mathbf{0 , 5}$ & $\mathbf{5 6 , 5}$ & 7,4 & 42,1 & 27,6 \\
2004 & 141,2 & $\mathbf{0 , 5}$ & $\mathbf{5 6 , 5}$ & 8,1 & 48,5 & 27,6 \\
2005 & 141,2 & $\mathbf{0 , 5}$ & $\mathbf{5 6 , 5}$ & 8,1 & 48,5 & 27,6 \\
2006 & 141,2 & $\mathbf{0 , 5}$ & $\mathbf{5 6 , 5}$ & 8,1 & 48,5 & 27,6 \\
2007 & 141,2 & $\mathbf{0 , 5}$ & $\mathbf{5 6 , 5}$ & 8,1 & 48,5 & 27,6 \\
2008 & 141,2 & $\mathbf{0 , 5}$ & $\mathbf{5 6 , 5}$ & 8,1 & 48,5 & 27,6 \\
2009 & 152,1 & $\mathbf{0 , 5}$ & $\mathbf{6 7 , 4}$ & 8,1 & 48,5 & 27,6 \\
2010 & 174,2 & $\mathbf{0 , 5}$ & $\mathbf{7 1 , 7}$ & 18,0 & 50,8 & 33,2 \\
2011 & 228,8 & $\mathbf{0 , 5}$ & $\mathbf{8 1 , 2}$ & 18,0 & 70,3 & 58,8 \\
& & & & & \\
\hline
\end{tabular}

Tabela 16 - Evolução da extensão de ciclovias, por Áreas de Planejamento no Rio de Janeiro 2000-2011. Fonte: SMAC - www.armazemdedados.rio.rj.gov.br

Para ter êxito na promoção dos SCB, é preciso tornar o transporte cicloviário rápido, prático, seguro e conveniente para o usuário. Para isso são necessárias políticas públicas abrangentes que integrem planejamento urbano, de transportes e campanhas educativas que possam, por um lado, 
desestimular o uso do automóvel particular e por outro transformar a bicicleta em um substituto viável e atrativo para as pessoas.

\section{6}

\section{Considerações finais sobre o Bike Rio}

Uma limitação encontrada para a realização deste trabalho foi a ausência de metas mensuráveis relacionadas ao Bike Rio. Seus objetivos incorporam o abrangente discurso da sustentabilidade, mas não oferecem parâmetros que permitam avaliar o seu desempenho. Da parte do poder público, tanto a Lei 5248/2011 ${ }^{139}$ quanto o Plano "Rio, Capital da Bicicleta"140 objetivam o aumento do uso da bicicleta como modal de transporte, especificando metas relacionadas exclusivamente ao aumento, em quilômetros, da malha cicloviária da cidade, que nem sempre é planejada ou executada considerando o conforto e as necessidades dos usuários ${ }^{141}$.

Os dados do PDTU (2013) indicaram uma tendência de redução no número de deslocamentos por meios não motorizados na cidade do Rio de Janeiro entre os anos 2003 e 2012, período no qual a malha cicloviária na cidade praticamente dobrou de extensão ${ }^{142}$. Isso indica a necessidade de uma visão mais abrangente do transporte cicloviário para que uma efetiva política de inserção da bicicleta nos deslocamentos diários possa ter êxito.

Esta pesquisa demonstrou que a participação do Bike Rio no sistema de transportes é muito reduzida, correspondendo a $0,025 \%$ do total de desloca-

\footnotetext{
${ }^{139}$ Política Municipal de Mudanças Climáticas

140 O Plano "Rio Capital da Bicicleta" faz parte do Plano Estratégico da Prefeitura do Rio de Janeiro 2009-2012. Pós 2016: O Rio mais integrado e competitivo, p. 113. No Plano Estratégico o Projeto é descrito como sendo de "manutenção de $150 \mathrm{~km}$ de ciclovias existentes, e implantação de $150 \mathrm{~km}$ de novas ciclovias, novos bicicletários e de estações públicas de guarda de bicicletas, integrando toda a malha cicloviária à rede de transportes públicos." Apesar dos objetivos descritos, os indicadores de desempenho se relacionam apenas ao aumento, em quilômetros, das ciclovias: "dobrar a malha cicloviária do município até 2012, tendo como referência o ano de 2008".

${ }^{141}$ Cabe neste caso observar que em 2014 a Prefeitura do Rio de Janeiro lançou o "Caderno de encargos para execução de projetos cicloviários" com o objetivo de "definir um padrão único para elaboração e execução de projetos de ciclovias na malha urbana". Por ser uma questão não diretamente relacionada a esta pesquisa e também pelo fato de ter sido lançado no mês de junho, seu conteúdo não foi abordado neste trabalho. Contudo, a publicação de um documento dessa natureza é um indicativo positivo de uma maior preocupação das autoridades para a qualidade da infraestrutura a ser executada na cidade. Disponível em: <http://www.rio.rj.gov.br/web/smac/caderno-de-encargos-municipal>. Acesso em: 10/08/2014.

142 Entre 2001 e 2011 a extensão em quilômetros passou de 134,10 para 228,80. Dados da Secretaria Municipal de Meio Ambiente. Fonte: <www.armazemdedados.rio.rj.gov.br>. Acesso em: 15/08/2014.
} 
mentos diários na cidade do Rio de Janeiro. Mesmo a sua participação nos deslocamentos por bicicleta é bastante restrita, limitando-se a 1,28\% das viagens.

Isso é uma consequência direta de sua escala de implantação: 60 estações e 600 bicicletas $^{143}$. Paris, por exemplo, implantou seu sistema inicialmente com 750 estações e 10.648 bicicletas e em menos de dois anos já contava com mais de 20.000 bicicletas (Nadal, 2007). O Bicing iniciou sua operação com 50 estações e 750 bicicletas em 2007, mas em pouco mais de um ano já contava com 400 estações e 6.000 bicicletas (Midgley, 2009). Mais recentemente, em 2013, Nova York começou a operar seu SCB com 328 estações e 5.531 bicicletas $^{144}$.

Se a escala é a grande responsável pelo reduzido impacto do Bike Rio, quando a avaliação leva em consideração o tamanho do sistema, isto é, o número de bicicletas, o Bike Rio se mostrou bastante eficiente, o que representa uma perspectiva favorável e um incentivo para sua expansão.

A influência do SCB na redução de congestionamentos e na redução da poluição do ar é diretamente proporcional a sua capacidade de transferir usuários do transporte individual motorizado para o transporte cicloviário. Nestes dois aspectos, o Bike Rio apresentou resultados bastante insatisfatórios. A reduzida taxa de transferência de usuários do TI não só limita seus impactos positivos como reduz a sua eficiência, deixando-a abaixo da média observada entre os SCB estudados.

Entretanto, a pouca influência na redução de congestionamentos e na redução da poluição do ar é uma característica que pode ser atribuída a todos os SCB avaliados. Mesmo em Barcelona, o sistema de melhor performance, o impacto na redução de veículos em circulação equivale a pouco mais de $0,15 \%$ dos deslocamentos realizados por TI na cidade.

\footnotetext{
143 Referência: ano 2013.

${ }^{144}$ NYC Bike Share July 2013 Monthly Report. Disponível em: <http://www.citibikenyc.com/assets/pdf/July_2013_Citi_Bike_Monthly_Report.pdf> Acesso em: 10/09/2014.
} 


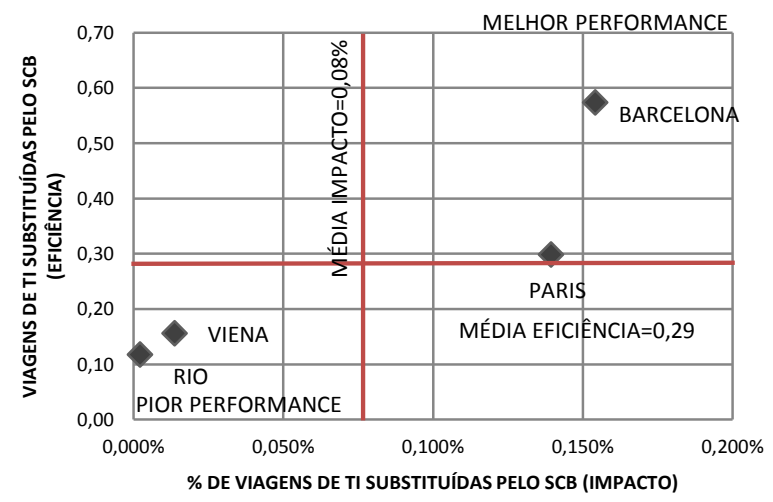

Figura 88 - Performance do SCB na redução do transporte individual.

A baixa taxa de transferência de usuários do TI também afeta diretamenete a eficácia do Bike Rio em atuar positivamente para a redução das emissões de GEE, especialmente o dióxido de carbono. Os resultados desta pesquisa indicaram que nas condições atuais (2013) o sistema responde por uma redução anual de $0,00035 \%{ }^{145}$ do total de emissões de $\mathrm{CO}_{2} \mathrm{e}$ decorrentes do sistema de transportes no Rio de Janeiro.

Para que o Bike Rio conseguisse, mantendo o índice de substituição do $\mathrm{TI}(2 \%)$ e a eficiência atuais $(5,9)$, reduzir em $1 \%$ o total de emissões de $\mathrm{CO}_{2}$ decorrentes do sistema de transportes no Rio de Janeiro, estima-se que seriam necessárias 1.722.348 bicicletas. Mesmo considerando o índice de substituição de Barcelona (9,60\%), seriam necessárias 358.822 bicicletas ${ }^{146}$. Um número expressivo até para os padrões asiáticos.

De fato, os resultados desta pesquisa vão de encontro à observação de Midgley (2011, p. 17) sobre a necessidade de maior cautela nas estimativas dos reais benefícios dos SCB para redução das emissões de GEE. O Bike Rio, assim como os demais SBC avaliados, ainda não se mostraram eficazes para atuar positivamente na redução de emissões.

\footnotetext{
145 Desconsiderando as emissões decorrentes da operação do Bike Rio.

${ }^{146}$ Considerado viagens com $4 \mathrm{~km}$ de distância; $192 \mathrm{~g}$ de $\mathrm{CO}_{2}$ por $\mathrm{km}$ percorrido e um índice de 5,86 viagens dia/bicicleta.
} 


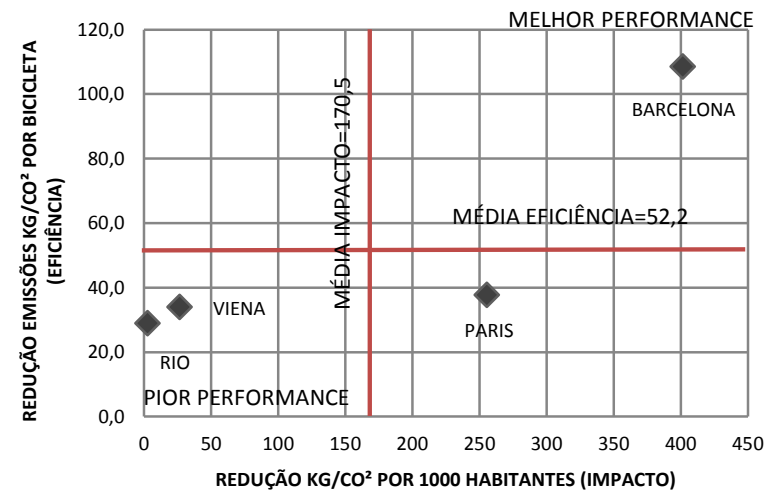

Figura 89 - Performance do SCB na redução das emissões de $\mathrm{CO}^{2}$.

Os resultados observados sugerem que o maior benefício associado ao Bike Rio está na integração e na substituição de outros modais de transporte. Como há uma significativa parcela de usuários do Bike Rio que possui veículo particular (39\%) mas faz uso de outros modais de transporte nos deslocamentos do dia-a-dia, usar o SCB para aumentar a atratividade do transporte público pode, indiretamente, levar a uma redução do uso do TI na cidade.

O papel do Bike Rio no aumento do uso do modal cicloviário se mostrou bastante significativo quanto à eficiência, já que a totalidade das viagens realizadas pelo SCB puderam ser consideradas como acréscimo no uso do modal cicloviário. Mas como em todos os outros indicativos, apresenta um impacto muito reduzido. A pesquisa de campo demonstrou que o sistema consegue captar usuários para o modal cicloviário que de outra forma não estariam utilizando a bicicleta, seja por não possuírem o equipamento, seja por receio de roubo ou por necessitar da bicicleta para apenas uma viagem por dia.

Entretanto, é importante considerar que esse resultado favorável pode estar relacionado ao alcance do Bike Rio. Um expressivo aumento no número de bicicletas alheio à demanda pelo serviço pode levar a uma redução nos índices de eficiência do sistema. A pesquisa pela internet indicou que $50 \%$ das pessoas que informaram serem usuárias de bicicleta mas que nunca fizeram uso do Bike Rio apontaram como principal razão o fato de já possuírem sua própria bicicleta. Uma pesquisa mais abrangente para determinar as razões para que o Bike Rio não seja utilizado por este público é indicada para auxiliar tanto na avaliação da real demanda como para prever melhorias capazes de atrair mais usuários para o sistema. 
A maior limitação para avaliar o papel desempenhado pelo SCB no aumento do uso da bicicleta, especialmente ao se comparar cidades com diferentes realidades sociais, econômicas e culturais, é que a adoção da bicicleta como meio de transporte não é necessariamente uma consequência direta da implantação do SCB. Contudo, disponibilizar a opção do transporte cicloviário de uma forma prática e barata para o usuário, característica dos SCB, é uma forma de atrair novos usuários para o transporte não motorizado sem a necessidade de adquirir uma bicicleta.

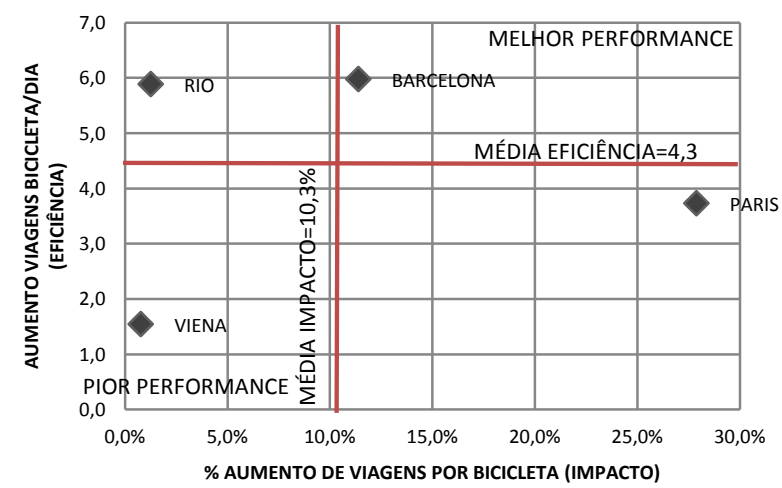

Figura 90 - Performance do SCB na participação no transporte cicloviário.

Independente de sua relação com o aumento da participação geral do transporte cicloviário, os SCB têm condições de exercer um papel significativo como modais de transporte público. O Velib', por exemplo, já chegou a alcançar 135.000 viagens em um único dia $^{147}$, um número de deslocamentos superior, por exemplo, à média de passageiros transportados diariamente através das barcas que ligam o Rio de Janeiro e Niterói. ${ }^{148}$

A pesquisa pela internet indicou que o sistema é amplamente conhecido pela população, mesmo por quem não faz uso da bicicleta ( $88 \%$ dos que pertencem a este grupo e responderam o questionário informaram conhecer o Bike Rio). A institucionalização do transporte cicloviário por meio do SCB e a disseminação do seu conhecimento pela população podem se constituir em elementos capazes de inserir na população a percepção da função da

\footnotetext{
${ }^{147}$ MAIRIE DE PARIS. Dossier de Presse: les 5 ans de Velib' - Ville de Paris. 2012. Disponível em: <http://www.velib.paris.fr/Espace-presse2>.

${ }_{148}$ Segundo o PDTU (2013), Tabela 3.1, são realizadas em média 105.000 viagens por ida através das barcas.
} 
bicicleta como modal de transporte e não apenas como um equipamento de lazer.

Quanto ao objetivo de "promover a prática de hábitos saudáveis e combater o sedentarismo da população", a eficiência apresentada pelo Bike Rio perimite supor que sua expansão poderá beneficiar uma parcela significativa de pessoas. Dos usuários entrevistados, $72 \%$ estariam utilizando um modal motorizado caso não houvesse o Bike Rio e $32 \%$ fazem uso do sistema quatro ou mais vezes por semana. Um cruzamento entre esses dois grupos indicou que $31 \%$ dos usuários que substituem modais motorizados fazem uso do SCB quatro ou mais vezes por semana. Além disso, $26 \%$ dos entrevistados informaram escolher o Bike Rio pela possibilidade de praticar exercício.

A paisagem é um fator relevante para o grupo que substitui o transporte motorizado pelo não motorizado. $20 \%$ dos entrevistados afirmaram substituir outros modais pela bicicleta por ser mais agradável. Com a expansão do sistema para bairros da zona norte, futuras pesquisas nessa região são indicadas para estudar a influência da paisagem para escolha do modal cicloviário como meio de transporte.

Quanto ao papel desempenhado pelo Bike Rio na "promoção da humanização do ambiente urbano", a ausência de uma definição clara sobre a real intenção do operador ao associar esse objetivo ao SCB limitou sua avaliação. Como, a partir especialmente do trabalho de Gehl (2010), esta pesquisa associou o conceito de humanização a um processo de qualificação do espaço público e da infraestrutura cicloviária, além da valorização do pedestre e da escala humana no planejamento urbano, reduzindo a influência do carro, não foi possível atribuir ao Bike Rio uma influência direta na humanização do ambiente urbano. A experiência de outras cidades nas quais a implantação e a qualificação da infraestrutura para bicicleta precedeu a implantação dos SCB permite supor que mais do que exercerem papel ativo, os SCB são beneficiários dos efeitos da "humanização".

Ainda que a implantação de um SCB aliada à publicidade incentive a percepção da bicicleta como modal de transporte, a pesquisa com usuários indicou que sua utilização é motivada especialmente pelo interesse pessoal. Apesar de $14 \%$ dos entrevistados terem declarado que os pontos positivos do uso da bicicleta estão relacionados a benefícios para o meio ambiente e melhoria do tráfego (benefícios socio-ambientais), quando perguntados por 
que optaram pelo uso do Bike Rio, esses mesmos entrevistados apresentam motivações de caráter pessoal, especialmente economia de tempo, agradabilidade e possibilidade de praticar exercício. Por isso esta pesquisa não encontrou evidências que possam relacionar diretamente o Bike Rio à promoção da "responsabilidade social das pessoas".

No primeiro trimestre de 2014 foi iniciado o processo de expansão do Bike Rio previsto no Processo n 05/550.508/2013. O aumento no número de bicicletas e de estações é, como sugerem os resultados desta pesquisa, fundamental para que o Bike Rio possa exercer um papel mais relevante como modal de transporte. Entretanto, estes mesmos resultados e os exemplos internacionais permitem algumas observações sobre esse processo.

A expansão prevista consiste em um acréscimo de 200 estações e 2000 bicicletas à frota atual, entretanto, a relação entre a quantidade de bicicletas e o número de habitantes, bem como a relação entre a quantidade estações e a área de alcance do $\mathrm{SCB}^{149}$, ainda deixarão o Bike Rio em uma posição desfavorável em comparação com o Velib', o Bicing e mesmo o CityBike, que apresentou os piores resultados de performance nesta pesquisa.

\begin{tabular}{lccccccc}
\hline Cidade & $\begin{array}{c}\text { Área efetiva } \\
\left(\mathrm{km}^{2}\right)\end{array}$ & $\begin{array}{c}\text { Quantidade de } \\
\text { estações }\end{array}$ & $\begin{array}{c}\text { Quantidade de } \\
\text { bicicletas }\end{array}$ & População & $\begin{array}{c}\text { Densidade de } \\
\text { estações } / \mathrm{km}^{2}\end{array}$ & $\begin{array}{c}\text { Quantidade de } \\
\text { bicicletas / estação }\end{array}$ & $\begin{array}{c}\text { Quantidade de } \\
\text { pessoas / bicicleta }\end{array}$ \\
\hline RIO & $\mathbf{1 3 3 , 9 3}$ & $\mathbf{2 6 0}$ & $\mathbf{2 6 0 0}$ & $\mathbf{6 2 3 0 4 4 6}$ & $\mathbf{1 , 9 4}$ & $\mathbf{1 0 , 0 0}$ & $\mathbf{2 3 9 6 , 3 3}$ \\
PARIS & 206,5 & 1800 & 23000 & 3395290 & 8,72 & 12,78 & 147,62 \\
VIENA & 56,96 & 116 & 1400 & 1781105 & 2,04 & 12,07 & 1272,22 \\
BARCELONA & 41 & 420 & 6000 & 1620943 & 10,24 & 14,29 & 270,16 \\
\hline
\end{tabular}

Tabela 17 - Comparativo entre diferentes SCB considerando expansão prevista do Bike Rio (Apêndice 3, 4 e 6)

Esses dados permitem uma reflexão sobre a real necessidade de se expandir, neste momento, o Bike Rio na direção da zona oeste. Caso toda expansão prevista para o sistema estivesse concentrada nos bairros da zona sul, grande Tijuca e centro, a densidade de estações por $\mathrm{km}^{2}$ subiria para 4,32, mesmo assim, metade da densidade do Velib'.

As 60 estações previstas para Barra da Tijuca e Recreio representarão uma densidade de 0,81 estação / km² em uma região cuja densidade popu-

\footnotetext{
149 Área efetiva, que, no caso do Rio de Janeiro, consiste na área dos bairros alcançados pelo Bike Rio subtraída das áreas situadas acima da cota 100.
} 
lacional é de 2.958 habitantes / $\mathrm{km}^{2^{150}}$. Para comparação, a densidade dos bairros da zona sul que serão alcançados pelo Bike Rio até o fim de 2014 é de $16.975 \mathrm{hab} / \mathrm{km}^{2}$. A da região da Grande Tijuca, $25.995 \mathrm{hab} / \mathrm{km}^{2}$.

A densidade urbana é um dos fatores capazes de influenciar positivamente o sucesso de um SCB (Translink, 2009, p.28), por isso cabe questionar os reais benefícios de expandir o sistema para uma área tão vasta e pouco densa da cidade quando os números observados nos SCB com melhor performance demonstram haver ainda potencial de mercado nas áreas já alcançadas pelo Bike Rio. Além disso, os bairros da Barra da Tijuca e Recreio juntos correspondem a um aumento de 123\% (Apêndice 3) da área de alcance do Bike Rio, o que poderá acarretar uma elevação nos custos de manutenção, logística e de distribuição de bicicletas.

Como a integração com outros modais de transporte se mostrou um dos aspectos nos quais o Bike Rio mais se destacou positivamente nesta pesquisa, os resultados sugerem que poderia ser estudada a expansão do sistema na direção da zona norte, integrando o SCB à rede de trens, de metrô e de BRT em um projeto que incluísse a execução de infraestrutura qualificada para o transporte cicloviário, oferecendo à população de uma região carente de investimentos na qualidade do ambiente urbano a opção de um modal não poluente e mais mais barato.

${ }^{150}$ Ver nota 149. 


\section{Conclusão}

O modelo de desenvolvimento urbano que privilegia o transporte motorizado individual provoca o aumento do consumo de energia e das emissões de gases poluentes, eleva os custos com a saúde da população, causa prejuízos à produtividade da economia, incentiva a ocupação contínua de terras no entorno urbano e pode tornar as cidades socialmente mais excludentes.

O crescimento da frota de veículos, especialmente nos países em desenvolvimento, reforça a necessidade de se buscar soluções capazes de minimizar as consequências sociais, econômicas e ambientais do uso do automóvel para as cidades. Entre as ações capazes de contribuir para redução do impacto do transporte individual motorizado está o incentivo ao transporte cicloviário. Com esta finalidade, muitas cidades têm investido na implantação de sistemas de compartilhamento de bicicletas.

A expansão global dos SCB é um processo relativamente recente e a real dimensão dos seus beneficios para a sustentabilidade e para a mobilidade urbana (ou mesmo seu potencial) ainda precisa ser melhor estudada. O principal objetivo deste trabalho foi, a partir da avaliação do SCB da cidade do Rio de Janeiro, o Bike Rio, contribuir para um maior conhecimento sobre a função que os SCB podem desempenhar para o desenvolvimento sustentável das cidades.

Essa avaliação foi feita a partir dos objetivos associados à implantação do Bike Rio. Esses objetivos, apesar de incorporarem o abrangente discurso da sustentabilidade nas suas dimensões social, econômica e ambiental, não estão relacionados a parâmetros ou a metas que permitam avaliar o desempenho do SCB. Desse modo, acabam por representar mais um conjunto de intenções capazes de criar uma imagem positiva do modal cicloviário do que seus reais benefícios.

Os deslocamentos diários feitos por meio do transporte cicloviário correspondem a aproximadamente $2,0 \%$ do total de viagens na cidade do Rio de Janeiro. O Bike Rio representa $1,28 \%$ desse total, o que equivale a 0,025\% das viagens diárias realizadas no município. Essa participação reduzida no total de deslocamentos está relacionada principalmente à escala 
do sistema. Com 60 estações e 600 bicicletas (dados de 2013), o Bike Rio é 10 vezes menor que o Bicing, de Barcelona, e quase quarenta vezes menor que o Velib', de Paris (cidades cujas área e população são menores que as do Rio de Janeiro).

Na última década observou-se um crescimento significativo no número de viagens diárias realizadas por meio do transporte motorizado, especialmente o individual, na cidade do Rio de Janeiro. No mesmo período houve um decréscimo, tanto em valores absolutos quanto em valores percentuais, do total de deslocamentos feitos por meios não motorizados.

Essa redução do transporte não motorizado na cidade pode estar relacionada à redução das taxas de desemprego e à elevação da renda das famílias, pois verificou-se que quanto maiores são a renda familiar e a taxa de emprego formal, maior é a participação dos transportes motorizados nos deslocamentos.

Isso demonstra a necessidade políticas públicas abrangentes, capazes de oferecer conforto, segurança e praticidade aos usuários do transporte cicloviário para que a bicicleta tenha condições de competir com outros modais e de se inserir de forma mais significativa como opção de transporte na cidade.

Pelos resultados da pesquisa de campo, a maioria dos usuários do Bike Rio é composta de jovens adultos do sexo masculino. Isso indica que o transporte cicloviário ainda precisa se tornar mais seguro para que a bicicleta possa incorporar um contingente maior de usuários do sexo feminino e das demais faixas etárias. A menor participação destes grupos evidencia que a infra-estrutura urbana ainda não está plenamente estruturada para o transporte cicloviário.

Tanto os resultados da pesquisa com usuários do Bike Rio quanto os resultados da pesquisa realizada pela internet indicaram que os aspectos negativos mais relevantes para 0 uso da bicicleta na cidade estão relacionados à segurança pública e aos riscos decorrentes do compartilhamento do mesmo espaço com veículos motorizados.

A simples construção de ciclovias ou ciclofaixas não se mostrou, isoladamente, um fator determinante para o aumento do uso da bicicleta. $\mathrm{Na}$ mesma década em que se observou o decréscimo do uso do transporte não motorizado, a rede de ciclovias praticamente dobrou de tamanho na cidade. 
Os resultados deste trabalho indicaram uma contribuição bastante reduzida do Bike Rio tanto para mobilidade quanto para a sustentabilidade. Isso se deve especialmente à pequena quantidade de bicicletas e de estações disponíveis e à baixa taxa de transferência de usuários do transporte individual motorizado para a bicicleta.

Apesar de uma parcela significativa de usuários do SCB possuir veículo próprio, o Bike Rio não se mostrou eficaz em captar usuários do transporte individual motorizado. Seus resultados são inferiores aos observados em Paris, Barcelona e Viena. Apenas $2 \%$ dos usuários informaram que a bicicleta compartilhada estava substituindo o TI motorizado.

Essa baixa taxa de transferência limita os benefícios do Bike Rio para a redução das emissões de gases poluentes, especialmente o dióxido de carbono, e para a redução de congestionamentos. O Bike Rio contribui com uma redução de apenas $0,00035 \%$ do total de emissões de $\mathrm{CO}_{2} \mathrm{e}$ anuais decorrentes do sistema de transportes no Rio de Janeiro. Quanto à redução de congestionamentos, as viagens por meio de bicicletas compartilhadas representam somente $0,002 \%$ do total de deslocamentos realizados por veículos particulares.

A pesquisa indicou que esse impacto limitado na redução de congestionamentos e na redução das emissões de gases poluentes é uma característica de todos os sistemas de compartilhamento avaliados. Mesmo em Barcelona, onde os resultados apresentaram melhor performance, o impacto na redução da circulação de veículos equivale a pouco mais de $0,15 \%$ dos deslocamentos realizados por meio do $\mathrm{TI}$ motorizado. Esses dados indicam a necessidade de maior cautela nas estimativas dos reais benefícios dos SCB.

Quanto à capacidade de atrair novos usuários para o transporte cicloviário, os resultados observados foram mais favoráveis ao Bike Rio. A maioria dos entrevistados (59\%) informou não possuir bicicleta particular e os demais (41\%) declararam que não utilizariam seu próprio equipamento para efetuar o deslocamento em questão. Isso indica que o Bike Rio tem condições de atuar positivamente no incentivo ao uso do transporte cicloviário, incorporando usuários que de outra forma não estariam utilizando a bicicleta.

Os resultados indicaram que o Bike Rio beneficia aproximadamente 1/3 dos seus usuários com a prática constante de exercício fisico. Não foi possível efetuar comparações com outros SCB mas a expansão do sistema, 
mantida essa proporção, indica uma perspectiva favorável para a promoção da prática de hábitos saudáveis na população.

Esta pesquisa não encontrou evidências capazes de relacionar diretamente o Bike Rio à promoção da "responsabilidade social das pessoas". Mesmo que os SCB sejam usualmente associados à sustentabilidade e a benefícios para qualidade de vida nas cidades, os resultados das entrevistas indicaram que sua utilização, pelo menos no Rio de Janeiro, é motivada principalmente por interesses pessoais. Ainda que 14\% dos entrevistados tenham associado o uso da bicicleta a benefícios socio-ambientais, as razões apresentadas para fazer uso do Bike Rio indicam motivações individuais, especialmente relacionadas à economia de tempo, à agradabilidade do uso da bicicleta e à possibilidade de praticar exercício.

Também não foi possível, por meio dos resultados observados, atribuir ao Bike Rio influência direta na "humanização do ambiente urbano", A experiência de cidades como Paris e Nova York, onde a expansão e a qualificação da infraestrutura cicloviária precedeu a implantação dos SCB, permite supor que mais do de promovê-la, os SCB são seus beneficiários.

A contribuição mais relevante do Bike Rio observada nesta pesquisa está na integração do SCB com o sistema de transportes da cidade. Como existe uma significativa parcela de usuários do Bike Rio que possui veículo particular mas faz uso de outros modais de transporte em seus deslocamentos diários, utilizar o SCB como elemento capaz de aumentar a atratividade do transporte público pode, indiretamente, se constituir em uma maneira de contribuir para a redução do uso do transporte individual.

Os resultados indicam que os SCB devem ser tratados como uma ferramenta capaz de auxiliar no incremento do uso da bicicleta como modal de transporte, mas não são um fator determinante para isso. Viena, cujo SCB apresentou os piores resultados de performance, é a cidade que apresenta maior participação do transporte cicloviário nos deslocamentos diários.

Se a escala é a maior responsável pelo reduzido impacto do Bike Rio nos indicadores avaliados, quando consideramos a dimensão do sistema, isto é, o número de bicicletas, o Bike Rio se mostrou bastante eficiente, o que representa uma perspectiva favorável para sua expansão.

Entretanto, esta alta taxa de eficiência pode estar relacionada ao reduzido número de bicicletas. A reduzida oferta pode ser a responsável pela alta rotatividade do Bike Rio. Um expressivo aumento no número de 
bicicletas, que não leve em consideração a real demanda pelo serviço, poderá acarretar a redução dos seus índices de eficiência.

No primeiro trimestre de 2014 foi iniciado o processo de expansão do Bike Rio. Mesmo com a previsão de implantação de 200 novas estações e o acréscimo de 2000 bicicletas à frota atual, a relação entre a quantidade de bicicletas e o número de habitantes, assim como a relação entre a quantidade de estações e a área de alcance do sistema, ainda deixarão o Bike Rio com índices inferiores aos do Velib', do Bicing e mesmo do CityBike. Ademais, a expansão territorial prevista irá criar um grande desafio logístico para a operação do sistema.

Os problemas operacionais são a maior fonte de reclamações dos usuários do Bike Rio. Destes, o mais relevante para os usuários são as falhas no sistema para retirar as bicicletas e para consultar a disponibilidade das estações. Isso é muito relevante para o operador do sistema pois essas falhas também foram apontadas como uma das principais razões para desistência em utilizar o SCB.

A operação de distribuição das bicicletas também foi um problema muito citado pelos usuários. Por isso, a expansão territorial prevista para o Bike Rio demanda especial atenção no dimensionamento da equipe de funcionários e dos recursos necessários para atender o provável aumento da demanda por serviços de redistribuição e de manutenção das bicicletas e das estações.

Recomenda-se um acompanhamento atento do processo de expansão do Bike Rio, observando as consequencias do aumento no número de estações e da frota de bicicletas e também do seu alcance territorial nos índices de eficiência do sistema.

Recomenda-se também que sejam feitas pesquisas mais abrangentes sobre os principais fatores que desestimulam as pessoas a utilizar o transporte cicloviário na cidade. Dessa forma será possível determinar com maior precisão a real demanda pelo uso da bicicleta e a melhor forma de enfrentar as limitações para que o modal cicloviário possa ocupar um papel mais relevante na mobilidade da cidade do Rio de Janeiro.

Consideramos que a importância desta pesquisa reside na discussão do papel desempenhado pelo Bike Rio e do seu potencial para contribuir para a mobilidade e para sustentabiliade urbana. Este trabalho não se pretende conclusivo, ao contrário, espera-se que os dados levantados possam contribuir e subsidiar outras pesquisas que aprimorem, complementem e 
tragam novas questões ao estudo do papel desempenhado pelos sistemas de compartilhamento de bicicletas, especialmente nas cidades brasileiras. $O$ pouco tempo de implantação do Bike Rio indica que há ainda um longo caminho a percorrer, e muito a ser estudado. 


\section{Referências bibliográficas}

ANDRADE, V. et al. Bike infrastructures. Aalborg Universitet. Architecture and Design. v. 37, 2011.

ASSOCIAÇÃO NACIONAL DE TRANSPORTES PÚBLICOS. Sistema de informações da mobilidade urbana: relatório comparativo 20032011. São Paulo: 2005. Disponível em: <http://www.antp.org.br /_5dotSystem/download/dcmDocument/2013/04/11/8757DC5C-26004326-977B-B784ACBDD4EF.pdf>.

BUIS, J.; WITTINK, R. The economic significance of cycling: a study to illustrate the costs and benefits of cycling policy. VNG uitgeverij, The Hague, 2000. Disponível em: <www.ocs.polito.it/biblioteca/mobilita/ EconomicSignificance.pdf>.

BÜTTNER, J. et al. Optmising bike sharing in European cities: a handbook. Intelligent Energy Europe, 2011. Disponível em:

$<$ http://obisproject.com/palio/html.run?_Instance=obis\&_PagelD=200\& LngID=21\&_Cat ID=13\&pic=0\&_CheckSum=1419726245>.

CERVERO, R. The transit metropolis: a global inquiry. Washington: Island Press, 1998.

CONFERÊNCIA DAS NAÇÕES UNIDAS SOBRE O MEIO AMBIENTE E DESENVOLVIMENTO. Agenda 21. Brasília: Câmara dos Deputados, 1995.

DEKOSTER, J.; SCHOLLAERT, U. Cycling: the way ahead for towns and cities. European Commission. Bruxelles, 1999.

DeMAIO, P.; GIFFORD, J. Will smart bikes succeed as public transportation in the United States? Journal of Public Transportation, v.7, n.2, p.1-15, 2004. Disponível em: <http://www.metrobike.net/wpcontent/uploads/2013/10/Will-Smart-Bikes-Succeed-as-PublicTransportation-in-the-US.pdf>.

DeMAIO, P. Bike-sharing: history, impacts, models of provision, and future. Journal of Public Transportation, v.12, n.4, p.40-56, 2004b.

DODMAN, D. Blaming cities for climate change? An analysis of urban greenhouse gas emission inventories. Environment and urbanization, v.21 n.1, 2009. Disponível em: <http://eau.sagepub.com /content/21/1/185>. 
EMPRESA BRASILEIRA DE PLANEJAMENTO DE TRANSPORTE GEIPOT. Manual de planejamento cicloviário. 3. ed. Brasília: 2001.

EWING, R. et al. Relationship between urban sprawl and physical activity, obesity, and morbidity. American Journal of Health Promotion. n. 18, p.47-57, 2003.

FERNÁNDEZ, A.C. The contribution of bike-sharing to sustainable mobility in Europe. 2011. 235 f. Tese (Doutorado) - Technischen Universität Wien, Viena, 2011

FISHMAN, E.; WASHINGTON, S.; HAWORTH, N. Bike share's impact on car use: evidence from the United States, Great Britain, and Australia. 2013. Disponível em: < http://eprints.qut.edu.au/67026/>.

FURTH, P.G. Bicycling Infrastrucutre for Mass Cycling: a Transatlantic Comparison In: City Cycling. Kindle edition. Cambridge: MIT press, 2012.

GARRARD, J.; RISSEL, C.; BAUMAN, A. Health Benefits of Cycling. In: City Cycling. Kindle edition. Cambridge: MIT press, 2012.

GEHL, J. Cities for people. Kindle edition. Washington: Island Press, 2010.

GIL, A.C. Métodos e técnicas de pesquisa social. São Paulo: Atlas, 1989.

GILBERT, R. Defining sustainable transportation. Winnipeg: The Centre for Sustainable Transportation, 2005. Disponível em: $<$ www.cst.uwinnipeg.ca/documentos/Defining_Sustainable_2005.pdf>.

GOEVERDEN, K.; GODEFROOIJ, T. The Dutch Reference Study: Cases of interventions in bicycle infrastructure reviewed in the framework of bikeability. Delft Univerity of Technology. Delft: 2011. Disponível em: <http://repository.tudelft.nl/view/ir/uuid\%3Acc6d7d3b6ebf-4ef7-a57c-2d4834bafe9d/>.

GOVERNMENT OF INDIA. Ministry of Urban Development. Public cycle sharing systems: a planning toolkit for Indian cities: Delhi. 2012.

HEINEN, E. Bicycle commuting. Sustainable Urban Areas, n. 43.

Amsterdam: IOS Press BV, 2011.

INSTITUTE FOR TRANSPORTATION \& DEVELOPMENT POLICY. The Bike-share Planning Guide. New York, 2013. Disponível em: < https://go.itdp.org/display/live/The+Bike-Share+Planning+Guide>. 
INTERGOVERNMENTAL PANEL ON CLIMATE CHANGE. Climate Change 2007: Synthesis Report. Disponível em: <www.ipcc.ch/ pdf/assessment-report/ar4/syr/ar4_syr.pdf>.

INSTITUTO PARA LA DIVERSIFICACÍON Y AHORRO DE LA ENERGIA. Espanha. Guía metodológica para la implantación de sistemas de bicicletas públicas en España. Madrid: 2007.

JACOBSEN, P.L. Safety in numbers: more walkers and bicyclists, safer walking and bicycling. Injury prevention, v.9, n.3, p.205-209, 2003.

JACOBSEN, P.L.; RUTTER, H. Cycling Safety. In: City Cycling. Kindle edition. Cambridge: MIT press, 2012.

JOHANSSON, R. Vision Zero: Implementing a policy for traffic safety. Safety Science, n.47, p.826-831, 2009. Disponível em: <http://linkinghub.elsevier.com/retrieve/pii/S0925753508001859>.

LAND TRANSPORT AUTHORITY. JOURNEYS. Singapore, n.7, 2011. Disponível em:

$<$ http://app.Ita.gov.sg/ltaacademy/doc/JOURNEYS_Nov2011\%20Revis ed.pdf $>$.

LEITE, C.; AWAD, J.C.M. Cidades sustentáveis, cidades inteligentes: desenvolvimento sustentável num planeta urbano. Porto Alegre: Bookman, 2012.

LEMOS, M.F.R.C. Adaptação de cidades para mudança climática: uma metodologia de análise para os planos diretores municipais. $295 \mathrm{f}$. Tese (Doutorado) - UFRJ/FAU, Rio de Janeiro, 2010.

LIBERATO, L.V.M. Bicicleta e tempo de contestação. Revista Xaman, n.1, 2004.

LITMAN, T; BURWELL, D. Issues in sustainable transportation. International Journal of Global Environmental Issues, v.6, n.4, p.331347, 2006.

LITMAN, T. Well Measured: developing indicators for sustainable and livable transport planning. Victoria Transport Policy Institute, 2014.

Developing Indicators for Comprehensive and

Sustainable Transport Planning. Victoria Transport Policy Institute, 2011. Disponível em: <www.vtpi.org/sus_tran_ind.pdf>. 
MARTENS, $K$. The bicycle as a feedering mode: experiences from three European countries. Transportation Research, part D, v.9, n.4, p.281-294, 2004.

MENDONÇA, C.P.; ANJOS, L.A. Aspectos das práticas alimentares e da atividade física como determinantes do crescimento do sobrepeso/obesidade no Brasil. Rio de Janeiro: Cadernos de Saúde Pública, n.20, p.698-709, 2004.

MIDGLEY, $P$. The role of smart bike-sharing systems in urban mobility. Journeys, p.23-31, may, 2009.

Bicycle-sharing schemes: enhancing sustainable mobility in urban areas. New York: United Nations Department of Economic and Social Affair, 2011.

MINISTÉRIO DAS CIDADES. Política nacional de mobilidade urbana sustentável. Cadernos Mcidades. n.6. novembro, 2004.

NADAL, L. Bike sharing sweeps Paris off its feet. Sustainable transport, n. 19, p.8-13, fall 2007.

NEGRÃO, C.E. et al. O papel do sedentarismo na obesidade. Revista Brasileira de Hipertensão, v.7, n.2, abril/junho 2000.

NERI, M.C. A nova classe média: o lado brilhante dos pobres. Rio de Janeiro: FGV/CPS, 2010.

NEWMAN, P.; KENWORTHY, J. Sustainability and cities: overcoming automobile dependence. Washington: Island Press, 1999.

NYC DEPARTMENT OF CITY PLANNING. Bike-share: opportunities in New York City. New York, 2009. Disponível em:

$<$ http://www.nyc.gov/html/dcp/pdf/transportation/bike_share_complete.p $\mathrm{df}>$.

PACCA, S. Veículos elétricos: uma esperança renovada de ganhos ambientais e econômicos para novos investidores em energia no Brasil. 2007. Disponível em:

$<$ http://www.abve.org.br/destaques/2007/destaque144.asp>.

PETERSEN, T. Identification of key attributes for bike sharing

systems - report. Intelligent Energy Europe. Berlin: 2010. Disponível em:

$<$ http://obisproject.com/palio/html.run?_Instance=obis\&_PagelD=200\& LngID=21\&_Cat $\mid \mathrm{D}=13 \& \mathrm{pic}=0$ \&_CheckSum $=1419726245>$.

PUCHER, J.; BUEHLER, R. (Ed.). City cycling. Kindle edition. Cambridge: MIT press, 2012. 
Making cycling irresistible: lessons from the Netherlands,

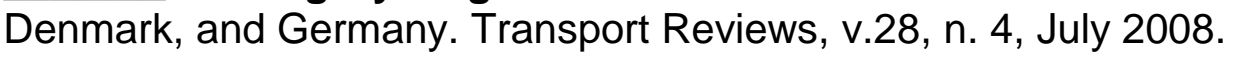

Integrating Bicycling and public transport in North America. Journal of Public Transportation, v.12, n.3, 2009.

PUCHER, J.; DILL J.; HANDY, S. Infrastructure, programs, and policies to increase bicycling: an international review. Preventive medicine 50, p. 106-125, 2010.

PUCHER, J.; DIJKSTRA, L. Making walking and cycling safer: lessons from Europe. Transportation Quarterly, v.54, n.3, 2000.

REPLOGLE, M.; HUGHES, C. Moving toward sustainable transport. State of the World 2012. World Watch Institute. Cap. 4. 2012. Disponível em: <www.itdp.org/documents/SOW12_chap_04.pdf>.

ROGERS, R. Cidades para um pequeno planeta. Barcelona: Editorial Gustavo Gilli SA, 2001.

RIETVELD, P.; DANIEL, V. Determinants of bicycle use: do municipal policies matter? Transportation Research part A, v.38, n.7, p.531-550, 2004.

RIO DE JANEIRO (Estado). Secretaria de Transportes. Atualização do Plano Diretor de Transporte Urbano da Região Metropolitana do Rio de Janeiro. Relatório 04, 2013.

Plano Diretor de Transporte Urbano da Região Metropolitana do Rio de Janeiro: Resultado da pesquisa origem/destino. 2003.

SANTOS, C.N.F. (coord.) Quando a rua vira casa: a apropriação de espaços de uso coletivo em um centro de bairro. São Paulo: Projeto, 1985.

SECRETARIA MUNICIPAL DE MEIO AMBIENTE. Inventário das emissões de gases de efeito estufa da cidade do Rio de Janeiro em 2012 e atualização do Plano de Ação Municipal para redução das emissões. 2013.

SHAHEEN, S.; GUZMAN, S.; ZHANG, H. Bikesharing in Europe, the Americas, and Asia: past, present, and future. Transportation Research Record: Journal of the Transportation Research Board. 2010. Disponível em: $<$ http://publications.its.ucdavis.edu/publication_detail.php?id=1487>.

Bikesharing across the Globe. In: City Cycling. Kindle edition. Cambridge: MIT press, 2012. 
SHAHEEN, S.; COHEN, A.; MARTIN, E. Public bikesharing in north America: early operator understanding and emergint trends. 2012b. Disponível em: < http://tsrc.berkeley.edu/node/611>.

Public bikesharing and modal shift behavior: a comparative study of early bikesharing systems in North America. International Journal of Transportation, v.1, n.1, p.25-54, 2013. Disponível em: <http://dx.doi.org/10.14257/ijt.2013.1.1.03>.

SHAHEEN, S.; ZHANG, H.; MARTIN, E. Hangzhou public bicycle: understanding early adoption and behavioral response to bikesharing in Hangzhou, China. Transportation Research Record, n. 2247, p.34-41.

SOUTH COAST BRITISH COLUMBIA TRANSPORTATION AUTHORITY-TRANSLINK. Translink public bike system feasibility study. 3v. Vancouver, 2008. Disponível em: <http://www.cleanairinstitute.org/cops/bd/file/tnm/19-bikesystem.pdf>.

THE OBSERVATOIRE. Paris transport and travel report. Paris, 2011.

TRANSPORT FOR LONDON. Mayor of London. London Cycling Design Standards (LCDS). 2005. Disponível em: $<$ https://www.tfl.gov.uk>.

Cycling revolution London. Londres, 2010.

VEIGA, J.E. Desenvolvimento sustentável: o desafio do século XXI. 3. ed. Rio de Janeiro: Garamond, 2008.

UNITED NATIONS. Report of the World Commission on Environment and Development: Our Common Future. 1987.

UNITED NATIONS DEPARTMENT OF ECONOMIC AND SOCIAL AFFAIRS. World Urbanization Prospects: the 2011 Revision. New York, 2012. Disponível em: <http://esa.un.org/unup/pdf/FINALFINAL_REPORT\%20WUP2011_Annextables_01Aug2012_Final.pdf>.

UNITED NATIONS ENVIRONMENT PROGRAME. Towards a green economy: pathways to sustainable development and poverty erradication. 2011. Disponível em: <www.unep.org/greeneconomy>.

WANG, R; LIU, C. Bicycle-transit integration in the United States, 2001-2009. Journal of Public Transportation, v.16, n.3, 2013. Disponível em: <http://www.nctr.usf.edu/wpcontent/uploads/2013/10/16.3_wang.pdf>.

WITTINK, R; GODEFROOIJ, T. (coord.). Cycling-Inclusive Policy Development: a handbook. Utrecht, 2009. 


\section{Apêndice 1}

Questionário aplicado aos usuários do sistema e conjunto de respostas

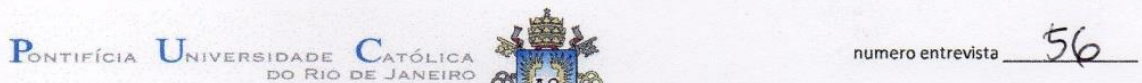

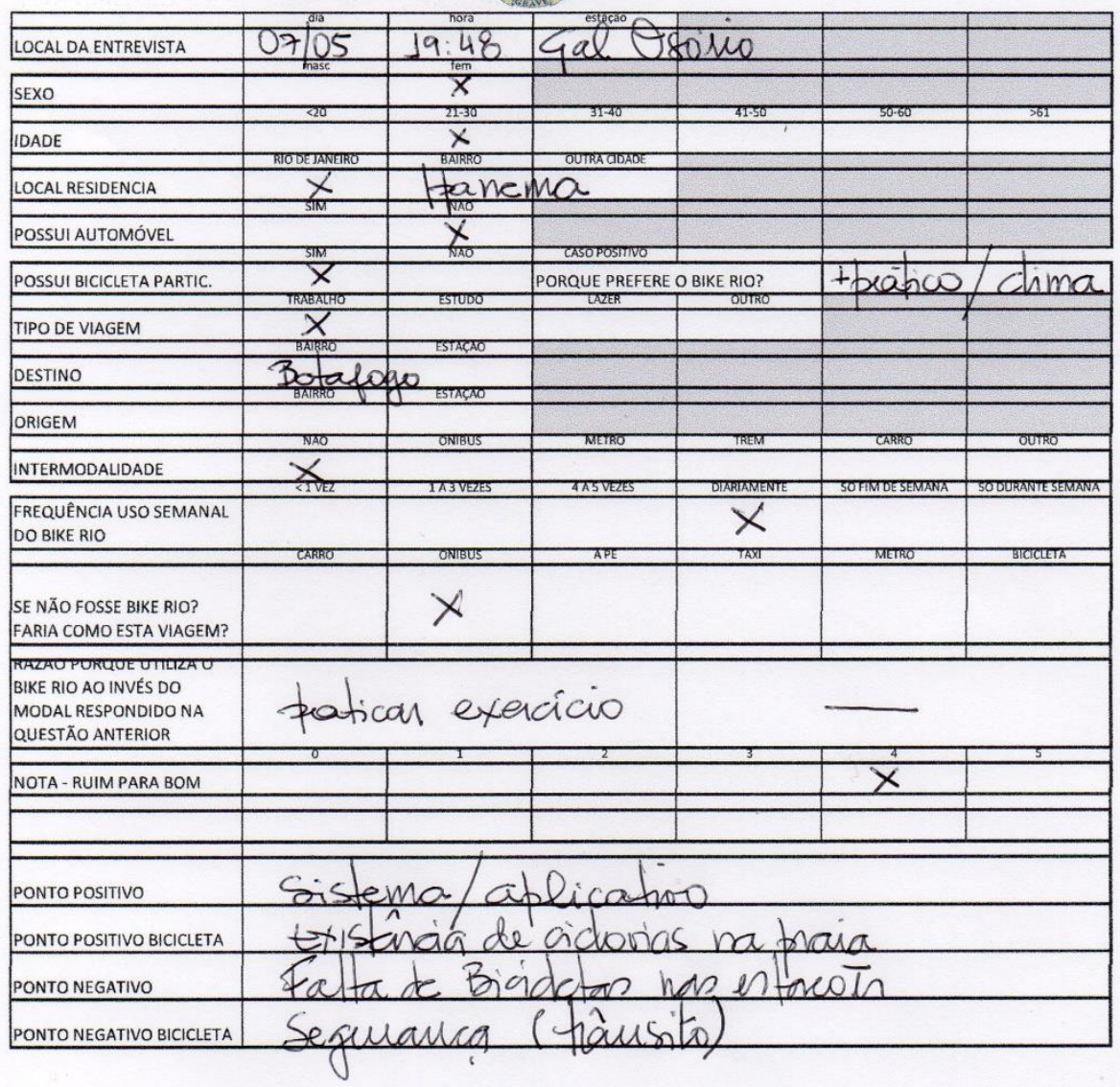




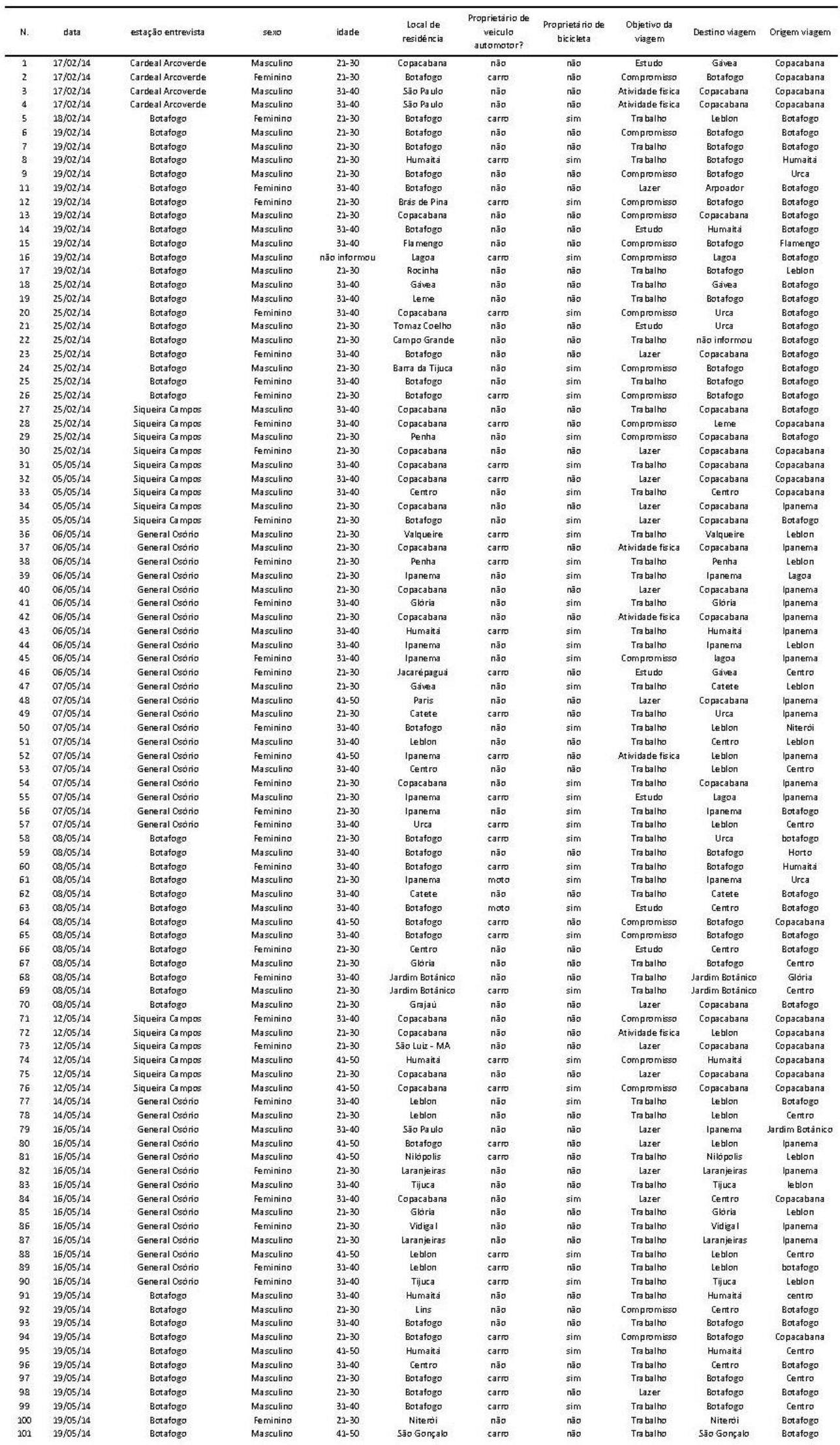

O formulário de número 10 foi anulado. 


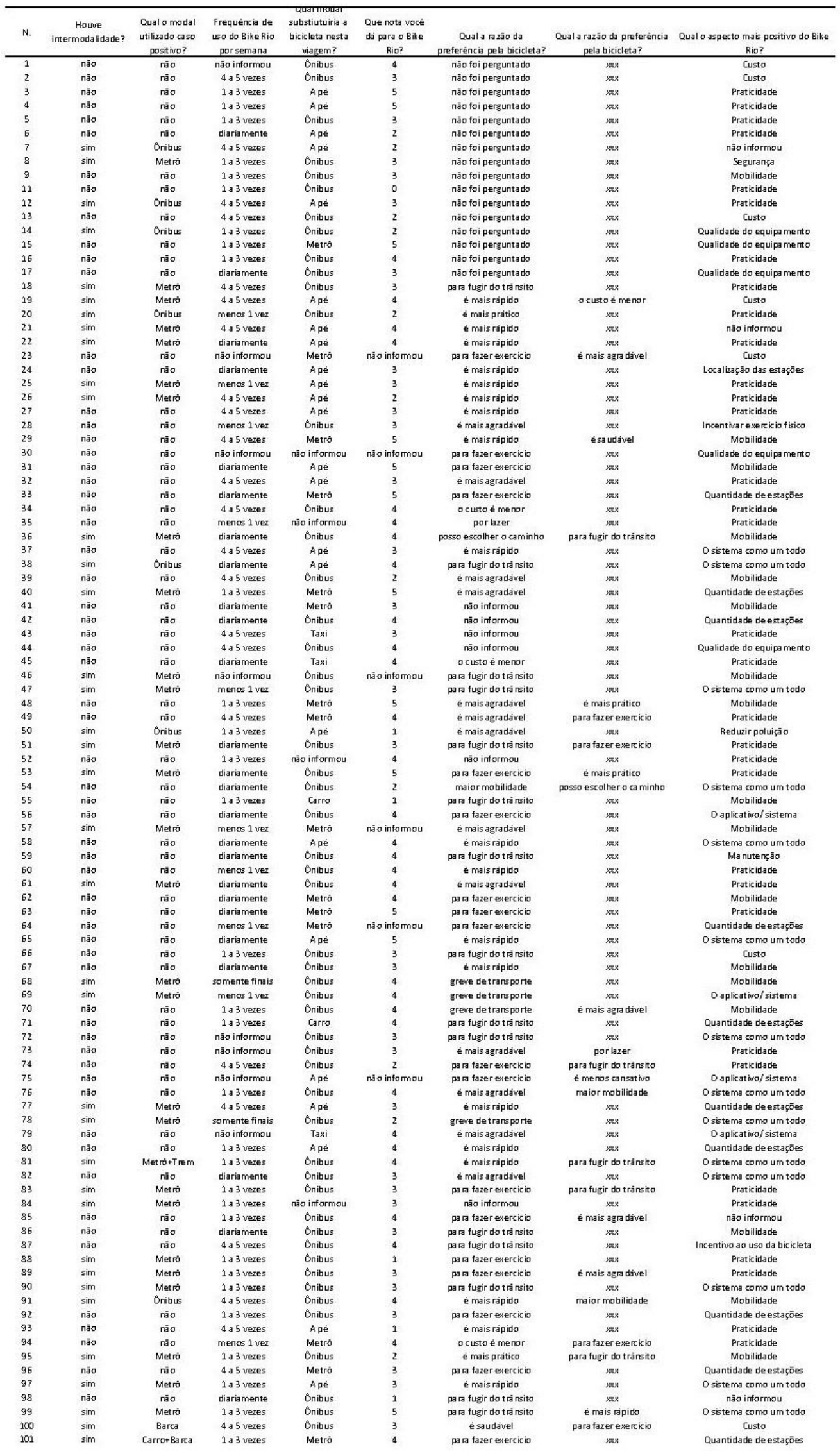

O formulário de número 10 foi anulado. 


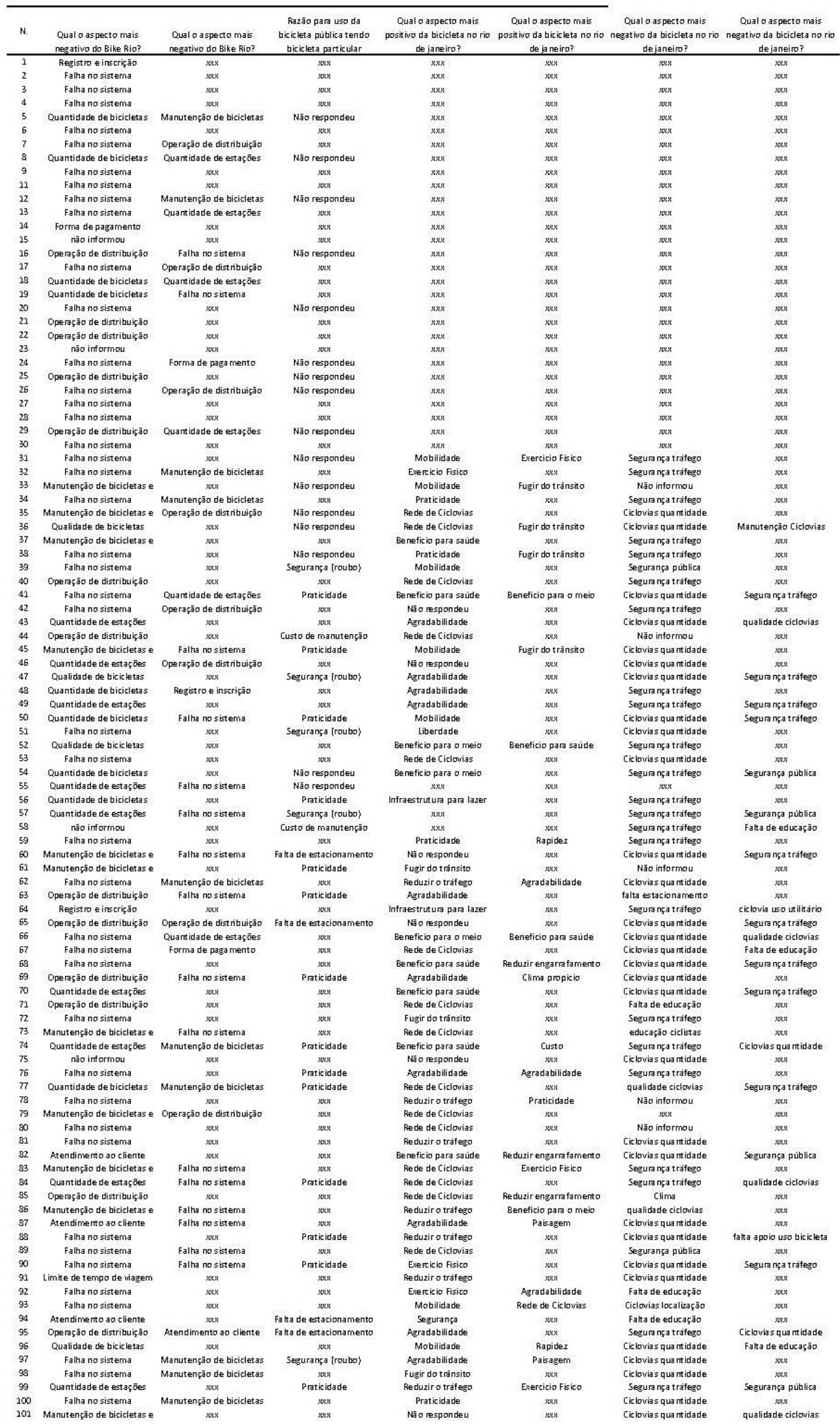

O formulário de número 10 foi anulado. 


\section{Apêndice 2}

Questionário aplicado via web - sequência de questões para quem não usa bicicleta
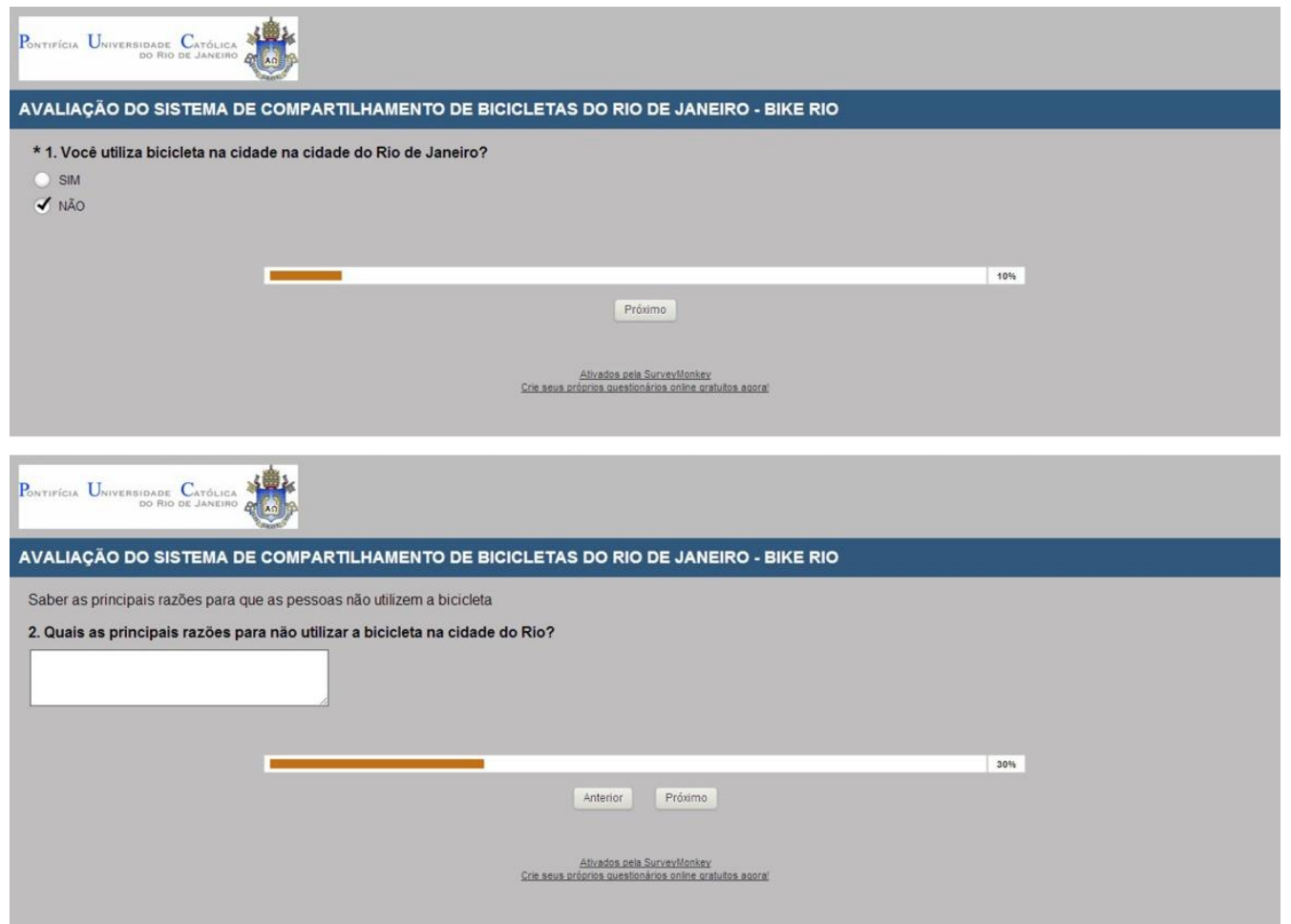

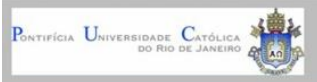

AVALIAÇÃO DO SISTEMA DE COMPARTLLAMENTO DE BICICLETAS DO RIO DE JANEIRO - BIKE RIO

*3. Você conhece o sistema de aluguel de bicicletas Bike Rio (ttaú) ?

$\checkmark \sin$

O Nล̄o

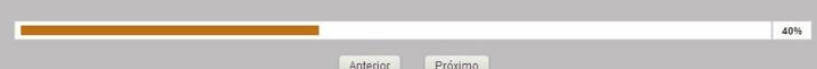




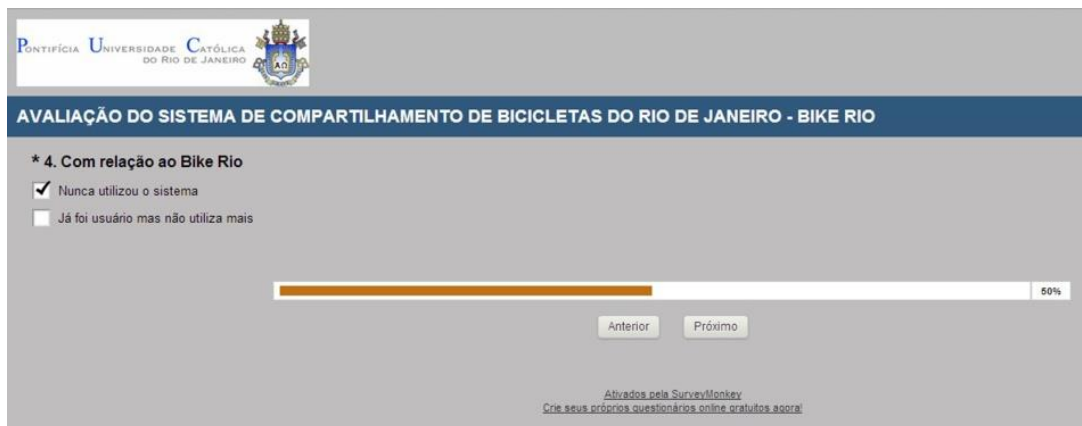

AVALIAÇĀO DO SISTEMA DE COMPARTILHAMENTO DE BICICLETAS DO RIO DE JANEIRO - BIKE RIO

* 5 . Em qual bairro reside?

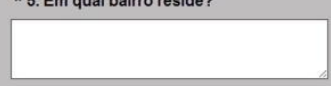

6. Em qual bairro trabalha?

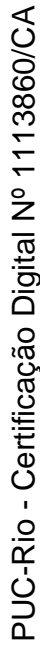

7. Em qual bairro estuda?

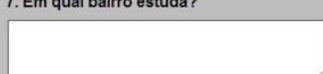

* 8. Sexo

Masculino

O Feminino

* 9 . Idade

00 a 20 anos

21 a 30 anos

41 a 50 anos

Anterior Concluido 


\section{Apêndice 3}

\section{Dados territoriais e demográficos do Rio de Janeiro}

\begin{tabular}{cccccccccc}
\hline Município & $\begin{array}{c}\text { Área total } \\
\text { (ha) }\end{array}$ & $\begin{array}{c}\text { Área } \\
\text { acima da } \\
\text { cota 100 }\end{array}$ & $\begin{array}{c}\text { Área } \\
\text { efetiva } \\
\text { (ha) }\end{array}$ & $\begin{array}{c}\text { População } \\
\text { (2010) }\end{array}$ & $\begin{array}{c}\text { População } \\
\text { masculina }\end{array}$ & $\begin{array}{c}\text { População } \\
\text { feminina }\end{array}$ & $\begin{array}{c}\text { Número de } \\
\text { domicílios } \\
(2010)\end{array}$ & $\begin{array}{c}\text { (20) } \\
\text { Rio de Janeiro }\end{array}$ \\
\hline 122456,01 & 27368,86 & 95087,15 & 6320446 & 2959817 & 46,83 & 3360629 & 53,1708 & 2408891
\end{tabular}

\begin{tabular}{|c|c|c|c|c|c|c|c|c|c|}
\hline BAIRRO & $\begin{array}{l}\text { Área total } \\
\text { (ha) }\end{array}$ & $\begin{array}{c}\text { Área } \\
\text { acima da } \\
\text { cota } 100\end{array}$ & $\begin{array}{c}\text { Área } \\
\text { efetiva } \\
\text { (ha) } \\
\end{array}$ & $\begin{array}{c}\text { População } \\
\text { (2010) }\end{array}$ & $\begin{array}{l}\text { População } \\
\text { masculina }\end{array}$ & $\%$ & $\begin{array}{c}\text { População } \\
\text { feminina }\end{array}$ & & $\begin{array}{l}\text { Número de } \\
\text { domicílios }\end{array}$ \\
\hline são conrado & 648,86 & 415,37 & 233,49 & 10980 & 4957 & 45,15 & 6023 & 54,8543 & 4349 \\
\hline Gávea & 257,96 & 106,68 & 151,28 & 16003 & 7048 & 44,04 & 8955 & 55,9583 & 7069 \\
\hline Leblon & 215,31 & 16,55 & 198,76 & 46044 & 20305 & 44,10 & 25739 & 55,9009 & 22259 \\
\hline Ipanema & 308,49 & 3,77 & 304,72 & 42743 & 18817 & 44,02 & 23926 & 55,9764 & 23018 \\
\hline Lagoa & 510,99 & 47,12 & 463,87 & 21198 & 9758 & 46,03 & 11440 & 53,9674 & 9361 \\
\hline Jardim Botânico & 268,92 & 0,84 & 268,08 & 18009 & 8019 & 44,53 & 9990 & 55,4723 & 7725 \\
\hline Copacabana & 410,09 & 73,31 & 336,78 & 146392 & 62406 & 42,63 & 83986 & 57,3706 & 81188 \\
\hline Leme & 97,72 & 13,23 & 84,49 & 14799 & 6538 & 44,18 & 8261 & 55,8213 & 7399 \\
\hline Urca & 231,9 & 59,11 & 172,79 & 7061 & 3327 & 47,12 & 3734 & 52,882 & 2842 \\
\hline Botafogo & 479,9 & 63,76 & 416,14 & 82890 & 36906 & 44,52 & 45984 & 55,4759 & 39435 \\
\hline Humaitá & 105,45 & 34,99 & 70,46 & 13285 & 5722 & 43,07 & 7563 & 56,9289 & 6546 \\
\hline Laranjeiras & 249,35 & 60,75 & 188,6 & 45554 & 20049 & 44,01 & 25505 & 55,9885 & 20268 \\
\hline Flamengo & 164,63 & 0 & 164,63 & 50043 & 21157 & 42,28 & 28886 & 57,7224 & 25854 \\
\hline Catete & 68,1 & 10,63 & 57,47 & 24057 & 10639 & 44,22 & 13418 & 55,7759 & 11351 \\
\hline Centro & 572,31 & 0 & 572,31 & 41142 & 19289 & 46,88 & 21853 & 53,116 & 22646 \\
\hline Madureira & 378,76 & 27,06 & 351,7 & 50106 & 22944 & 45,79 & 27162 & 54,2091 & 18937 \\
\hline Gloria & 114,01 & 0 & 114,01 & 9661 & 4311 & 44,62 & 5350 & 55,3773 & 5188 \\
\hline Cosme Velho & 89,25 & 40 & 49,25 & 7178 & 3322 & 46,28 & 3856 & 53,7197 & 2491 \\
\hline Saúde & 36,38 & 0 & 36,38 & 2749 & 1388 & 50,49 & 1361 & 49,5089 & 1162 \\
\hline Santo Cristo & 168,47 & 0 & 168,47 & 12330 & 5847 & 47,42 & 6483 & 52,5791 & 4623 \\
\hline Catumbi & 53,95 & 3,43 & 50,52 & 12556 & 5837 & 46,49 & 6719 & 53,5123 & 4384 \\
\hline Estácio & 98,04 & 3,85 & 94,19 & 17189 & 8034 & 46,74 & 9155 & 53,2608 & 6386 \\
\hline Maracanã & 166,73 & 0 & 166,73 & 25256 & 11153 & 44,16 & 14103 & 55,8402 & 10902 \\
\hline Tijuca & 1006,56 & 410,02 & 596,54 & 163805 & 71565 & 43,69 & 92240 & 56,3109 & 67183 \\
\hline Vila Isabel & 321,71 & 26,77 & 294,94 & 86018 & 38103 & 44,30 & 47915 & 55,7035 & 33580 \\
\hline São Cristóvão & 410,56 & 0 & 410,56 & 26510 & 13269 & 50,05 & 13241 & 49,9472 & 9991 \\
\hline Barra da Tijuca & 4815,06 & 101,39 & 4713,67 & 135924 & 63719 & 46,88 & 72205 & 53,1216 & 65369 \\
\hline Recreio dos Bandeirantes & 3065,56 & 402,98 & 2662,58 & 82240 & 39717 & 48,29 & 42523 & 51,706 & 38705 \\
\hline TOTAL & 4968,74 & 933,17 & 4035,57 & 630306 & 277881 & 44,09 & 352425 & 55,9133 & 310247 \\
\hline$\%$ do município & 4,06 & 3,41 & 4,24 & 9,97 & 9,39 & & 10,49 & & 12,88 \\
\hline TOTAL & 10346,28 & 988,44 & 9357,84 & 581416 & 266265 & 45,80 & 315151 & 54,204 & 249964 \\
\hline$\%$ do município & 8,45 & 3,61 & 9,84 & 9,20 & 9,00 & & 9,38 & & 10,38 \\
\hline
\end{tabular}




\section{Apêndice 4}

\section{Dados sobre cidades européias}

\begin{tabular}{|c|c|c|c|c|}
\hline Cidade & Paris & Viena & Barcelona & fonte \\
\hline Nome Comercial & Vélib' & Citybike & Bicing & 1 \\
\hline Início operação & $15 / 07 / 2007$ & $11 / 06 / 2003$ & $24 / 03 / 2008$ & 1 \\
\hline \multicolumn{5}{|l|}{ DADOS SOBRE OS SCB } \\
\hline Quantidade de estações & 1800 & 116 & 420 & $2,3,4$ \\
\hline Quantidade de bicicletas & 23000 & 1400 & 6000 & $2,3,4$ \\
\hline Quantidade de viagens anual SCB & 31.321 .253 & 790.084 & 13.081 .641 & $2,3,4$ \\
\hline Quantidade de viagens média diária & 85.812 & 2.165 & 35.840 & $2,3,4$ \\
\hline $\begin{array}{l}\text { Distância média percorrida por viagem } \\
\qquad(\mathrm{km})\end{array}$ & 1,8 & 3,1 & 2,75 & 1 \\
\hline $\begin{array}{l}\text { Usuários que se transferiram de outros } \\
\text { modais }\end{array}$ & $100,0 \%$ & $96,0 \%$ & $100,0 \%$ & 1 \\
\hline $\begin{array}{l}\text { Usuários que se transferiram do } \\
\text { transporte individual }\end{array}$ & $8,0 \%$ & $14,1 \%$ & $9,6 \%$ & 1 \\
\hline $\begin{array}{l}\text { Usuários que se transferiram do } \\
\text { transporte público }\end{array}$ & $65,0 \%$ & $69,4 \%$ & $51,3 \%$ & 1 \\
\hline $\begin{array}{l}\text { Usuários que se transferiram do } \\
\text { transporte cicloviário }\end{array}$ & NA & $16,4 \%$ & NA & 1 \\
\hline $\begin{array}{l}\text { Usuários que se transferiram de } \\
\text { caminhadas }\end{array}$ & $20,0 \%$ & NS & $26,1 \%$ & 1 \\
\hline Viagens para trabalho e educação & $61,0 \%$ & $20,0 \%$ & $66,8 \%$ & 1 \\
\hline Viagens que incluem outro modal & $79,0 \%$ & $24,0 \%$ & $30,0 \%$ & 1 \\
\hline $\begin{array}{l}\text { Tempo de duração médio das viagens } \\
\text { (minutos) }\end{array}$ & 18,00 & 23,00 & 14,35 & 1,4 \\
\hline \multicolumn{5}{|l|}{ DADOS SOBRE AS CIDADES } \\
\hline População & $3.395 .290^{*}$ & 1.781 .105 & 1.620 .943 & $10,11,12$ \\
\hline Área $(\mathrm{km} 2)$ & $762^{*}$ & 414,6 & 102,2 & $10,11,12$ \\
\hline Quantidade de deslocamentos diários & 12.300 .000 & 4.536 .718 & 7.851 .000 & 1,5 \\
\hline participação transporte cicloviário (\%) & 2,50 & 6,00 & 4,00 & $7,8,9$ \\
\hline participação modal transporte individual & $40,0 \%$ & $35,0 \%$ & $28,4 \%$ & 1 \\
\hline $\begin{array}{l}\text { participação modal transporte transporte } \\
\text { público }\end{array}$ & $20,0 \%$ & $34,0 \%$ & $40,1 \%$ & 1 \\
\hline
\end{tabular}

1 Fernàndez (2011, p.212)

2 Paris: Dossier de Presse: les 5 ans de Velib' - Ville de Paris. Disponível em <http://www.velib.paris.fr/Espacepresse2>

3 Viena: Press release (2013). Disponível em <www.citybikewien.at $>$

4 Barcelona: Información del sistema. Disponível em: <https://www.bicing.cat/es/content/informaci\%C3\%B3ndel-sistema>

5 Paris: Paris transport and travel report (2011) . Disponível em <http://www.paris.fr/english/guide-for-foreignresidents/transportation/rub_8140_stand_33682_port_18786>

6 Obis Project Data Collection. Disponível em: <http://obisproject.com/palio/html.run?_Instance=obis\&_PagelD=200\&_LngID=21\&_CatID=13\&pic=0\&_CheckS um=1419726245>.

7 Viena: Weninger, A. From 5\% to 10\%: The challenge to Double Vienna's Modal Share of Cycling. Viena: 2012

8 Pucher et al. (2012)

9 Barcelona: The Copenhagenize Index 2013. Disponível em: <copenhagenize.eu/index/17.html>.

10 Paris: Prefeitura de Paris. Disponível em: Prefeitura de Paris <http://www.paris.fr/english/presentation-of-thecity/demographics-a-cosmopolitan-city/rub_8125_stand_29896_port_18748>

11 Barcelona: Prefeitura de Barcelona: <http://www.bcn.cat/castella/laciutat/barcelona/situacio.htm>

12 Paris: http://en.wikipedia.org/wiki/Demographics_of_Paris

* Os dados de Paris considera o departamento 75 (cidade de Paris) e as comunas onde está implantado o Velib'. 


\section{Apêndice 5}

\section{Área de abrangência do Velib' (Paris)}

\begin{tabular}{|c|c|c|c|}
\hline & Área $\left(\mathrm{km}^{2}\right)$ & população & font \\
\hline PARIS & 105,00 & 2.125 .246 & 1 \\
\hline \multicolumn{4}{|l|}{ COMUNAS } \\
\hline SOURESNES & 3,79 & 46.876 & 2 \\
\hline CLICHY & 3,08 & 59.458 & 2 \\
\hline LEVALLOIS-PERRET & 2,41 & 64.629 & 2 \\
\hline NEULLY SUR SEINE & 3,73 & 61.797 & 2 \\
\hline PUTEAUX & 3,19 & 44.683 & 2 \\
\hline SAINT DENIS & 12,36 & 107.762 & 2 \\
\hline SAINT OUEN & 4,31 & 47.783 & 2 \\
\hline AUBERVILLIERS & 5,76 & 75.598 & 2 \\
\hline LE PRÉ-ST-GERVAIS & 0,70 & 18.075 & 2 \\
\hline PANTIN & 5,01 & 53.797 & 2 \\
\hline LES LILAS & 1,26 & 22.505 & 2 \\
\hline BAGNOLET & 2,57 & 34.513 & 2 \\
\hline MONTREUIL & 8,92 & 103.068 & 2 \\
\hline VINCENNES & 1,91 & 48.649 & 2 \\
\hline FONTENAY SUS BOIS & 5,58 & 52.723 & 2 \\
\hline BOULOGNE BILLANCOURT & 6,18 & 18.806 & 2 \\
\hline ISSY-LES-MOULINEAUX & 4,52 & 65.326 & 2 \\
\hline VANVES & 1,56 & 27.022 & 2 \\
\hline MALAKOFF & 2,07 & 30.768 & 2 \\
\hline MONTROUGE & 2,07 & 48.710 & 2 \\
\hline GENTILLY & 1,18 & 16.892 & 2 \\
\hline ARCUEIL & 2,33 & 20.100 & 2 \\
\hline LE KREMILIN BICÊTRE & 1,54 & 26.131 & 2 \\
\hline IVRY-SUR-SEINE & 6,10 & 58.185 & 2 \\
\hline CHARENTON-LE-PONT & 1,85 & 29.562 & 2 \\
\hline SAINT MAURICE & 1,43 & 14.586 & 2 \\
\hline JOINVILLE-LE-PONT & 2,31 & 17.953 & 2 \\
\hline NOGENT-SUR-MAINE & 2,86 & 31.795 & 2 \\
\hline SAINT-MANDÉ & 0,92 & 22.292 & 2 \\
\hline TOTAL & 101,50 & 1.270 .044 & \\
\hline TOTAL & 206,50 & 3.395 .290 & \\
\hline
\end{tabular}

1.http://www.paris.fr/english/presentation-of-the-city/demographics-a-cosmopolitan-city/rub_8125_stand_29896_port_18748 2.http://fr.wikipedia.org/wiki/Unit\%C3\%A9_urbaine_de_Paris 


\section{Apêndice 6}

\section{Avaliação do Bike Rio}

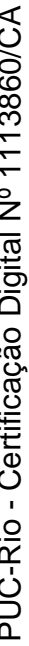

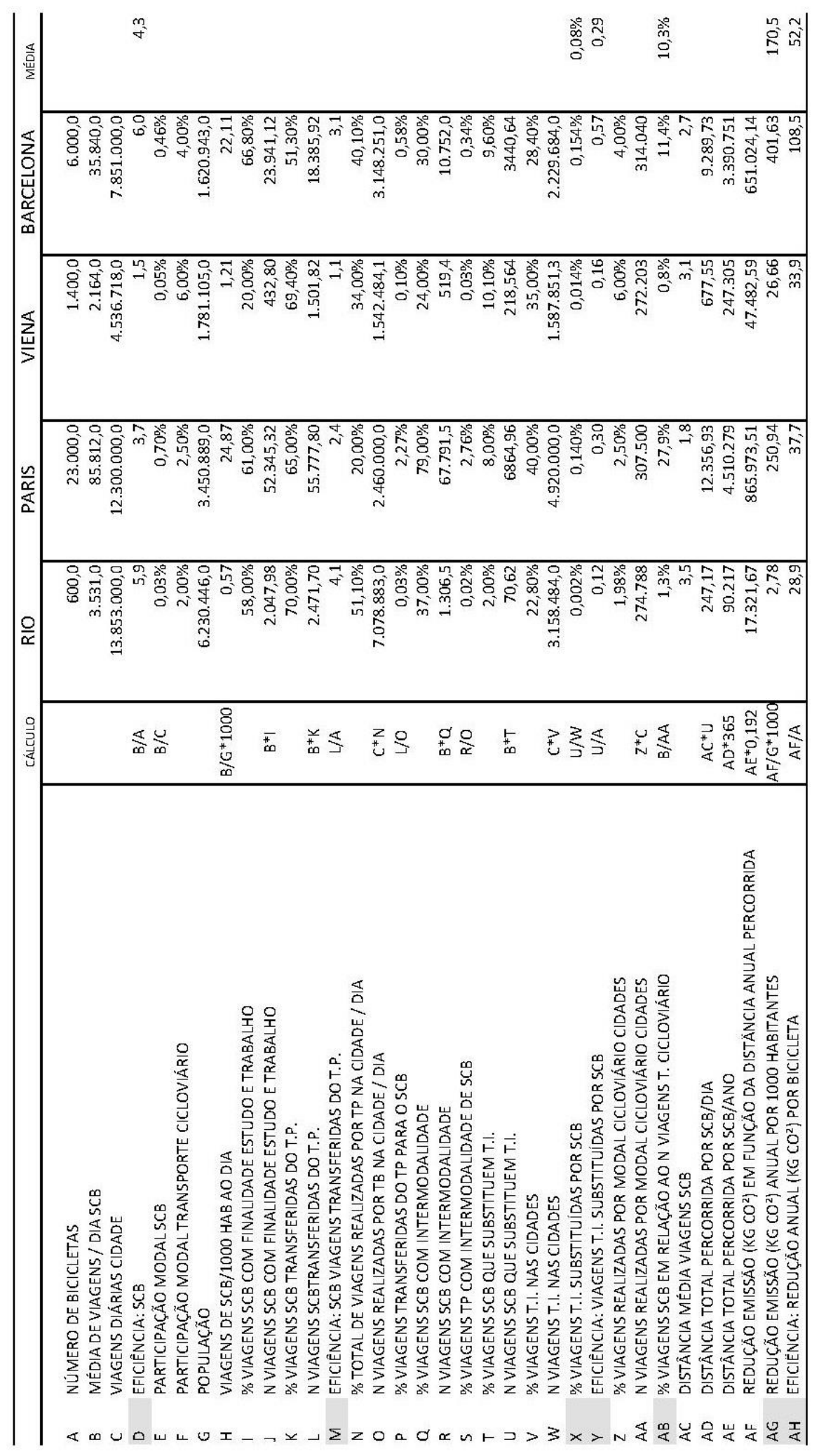

